RAFAEL CELEGHINI SANTIAGO

DESEMPENHO AO IMPACTO DE LAMINADOS

FIBRA-METAL UTILIZANDO REFORÇOS TERMOPLÁSTICOS

Tese apresentada à Escola

Politécnica da Universidade de São

Paulo para obtenção do título de

Doutor em Engenharia

São Paulo

2014 

RAFAEL CELEGHINI SANTIAGO

\section{DESEMPENHO AO IMPACTO DE LAMINADOS \\ FIBRA-METAL UTILIZANDO REFORÇOS TERMOPLÁSTICOS}

Tese apresentada à Escola

Politécnica da Universidade de São

Paulo para obtenção do título de

Doutor em Engenharia

Área de concentração:

Projeto e fabricação

Orientador:

Prof. Dr. Marcílio Alves,

Universidade de São Paulo

Co-orientador:

Prof. Dr. Wesley Cantwell

Universidade de Liverpool

São Paulo

2014 
Este exemplar foi revisado e corrigido em relação à versão original, sob responsabilidade única do autor e com a anuência de seu orientador.

São Paulo, 25 de junho de 2014.

Assinatura do autor

Assinatura do orientador

FICHA CATALOGRÁFICA

Santiago, Rafael Celeghini

Desempenho ao impacto de laminados fibra-metal utilizando reforços termoplásticos / R.C. Santiago. -- versão corr. -- São Paulo, 2014.

254 p.

Tese (Doutorado) - Escola Politécnica da Universidade de São Paulo. Departamento de Engenharia Mecatrônica e de Sistemas Mecânicos.

1.Materiais compósitos (Impacto) 2.Laqminados 3.Método dos elementos finitos 4.Materiais termoplásticos I.Universidade de São Paulo. Escola Politécnica. Departamento de Engenharia Mecatrônica e de Sistemas Mecânicos Il.t.

Autorizo a reprodução e/ou divulgação total ou parcial da presente obra, por qualquer meio convencional ou eletrônico, desde que citada a fonte. - $\mathrm{O}$ autor. 
Dedico a toda minha família. 



\section{AGRADECIMENTOS}

Agradeço aos meus pais Inês e Roberto, à minha irmã Mariana e de minha noiva Natália, pela paciência, atenção e apoio em minhas decisões.

Agradeço ao professor Marcílio Alves, pela paciência ao longo desses 9 anos de pesquisas. Ao professor Wesley Cantwell e Dr. Robert Birch pela atenção durante o estágio em Liverpool. Aos professores Normam Jones, Larissa Driemeier e Roberto Ramos.

Ao corpo técnico da Universidade de São Paulo e da Universidade de Liverpool que me ajudaram no desenvolvimento experimental desta pesquisa.

Aos amigos do Grupo de Mecânica dos Sólidos e Impacto em Estruturas, pela disposição em ajudar sempre que necessitei. Aos colegas Marcos Rabelo, Mohamed Alteinaiji e Marco Ceze.

Ao apoio financeiro da FAPESP (Fundação de Amparo a Pesquisa do Estado de São Paulo), pela bolsa de doutorado direto 2009/14839-7, fundamental para o desenvolvimento desta tese.

Às empresas Lynx, Lankhorst Bv. e Embraer.

Agradeço a Deus, por me guiar em todos os momentos de minha vida. 

"O tempo destrói tudo aquilo que ele não ajudou a construir."

(Emmanuel) 



\section{RESUMO}

Neste trabalho estuda-se o comportamento de laminados fibra-metal em regime de impacto, a partir de uma abordagem teórica, numérica e experimental. Os materiais estudados consistem em camadas finas intercaladas de alumínio 2024-T4 e de um novo material termoplástico de polipropileno (PP) de alta resistência mecânica. Eventos de impacto de baixa e alta velocidade contra placas destes laminados foram realizados a partir de um martelo de impacto e de um canhão pneumático, respectivamente. Nestes experimentos buscou-se identificar as condições limite de ruptura e perfuração das amostras, assim como parâmetros de comportamento do material. O laminado fibra metal de PP (ou TFML) e seus constituintes foram caracterizados a taxas de deformação entre $10^{-4} / s$ e $10^{2} / s$, utilizando-se máquinas de ensaio universal comerciais e um dispositivo desenvolvido especificamente para este estudo, capaz de caracterizar materiais em taxas intermediárias de deformação.

Os modelos teóricos de Jones e Reid-Wen foram adaptados para utilização com TFMLs, sendo capazes de identificar o comportamento do material em regime de baixa e alta velocidade de impacto, respectivamente. Um modelo numérico do TFML em regime de impacto foi desenvolvido utilizando o programa comercial LSDyna. Resultados experimentais e teóricos foram confrontados com esse, apresentado boa correlação na predição do limiar de falha e limite balístico do material.

Uma vez que o comportamento do TFML ao impacto foi modelado, buscou-se identificar o efeito da distribuição de camadas e composição de constituintes no comportamento do material ao impacto. Estudos também foram conduzidos com o intuito de identificar a influência da taxa de deformação, geometria do indentador e localização do impacto no comportamento dos laminados. Por fim, uma configuração de TFML foi proposta visando melhoria de seu desempenho ao impacto.

Palavras-chave: impacto mecânico, laminados fibra-metal, FML, compósitos termoplásticos, caracterização dinâmica de materiais, método dos elementos finitos. 



\begin{abstract}
In this work, the behaviour of fibre-metal laminates under impact loading is studied by using theoretical, numerical and experimental approaches. The material is a combination of thin aluminium 2024-T3 layers and an innovative high strength thermoplastic polypropylene material. Low and high velocity impact events were performed using a falling weight machine and a gas-gun projectile launcher, respectively. The thermoplastic fibre-metal laminates (or TFML) and its constituents were mechanically characterized in the range of strain rates between $10^{-4} / \mathrm{s}$ and $10^{2} / \mathrm{s}$, using commercial universal testing machines and a specifically designed rig for tensile tests at intermediate strain rates.

The Jones and Reid-Wen theoretical models were adapted to be used with TFML plates. A finite element model of the TFML under impact events was developed using LS-Dyna software. The numerical model revalled results that were compared with the theoretical models and the experimental data, providing reasonably similar results.

Once the TFML impact behaviour was identified and modelled, the effect of the layers distribution and constituent composition on the TFML impact response was studied. Studies of the strain rate effect, identor geometry and the impact location were also performed. Finally, a TFML configuration was suggested in order to improve the TFML impact performance.
\end{abstract}

Keywords: Impact loading, fibre-metal laminates, FML materials, thermoplastic composites, material dynamic characterization, finite element models. 

Figura 1: Ícones da aviação comercial: (a) Lockheed Constellation e (b) Boeing 747

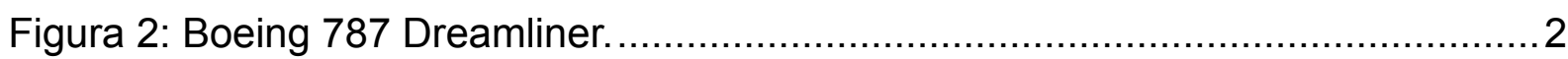

Figura 3: Impacto de um caminhão tanque contra a turbina de um A-320. 5

Figura 4: (a) Aeronave Concorde durante a decolagem, com turbina em chamas e (b) peça metálica de outra aeronave deixada na pista, que ocasionou o estouro do pneu.

Figura 5: Aeronave Airbus A-320 após pouso de emergência no rio Hudson. 6

Figura 6: (a) Aeronave em manutenção para reparo de impacto em fuselagem e

(b) detalhe do processo de inspeção e reparo. 7

Figura 7: Representação esquemática de um laminado fibra-metal (FML). .7

Figura 8: (a) Aeronave Boeing 747 e (b) imagens do acidente em Lockerbie (Escócia)

Figura 9: (a) Impacto de um caminhão plataforma na asa de um Airbus A-380 e (b) impacto da asa de um Airbus A-380 contra um prédio durante movimentação e solo.

Figura 10: Explosão de umas das turbinas de uma Airbus A-380 durante o voo.

Detalhe na perfuração da asa causado no incidente. 10

Figura 11: Tríplice abordagem teórica, numérica e experimental. 12

Figura 12: Espiral de projeto.

Figura 13: Comparação da resistência ao impacto do ARALL, GLARE e alumínio 7075-T6 (Vlot, 1996).

Figura 14: Eventos de impacto de alta velocidade em TFML (Abdullah, 2006)...... 19

Figura 15: Eventos de impacto explosivos em TFML: (a) amostra em corte, com descolamento da face oposta, e (b) deformação do material em forma crunciforme. (Langdon, Cantwell e Nurick, 2005; Lemanski et al., 2007).....20

Figura 16: Comparação numérico-experimental de resultados para estudo de eventos explosivos em TFML (Karagiozova et al., 2010).

Figura 17: Comparação numérico-experimental do impacto de uma ave em um bordo fabricado com GLARE (Mccarthy, Xiao, Mccarthy, et al., 2004; Mccarthy, Xiao, Petrinic, et al., 2004). 
Figura 18: (a) Remo náutico fabricado em Twintex, (b) mala de viagem fabricada em Curv e (c) capacete de proteção a explosões fabricado em Pure.

Figura 19: Equipamentos utilizados para realização de ensaios de caracterização mecânica em diferentes taxas de deformação (Sharpe, 2008).

Figura 20: Esquema de funcionamento de uma barra de Hopkinson (Sharpe, 2008).

Figura 21: Dispositivos para a caracterização de materiais sob médias taxas de deformação: (a) MTS 819, (b) dispositivo desenvolvido utilizando um atuador hidráulico (Shokrieh e Omidi, 2009c), (c) dispositivo pneumático (Avalle, Peroni e Peroni, 2008), (d) dispositivo hidropneumático (Tarigopula et al., 2009), (e) dispositivo tipo "flyingwedge" (Sturges e Cole, 2001), e (f) dispositivo utilizando um equipamento de queda de peso (Brown, Brooks e Warrior, 2010) e (g) dispositivo utilizando um equipamento de queda de peso com compro de prova centrado (Mott et al., 2007).

Figura 22: (a) Esboço conceitual da solução escolhida a ser utilizado no (b) martelo de impacto pertencente ao GMSIE-USP.

Figura 23: Simulação numérica do equipamento desenvolvido para ensaios de médias taxas de deformação.

Figura 24: (a) Geometria básica adotada para o corpo de prova, (b) sistema de fixação do corpo de prova e (c) análise em elementos finitos estática do corpo de prova.

Figura 25: Elemento impactante.

Figura 26: (a) Fixação da célula de carga e (b) anteparo de medição do deslocamento pelo

Figura 27: (a) Estrutura base do equipamento e (b) detalhe entre a massa de impacto e a estrutura da máquina.

Figura 28: Dispositivo desenvolvido para ensaios de caracterização mecânica em médias taxas de deformação.

Figura 29: Avaliação qualitativa do desempenho do equipamento. 
Figura 30: Histórico de (a) deformação e (b) tensão aplicada no espécime. (c) Exemplos de curva tensão-deformação de engenharia obtidas na taxa de deformação de 133 /s, 135 /s e 157 /s.

Figura 31: Esquema de fabricação do SRPP denominado PURE (Lankhorst, 2011)

Figura 32: (a) Constituintes do FML, sendo (da esquerda para direita): camadas de alumínio, camadas de adesivos Xiro e camadas de SRPP-PURE. (b) Prensa pneumática com aquecimento Meyer e (c) TFML durante o processo de fabricação

Figura 33: (a) Martelo de impacto e indentador, e (b) aparato de fixação das amostras.

Figura 34: (a) Vibrômetro a laser, (b) câmera de alta velocidade e (c) relógio comparador

Figura 35: Modos de falha identificados: (a) falha na face oposta, (b) falha na face impactada e (c) descolamento de camadas.

Figura 36: Ocorrência dos modos de falha nos materiais testados.

Figura 37: Comportamento do material P3A043 durante o impacto de baixa velocidade.

Figura 38: Comportamento dos materiais P3B039 e P5A044 durante o impacto de baixa velocidade.

Figura 39: Comportamento dos materiais G3B054 e G5B027 durante o impacto de baixa velocidade.

Figura 40: Deslocamento residual central adimensional para as amostras testadas sem ocorrência de falha.

Figura 41: Canhão pneumático lançador de projéteis: (a) reservatório pneumático e válvula de abertura rápida, (b) tubo de aceleração e (c) dispositivos de proteção, sensor de velocidade e câmera de alta velocidade.

Figura 42: Secção transversal da amostra P4B039 após impacto. 76

Figura 43: Orientação adotada para a direção das velocidades. .77

Figura 44: Formas de falha observados nas amostras testadas: (a) pétala, (b) rasgamento, (c) mista e (d) descolamento e falha no suporte.

Figura 45: Diagrama de velocidades incidente e residual.

Figura 46: Máquina de ensaio universal Instron 3369. 
Figura 47: Máquina de ensaios dinâmicos ElectroPuls E10000.

Figura 48: Máquina de ensaios em médias taxas de deformação........................... 86

Figura 49: Martelo de impacto utilizado para ensaios de compressão dinâmico. ..... 86

Figura 50: Exemplo de utilização de DIC de campo completo.................................. 87

Figura 51: Exemplo de utilização de DIC com acompanhamento de marcadores.

Figura 52: (a) Nikon D90 em ensaio quase estático em Instron 3369; Photron APX-RS em ensaios dinâmicos em (b) Instron ElectroPuls E10000 e (c) dispositivo desenvolvido para ensaios em médias taxas de deformação. ... 88

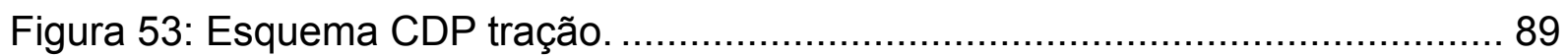

Figura 54: Esquema simplificado do ensaio de cisalhamento do SRPP Pure. ......... 91

Figura 55: Configurações de espécimes utilizadas: (a) Configuração A, escala 1:2; (b) Configuração $B$, escala 1:1 e (c) Configuração $C$, escala 1:2 (Dimensões em milímetros).

Figura 56: Curva tensão-deformação quase estática do alumínio 2024-T3 utilizando diferentes configurações de espécimes: (a) deformações medidas por extensômetro ou sensores de deslocamento e (b) deformação medidas utilizando técnica DIC............................................... 94

Figura 57: Ruptura dos espécimes da liga de alumínio 2024-T3 ........................... 95

Figura 58: Curvas tensão-deformação do alumínio 2024-T3 realizada em diferentes taxas de deformação. 96

Figura 59: Comparação da curva tensão-deformação do alumínio 2024-T3 em diferentes taxas de deformação.

Figura 60: Obtenção do coeficiente de Poisson para a liga de alumínio 2024T3 98

Figura 61: Modelo numérico do ensaio de tração do alumínio 2024-T3. 100

Figura 62: Comparação numérico-experimental da curva tensão-deformação para o alumínio 2024-T3. 100

Figura 63: Configurações de espécimes de SRPP utilizadas: (a) configuração $D$, escala 1:4; (b) configuração $E$, escala 1:4; (c) configuração $F$, escala 1:4; (d) configuração $G$, escala 1:4; e (e) configuração $H$, escala 2:1 (Dimensões em milímetros).

Figura 64: (a) Distribuição de marcadores para medição bidirecional de deformação e (b) medição de deformação utilizando técnica DIC. 
Figura 65: Curvas tensão-deformação para o SRPP Pure com medição bidirecional de deformação.

Figura 66: Espécimes com configuração (a) D, (b) $E$ e (c) $F$, com os marcadores alinhados ao longo da direção principal.

Figura 67: Sequência de imagens exemplificado o modo de ruptura observado no SRPP Pure.

Figura 68: Espécimes de configuração (a) D, (b) E e (c) F após a realização dos experimentos.

Figura 69: Curvas tensão-deformação do SRPP Pure, realizada a diferentes taxas de

Figura 70: Comparação do comportamento do SRPP Pure em diferentes taxas de deformação.

Figura 71: (a) Distribuição de marcadores para medição e (b) medição de deformações em ensaio de caracterização em cisalhamento.

Figura 72: Comportamento do material SRPP Pure quando solicitado à direção $\left[+/-45^{\circ}\right]$ 108

Figura 73: (a) Espécimes utilizando para a caracterização mecânica do material em cisalhamento. (b) Detalhe da ruptura do material.

Figura 74: Espécimes de configuração $H$ utilizados para caracterização do SRPP Pure em compressão.

Figura 75: (a) Sequencia de imagens obtidas durante o ensaio de compressão do SRPP Pure e (b) espécimes antes e após a realização do experimento.

Figura 76: Curvas tensão-deformação do SRPP Pure em compressão, realizada em diferentes taxas de deformação.

Figura 77: Comparação do comportamento do SRPP Pure em compressão a diferentes taxas de deformação.

Figura 78: Representação gráfica dos parâmetros para definição do comportamento não-linear do material em cisalhamento (Hallquist, 2006).

Figura 79: Modelagem numérica do ensaio de tração do SRPP Pure. 114

Figura 80: Modelagem numérica do ensaio de tração do SRPP Pure, utilizando modelo de material MAT-58. 
Figura 81: Modelagem numérica do ensaio de tração do SRPP Pure, utilizando modelo de material MAT-24.

Figura 82: Configuração I de espécimes de TFML utilizada, escala 2:1 (dimensões em milímetros).

Figura 83: Especimes de TFML após a realização do ensaio de tração: (a) P3A044, (b) P4B039 e (c) P5A043. (d) Detalhe a ruptura de uma amostra P4B039.

Figura 84: Curvas tensão-deformação para as amostras de TFML ensaiadas.

Figura 85: Comparação do comportamento do das amostras de TFMLs ensaiadas.

Figura 86: Aproximações rígido-plástico e elasto-plástico perfeito para a curva tensão-deformação de um material dúctil.

Figura 87: Perfil de tensão de uma viga submetida à flexão.

Figura 88: Esforços considerados em um elemento infinitesimal da placa circular.

Figura 89: Perfil de tensão em uma placa monolítica e laminada híbrida.

Figura 90: Definição de tensão $\sigma_{0}$ para (a) alumínio 2024-T3 e (b) SRPP Pure... 129

Figura 91: Modelo teórico para impacto de baixa velocidade em chapas planas circulares.

Figura 92: Perfil da placa após o impacto.

Figura 93: Esforços atuantes em um elemento infinitesimal da placa.

Figura 94: Condição de escoamento definindo o acoplamento entre momento fletor e tensão de membrana.

Figura 95: Predição do deslocamento residual para placas circulares de TFML submetidas ao impacto central, utilizando Regra das misturas para obtenção de propriedades equivalentes.

Figura 96: Predição do deslocamento residual para placas circulares de TFML submetidas ao impacto central, utilizando Técnica da Conservação de $M_{0}$ para obtenção de propriedades equivalentes.

Figura 97: Exemplos de malhas com diferentes tamanhos de elementos: área média dos elementos centrais de (a) 1,10 x 1,10 $\mathrm{mm}^{2}$ e (b) 0,32 x 0,32 $m m^{2}$

Figura 98: Análise de sensibilidade de malha. 
Figura 99: Malha utilizada para análise numérica.

Figura 100: Comparação numérico-experimental do diagrama de falha do TFML P4B039.

Figura 101: Comparação numérica, teórica e experimental para o deslocamento central residual do TFML P4B039 em impacto de baixa velocidade.

Figura 102: Comparação numérico-experimental da curva força-deslocamento para o TFML P4B039.

Figura 103: Ruptura das camadas metálicas nos modelos MN-1 e MN-2, não observadas experimentalmente.

Figura 104: Resultados numéricos e experimentais para o diagrama de velocidade do material P4B039.

Figura 105: Resultados numérico, teórico e experimental para o limite balístico do material P4B039.

Figura 106: Histórico de deformação para o TFML em evento de impacto de baixa velocidade.

Figura 107: Histórico de deformação para o TFML em evento de impacto de baixa velocidade.

Figura 108: Comparação qualitativa do comportamento do TFML em impacto de mesma energia e velocidades diferentes: (a) $10 \mathrm{~kg} / 1,9 \mathrm{~m} / \mathrm{s}$ e (b) 15 $\mathrm{g} / 50 \mathrm{~m} / \mathrm{s}$.

Figura 109: Curva força-deslocamento para o TFML ao impacto em baixa e alta velocidade.

Figura 110: Comparação qualitativa do impacto em TFML sem ruptura com projéteis (a) esférico e (b) cilíndrico.

Figura 111: Forma de ruptura observada em eventos de impacto em TFML com indentadores (a) esférico e (b) cilíndrico. 168

Figura 112: (a) Deslocamento residual máximo para impacto $40 \mathrm{~J}$ a baixa velocidade e (b) velocidade balística para materiais equivalentes ao TFML 4/3 (P4B039).

Figura 113: Resultado qualitativo das análises (a) MA-1 e (b) MA-2 ....................173

Figura 114: Resultado qualitativo das análises (a) MA-1, (b) MA-3 e (c) MA-5 ......175

Figura 115: Comparação de resultados qualitativo das análises (a) MA-5, (b) MA-1, (c)MA-6, (d)MA-7 e (e)MA-2. 
Figura 116: Resultados de deslocamento máximo e velocidade residual TFMLs com várias espessuras de SRPP e monolítico equivalentes.

Figura 117: Secção transversal das amostras (a)MA-1, (b)MA-8, (c)MA-9, (d)MA-10, (e)MA-11 após impacto.

Figura 118: Comparação do comportamento de (a) MA-14 e (b) MA-15............... 182

Figura 119: Comparação do comportamento de MA-1 e MA-16 após o impacto. .. 183 


\section{LISTA DE TABELAS}

Tabela 1: Aplicações para diferentes configurações de GLARE (Sinmazçelik, 2011)

Tabela 2: Matriz de decisão para escolha da configuração. 39

Tabela 3: Propriedades idealizadas para um alumínio aeronáutico. 40

Tabela 4: Código alfabético para identificação de espessuras das camadas metálicas. 56

Tabela 5: Amostras utilizadas para realização de experimentais de impacto. 62

Tabela 6: Perfil pós-impacto de P3A043. .63

Tabela 7: Perfil pós-impacto de P4B039. 64

Tabela 8: Perfil pós-impacto de P5A044. 64

Tabela 9: Perfil pós-impacto de G3B054. .64

Tabela 10: Perfil pós-impacto de G5B027. 64

Tabela 11: Código de identificação para falha no material para impacto de baixa velocidade. 64

Tabela 12: Resultados experimentais para o material P3A043. .65

Tabela 13: Resultados experimentais para o material P4B039. 65

Tabela 14: Resultados experimentais para o material P5A044. .65

Tabela 15: Resultados experimentais para o material G3B054. .66

Tabela 16: Resultados experimentais para o material G5B027. .66

Tabela 17: Resultados experimentais comparativos. .70

Tabela 18: Perfil pós-impacto de P3A043. .74

Tabela 19: Perfil pós-impacto de P4B039. ………...........................................

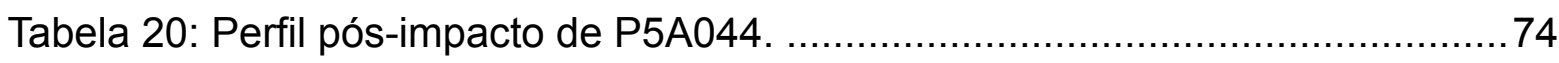

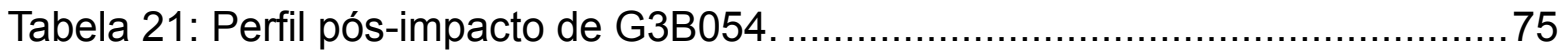

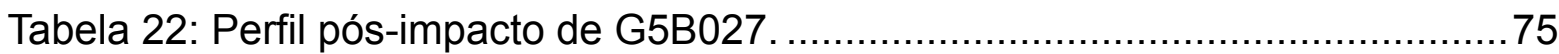

Tabela 23: Vista da face oposta a impacto, material: P3A043 …….....................75

Tabela 24: Vista da face oposta a impacto, material: P4B039 ...............................75

Tabela 25: Vista da face oposta a impacto, material: P5A044 ..............................76

Tabela 26: Vista da face oposta a impacto, material: G3B054 …….....................76

Tabela 27: Vista da face oposta a impacto, material: G5B027. ............................76 
Tabela 28: Código de identificação para falha no material para impacto de alta velocidade.

Tabela 29: Resultados experimentais para o material P3A043 ............................ 78

Tabela 30: Resultados experimentais para o material P4B039............................. 78

Tabela 31: Resultados experimentais para o material P5A044 ........................... 78

Tabela 32: Resultados experimentais para o material G3B054 ........................... 79

Tabela 33: Resultados experimentais para o material G5B027 .......................... 79

Tabela 34: Resultados experimentais comparativos......................................... 81

Tabela 35: Efeito da taxa de deformação no comportamento da liga de

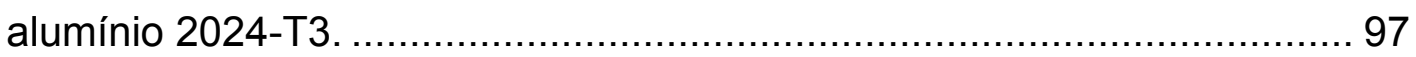

Tabela 36: Efeito da taxa de deformação no comportamento do SRPP Pure....... 106

Tabela 37: Parâmetros do SRPP Pure obtidos do ensaio de cisalhamento........... 108

Tabela 38: Efeito da taxa de deformação no comportamento do SRPP Pure

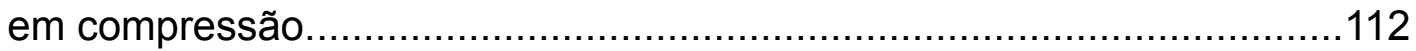

Tabela 39: Parâmetros de comportamento das amostras de TFMLs...................119

Tabela 40: Valores de tensão plástica perfeita definidas para o Alumínio 2024-

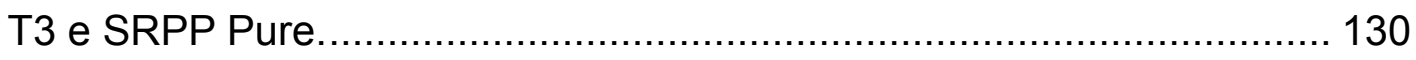

Tabela 41: Valores de tensão plástica equivalente para a amostra P3A043 ......... 130

Tabela 42: Valores de tensão plástica equivalente para a amostra P4B039........ 130

Tabela 43: Valores de tensão plástica equivalente para a amostra P5A044......... 131

Tabela 44: Predição do limite balístico utilizando o modelo teórico de Reid-

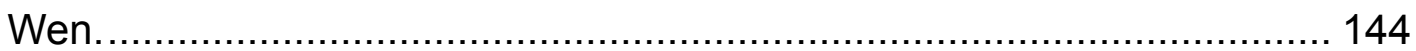

Tabela 45: Propriedades da camada adesiva (Reyes e Cantwell, 1998)............. 149

Tabela 46: Especificações dos modelos numéricos analisados........................... 150

Tabela 47: Comparação qualitativa de resultados numéricos e experimentais..... 152

Tabela 48: Comparação numérica e experimental das formas de falha identificadas para o TFML P3B039 em eventos de impacto de baixa velocidade.

Tabela 49: Resultados quantitativos da modelagem numérica do TFML P4B039.

Tabela 50: Resultados numéricos e experimentais da velocidade residual do indentador para o material P4B039 após o impacto. .............................. 154

Tabela 51: Velocidade limite de falha visual para o TFML P4B039...................... 156 
Tabela 52: Comparação qualitativa de resultados numéricos e experimentais: ruptura na face oposta ao impacto.

Tabela 53: Comparação qualitativa de resultados numéricos e experimentais: tipos de falha.

Tabela 54: Comparação qualitativa de resultados numéricos e experimentais. ....158

Tabela 55: Resultados numéricos para o material TFML P4B039 em impacto de alta velocidade.

Tabela 56: Resultados numéricos e experimentais para o material TFML P4B039 em impacto de alta velocidade.

Tabela 57: Limite balístico para o material P4B039.

Tabela 58: Resultado da análise comparativa de TFML de referência e a configuração proposta.

Tabela 59: Desempenho das amostras de TFML ao impacto de ruptura, utilizando indentadores esféricos e cilíndricos

Tabela 60: Desempenho das amostras de TFML ao impacto com ruptura, utilizando indentadores esféricos e cilíndricos.

Tabela 61: Modelos utilizados para avaliação do efeito de excentricidade do impacto do TFML.

Tabela 62: Resultados na análise da excentricidade no impacto em TFMLs.

Tabela 63: Característica dos modelos utilizados para análise comparativa com materiais monolíticos.

Tabela 64: Resultado da análise comparativa com materiais monolíticos

Tabela 65: Característica dos modelos utilizados para análise comparativa com outras configurações de TFML.

Tabela 66: Resultado da análise comparativa de TFML com configurações diferentes.

Tabela 67: Característica dos modelos utilizados para análise comparativa com outras configurações de TFML.

Tabela 68: Resultado da análise comparativa de TFML com diferentes espessuras de SRPP.

Tabela 69: Resultado da análise comparativa de TFML com diferentes espessuras de SRPP.

Tabela 70: Característica dos modelos utilizados para análise comparativa de TFML com diferentes espessuras de camadas metálicas. 
Tabela 71: Resultado da análise comparativa de TFML com diferentes espessuras de SRPP.

Tabela 72: Configuração de TFML proposta.

Tabela 73: Resultado da análise comparativa de TFML de referência e a configuração proposta. 


\section{LISTA DE ABREVIATURAS E SIGLAS}

TFML Laminado fibra-metal com reforço termoplástico (em inglês)

FML Laminado fibra-metal (em inglês)

GLARE Glass-reinforced aluminium (acrônimo)

ARALL Aramid aluminium laminate (acrônimo)

GMSIE Grupo de Mecânica dos Sólidos e Impacto em Estruturas

USP Universidade de São Paulo

CAD-3D Desenho tridimensional auxiliado por computador (em inglês)

PP Polipropileno

CLLC Composite laminate layup code

SF Sem falha (aparente)

FO Face oposta (ao impacto)

FI Face impactada

DC Descolamento de camadas

$P \quad$ Pétala (forma de falha)

R Rasgamento (forma de falha)

DFS Descolamento com falha no suporte

SRPP Material auto reforçado de polipropileno

DIC Correlação digital de imagens (em inglês)

FPS Quadros por segundo (em inglês)

ASTM American Society for Testing and Materials

MN Modelo numérico

ME Modelo (numérico) de excentricidade

MA Modelo (numérico) de análise

VLF Velocidade limite de falha

ELF Energia limite de falha 



\section{LISTA DE SÍMBOLOS}

\begin{tabular}{|c|c|}
\hline$\varepsilon$ & Deformação \\
\hline$t$ & Tempo \\
\hline$l_{0}$ ou $l_{i}$ & Comprimento inicial \\
\hline$l_{f}$ & Comprimento final \\
\hline$v$ & Velocidade (genérico) \\
\hline$E$ & Módulo elástico (genérico) ou Energia (genérica) \\
\hline$\sigma_{0}$ & Tensão de escoamento \\
\hline$\sigma_{u}$ & Tensão última \\
\hline$\varepsilon_{u}$ & Deformação última \\
\hline$g$ & Aceleração da gravidade \\
\hline$h$ & Altura (genérica) \\
\hline$m$ & Massa (genérica) \\
\hline$\sigma_{e n g}$ & Tensão de engenharia \\
\hline$F$ & Força (genérica) \\
\hline$H$ & Espessura da chapa ou altura da viga \\
\hline$\rho$ & Densidade volumétrica ou adimensional de raios \\
\hline$G$ & Massa de impacto \\
\hline$E_{i m p}$ & Energia de impacto \\
\hline$V_{i n c}$ ou $V_{0}$ & Velocidade incidente ou de impacto \\
\hline$V_{\text {res }}$ & Velocidade residual \\
\hline$E_{a b s}$ & Energia absorvida \\
\hline$w_{f}$ & Deslocamento central da placa \\
\hline$K_{p}$ & Rigidez da placa ao impacto \\
\hline$V_{b}$ & Velocidade balística \\
\hline$E_{b}$ & Energia balística \\
\hline$a_{0}$ & Largura inicial \\
\hline$b_{0}$ & Espessura inicial \\
\hline$A_{0}$ & Área inicial \\
\hline$a$ & Largura \\
\hline
\end{tabular}




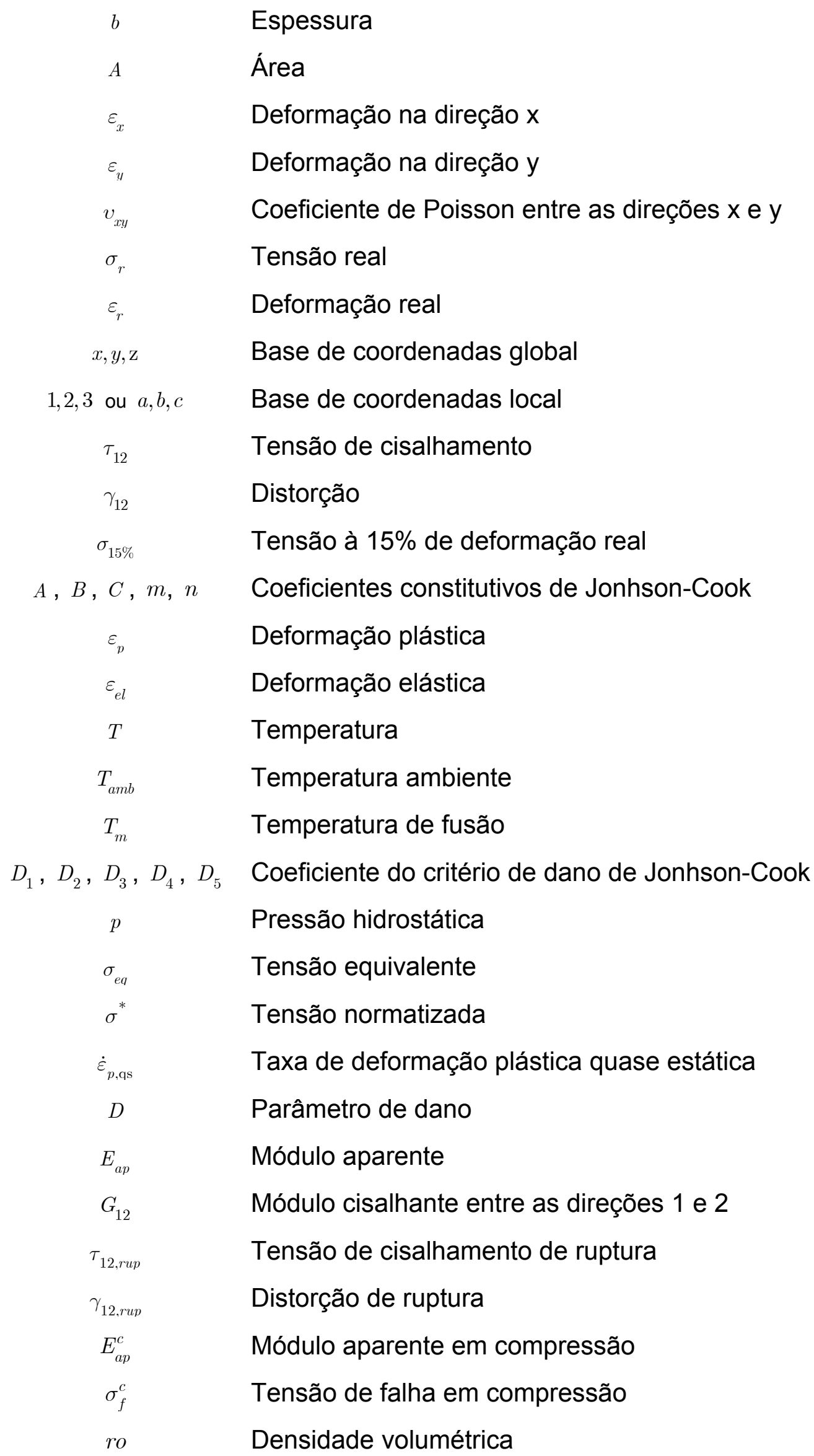




\begin{tabular}{|c|c|}
\hline$e a$ & Módulo elástico na direção a \\
\hline$e b$ & Módulo elástico na direção b \\
\hline prab & Coeficiente de Poisson entra as direções a e b \\
\hline$g a b$ & Módulo cisalhante entre as direções a e b \\
\hline$T A U 1$ & Tensão limite para comportamento não linear \\
\hline GAMMA1 & Distorção limite para comportamento não-linear \\
\hline$S C$ & Tensão de cisalhamento máxima \\
\hline$G M S$ & Distorção máxima \\
\hline$X C$ & Tensão máxima na direção 1 em compressão \\
\hline$X T$ & Tensão máxima na direção 1 em tração \\
\hline$Y C$ & Tensão máxima na direção 2 em compressão \\
\hline$Y T$ & Tensão máxima na direção 2 em tração \\
\hline$S L I M, x x$ & Coeficiente para comportamento após condição limite \\
\hline$e 11 c$ & Deformação máxima na direção 1 em compressão \\
\hline$e 11 t$ & Deformação máxima na direção 1 em tração \\
\hline$e 22 c$ & Deformação máxima na direção 2 em compressão \\
\hline$e 22 t$ & Deformação máxima na direção 2 em tração \\
\hline$M$ & Momento fletor \\
\hline$I$ & Momento de inércia \\
\hline$B$ & Largura da viga \\
\hline$M_{r}$ & Momento na direção radial \\
\hline$M_{\theta}$ & Momento na direção circunferencial \\
\hline$N_{r}$ & Tensão de membrana radial \\
\hline$N_{\theta}$ & Tensão de membrana circunferencial \\
\hline$R$ & Raio da placa \\
\hline$r, \theta, z$ & Base de coordenadas cilíndrica \\
\hline$P_{2}, \ldots, P_{n}$ & Propriedade genérica de n-ésimo materiais \\
\hline${ }_{1}, V_{2}, \ldots, V_{n}$ & Fração volumétrica do n-ésimo material \\
\hline$h_{1}, h_{2}, \ldots, h_{n}$ & Espessura do n-ésimo material \\
\hline$M_{0}$ & Momento plástico \\
\hline$M_{0}^{\prime}$ & Momento plástico por unidade de comprimento \\
\hline
\end{tabular}




\begin{tabular}{|c|c|}
\hline$W$ & Deslocamento da massa de impacto \\
\hline$w$ & Deslocamento da placa \\
\hline$\mu$ & Densidade superficial \\
\hline$\kappa_{r}$ & Curvatura radial \\
\hline$\kappa_{\theta}$ & Curvatura circunferencial \\
\hline$Q_{r}$ & Esforços cortantes \\
\hline$G$ & Massa de impacto \\
\hline$a$ & Diâmetro da massa de impacto \\
\hline$\gamma$ & Adimensional de energia cinética \\
\hline$\lambda$ & Adimensional de massa de impacto \\
\hline$\varepsilon_{r}$ & Deformação radial \\
\hline$\varepsilon_{\theta}$ & Deformação circunferencial \\
\hline$M$ & Momento (genérico) \\
\hline$N$ & Tensão de membrana (genérico) \\
\hline$N_{0}$ & Tensão de membrana plástica \\
\hline$E_{f}$ & Energia de falha \\
\hline$\sigma_{0,1}, \sigma_{0,2}, \sigma_{0,3}$ & Níveis de tensão plástica \\
\hline$E_{l}$ & Energia de falha local \\
\hline$E_{q}$ & Energia de fala global \\
\hline$D$ & Diâmetro do impactante \\
\hline$L$ & Dimensão lateral da chapa \\
\hline$A$ & Parâmetro empírico \\
\hline$\beta_{1}$ & Parâmetro empírico \\
\hline$\beta_{2}$ & Parâmetro empírico \\
\hline$\phi$ & Fator intensificador dinâmico \\
\hline$E_{f d}$ & Energia de falha dinâmica \\
\hline$V_{0}$ & Velocidade de transição \\
\hline$V_{i}$ & Velocidade média de impacto \\
\hline$\sigma_{n}$ & Tensão limite normal \\
\hline$\sigma_{t}$ & Tensão limite tangencial \\
\hline$G_{I}$ & Rigidez ao descolamento em Modo I \\
\hline
\end{tabular}




$\begin{array}{cl}G_{I I} & \text { Rigidez ao descolamento em Modo II } \\ \text { TSSFAC } & \text { Fator de escalonamento do passo de tempo } \\ V_{b, t} & \text { Velocidade balística teórica } \\ (\cdot) & 1^{\text {a }} \text { derivação } \\ (\cdot) & 2^{\text {a }} \text { derivação } \\ \int & \text { Integral } \\ \sum & \text { Somatório } \\ ()^{e q} & \text { Parâmetro (genérico) equivalente }\end{array}$





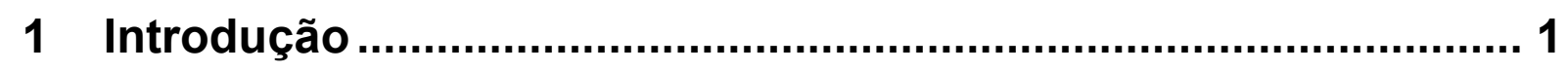

$1.1 \quad$ Estruturas leves na indústria aeronáutica...............................................

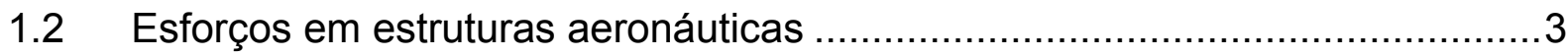

1.3 Laminados fibra-metal: um novo material aeronáutico ..............................

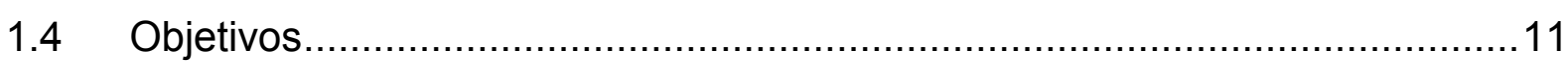

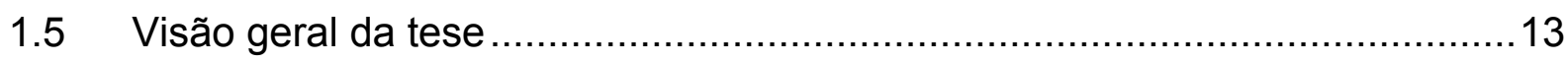

2 Revisão Bibliográfica ........................................................ 15

2.1 O desenvolvimento dos laminados fibra-metal ..................................... 15

2.2 Impacto em laminados fibra-metal .................................................... 16

2.3 Estudo teórico do impacto em FMLs ................................................ 21

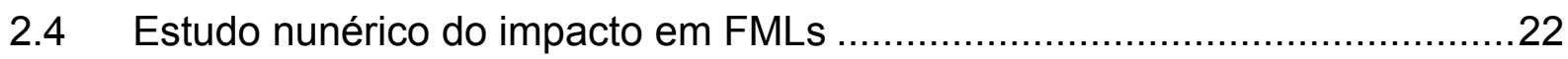

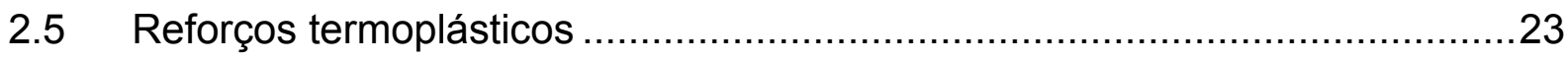

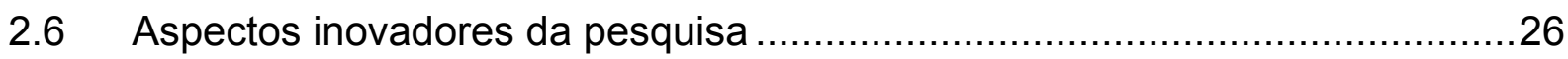

\section{Um dispositivo para caracterização de materiais em taxas} intermediárias de deformação......................................................... 29

3.1 Dispositivos de ensaios de caracterização mecânica em médias taxas de deformação 30

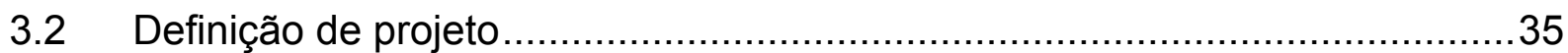

3.3 Escolha da configuração do dispositivo .............................................. 36

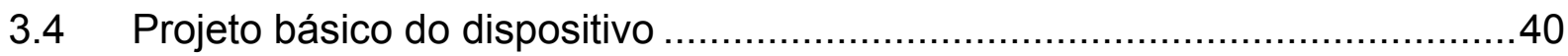

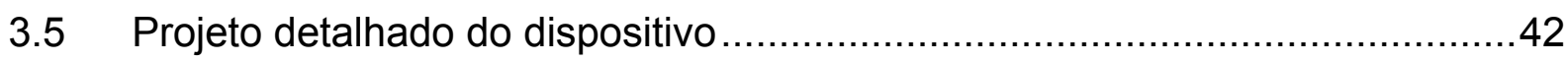

3.6 Avaliação do desempenho do dispositivo ...........................................46

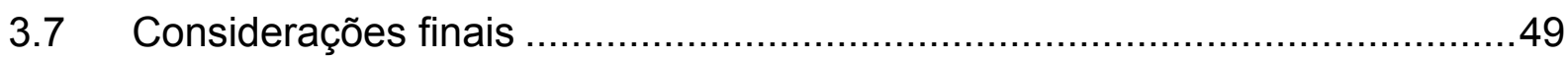

4 Fabricação e descrição dos materiais .................................... 51

4.1 Laminados fibra-metal termoplásticos ............................................ 51

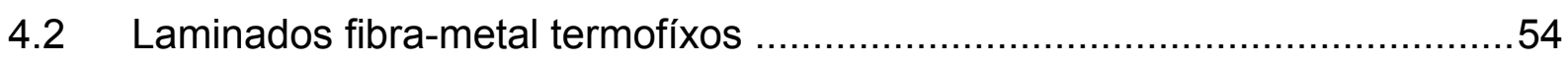

4.3 Amostras de constituintes do TFML para testes de caracterização mecânica55

4.4 Definições e código de identificação dos materiais ...................................55

5 Estudo experimental de impacto em FML ........................... 59

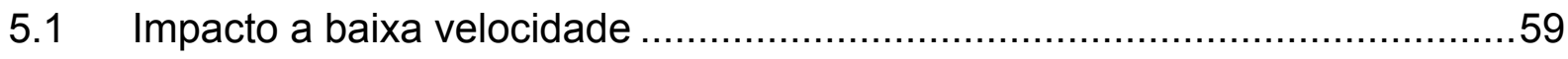


5.1.1 Equipamentos e procedimento experimental .................................... 59

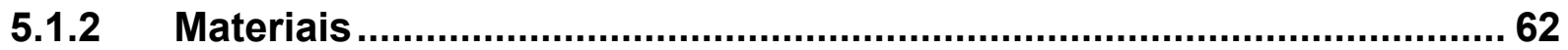

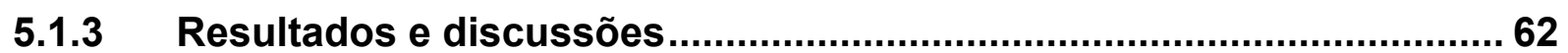

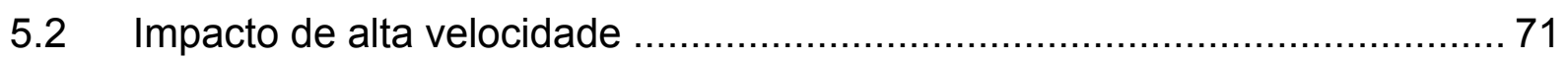

5.2.1 Equipamentos e procedimento experimental ....................................... 71

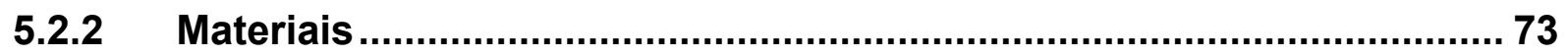

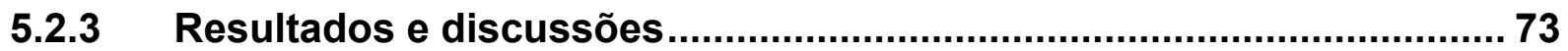

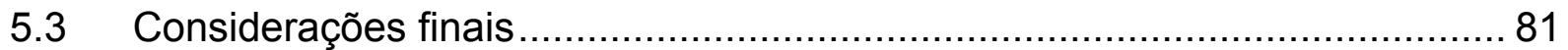

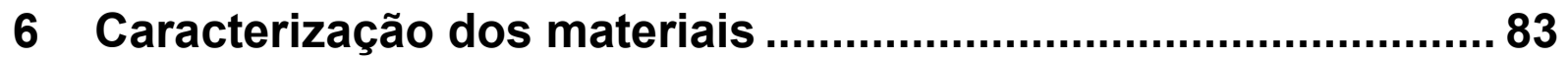

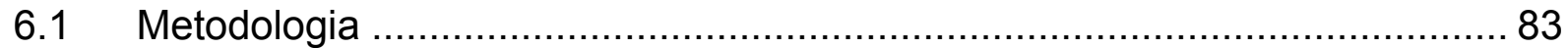

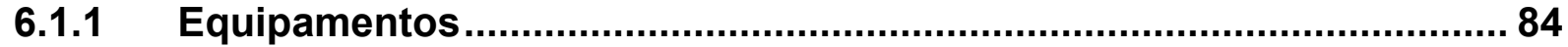

6.1.2 Medição de deformação por correlação de imagens …....................... 86

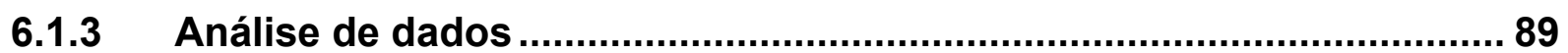

6.2 Caracterização mecânica do alumínio 2024-T3 ........................................... 92

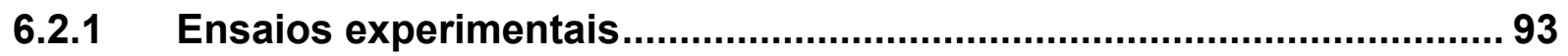

6.2.2 Definição de parâmetros constitutivos ………………......................... 98

6.3 Caracterização do material autoreforçado de polipropileno ........................ 100

6.3.1 Ensaios experimentais......................................................................... 101

6.3.2 Definição de parâmetros constitutivos ............................................... 112

6.4 Caracterização mecânica dos TFMLs ....................................................... 116

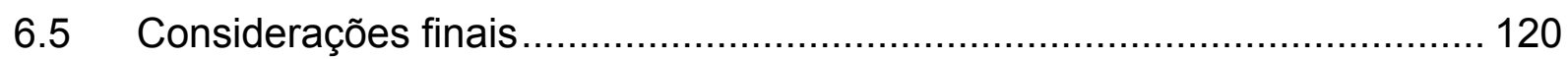

7 Análise teórica do impacto em FML termoplástico .................. 121

7.1 Formulação básica de vigas e placas submetidas ao impacto mecânico .... 122

7.2 Métodos de homogenização de propriedades em materiais híbridos .......... 126

7.3 Obtenção de propriedades para os materiais estudados............................ 129

7.4 Modelo teórico para impacto de baixa velocidade ..................................... 131

7.4.1 Resultados e discussões................................................................ 137

7.5 Modelo teórico para impacto de alta velocidade ...................................... 140

7.5.1 Resultados e discussões............................................................... 143 
7.6 Considerações finais

8 Análise numérica do impacto em TFML ..................................145

8.1 Descrição do modelo numérico ………………....................................146

8.2 Avaliação do desempenho dos modelos numéricos ....................................151

8.2.1 Impacto em baixa velocidade .............................................................151

8.2.2 Impacto em alta velocidade ..............................................................156

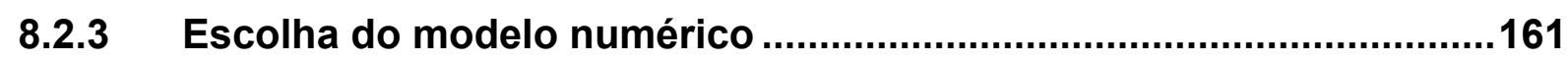

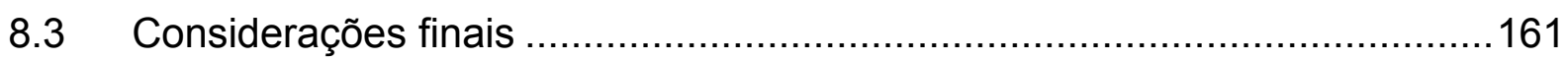

9 Avaliação do comportamento do TFML ao impacto .................163

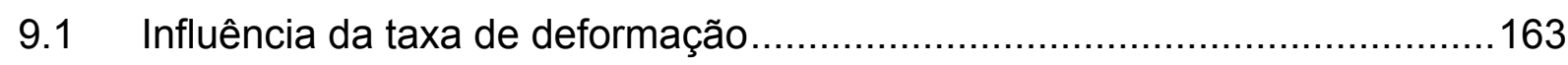

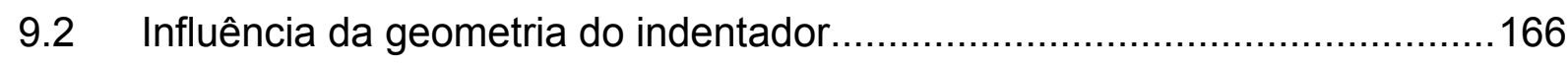

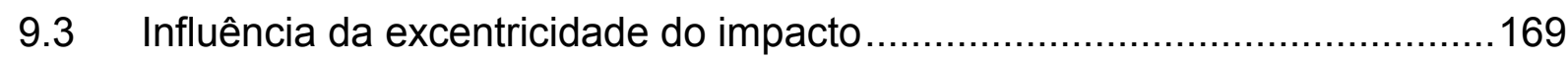

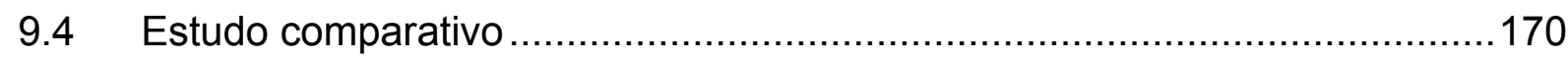

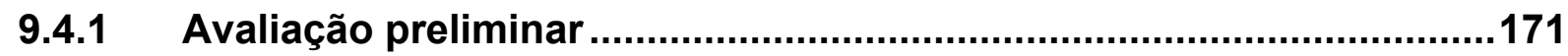

9.4.2 Comparação com materiais monolíticos equivalentes..........................172

9.4.3 Comparação com diferentes configurações de TFML..........................174

9.4.4 Comparação com TFML com diferentes espessuras de SRPP ..........175

9.4.5 Comparação TFML 4/3 com diferentes espessuras de metais ............180

9.4.6 Proposição de uma configuração de TFML .......................................182

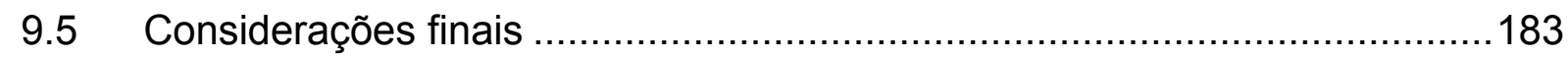

10 Conclusões ........................................................................185

11 Referências bibliográficas ................................................189

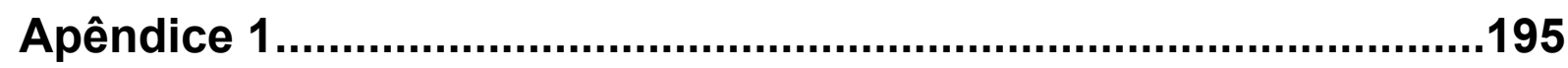

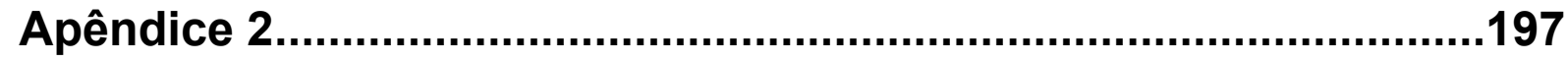

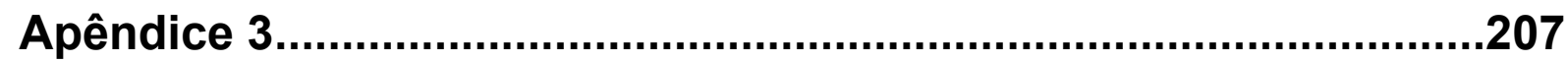





\section{INTRODUÇÃO}

\subsection{ESTRUTURAS LEVES NA INDÚSTRIA AERONÁUTICA}

A redução do peso estrutural de aeronaves é uma busca constante no setor aeronáutico, gerando impacto direto no desempenho e viabilidade econômica destas. Com a redução do peso estrutural de uma aeronave, pode-se aumentar a carga paga transportada por esta, reduzir seu consumo de combustível, assim como diminuir a poluição ambiental gerada. No entanto, aspectos como segurança, confiabilidade e custo não podem ser deixados em segundo plano, o que torna a redução do peso estrutural um processo oneroso, contínuo e frequentemente calcado em avanços tecnológicos.

$\mathrm{O}$ advento das ligas de alumínio aeronáutico foi um importante fator para $\mathrm{o}$ desenvolvimento da aviação comercial e militar nos moldes de hoje. Anteriormente, a aviação estava limitada a projetos estruturais de pequeno porte, com estruturas baseadas em madeira e aço. Tais ligas possibilitam uma maior flexibilidade no projeto estrutural aeronáutico e a fabricação de aeronaves de grande porte. Aviões como o Lockheed Constellation e Boeing 747 são ícones da aviação comercial da década de 40 e 70, respectivamente, apresentando projetos estruturais calcados em ligas de alumino aeronáutico, Figura 1.

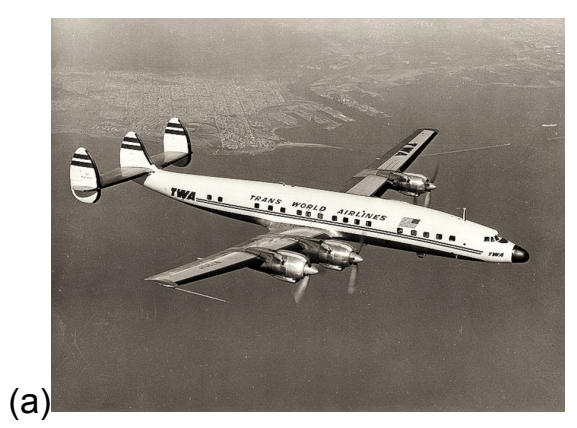

(b)

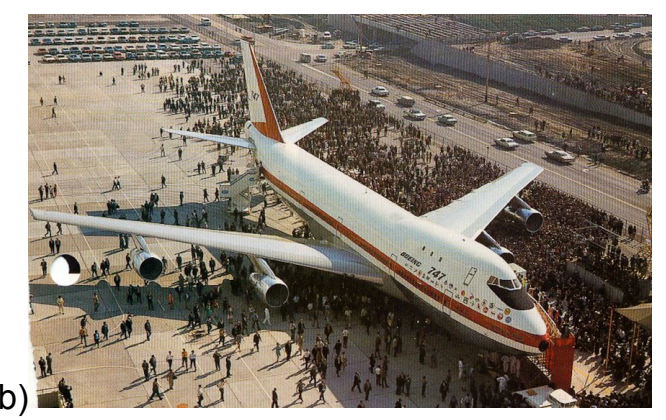

Figura 1: Ícones da aviação comercial: (a) Lockheed Constellation e (b) Boeing 747.

As ligas de alumínio, quando comparadas ao aço, apresentam resistência mecânica semelhante, maior tenacidade, maior resistência à corrosão e densidade 
cerca de 60\% menor. Apesar disso, as desvantagens do alumínio estão na baixa resistência à fadiga e alto coeficiente de expansão térmica.

A partir da década de 60 houve o desenvolvimento dos materiais compósitos voltados à indústria aeronáutica. Estes materiais são constituídos por fibras de alta resistência, como fibra de vidro ou carbono, embebida em uma matriz polimérica, como epóxi ou vinil-éster. Uma vez que estas fibras podem ser organizadas em direções diversas, ou mesmo tecidos, diferente comportamento são obtidos destes materiais. Assim, é possível desenvolver elementos com elevado desempenho mecânico e peso reduzido, para aplicações altamente específicas.

Os materiais compósitos na indústria aeronáutica foram utilizados inicialmente para aplicações militares. O intervalo de tempo que existiu entre a concepção e aplicação dos compósitos foi causado pela necessidade de estudo e experimentação de tais materiais, praticamente novos para o meio científico. No entanto a grande alavanca para a aplicação deste apenas se deu com a viabilização do processo de fabricação de peças com materiais compósitos, dentro das especificações requeridas pelo setor. O processo de fabricação dos compósitos é diversificado, sendo especifico para cada aplicação, podendo ser exemplificado a técnica de laminação de fibras pré-impregnadas e a técnica do filamento contínuo (Daniel e Ishai, 2006). Nota-se que tais processos são completamente distintos dos utilizados para fabricação de peças com materiais metálicos, necessitando de grandes alterações no processo produtivo.
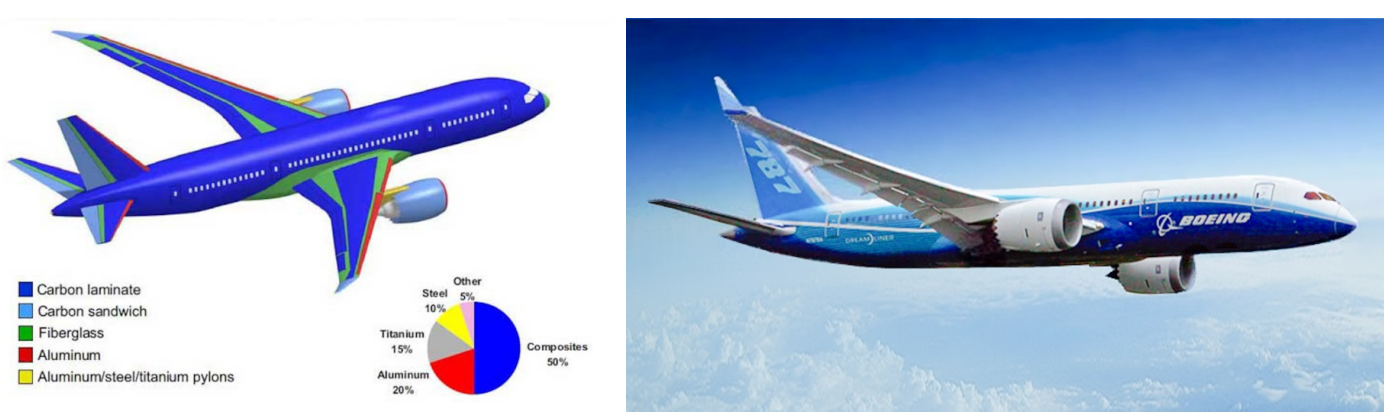

Figura 2: Boeing 787 Dreamliner.

O Boeing 787 Dreamliner, lançado em 2009, é o ícone do uso extensivo de materiais compósitos na indústria aeronáutica, possuindo estrutura altamente calcada em compósitos de carbono/epóxi, Figura 2.

As vantagens do uso de materiais compósitos são: 
- Elevada rigidez,

- Elevada resistência em fadiga,

- Boa resistência em fratura,

- Elevada resistência à corrosão,

- Boa resistência ao impacto e dano,

- Baixa expansão térmica.

Apesar destas, os compósitos apresentam desvantagens como:

- Processo de fabricação complexo,

- Geração de fumaça tóxica em combustão;

- Procedimentos exclusivo de projeto e montagem;

- Defeitos durante o processo de fabricação;

- Elevado custo de produção.

\subsection{ESFORÇOS EM ESTRUTURAS AERONÁUTICAS}

Uma aeronave está sujeita a diversos tipos de esforços, que devem ser considerados no projeto estrutural. São exemplos de esforços em uma estrutura aeronáutica:

- Esforços atuantes nas asas e fuselagem para suportar o peso próprio da aeronave;

- Esforços aerodinâmicos em asas e empenagens, durante o voo e manobras;

- Pressurização interna da aeronave para respiração e conforto dos ocupantes;

- Peso próprio e impacto com o solo em locais de fixação do trem de pouso.

- Efeitos de concentração de tensão causados pelas janelas; 
- Flutuações de esforços aerodinâmicos causado por turbulências.

Deve-se considerar que uma aeronave é projetada para atuar em regime contínuo de operação, podendo realizar diversos ciclos de voo durante todos os dias de operação. Além disso, existe uma diferença acentuada entre a temperatura no solo e durante o voo. Assim, é fácil observar que, além da resistência mecânica, que a resistência à fadiga (mecânica e térmica) é um aspecto fundamental para a seleção de materiais para estruturas aeronáuticas.

As cargas de impacto sofridas por uma aeronave também são importantes. Tais cargas são frequentes durante o tempo de operação de uma aeronave, podendo causar até danos irreparáveis à estrutura ou mesmo a queda de uma aeronave.

O impacto mecânico pode ser dividido em impacto de baixa e alta velocidade. Os impactos de baixa velocidade ocorrem com velocidades de até $5 \mathrm{~m} / \mathrm{s}$, podendo ser oriundos de

- Equívocos durante a manobra de aeronaves;

- Impacto de plataformas ou caminhões de apoio;

- Queda de ferramentas durante a manutenção;

- Impacto de bagagens no interior da aeronave.

Estes tipos de impacto, apesar de aparentemente pequenos, podem causar grandes prejuízos à estrutura, devendo ser reparados quando possível. Além disso, muitas vezes estes incidentes não são percebidos, podendo acumular dano ou gerar fissuras que podem prejudicar o funcionamento da aeronave em longo prazo. Por exemplo, em 2013, um caminhão de abastecimento do aeroporto de Imperatriz (Brasil), chocou-se contra a turbina de uma aeronave Airbus A-320, Figura 3. A aeronave ficou impossibilitada de voar, devendo ser reparada. 


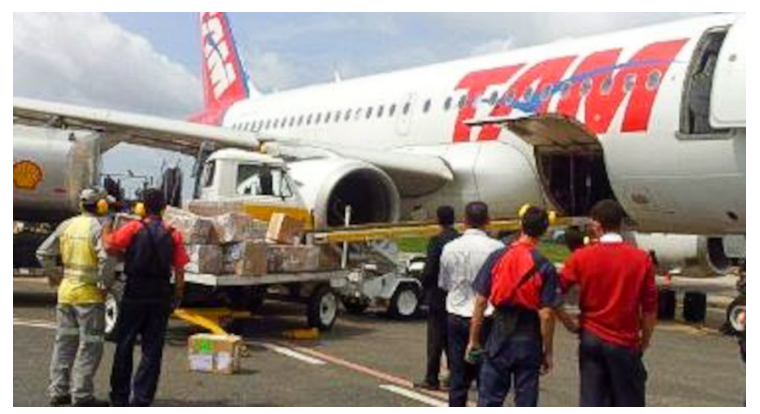

Figura 3: Impacto de um caminhão tanque contra a turbina de um A-320.

O impacto de alta velocidade ocorre com objetos em velocidades a partir de $50 \mathrm{~m} / \mathrm{s}$ chocando-se contra a aeronave. Em geral, o poder de destruição desse impacto é maior, podendo gerar grandes prejuízos à aeronave. A origem destes pode ser

- Impacto de pássaros;

- Impacto de objetos deixados na pista;

- Impacto de granizo;

- Impacto com o solo durante pouso ou queda;

- Explosões;

- Impacto balístico.

Um exemplo desse tipo de impacto ocorreu em julho de 2000, quando a aeronave Concorde caiu sobre a comunidade Gonesse, na França, causando a morte de 113 pessoas, Figura 4. Após investigação da agência do governo francês responsável, concluiu-se que o motivo da queda foi o impacto de um pedaço de pneu da própria aeronave, que estourou durante a decolagem devido a uma peça de outra aeronave deixada na pista. $\mathrm{O}$ impacto do pedaço de pneu ocorreu a aproximadamente $140 \mathrm{~m} / \mathrm{s}$ contra o tanque de combustível do Concorde, ocorrendo o vazamento de combustível e incêndio no motor esquerdo da aeronave. Posteriormente houve perda de potência dos motores e queda após 80 segundos de sua decolagem. Após o ocorrido, os tanques de combustível do Concorde receberam uma blindagem, no entanto, este acidente foi um dos causadores para o fim das operações dessa aeronave, em outubro 2003. 
(a)

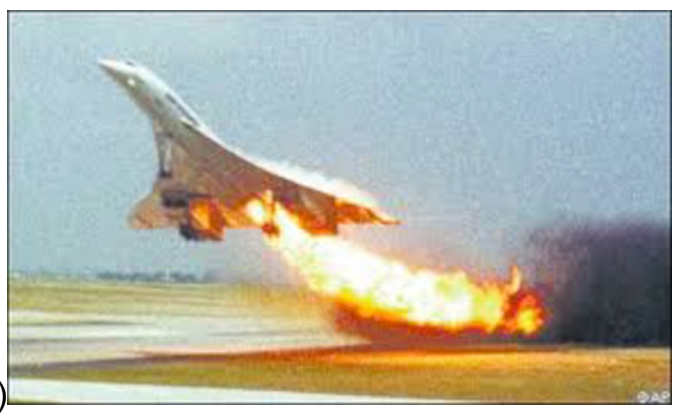

(b)

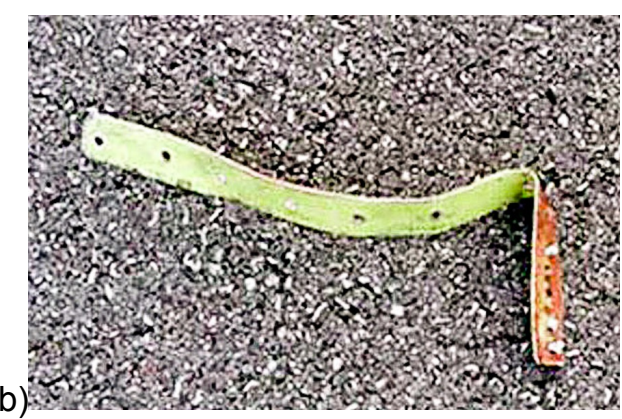

Figura 4: (a) Aeronave Concorde durante a decolagem, com turbina em chamas e (b) peça metálica de outra aeronave deixada na pista, que ocasionou o estouro do pneu.

Em janeiro de 2009, um Airbus A-320 chocou-se contra um grupo de gansos durante o voo que partiu de Nova lorque, no Estado Unidos, Figura 5. Com isso, houve perda de potência da aeronave, uma vez que as turbinas foram atingidas. Impossibilitado de realizar o retorno ao aeroporto, o piloto foi forçado a realizar um pouso de emergência nas águas do rio Hudson. Apesar da gravidade do evento, a habilidade do piloto possibilitou um pouso com sucesso e os 155 passageiros e tripulantes saíram ilesos do acidente.

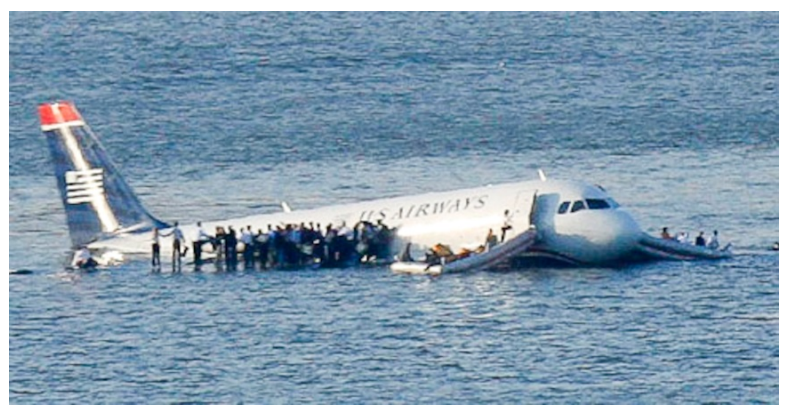

Figura 5: Aeronave Airbus A-320 após pouso de emergência no rio Hudson.

Diversas partes de aeronaves devem ser projetadas a fim de que suportem cargas de impacto. São exemplos destas os bordos de ataque de asas e empenagens, janelas frontais, revestimento de turbinas e parte frontal da cabine. Assim, o conhecimento do comportamento de materiais aeronáuticos quando submetido a cargas de impacto de alta e baixa velocidade é fundamental para o projeto estrutural aeronáutico. Além disso, uma vez ocorrido impacto, é necessário saber avaliar a possibilidade de continuidade de operação, reparo ou mesmo descarte da aeronave. $\mathrm{Na}$ Figura 6 é apresentado o processo de reparo de impactos ocorridos na fuselagem de um Airbus A-320 durante manutenção preventiva. 
(a)

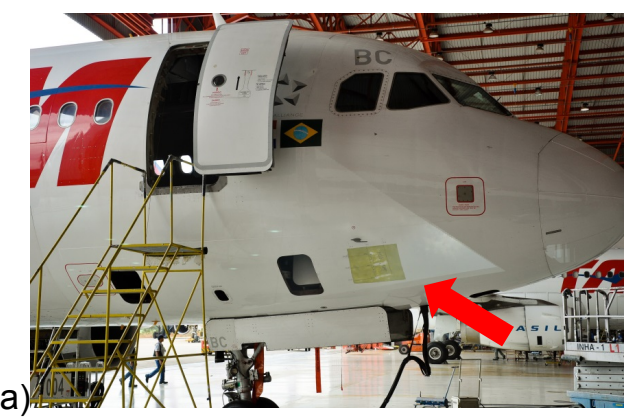

(b)

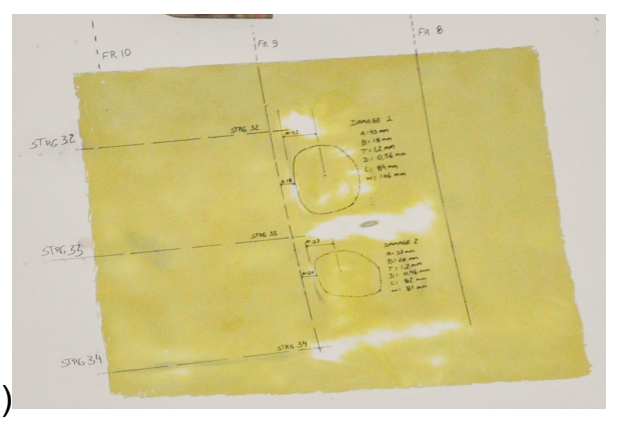

Figura 6: (a) Aeronave em manutenção para reparo de impacto em fuselagem e (b) detalhe do processo de inspeção e reparo.

\subsection{LAMINADOS FIBRA-METAL: UM NOVO MATERIAL AERONÁUTICO}

$\mathrm{Na}$ busca por novos materiais para uso em estruturas aeronáuticas, a Universidade tecnológica de Delft, na Holanda, desenvolveu pesquisas relacionadas com painéis colados e materiais híbridos, chegado ao desenvolvimento dos Laminados Fibra-Metal (ou FML do inglês, Fibre-Metal Laminates). Estes materiais são constituídos por camadas finas de alumínio aeronáutico e compósitos coladas, Figura 7. Os primeiros materiais desenvolvidos eram combinações de carbono/epóxi ou aramida/epóxi com lâminas de alumínio, titânio ou aço. Porém, apenas na década de 90 houve o desenvolvimento de um material promissor denominado GLARE (acrônimo para e expressão em inglês Glass Reinforced), constituído por compósitos préimpregnados de vidro/epóxi com lâminas de liga de alumínio aeronáutico.
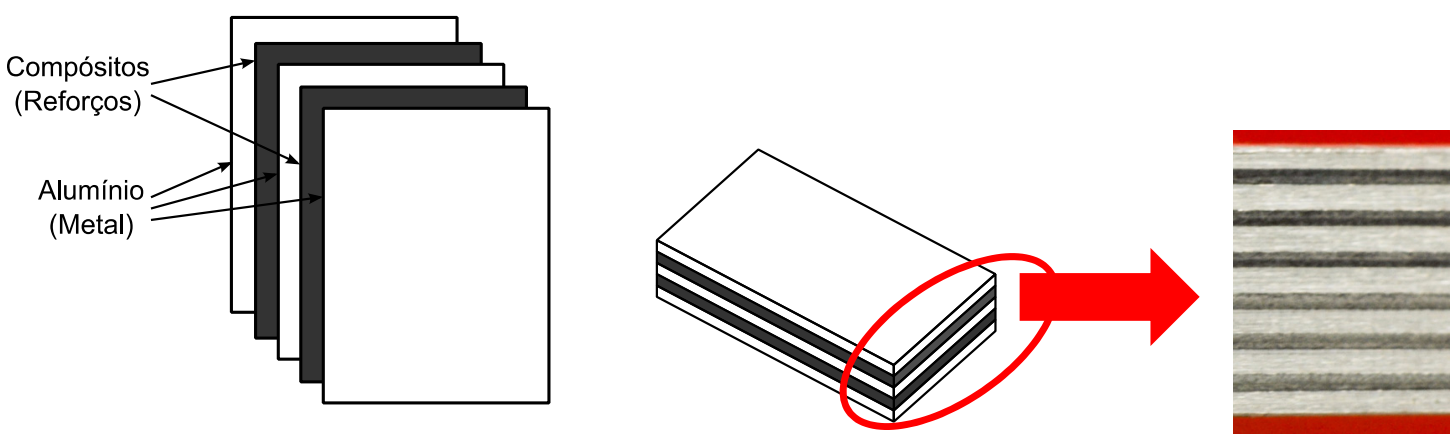

Figura 7: Representação esquemática de um laminado fibra-metal (FML). 
O desenvolvimento deste material foi motivado incialmente pela melhoria da vida em fadiga da estrutura, sendo apenas posteriormente observado um bom desempenho para absorção de cargas de impacto. Após um extenso trabalho de desenvolvimento e certificação do GLARE, este material foi selecionado para utilização em partes da fuselagem superior e bordos de ataque de asas e empenagens da aeronave Airbus A380 (Vlot, 2001), sendo fabricado pela empresa Stork Fokker, na Holanda. Além deste, os FMLs são utilizado na aeronave MacDonnell Douglas C-17.

De forma geral, as vantagens para o uso de FML são:

- Baixo peso específico;

- Alta resistência mecânica;

- Boa tolerância ao dano;

- Resistência à corrosão;

- Resistência à fadiga;

- Resistência ao fogo;

- Alta resistência ao impacto;

- Fácil reparação;

- Baixa manutenção;

- Isolamento térmico;

- Processo de usinagem semelhante dos metais.

O GLARE (ou FMLs), assim como compósitos, apresentam comportamento diferenciando com a mudança de direção de alinhamento das fibras ou forma de empilhamento deste. Assim, determinadas configurações de FML podem possuir aplicações específicas em estruturas aeronáuticas, como exemplificado na Tabela 1. 
Tabela 1: Aplicações para diferentes configurações de GLARE (Sinmazçelik, 2011).

\begin{tabular}{lcccccc}
\hline Tipo & Sub. & $\begin{array}{c}\text { Tipo de } \\
\text { Metal }\end{array}$ & $\begin{array}{c}\text { Espessura } \\
\text { do metal } \\
(\mathbf{m m})\end{array}$ & $\begin{array}{c}\text { Espessura } \\
\text { do com- } \\
\text { pósito }\end{array}$ & $\begin{array}{c}\text { Orientação } \\
\text { do com- } \\
\text { pósito } \mathbf{~}^{\circ}\end{array}$ & Aplicação \\
\hline GLARE 1 & - & $\begin{array}{c}7475- \\
\text { T761 }\end{array}$ & $0,3-0,4$ & 0,266 & $0 / 0$ & Fadiga, resistência. \\
\hline GLARE2 & 2A & $2024-T 3$ & $0,2-0,5$ & 0,266 & $0 / 0$ & Fadiga, resistência. \\
\hline GLARE 3 & 2B & $2024-T 3$ & $0,2-0,5$ & 0,266 & $90 / 90$ & Fadiga, resistência. \\
\hline GLARE 4 & 4A & $2024-T 3$ & $0,2-0,5$ & 0,266 & $0 / 90$ & Fadiga, impacto \\
\hline GLARE 5 & 4B & $2024-T 3$ & $0,2-0,5$ & 0,266 & $0 / 90 / 0$ & Fadiga, resistência em $0^{\circ}$. \\
\hline GLARE 6 & 6A & $2024-T 3$ & $0,2-0,5$ & 0,266 & $90 / 0 / 90$ & Fadiga, resistência em $90^{\circ}$. \\
\hline
\end{tabular}

Em dezembro de 1988 um atentado terrorista detonou um explosivo que estava dentro de uma mala no compartimento de bagagem de um Boeing 747, durante o voo partido de Londres (Inglaterra), Figura 8. Esta explosão causou a queda da aeronave na cidade escocesa de Lockerbie, deixando 270 mortos. Segundo (Fleisher, 1996), se os contêineres de bagagem desta aeronave fossem fabricados com FML, estes poderiam absorver a carga de impacto da explosão, o que impediria este acidente.

(a)
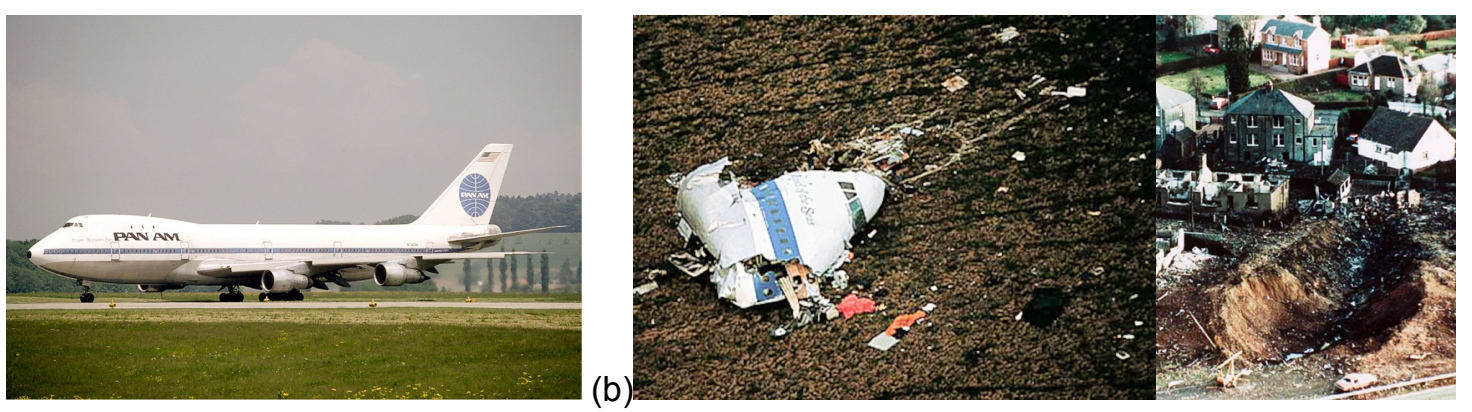

Fiqura 8: (a) Aeronave Boeing 747 e (b) imaqens do acidente em Lockerbie (Escócia).

Em dezembro de 2010, em Toronto (Canadá), um caminhão plataforma chocou-se contra a asa de um Airbus A-380, Figura 9a, deixando a aeronave fora de operação. Em abril de 2011, a ponta da asa de outro Airbus A-380 foi danificada ao ser impactada contra um prédio durante a movimentação da aeronave no aeroporto de Le Bourget (França), Figura 9b. 
(a)

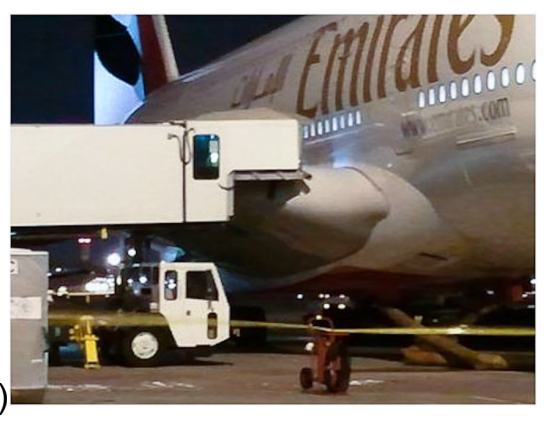

(b)

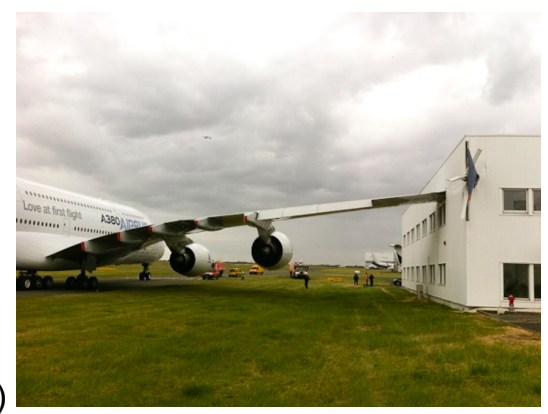

Figura 9: (a) Impacto de um caminhão plataforma na asa de um Airbus A-380 e (b) impacto da asa de um Airbus A-380 contra um prédio durante movimentação e solo.

Em outubro de 2010, uma das turbinas de um Airbus A-380 despalhetou durante o vôo por uma falha de projeto desta. Com a despalhetamento, uma peça da turbina da aeronave foi lançada em alta velocidade, atravessando completamente a asa esquerda desta, Figura 10. O voo partia da Australia e foi forçado a realizar um pouso de emergência em Singapura, com todos os passageiros e tripulantes em segurança.

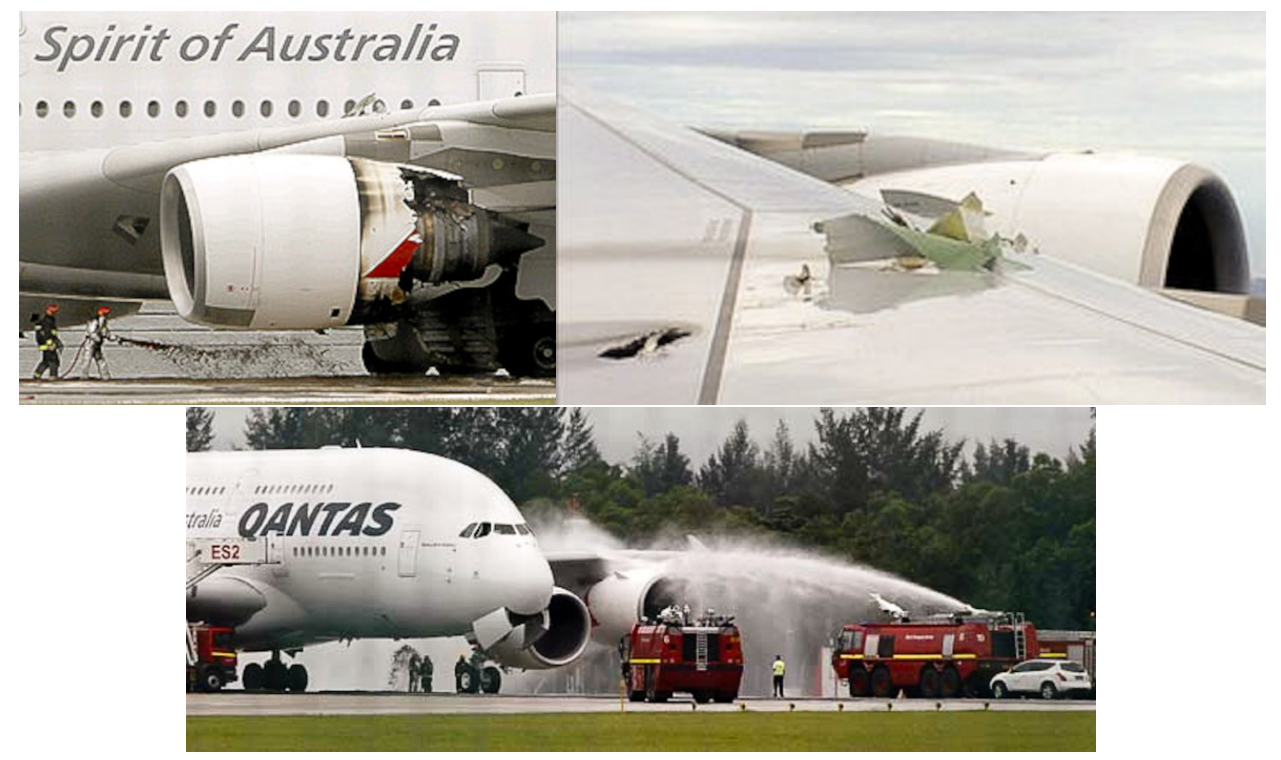

Figura 10: Explosão de umas das turbinas de uma Airbus A-380 durante o voo. Detalhe na perfuração da asa causado no incidente.

Segundo normas da FAA (Federal Aviation Adminstration), toda a região próxima às turbinas de aeronave devem ser projetadas para suportar uma eventual despalhetamento desta, possibilitando um pouso em segurança da aeronave. Assim, tendo em vista os casos apresentados acima, é necessário o conhecimento do com- 
portamento dos materiais aeronáuticos, como os FMLs ou o GLARE, em regime de impacto para projeto de estruturas aeronáuticas.

O grupo de pesquisa liderado por W. Cantwell realiza o desenvolvimento de uma nova geração de FML, com base em compósitos termoplásticos (Reyes e Cantwell, 1998; Abdullah, 2006; Nurick et al., 2007). Os TFMLs (do inglês, termoplastic fibre-metal laminates), visam reduzir custos de produção, aumentar a reciclabilidade e, principalmente, melhorar o desempenho para absorção de cargas de impacto do material. Estes materiais vêm sendo desenvolvido nos últimos 10 anos na Universidade de Liverpool (Inglaterra) e outras cooperadas, visando aplicações aeronáuticas, como também uso em outras estruturas leves submetidas ao impacto.

Em função do comportamento visco-elástico do termoplástico, os TFMLs apresentam bom comportamento em absorção de cargas de impacto. Em geral, o material de reforço termoplástico utilizado é constituído por fibras de vidro tipo S2 com matriz de polipropileno, denominado Twintex, ou fibras e matriz de polipropileno, cujo nome comercial é Curv.

\subsection{OBJETIVOS}

O presente trabalho visa estudar o comportamento ao impacto de laminados fibra-metal com reforços de um material inovador termoplásticos, constituído por fitas de alta resistência de polipropileno termomoldadas, sem existência de matriz polimérica. Com isso, objetiva-se propor uma melhor configuração de chapas planas circulares fabricadas deste, para fins de aplicação de impacto.

Para tanto, o presente trabalho almeja os seguintes objetivos secundários:

- Projeto de um dispositivo para realização da caracterização mecânica do TFML em taxas intermediárias de deformação;

- Fabricação de amostras de TFML a serem utilizadas para estudo proposto.

- Realização de uma campanha experimental de impacto de alta e baixa velocidade, visando identificar o comportamento do TFML ao impacto, assim como realizar a comparação do desempenho deste com FML 
termofíxos (semelhante a materiais comerciais) submetidos a mesma condição de impacto.

- Caracterização mecânica dos materiais constituintes do TFML em baixas, médias e altas taxas de deformação; sendo obtidos parâmetros constitutivos destes para fins de análise teórica e numérica.

- Avaliação teórica do desempenho de TFML, propondo adaptações a modelos teóricos para impacto de alta e baixa velocidade existentes, visando a aplicação de TFML.

- Desenvolvimento de um modelo numérico com o software comercial LS-Dyna v.971 capaz de representar o comportamento do TFML em cargas de impacto.

- Utilização dos modelos teóricos e numéricos para proposição de uma configuração ótima de TFML para aplicações em condições de impacto mecânico.

Para o desenvolvimento desta tese de doutorado foi adotada uma tríplice análise do fenômeno de impacto: teórica, numérica e experimental, conforme ilustra a Figura 11. Assim, é proposta a realização de uma campanha experimental, na qual é identificado o comportamento real do material em eventos de impacto controlados. Posteriormente, o fenômeno em questão é abordado de forma analítica, sendo compreendido o princípio básico que regem o evento de impacto em questão. Por fim, com a abordagem numérica, um modelo utilizando elementos finitos é desenvolvido, buscando representar o comportamento do material.

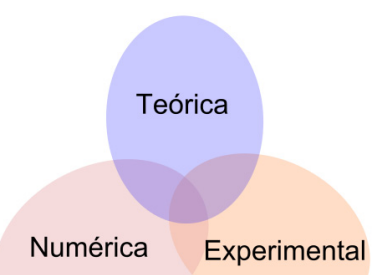

Figura 11: Tríplice abordagem teórica, numérica e experimental. 
A utilização desta abordagem possibilita a comparação e avaliação de resultados provenientes de análises distintas, provendo credibilidade aos resultados obtidos. Além disso, a compreensão do fenômeno por diferentes prismas gera embasamento para a formulação (ou questionamento) de hipóteses simplificadoras.

A Espiral de Projetos (Kaminski, 2000) foi utilizada para desenvolvimento das atividades deste doutoramento. Neste, todas as etapas do doutorado são desenvolvidas sucessivamente e de forma interativa, sendo aprofundada ao longo de cada interação. Ao final das interações, o desenvolvimento global do projeto é encaminhado ao um ponto ótimo de desenvolvimento, que define o final da pesquisa. A Figura 12 sumariza a Espiral de Projeto realizada para desenvolvimento deste trabaIho.

Assim, o trabalho aqui reportado é fruto de um desenvolvimento contínuo realizado de fevereiro/2009 a outubro/2013. Os resultados apresentado são as versões finais obtidas depois de abordagens interativas dos estudos propostos.

Por fim, vale ressaltar que o desenvolvimento deste doutorado foi realizado em cooperação com a Universidade de Liverpool (Inglaterra).

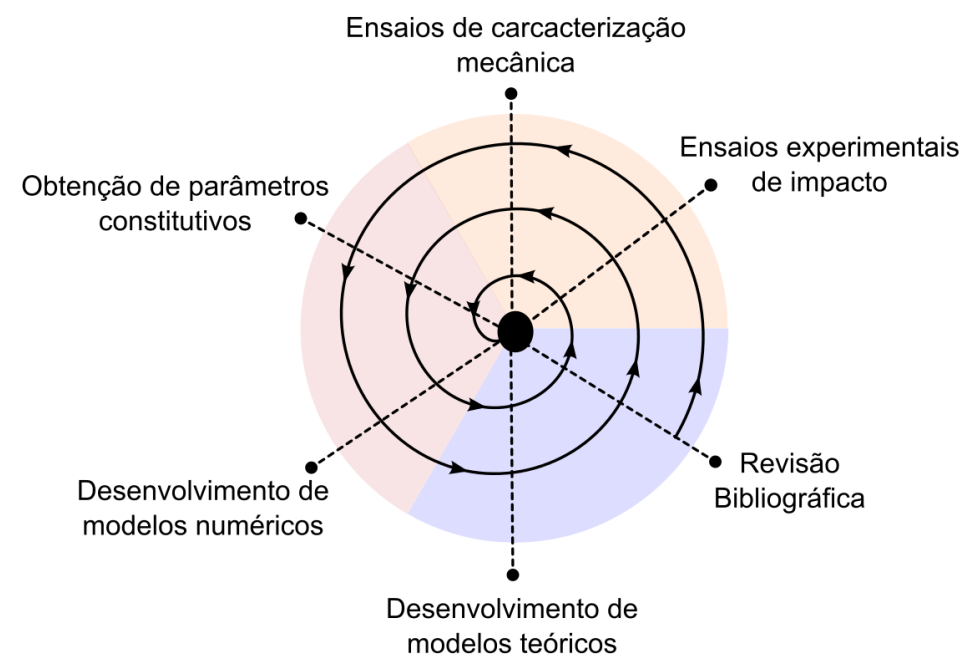

Figura 12: Espiral de projeto.

\subsection{VISÃO GERAL DA TESE}

No Capítulo 2 é realizada a revisão bibliográfica dos temas relevantes a serem abordados nessa tese, como caracterização mecânica de materiais, desempe- 
nho ao impacto de FML e TFML, estudos teóricos e numéricos de FML em eventos de impacto.

No Capítulo 3 é apresentado o desenvolvimento de um dispositivo para realização de ensaios de caracterização mecânica de materiais em taxas intermediárias de deformação, condição de solicitação relevante para caracterização de materiais termoplásticos.

O Capítulo 4 consta de detalhes do processo de fabricação utilizado nas amostras de TFML, assim como uma nomenclatura de identificação dos materiais estudados. Já no Capítulo 5 é apresentada a campanha experimental de impacto de baixa e alta velocidade em placas circulares, utilizando o martelo de impacto e canhão pneumático lançador de projéteis, respectivamente. Nestes experimentos busca-se a identificação da condição limite de falha e limite balístico, em eventos de impacto de alta e baixa velocidade. Amostras de FML termofíxos, similares a materiais comercias, também foram ensaiadas sob mesmas condições a fim de obter parâmetro de comparação de desempenho.

Os ensaios de caracterização mecânica para a caracterização dos constituintes do TFML são descritos no Capítulo 6. Os testes são realizados em uma ampla faixa de taxas de deformação, em diferentes formas de carregamento e utilizando técnicas de medição de deformação por imagens. Como parte final do processo de caracterização mecânica, parâmetros constitutivos dos materiais foram obtidos.

Com a conhecimento do comportamento experimental das amostras de TFML ao impacto (Capítulo 5) e caracterização mecânica dos materiais (Capítulo 6), no Capítulo 7 são propostos ajustes a modelos teóricos para ensaios de baixa e alta velocidade, visando sua aplicação em TFML.

No Capítulo 8 é desenvolvido o modelo numérico com o programa comercial Ls-Dyna v.971, utilizando parâmetros constitutivos definidos no Capítulo 5.

Com o conhecimento obtido do desenvolvimento do estudo experimental (Capítulos 5-6), teórico (Capítulo 7) e numérico (Capítulo 8), no Capítulo 9 é explanado o comportamento do impacto de TFMLs, sendo proposta uma configuração de TFML, ótima para aplicações em regime de impacto.

Por fim, o Capítulo 10 sumariza as conclusões obtidas ao longo deste trabaIho. 


\section{REVISÃO BIBLIOGRÁFICA}

\subsection{O DESENVOLVIMENTO DOS LAMINADOS FIBRA-METAL}

O desenvolvimento dos laminados fibra-metal (FML do inglês fibre-metal laminates) data do início dos anos 70 , oriundo da visão empreendedora da Universidade Tecnológica de Delft em cooperação com empresas do setor aeronáutico. Em (Vlot, 2001), o desenvolvimento deste material é descrito, sendo classificado como a quarta geração de materiais para estruturas aeronáuticas, após a madeira, alumínio aeronáutico e compósitos.

Assim como esperado dos materiais aeronáuticos, a resistência à fadiga foi o grande motivador para o desenvolvimento dos FMLs. O professor Boud Vogelesang, com experiência obtida com estudo de colagem de metais, deu inicio ao desenvolvimento do ARALL, sendo este um FML constituído por camadas de alumínio e compósitos de aramida/epóxi. Este material chega a apresentar vida em fadiga duas vezes maior que ligas de alumínio aeronáutico, tendo sido patenteado e utilizado em estruturas aeronáuticas de forma experimental. No entanto, foi descoberto que, apesar da boa de resistência à fadiga e resistência em cargas tração, o ARALL apresentava baixa resistência ao dano quando submetido a cargas de compressão. Nestes casos, a falha das fibras de aramida em compressão causava o descolamento das camadas do FMLs. Além disso, o processo de deteç̧ão dessa forma de falha era difícil e seu reparo de alto custo. Desse modo, o uso do ARALL em estruturas aeronáuticas primárias foi rejeitado, sendo destinado apenas à utilização em estruturas de baixo comprometimento mecânico.

Após o declínio do ARALL, no início dos anos 90, as atenções foram voltadas ao uso de compósitos vidro/epóxi como uma variação da aramida/epóxi. Esta nova combinação era motivada pela melhor adesão entre fibra-adesivo, o que possibilita a utilização de camadas mais finas de compósitos, além de haver boa combinação química do vidro com o alumínio. Este novo material foi denominado GLARE, sendo constituído por lâminas de alumínio aeronáutico e compósitos vidro/epóxi. Com a utilização de fibra de vidro tipo S2, de maior resistência mecânica, o GLARE apresentou comportamento a fadiga similar ou superior ao ARALL, com resistência ao 
dano e sem deficiências de adesão entre a fibra e o adesivo. Em 1991, Ad Vlot, então estudante de doutorado e posteriormente professor da Universidade de Delt, foi o responsável por identificar que o GLARE, além das boas propriedades em fadiga, possuía um excelente desempenho mecânico em regime de impacto.

Com o fracasso do ARALL como material aeronáutico, o GLARE precisou galgar sua aplicação em estruturas aeronáuticas, uma vez que naquele momento a indústria estava receosa com o uso de FMLs. O GLARE foi utilizado de forma experimental no estabilizador horizontal do Boeing $\mathrm{C}-17$ e o piso do compartimento de carga do Boeing 777. Apenas em 2001 o GLARE foi consagrado como material importante na indústria aeronáutica, com sua utilização na parte superior da fuselagem do AIRBUS A-380, a maior aeronave comercial em número de passageiros da atualidade.

\subsection{IMPACTO EM LAMINADOS FIBRA-METAL}

Os primeiros estudos de FML em regime de impacto foram realizados em (Vlot, 1987; Vlot, 1996), sendo comparado o desempenho de GLARE, ARALL, ligas de alumínio 2024-T3 e 7075-T6 e laminados de carbono/epóxi, quando solicitados em regime estático, em baixas e altas velocidades de impacto. Nestes estudos, os FMLs foram divididos em duas categorias: os FMLs com "comportamento crítico pelo compósito", como o ARALL, e os FMLs com "comportamento crítico pelo metal", como GLARE. Apesar do ARALL apresentar menor densidade e maior rigidez, o GLARE apresentou melhor desempenho ao impacto e maior tolerância ao dano.

Ainda nestes estudos, foi relatado que o GLARE apresenta comportamento semelhante às ligas de alumínio 2024-T3 e superior aos laminados de carbono/epóxi, em regime de baixa velocidade de impacto. Pelo motivo do vidro/epóxi apresentar comportamento sensível à taxa de deformação, o GLARE apresenta comportamento superior aos outros materiais quando solicitado à altas velocidades de impacto, Figura 13. 


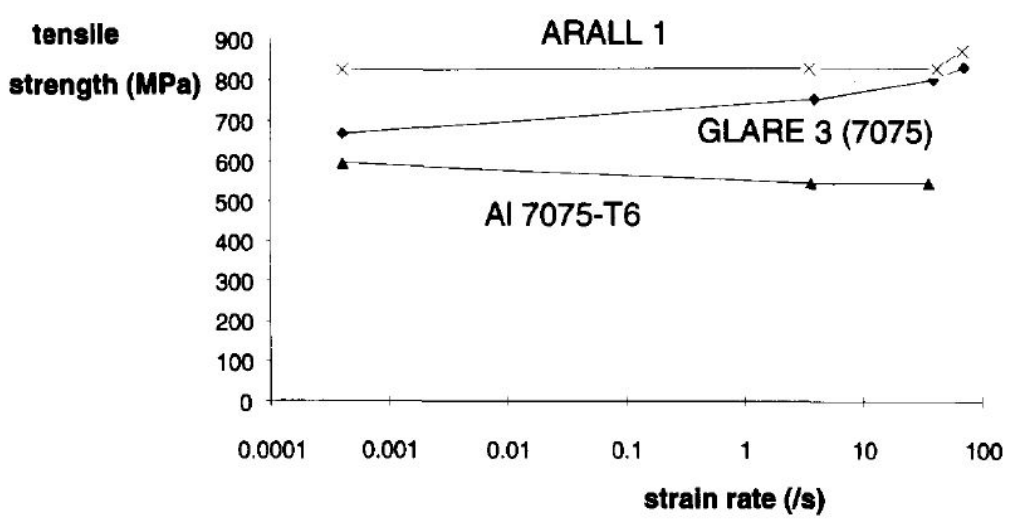

Figura 13: Comparação da resistência ao impacto do ARALL, GLARE e alumínio 7075-T6 (Vlot, 1996).

Vlot também observou que, uma vez que a liga de alumínio 7075 é mais rígida, com falha frágil, e que as ligas 2024 são menos rígidas, com comportamento dúctil, o GLARE fabricado com ligas 7075 (GLARE-1) apresenta energia até a ruptura em impacto cerca de 1/3 menor que energia até a ruptura de um GLARE semeIhante, mas com liga de alumínio 2024 (GLARE-2).

Em (Fatt et al., 2003) foi realizado o estudo do impacto de alta velocidade em GLARE, sendo observado que este material apresenta limite balístico cerca de 15\% maior que amostras de materiais monolíticos de alumínio 2024-T3 com a mesma densidade por área. Neste mesmo estudo, o autor avaliou o mecanismo de absorção de energia atuante no material, sendo observado que os esforços de flexão e de membrana absorvem cerca de $84 \%$ a $92 \%$ da energia; as delaminações são responsáveis por $2 \%$ a $9 \%$ de absorção de energia e cerca de $7 \%$ da energia é absorvida pela ruptura do material. $\mathrm{O}$ autor também afirma que os painéis mais finos conseguem absorver mais energia de impacto que os painéis mais espessos.

Ensaios de resistência pós-impacto em GLARE-5 foram conduzidos por Wu (Wu, Yang e Hahn, 2007) em espécimes submetidos ao impacto de 10 a $35 \mathrm{~J}$, sendo comparados com espécimes monolíticos de alumínio 2024-T3. Foram observados que ambos os materiais apresentam queda significativa de propriedades, quando submetidos a cargas de impacto maiores que 10J, porém o GLARE oferece resistência residual maior em todas as condições. Este autor, assim como em Vlot (Vlot, 1987), ressalta que o GLARE sempre apresenta uma identação visível a olho nu em locais de ocorrência de impacto, diferentemente dos materiais compósitos, o que torna a inspeção deste material mais fácil. 
Outras variantes de FML termofíxos também foram estudadas, como por exemplo, com carbono/epóxi e ligas de alumínio (Vlot, 1996) e vidro/epóxi com ligas de magnésio (Cortes e Cantwell, 2004). Apesar de algumas características peculiares encontradas em tais materiais, como blindagem eletromagnética ou aspectos de corrosão, poucos trabalhos foram encontrados sobre tais FMLs, mesmo assim, Sadighi (Sadighi, Alderliesten e Benedictus, 2012) concluí que a utilização desses materiais em estruturas aeronáuticas não irá prover melhorias significativas que justifique seu uso.

Praticamente todos os FMLs com aplicação aeronáutica utilizam compósitos de matrizes termofíxas, que proporcionam maiores rigidez, resistência e um bom desempenho em diferentes temperaturas. No entanto estes tipos de compósitos apresentam desvantagens, como fragilidade e longos processos para cura e adesão com o metal. Neste cenário, os FMLs com compósitos termoplásticos (ou TFML, do inglês termoplastic fibre-metal laminates) têm chamado atenção por propiciarem meIhoria da resistência, reciclabilidade e por utilizarem processos de fabricação mais rápidos e potencialmente mais baratos (Reyes e Kang, 2007).

Compston (Compston et al., 2001) estudou fratura de TFML e o mecanismos de absorção de energia destes materiais em regime de impacto. Neste trabalho foi observado que a sensibilidade à taxa de deformação, assim como a compressão transversal das camadas de compósitos termoplásticos são responsáveis pela absorção de energia neste material. Foi relatado também que a adesão compósitometal é fraca, o que pode fragilizar o TFML, mas também contribuir para a absorção de energia em alguns casos. Reyes (Reyes e Cantwell, 2000) caracterizou a camada adesiva de TFML utilizando a técnica do "Single Cantilivier Beam" em diferentes velocidades. Foi observado que a taxa de deformação influencia o comportamento da camada adesiva, apresentando um aparente aumento da energia de deslocamento por área. Reyes também identificou que a Regra das misturas é capaz de prever razoavelmente bem o comportamento do TFML a partir do comportamento de cada um dos seus constituintes e a respectiva proporção volumétrica destes.

Composton (Compston et al., 2001) também observou que o limite balístico TFML durante impacto de alta velocidade pode ser até $50 \%$ maior que ligas de alumínio monolítico equivalente. Uma vez que o GLARE apresenta limite balístico cerca de $35 \%$ maior que o alumínio equivalente, segundo (Fatt et al., 2003), pode-se concluir que o TFML pode apresentar limite balístico cerca de $15 \%$ maior que o GLARE. 
Aquele trabalho também avaliou o comportamento de TFML quando impactado por diferentes geometrias de indentadores. Foi observado que os indentadores de face plana acabam extraindo um disco da região de impacto no TFML, produzindo falha por cisalhamento. Por sua vez, os indentadores semi-hemisféricos produzem grandes deformações plásticas e ruptura por esforços de membrana, absorvendo mais energia que o primeiro caso.

Vale frisar que durante o processo de fabricação dos TFML, o material pode ser submetido a temperaturas próximas de até $240^{\circ} \mathrm{C}$, o que podem causar perda na ductilidade da liga de alumínio 2024-T3 (Vlot, 1987).

Abdullah (Abdullah e Cantwell, 2006; Abdullah, 2006) desenvolveu o estudo de impacto de TFML em eventos de impacto de alta e baixa velocidade, estudando o desempenho de diferentes configurações de materiais, Figura 14. Em eventos de baixa velocidade de impacto foi observado um comportamento semelhante para TFML com configuração 2/1 e 3/2, e um desempenho menor do TFML 4/3, com relação à absorção de energia de impacto.

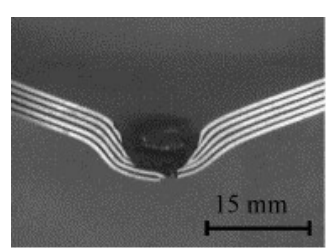

(a) Impact energy $=228.4 \mathrm{~J}$

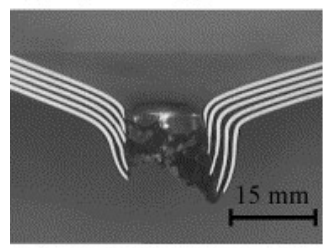

(b) Impact energy $=244.2 \mathrm{~J}$

(i)

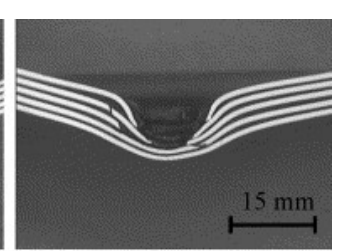

(c) Impact energy $=299.7 \mathrm{~J}$

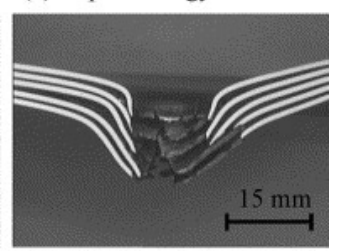

(d) Impact energy $=353.7 \mathrm{~J}$

(ii)

Figura 14: Eventos de impacto de alta velocidade em TFML (Abdullah, 2006).

Neste estudo os autores propuseram uma comparação inovadora de desempenho de uma TFML com configuração 3/2 com outro material semelhante, constituído por duas camadas de alumínio coladas, sem a camada interna de compósito. Neste caso, foi observado que o TFML propiciou um desempenho três vezes maior que o material de comparação, com relação à absorção de cargas de impacto.

Outra análise realizada neste trabalho foi conduzida com o intuito de manter a espessura final do TFML, variando-se a espessura e configuração das camadas de 
alumínio e compósito. Foi observado que o TFML com lâminas de alumínio mais espessas apresentam melhor desempenho com relação à absorção de cargas de impacto. No entanto, quando a energia normalizada pela espessura de metal é avaliada, observa-se que o desempenho começa a cair, como consequência da diferenciação da forma de ruptura do material de estiramento para cisalhamento. Foi observado que a utilização de compósitos de baixo módulo (como os termoplásticos) possibilita o comportamento praticamente independente das camadas de alumínio, produzindo com comportamento do TFML dominado pelo comportamento do metal. Assim, a utilização de camadas mais finas de alumínio possibilita a absorção de maiores cargas de impacto.

Um extenso estudo de cargas explosivas em FML e TFML foi conduzido por Langdon (Langdon, Cantwell e Nurick, 2005; 2007; Langdon, Lemanski, et al., 2007; Langdon, Nurick, et al., 2007; Lemanski et al., 2007; Langdon, Nurick e Cantwell, 2008; Langdon et al., 2009), sendo ensaiadas diversas configurações de materiais e formas de solicitação, Figura 15. As explosões localizadas geram grandes deformações de membrana, sendo que, para os painéis mais espessos, foi observado o descolamento da ultima camada oposta ao impacto. Em alguns casos foi observada deformação do material em forma cruciforme (ou ruptura tipo formato de diamante). Um estudo limitado foi realizado com a utilização de GLARE, sendo observado que este material é mais propício a formações de buracos após a explosão, possivelmente em virtude do comportamento frágil do compósito termofíxo. Para ensaios de explosões distribuídas, um comportamento indesejável foi obtido, com o estiramento das extremidades dos painéis.

(a)

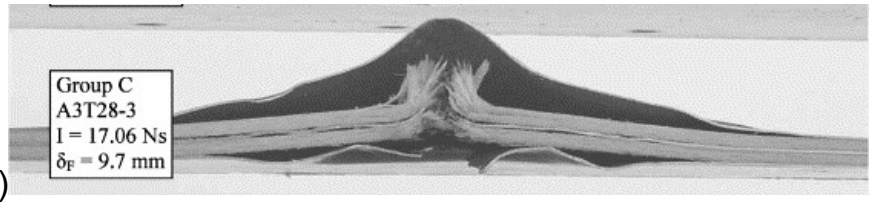

(b)

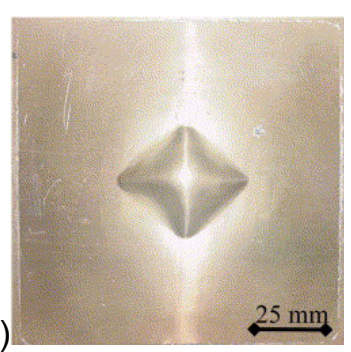

Figura 15: Eventos de impacto explosivos em TFML: (a) amostra em corte, com descolamento da face oposta, e (b) deformação do material em forma crunciforme. (Langdon, Cantwell e Nurick, 2005; Lemanski et al., 2007). 


\subsection{ESTUDO TEÓRICO DO IMPACTO EM FMLS}

Conforme pesquisa bibliográfica realizada sobre o tema de impacto mecânico em FML, foi observado que a grande maioria dos estudos é baseada em abordagens experimentais sobre o evento. Poucos estudos foram identificados no tocante de modelagem teórica do evento de impacto em FML.

Um exemplo de abordagem teórica foi conduzida por Vlot (Vlot, 1996) que utilizou as equações de Von Kármán para pequenos deslocamentos e deslocamentos moderadamente grandes para uma placa circular submetida ao impacto central de baixa velocidade. A energia absorvida pela placa foi estimada com a definição de um perfil de deslocamento da placa durante o impacto, sendo, assim, possível prever o deslocamento central residual de amostras de GLARE-3 e ligas de alumínio 2024T3.

Hoo Fatt (Fatt et al., 2003) formulou uma análise teórica do evento de impacto de alta velocidade em amostras de GLARE-5. O autor dividiu a energia total absorvida pela placa em energia absorvida por deformações plásticas; por delaminações nas camadas de compósito; por descolamento nas interfaces metal/compósito; por ruptura do compósito; e para a separação das camadas de alumínio. Tais energias foram devidamente modeladas, sendo capazes de estimar o limite balístico do material. Além disso, esta abordagem possibilitou a avaliação da contribuição de cada solicitação no comportamento do material, conforme apresentado no Item 2.2.

Abdullah (Abdullah, 2006) utilizou a formulação de Reid-Wen (Reid e Wen, 2000), originalmente desenvolvida para impacto balístico em materiais sanduiches, para a predição do limite balístico compósitos e ligas de alumínio monolíticas com razoável acurácia.

Karagiozova (Karagiozova et al., 2010) desenvolveu um modelo elásticolinear para estudo de TFMLs submetidos a cargas explosivas. Tal modelo foi capaz de prever o deslocamento das camadas do material durante a fase inicial do fenômeno. 


\subsection{ESTUDO NUNÉRICO DO IMPACTO EM FMLS}

Na pesquisa bibliográfica realizada, foi observado um aumento do número de trabalhos publicados nos últimos cinco anos envolvendo análises numérica de impacto em FML.

Fan (Fan, Guan e Cantwell, 2011) realizou a simulação numérica de GLARE em eventos de impacto de baixa velocidade, utilizando o programa comercial Abaqus. O alumínio foi modelado com formulação elasto-plástica, com critério de escoamento e dano de Von Mises e o compósito foi modelado utilizando formulação ortotrópica e critério de falha de Hashin. Diferentes configurações de empilhamento do material, formas de carregamento e indentadores foram estudados.

Karagiosova (Karagiozova et al., 2010) desenvolveu a modelagem numérica do estudo de eventos explosivos em TFML realizados por Langdon (Langdon, Lemanski, et al., 2007; Lemanski et al., 2007), Figura 16. O autor utilizou o programa comercial Abaqus, sendo consideradas oito configurações do material. O modelo foi capaz de prever as duas fases do movimento: uma relacionada com a compressão das camadas do material e outra relacionada com o movimento global do espécime. Efeitos de descolamento de camadas foram também identificados pelo modelo. Por fim, foi concluído que o efeito de taxa de deformação exerce grande influência no comportamento do material, uma vez que foi observado que este pode chegar à valores próximos a $10^{4} / \mathrm{s}$. Foi ressaltando também a capacidade da ferramenta numérica em modelar eventos explosivos em TFML, com a ressalva apenas para a limitação dos modelos de dano existente no programa, que forneceram resultados insatisfatórios. Critérios de falha e dano não foram explorados.

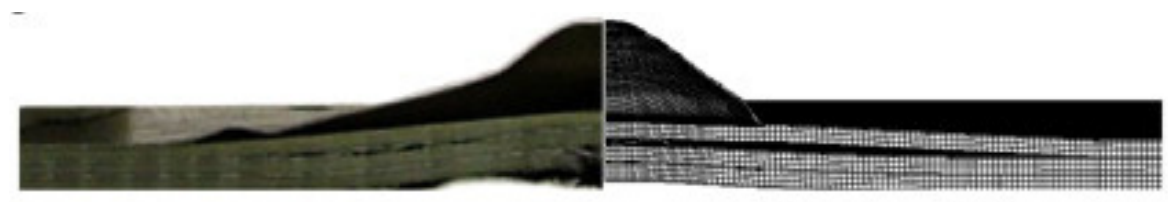

Figura 16: Comparação numérico-experimental de resultados para estudo de eventos explosivos em TFML (Karagiozova et al., 2010). 
Guan (Guan, Cantwell e Abdullah, 2009) modelou o impacto de alta velocidade em amostras de TFML, utilizando o programa comercial Abaqus. O alumínio e compósito foram modelados com elemento sólidos, modelo de material elastoplástico e isotrópico, respectivamente. A camada adesiva não fora modelada, estando os elementos perfeitamente aderidos. Apesar da aparente simplicidade na modelagem do material, uma boa correspondência foi obtida com relação ao modelo de deformação e mecanismos de falha para diferentes configurações de materiais.

McCarthy (Mccarthy, Xiao, Mccarthy, et al., 2004; Mccarthy, Xiao, Petrinic, et al., 2004) realizou a simulação numérica do impacto de pássaros em um bordo de asa fabricado com GLARE, utilizando o programa comercial PAM-CRASH. Atenção foi dada a modelagem dinâmica do material e utilização de elementos SPH (Smooth Particles Hydrodynamics) para modelagem da ave. O modelo pode prever a extensão do dano na estrutura, porém superestimou a força máxima exercida por este. Um boa correlação foi identificada com o comportamento global da estrutura, apesar de apresentar menor deformação e modo diferente de dobra do material quando comparado com ensaios experimentais. A plasticidade não foi considerada nesta análise.
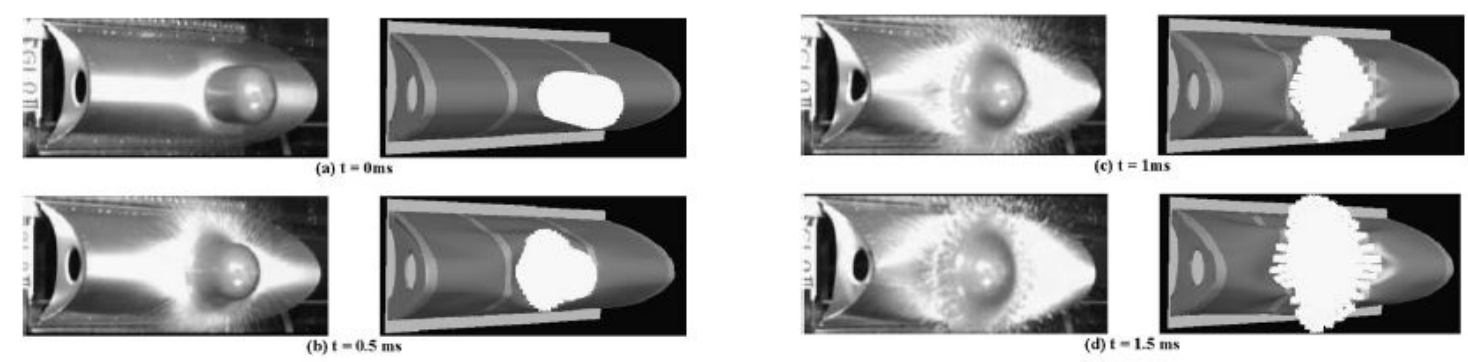

Figura 17: Comparação numérico-experimental do impacto de uma ave em um bordo fabricado com GLARE (Mccarthy, Xiao, Mccarthy, et al., 2004; Mccarthy, Xiao, Petrinic, et al., 2004).

\subsection{REFORÇOS TERMOPLÁSTICOS}

Os compósitos termoplásticos têm ganhado cada vez mais destaque na indústria e pesquisas, em parte devido a redução de custo de fabricação, reciclabilidade e melhor resistência mecânica, à fadiga e impacto. É importante frisar que os 
compósitos termofíxos, como os epóxis, vinil-esteres ou poliéster, não são recicláveis, o que praticamente inviabiliza a utilização extensiva em determinados setores, como o automotivo ou de eletrodomésticos, onde existem normas rígidas para o descarte dos materiais utilizados. Além disso, o processo de fabricação de compósitos termofíxos é caro e muitas vezes tóxico. Assim, as atenções têm sido voltadas para os compósitos termoplásticos como a aposta do setor para aplicações com maiores restrições ambientais e orçamentárias. Os compósitos termoplásticos possuem menor custo produtivo e são recicláveis, porém ainda apresentam propriedades mecânicas menores que os demais.

Apesar da aparente desvantagem destes em função das propriedades mecânicas inferiores, os compósitos termoplásticos apresentam características próprias que muitas vezes justificam a sua utilização. Os polímeros termoplásticos podem atingir grandes níveis de deformação em virtude de seu comportamento viscoelástico. Do mesmo modo, o efeito de taxa de deformação destes materiais, em geral, aumenta da rigidez quando este é solicita em taxas mais elevadas. Por fim, os termoplásticos podem apresentar ruptura dúctil e baixa densidade. Assim, tais propriedades acima descritas claramente mostram que os compósitos termoplásticos podem apresentar um bom desempenho para absorção de cargas de impacto e fabricação de estruturas leves.

Os compósitos termoplásticos fabricados com polipropileno (PP) são os mais extensivamente pesquisados. Este material apresenta baixo custo e pode apresentar alterações significativas em seu comportamento quando a este são adicionados aditivos ou outros processos produtivos são utilizados. Por exemplo, a adição de aditivos maleicos pode melhorar a adesão deste com materiais metálicos ou o estiramento as moléculas durante a polimerização, para aumentar o grau de alinhamento das moléculas e, consecutivamente, sua resistência mecânica.

Nos últimos anos foi observado o uso de compósitos termoplásticos no mercado. O Twintex (Figura 18a) é fabricado pela empresa Fiber Glass Industries (Fgi, 2013) e consiste em fibras de vidro embebidas em uma matriz de PP. Este material é fornecido em forma de fitas unidirecionais ou tecido, e utiliza o processo da termomoldagem para fabricação de peças. Os trabalhos de Langdon (Langdon, Lemanski, et al., 2007; Lemanski et al., 2007) utilizaram Twintex para fabricação de amostras de TFML, apresentado bom desempenho para eventos explosivos. 
O Curv (Figura 18-b) é um tecido totalmente fabricado em PP, contendo micro-fitas ('tapes") de PP embebidos em uma matriz do mesmo material, sendo fabricado pela empresa Propex. Pelo motivo dos filamentos e matriz possuírem aditivos distintos em sua formulação e alta grau de alinhamento das moléculas dos filamentos, a fusão dos micro filamentos e matriz não ocorre se o material for termomoldado dentro de uma faixa de temperatura especificada pelo fabricante. Assim, para o material Curv é possível identificar visualmente a existência de filamentos de alta resistência envoltos em uma matriz polimérica, ambas de PP. Este material é utilizado para fabricação de capacetes, joelheiras e outros equipamentos de proteção pessoal. Em trabalhos como o de Reyes (Reyes e Kang, 2007) e Abdullah (Abdullah, 2006), o Curv foi utilizado para fabricação de TFMLs, apresentando bom desempenho para eventos de impacto de baixa e alta velocidade.

A empresa Lanhorst recentemente desenvolveu um novo compósito totalmente constituído por PP, denominado PURE (Figura 18-c), constituído por micro-fitas ("tapes") de alta resistência de PP sem a existência de uma matriz polimérica. Neste material, as próprias fitas possuem um revestimento que propicia sua adesão entre estas. O Pure, assim como os demais, apresenta um bom desempenho ao impacto, sendo utilizado para fabricação de dispositivos de proteção a explosões, com containers, revestimentos militares e capacetes. O Pure tem sido classificado como um substituto para os compósitos de aramida/epóxi.

Nos trabalhos de Alcock (Alcock et al., 2006; Alcock, Cabrera, Barkoula, Reynolds, et al., 2007) o processo de fabricação do PURE foi realizado, assim como sua caracterização química e mecânica. Foi observado que o Pure apresenta comportamento sensível à taxa de deformação, à temperatura e também ao processo produtivo adotado, principalmente à temperatura e pressão utilizada na termoldagem. Em determinadas condições de fabricação, o Pure apresenta resistência ao impacto maior que compósitos vidro/PP (similares ao Curv) e desempenho superior ao vidro/epóxi e aramida/epóxi quando a densidade do material é levada em consideração. 
(a)

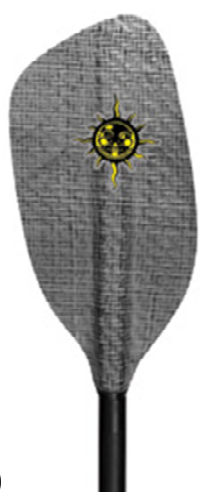

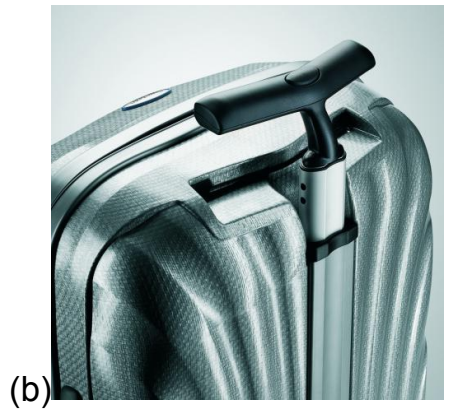

(c)

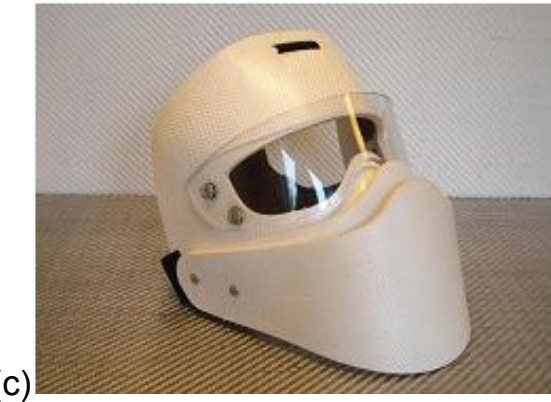

Figura 18: (a) Remo náutico fabricado em Twintex, (b) mala de viagem fabricada em Curv e (c) capacete de proteção a explosões fabricado em Pure.

O Pure foi utilizado para a fabricação dos TFMLs utilizados para o desenvolvimento desta tese e mais detalhes sobre este material serão apresentados no Capítulo 4.

\subsection{ASPECTOS INOVADORES DA PESQUISA}

Com base na revisão bibliográfica apresentada anteriormente, esta tese de doutorado apresenta os seguintes aspectos inovadores:

- Não foram encontrados relatos de utilização de Pure para fabricação de TFML.

- A caracterização de polímeros, em médias taxas de deformação, assim como o desenvolvimento de um equipamento para este fim, é um campo continuamente pesquisado, dado margem a novos desenvolvimentos.

- Não foram encontradas pesquisas sobre impacto em FML onde o fenômeno é abordado de forma ampla em um único estudo.

- Estudo concomitante do impacto a baixa e alta velocidade.

- Abordagem ampla, envolvendo aspectos de fabricação, caracterização, experimentação, modelagem teórica, modelagem numérica e otimização para o material em questão. 
- Desenvolvimento de modelos teóricos e numéricos capazes de representar o comportamento do TFML ao impacto são contribuições relevantes para projetos de dispositivos fabricados com tais materiais.

- Este estudo busca continuamente confrontar resultados teóricos e numéricos contra ensaios experimentais de impacto e caracterização mecânica, buscando uma avaliação e questionamento dos resultados provenientes destes. 



\section{UM DISPOSITIVO PARA CARACTERIZAÇÃO DE MATERIAIS EM TAXAS INTERMEDIÁRIAS DE DEFORMAÇÃO}

Neste capítulo será apresentado o projeto de um dispositivo para testes de caracterização de materiais em taxas intermediárias de deformação. Este será utilizado para a identificação do comportamento do FML termoplástico e seus constituintes em regime dinâmico. Com base em (Sharpe, 2008), as taxas intermediárias de deformação de deformação definidas entre $1 / s$ e $10^{2} / s$.

O projeto de um dispositivo para este fim envolve cargas substancialmente altas (da ordem de até $100 \mathrm{kN}$ ), aplicada abruptamente em um intervalo de tempo da ordem de poucos milissegundos. Ressonâncias e vibrações causadas pelo carregamento súbito podem interferir na qualidade da medição realizada. Por esse motivo, não existe um consenso entre os pesquisadores sobre a melhor configuração de um equipamento para ensaios sob tais condições. Na Figura 19 são apresentados diferentes equipamentos utilizados para ensaios de caracterização em diversas taxas de deformação. Nota-se que não existe uma definição de equipamento para o intervalo de taxa de deformação abordado.

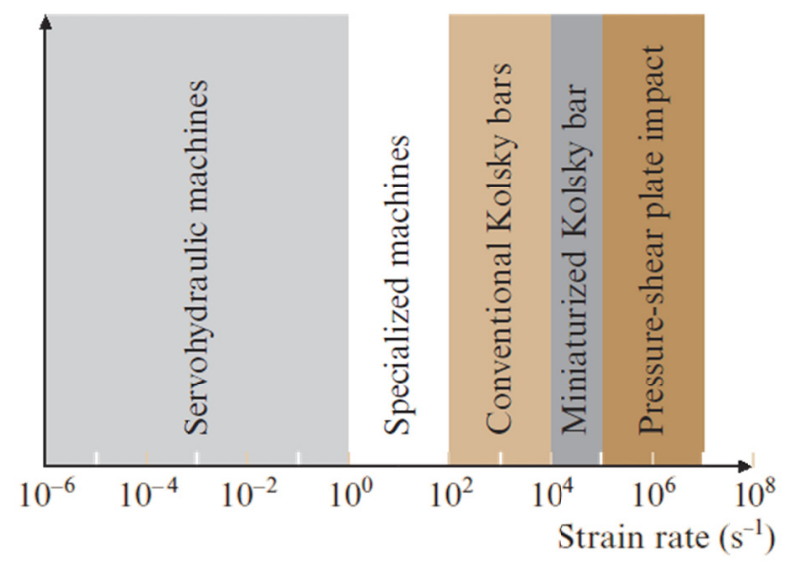

Figura 19: Equipamentos utilizados para realização de ensaios de caracterização mecânica em diferentes taxas de deformação (Sharpe, 2008).

Neste capítulo serão apresentados alguns equipamentos utilizados nesta aplicação, sendo então definidas as limitações de projeto e seleção de uma configuração a ser adotada. Esta configuração será desenvolvida utilizando ferramentas CAD 
e método dos elementos finitos. Por fim, um teste de tração em taxa de deformação intermediária será apresentado, a fim de avaliar o desempenho do equipamento projetado.

\subsection{DISPOSITIVOS DE ENSAIOS DE CARACTERIZAÇÃO MECÂNICA EM MÉ- DIAS TAXAS DE DEFORMAÇÃO}

Em condições gerais, uma máquina de ensaio de tração universal realiza o ensaio de tração em regime quase estático $\left(10^{-4} / s \leq \dot{\varepsilon} \leq 1 / s\right)$. Neste caso, um corpo de prova com comprimento relativamente longo (da ordem de dezenas de milímetros) é tracionado à velocidade baixa (geralmente da ordem de poucos milímetros por minuto). Isto define um regime praticamente estático, onde todo o comprimento útil do espécime é submetido ao mesmo regime de solicitação, não sendo geradas vibrações ou desequilíbrios ao longo deste. Estes equipamentos utilizam atuadores eletromecânicos ou hidráulicos, com possibilidade de controle por malha fechada. A força aplicada ao espécime é usualmente medida em célula de carga resistiva, e a medição de deformação é realizada por extensômetros tipo "clip-gage". Uma vez que este teste é realizado a baixa velocidade, tanto a célula de carga quando o extensômetro não apresentam alta resposta no domínio da frequência.

Para a identificação do comportamento do material em altas taxas de deformação $\left(10^{2} / s \leq \dot{\varepsilon} \leq 10^{4} / s\right)$, tem-se observado um consenso no uso da barra de Hopinson ou barra de Kolsky (Sharpe, 2008), Figura 20. Neste, o espécime testado é fixado entre duas barras longas e uma barra menor, denominada striker, é acelerada contra uma extremidade da barra de entrada. Este impacto gera um pulso elástico de compressão, o qual é propagado ao longo das barras. Ao chegar na extremidade oposta, parte do pulso é transmitido à barra de saída, atravessando o espécime, e a outra parte é refletida, permanecendo na primeira barra. Os pulsos gerados nas barras são medidos com o uso de extensômetros fixados na superfície das barras. A partir da superposição de tais pulsos, e utilizando teoria de propagação de ondas, é possível identificar a curva tensão-deformação do material em elevadas taxas de deformação. 


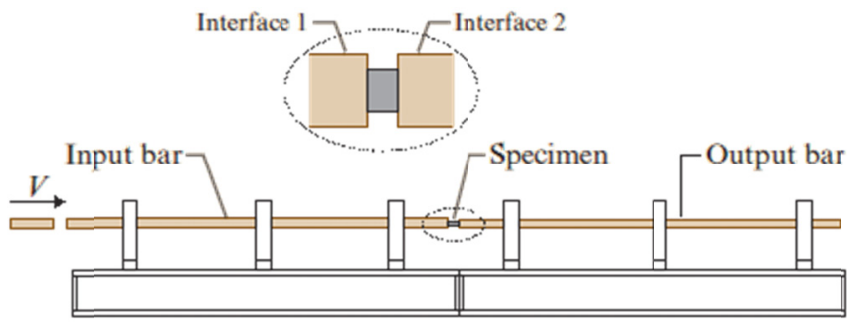

Figura 20: Esquema de funcionamento de uma barra de Hopkinson (Sharpe, 2008).

É importante frisar que a condição de equilíbrio dinâmico é uma premissa para utilização da teoria de propagação de ondas elásticas, devendo esta ser avaliada durante a realização do teste neste equipamento. A condição de equilíbrio consiste em avaliar as forças nas extremidades do espécime, que devem ser o mais uniforme possível. Este equilíbrio é mais facilmente atingido em corpos de prova com pequenas dimensões, de onde o uso de corpos de prova com poucos milímetros de comprimento útil (usualmente de $1 \mathrm{~mm}$ a $10 \mathrm{~mm}$ ) são normalmente empregados na barra de Hopkinson. Geralmente, a condição de equilíbrio não é observada nos instantes iniciais do teste, sendo o equilíbrio dinâmico normalmente atingido nas porções finais deste. Por este motivo, os resultados da barra de Hopkinson são aplicáveis apenas para grandes deformações e podem apresentar uma curva tensãodeformação com oscilações. Além da condição de equilíbrio, aspectos como dispersão de ondas, atrito, e desalinhamento das barras podem também interferem na qualidade da medição realizada neste equipamento. Estes aspectos não são escopo deste estudo, sendo profundamente abordados em (Sharpe, 2008; Moura et al., 2009; Chen e Song, 2011; Alves et al., 2012; Kariem, Beynon e Ruan, 2012).

O princípio de funcionamento de uma máquina de ensaio universal é de natureza completamente distinta. A máquina de ensaio universal, pelo motivo de aplicar a solicitação em um intervalo de tempo relativamente longo, possibilita a utilização de atuadores de baixa potência (como servo-motores) e capacidade de movimentar massas fixas ao espécime, como garras e cabeçotes. A barra de Hopkinson, por sua vez, realiza a solicitação no espécime através da energia cinética acumulada no striker, o qual é acelerado mecânica ou pneumaticamente. Pode-se considerar que as barras são basicamente um modo utilizado para medir força e deslocamento de maneira eficaz e com menor interferência no fenômeno a ser medido. Observa-se que 
poucos elementos são movimentados durante o teste na barra de Hopkinson, sendo que teoricamente não há movimento do centro de massa das barras durante o teste, ou seja, apenas ondas elásticas são propagadas. Isso se dá pelo motivo de que, considerando o curto espaço de tempo em que a força deve ser aplicada sobre o espécime, uma elevada quantidade de potência seria necessária para movimentação de qualquer massa adicional que fosse utilizada.

É importante enfatizar que o comprimento do espécime influencia a taxa de deformação aplicada. Uma vez que a taxa de deformação, $\dot{\varepsilon}$, pode ser escrita da forma

$$
\dot{\varepsilon}=\frac{d \varepsilon}{d t}=\frac{d\left(\Delta l / l_{0}\right)}{d t}=\frac{1}{l_{0}} \frac{d(\Delta l)}{d t}=\frac{v}{l_{0}},
$$

sendo $l_{0}$ o comprimento inicial do espécime e $v$ a velocidade de solicitação deste, pode-se amplificar ou reduzir a taxa de deformação com o aumento ou diminuição do comprimento útil do espécime respectivamente. Portanto, os níveis de taxa de deformação praticadas pela máquina de ensaio universal e barra de Hopkinson são frutos da combinação entre a concepção do equipamento e o comprimento do espécime utilizado.

Com relação de ensaios em médias taxas de deformação, algumas máquinas servo-hidráulicas comerciais, como a MTS 819 (Figura 21) e Instron 8800, foram desenvolvidas para a realização desse tipo de experimento. Estes equipamentos utilizam sistemas hidráulicos de alta pressão e diversos acumuladores hidropneumáticos a fim de atingir as condições de carga e velocidade necessárias para esse teste. Neste caso, incialmente os acumuladores são carregados pelo compressor hidráulico, sendo rapidamente descarregados por uma servo-válvula com controle por maIha fechada. No entanto, em (Othman et al., 2009) foi descrita uma limitação na utilização do equipamento MTS 819 para caracterização de alumínio em velocidades acima de $16 \mathrm{~m} / \mathrm{s}$. Nesta condição, é relatada a ocorrência de oscilações elásticas que inviabilizam o processamento dos resultados. Neste trabalho foi proposta uma técnica de reconstrução de ondas elásticas, similar à técnica da barra de Hopkinson, capaz de melhorar a qualidade do sinal obtido neste equipamento. 
Alguns autores optaram por desenvolver máquinas próprias para a caracterização de materiais em médias taxas de deformação. Nos trabalhos de (Shokrieh e Omidi, 2009a; b; c; 2011) é realizada a caracterização em médias taxas de deformação de laminados de fibra de vidro e resina epóxi utilizando atuador hidráulico com sistema de controle por malha fechada (Figura 21). Neste trabalho, diferentes comprimentos de corpos de prova foram utilizados para variação da taxa de deformação e não foram relatados efeitos de vibrações prejudiciais ao desenvolvimento do teste.

Em (Mckown e Cantwell, 2007) foi realizada a caracterização de um compósito autoreforçado denominado Curv sob taxas de deformação de até $10^{-1} / s$, utilizando um equipamento servo-hidráulico munido de um sistema óptico de medição de deslocamentos e controle por malha fechada. Neste trabalho foi relatada uma grande quantidade de ensaios necessários para a obtenção de um resultado válido. Também foi observada a ocorrência de grande dispersão e oscilações nos resultados.

Em (Avalle, Peroni e Peroni, 2008) foi utilizado um equipamento pneumático para a caracterização de materiais em médias taxas de deformação (Figura 21). Este equipamento utiliza um atuador pneumático e um dispositivo de sacrifício (fusível mecânico) para o início do experimento. Neste, um cilindro pneumático é pressurizado sob alta pressão e, ao atingir uma condição limite, ocorre o rompimento de um fusível mecânico, dando início à tração do espécime. Neste equipamento não existe atuação de um sistema de controle, sendo utilizado para a caracterização de um compósito de polipropileno e borracha sob até $15 \mathrm{~m} / \mathrm{s}$ com sucesso.

O Structural Impact Laboratory (SIMLab) da Norwegian University of Science and Technology (NTNU) desenvolveu um dispositivo hidro-pneumático capaz de testar materiais à taxas de deformação entre 10 /s e 200 /s (Tarigopula et al., 2009). Este dispositivo utiliza um cilindro hidropneumático (Figura 21), sendo um lado do êmbolo preenchido com água e o outro com ar pressurizado. Com o aumento da pressão do lado pneumático, há a pressurização da câmara hidráulica. Quando uma condição limite é atingida, uma membrana de ruptura se abre, causando o esvaziamento da câmara hidráulica e movimentação do pistão. A manutenção de velocidade constante ocorre em virtude do incompressividade da água ao passar por um orifício sob pressão praticamente constante exercida pela câmara pneumática. 
(a)

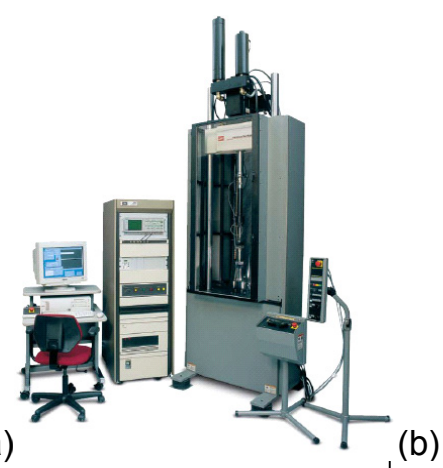

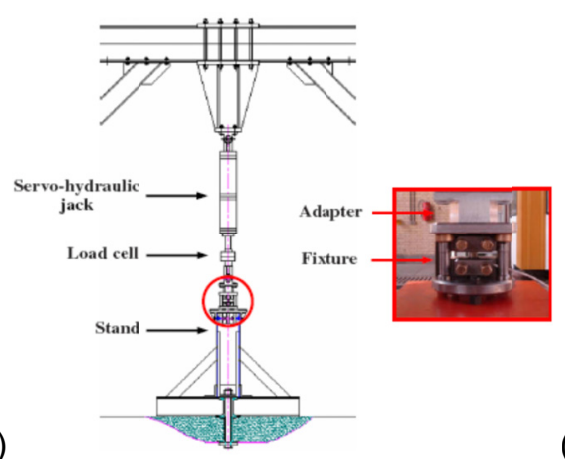

(c)

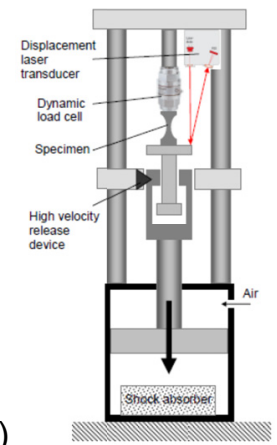

(d)

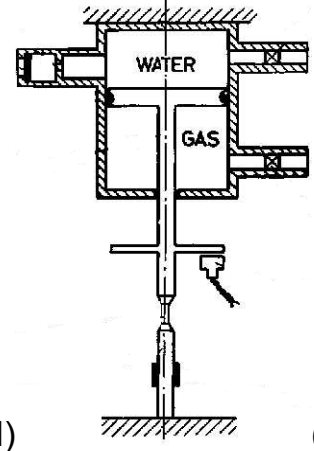

(e)
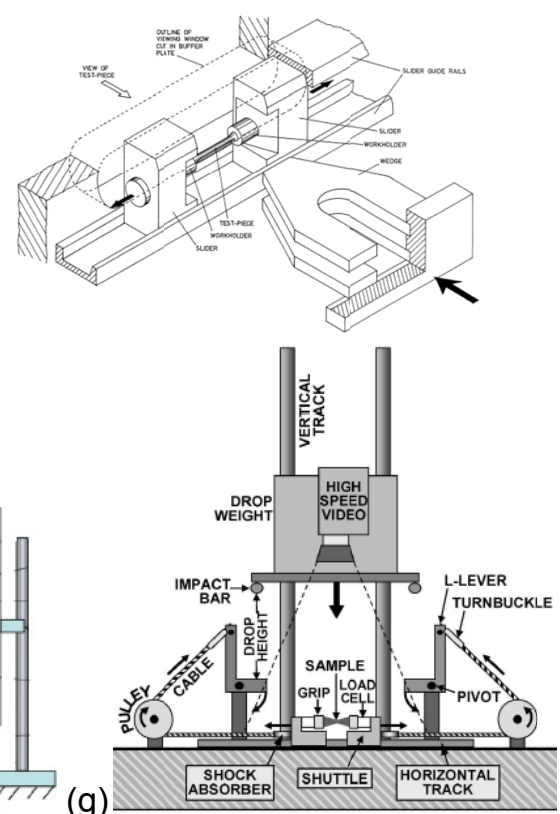

(g)

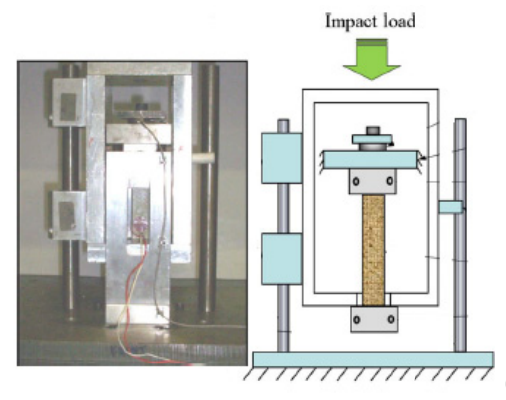

(f)

Figura 21: Dispositivos para a caracterização de materiais sob médias taxas de deformação: (a) MTS 819, (b) dispositivo desenvolvido utilizando um atuador hidráulico (Shokrieh e Omidi, 2009c),

(c) dispositivo pneumático (Avalle, Peroni e Peroni, 2008), (d) dispositivo hidropneumático (Tarigopula et al., 2009), (e) dispositivo tipo "flying-wedge" (Sturges e Cole, 2001), e (f) dispositivo utilizando um equipamento de queda de peso (Brown, Brooks e Warrior, 2010) e (g) dispositivo utilizando um equipamento de queda de peso com compro de prova centrado (Mott et al., 2007).

Em (Sturges e Cole, 2001; Cole e Sturges, 2003) foi projetado um dispositivo utilizando um canhão lançador de projéteis e o "efeito cunha", denominado flyingwedge (Figura 21). O contato em cunha possibilita o controle da relação força e velocidade aplicada sobre o espécime testado. Segundo o trabalho, este dispositivo é capaz de caracterizar materiais sob uma ampla faixa de taxas de deformação, entre elas, a taxas de deformação intermediárias.

Em (Fernie e Warrior, 2002; Brown, Brooks e Warrior, 2010) foi desenvolvido um dispositivo acoplado a um equipamento para ensaios de queda dle peso (Figura 21) capaz de realizar a caracterização mecânica de polímeros de compósitos até 
taxas de deformação de $70 \mathrm{~s}^{-1}$. Tal dispositivo pode ser utilizado para ensaios de tração e compressão. Este utiliza uma célula de carga piezoeléctrica para medição de carga e extensômetros colados ao espécime para medição de deformação. Neste trabalho foi relatada a existência de oscilações indesejáveis durante o experimento, sendo este efeito reduzido com o reposicionando da célula de carga e utilização de filtros para tratamento do sinal.

Em (Mott et al., 2007) também foi utilizando um dispositivo de queda de peso capaz de tracionar espécimes poliméricos (Figura 21). Buscando minimizar o deslocamento de massa durante o teste, este equipamento é capaz de tracionar as duas extremidades do corpo de prova, mantendo o centro de gravidade praticamente estacionário. Nota-se uma redução de vibrações nos resultados apresentado neste trabalho quando comparado com outros trabalhos similares.

No tocante de equipamentos utilizados para ensaios em médias taxas de deformação, foi observado que não há um consenso com relação à configuração utilizada. No entanto, é possível observar que os equipamentos encontrados apresentam características existentes na barra de Hopkinson, como ensaio realizado por liberação abrupta de energia acumulada, efeitos de propagação de onda e oscilações (falta de equilíbrio dinâmico, por exemplo); como também, aspectos observados em máquinas de ensaio universal, como existência de elementos móveis, utilização de células de carga e extensômetros para medição de deformação e corpos de prova relativamente grandes. A variação do comprimento útil do espécime para controle da taxa de deformação aplicada também é observada nos equipamentos pesquisados.

\subsection{DEFINIÇÃO DE PROJETO}

O equipamento a ser projetado deve ser capaz de realizar a caracterização de materiais em médias taxas de deformação, ou seja, entre $10 / \mathrm{s}$ e $10^{2} / \mathrm{s}$. O equipamento deve ser projetado para a caracterização de materiais metálicos, compósitos e poliméricos. Assim como a realização de experimentos em diferentes temperaturas é desejável. Define-se que a carga resultante no espécime não deve ultrapassar 40 
$\mathrm{kN}$, devendo esta ser mensurada por uma célula de carga a ser instalada no equipamento. Além disso, o equipamento deve possibilitar a observação por câmera de alta velocidade, assim para utilização posterior da técnica de correlação digital de imagens para medição do campo de deformações.

\subsection{ESCOLHA DA CONFIGURAÇÃO DO DISPOSITIVO}

As seguintes opções foram selecionadas para a concepção do equipamento para caracterização em médias taxas de deformação:

- $\quad$ Aquisição de um dispositivo comercial: Esta opção consiste na aquisição de um sistema comercial completo, considerando os modelos comerciais MTS 819 e Instron 8800. Deve-se considerar o problema de operação destes equipamentos em alta velocidade, como apresentado por (Othman et al., 2009) e também a necessidade de infraestrutura local, treinamento e manutenção periódica. Não há necessidade de execução do projeto do equipamento neste caso.

- $\quad$ Dispositivo utilizando um sistema servo-hidráulico: Nesta opção seria desenvolvido um dispositivo empregando um atuador servo-hidráulico comercial. Para isso há a necessidade de adquirir um sistema atuador, contendo atuador hidráulico sensorizado, unidade hidráulica, servo válvula, e controlador em malha fechada de uma empresa terceirizada. Os dispositivos de fixação dos espécimes, sensores, estrutura e dispositivo de segurança devem ser projetados e fabricados. Esta opção baseia-se no trabalho de (Shokrieh e Omidi, 2009c).

- Dispositivo utilizando um sistema hidropneumático: Esta opção consiste no projeto e fabricação de um dispositivo utilizando um atuador hidropneumático, baseando-se no trabalho de (Tarigopula et al., 2009). O projeto deste equipamento deve ser detalhado, tendo em vista a complexidade do atuador. A segurança de operação deve ser considerada tendo em vista os altos níveis de pressão de trabalho, principalmente quando aplicado em fluidos compressíveis, o que pode causar acidentes catastróficos em caso de falha. Sensores de deslocamento de força devem ser adquiridos assim com o serviço de usinagem de precisão deve ser contratado. 
Para a compressão do gás pode ser adquirido um compressor comercial ou utilização de cilindros pressurizados alugados.

- Dispositivo pneumático: Nesta opção seria projetado um equipamento totalmente pneumático para a execução do teste almejado. Este equipamento consiste em um pistão pneumático o qual é pressurizado com um gás, sendo o ensaio iniciado ao rompimento de um fusível mecânico. Dependendo da concepção do projeto, o gás pode ser pressurizado em alta ou baixa pressão. Todo o cilindro, dispositivo de fixação e segurança devem ser projetados, havendo possibilidade de aquisição de componentes comerciais, como válvulas. O gás pode ser comprimido por um compressor comercial ou utilizando cilindros pressurizados locados. Sensores de deslocamento e força devem ser adquiridos. O trabalho de (Avalle, Peroni e Peroni, 2008) proveu o embasamento necessário para este opção.

- Dispositivo do tipo "flying-wedge": Nesta opção, seria projetado um equipamento utilizando o sistema "flying-wedge", conforme apresentado em (Sturges e Cole, 2001; 2003). Um gas-gun deverá ser projetado especificamente para este fim, devendo ser projetado o dispositivo para transmissão de carga para o espécime. Dispositivos de segurança devem ser projetados. Sensores de força e deslocamento devem ser adquiridos. Deve-se frisar a experiência existente no GMSIE-USP no tocante de projeto de gas-gun, uma vez que já fora realizado no passado.

- Dispositivo utilizando o martelo de impacto: Nesta opção, o espécime é tracionado utilizando uma massa em queda livre. O pequeno deslocamento do espécime durante o experimento, assim como o grande montante de energia existente na massa em queda livre garante a velocidade praticamente constante e força necessária para o ensaio de tração. Essa opção pode ser utilizada junto a dispositivos já existentes no GMSIE-USP, como martelo de impacto de baixa energia. Célula de carga para mediação de força e sensor de deslocamento devem ser adquiridos. As referencias (Sharpe, 2008; Brown, Brooks e Warrior, 2010) foram adotadas com base para este equipamento.

- Dispositivo utilizando o martelo de impacto com carga redirecionada: Esta opção é similar à anterior, no entanto a carga causada pela queda da massa é redirecionada durante a aplicação sob o espécime a fim de mantê-lo centrado durante a realização do ensaio. Este dispositivo pode utilizar o martelo de impacto de baixa energia já existes no GMISE-USP. A referência (Mott et al., 2007) é utilizada como base para este estudo. Deve-se frisar que, apesar de não ser relatado na refe- 
rência, acredita-se que haverá efeitos de inércia e vibrações em virtude deste utilizar cabos de aço longos para redirecionamento da força.

Uma matriz de decisão foi utilizada para a escolha da configuração de equipamento a ser projetado. Foram definidos os seguintes critérios para avaliação:

- $\quad$ Custo (Peso 5): Este critério avalia uma estimativa de custo do equipamento. Deve-se frisar que esta estimativa deve conter o custo relativo ao sistema atuador, estrutura, dispositivos de fixação, sensores e dispositivos de segurança. Quanto maior este critério, menor o custo do equipamento.

- $\quad$ Complexidade (Peso 3): Este critério avalia a quantidade de sistemas a serem empregados para o funcionamento do dispositivo. São avaliadas a necessidade de aquisição regular de equipamentos ou serviços (como cilindros pressurizados e manutenção periódica), utilização de unidades hidráulicas, necessidade de treinamento específica, área necessária para instalação do mesmo. Quanto maior este critério, menor a complexidade do equipamento.

- Sensoriamento (Peso 2): Neste critério são avaliadas a possibilidade de sensoriamento do espécime, como a possibilidade de fixação de sensores redundantes e a possibilidade da utilização de correlação digital de imagens. Quanto maior este critério, mais possibilidades de sensoriamento o equipamento possibilita.

- Flexibilidade (Peso 1): Este critério avalia a aplicabilidade deste dispositivo para a realização de ensaios de tração, assim com outros tipos de ensaios, como compressão e flexão; assim como a realização de experimentos em diferentes temperaturas. Quanto maior este critério, mais flexível é o dispositivo.

- Operação e risco (Peso 2): Este critério avalia o risco na utilização deste equipamento, sendo considerada a utilização de gases altamente pressurizados, projéteis em alta velocidade e massa em queda livre. Quanto maior este critério, mais seguro é o equipamento.

- Controle do experimento (Peso 1): Este critério avalia a capacidade do dispositivo em garantir uma velocidade constante e força necessária nesta condição para o experimento desejado. Quanto maior este critério, maior é a capacidade para desenvolver velocidade constante e força necessária. 
- $\quad$ Histórico (Peso 2): Este critério avalia se a solução já foi empregada assim com a qualidade dos resultados providos por esta. Quanto maior este critério, melhores são os resultados providos por este equipamento em aplicações anteriores.

Tabela 2: Matriz de decisão para escolha da configuração.

\begin{tabular}{|c|c|c|c|c|}
\hline & $\begin{array}{l}\text { Sistema } \\
\text { comercial }\end{array}$ & $\begin{array}{c}\text { Sistema } \\
\text { hidráulico }\end{array}$ & $\begin{array}{c}\text { Sistema } \\
\text { hidroneu- } \\
\text { mático }\end{array}$ & $\begin{array}{c}\text { Sistema } \\
\text { pneumátco }\end{array}$ \\
\hline Custo (5) & 1,0 & 2,5 & 5,0 & 5,0 \\
\hline Complexidade (3) & 4,0 & 2,5 & 5,0 & 6,0 \\
\hline Sensoriamento (2) & 3,0 & 5,0 & 5,0 & 5,0 \\
\hline Flexibilidade (1) & 7,0 & 10,0 & 2,5 & 7,0 \\
\hline Operação e Riscos (2) & 8,0 & 7,5 & 2,5 & 5,0 \\
\hline Controle (1) & 5,0 & 5,0 & 5,0 & 3,0 \\
\hline Histórico (2) & 2,0 & 5,0 & 7,5 & 4,0 \\
\hline \multirow[t]{2}{*}{ Nota } & 55,0 & 70,0 & 77,5 & 81,0 \\
\hline & \multicolumn{2}{|c|}{$\begin{array}{c}\text { Sistema } \\
\text { "Flying wedge" }\end{array}$} & $\begin{array}{l}\text { a de } \\
0\end{array}$ & $\begin{array}{l}\text { eda de peso } \\
\text { direcionado }\end{array}$ \\
\hline Custo (5) & \multicolumn{2}{|c|}{4,0} & & 6,0 \\
\hline Complexidade (3) & \multicolumn{2}{|l|}{3,0} & & 7,5 \\
\hline Sensoriamento (2) & \multicolumn{2}{|l|}{4,0} & & 2,5 \\
\hline Flexibilidade (1) & \multicolumn{2}{|l|}{3,0} & & 5,0 \\
\hline Operação e Riscos (2) & \multicolumn{2}{|l|}{2,0} & & 4,0 \\
\hline Controle (1) & \multicolumn{2}{|l|}{2,0} & & 2,5 \\
\hline Histórico (2) & \multicolumn{2}{|c|}{4,0} & & 2,5 \\
\hline Nota & \multicolumn{2}{|c|}{54,0} & & 78,0 \\
\hline
\end{tabular}

Os dispositivos considerados foram avaliados considerando tais critérios, sendo atribuídos a estes um valor de 0 a 10 . Estes valores foram tomando considerando pesquisa prévia desenvolvida pelo autor, sendo multiplicados pelos pesos respectivos e posteriormente somados para atribuição de uma nota final para cada solução. O maior valor apresenta a solução que melhor se adéqua aos critérios atribuídos. Os valores utilizados para a matriz de decisão estão apresentados na Tabela 2.

Com base na matriz de decisão e consenso do autor, o desenvolvimento de um dispositivo utilizando o martelo de impacto foi adotado como a solução escolhida para o desenvolvimento do dispositivo para realização de ensaios de caracterização mecânica em médias taxas de deformação. 


\subsection{PROJETO BÁSICO DO DISPOSITIVO}

As propriedades do material metálico a ser testado foram baseadas em um alumínio aeronáutico 2024-T3, apresentado um comportamento elasto-plástico, com propriedades apresentadas na Tabela 3. Como configuração básica do corpo de prova, adotou-se um comprimento útil de $20 \mathrm{~mm}$ e secção transversal de $10 \mathrm{~mm}^{2}$, proporcionando uma força de $4 \mathrm{kN}$ e deslocamento máximo de $4 \mathrm{~mm}$ até a ruptura do material. Em condição limite, o material necessitará da energia de $16 \mathrm{~J}$ para realização do teste de tração. Uma vez que taxas de deformação de $1 / s$ a $100 / s$ são desejadas, considerando a equação (1) e comprimento efetivo adotado, tem-se que o dispositivo deve tracionar o corpo de prova à velocidade de $0,05 \mathrm{~m} / \mathrm{s}$ a $2,00 \mathrm{~m} / \mathrm{s}$.

Tabela 3: Propriedades idealizadas para um alumínio aeronáutico.

\begin{tabular}{cc}
\hline$E$ & $70 \mathrm{GPa}$ \\
$\sigma_{0}$ & $300 \mathrm{MPa}$ \\
$\sigma_{u}$ & $400 \mathrm{MPa}$ \\
\hline$\varepsilon_{u}$ & $20 \%$ \\
\hline
\end{tabular}

Dentre os equipamentos disponíveis no GMSIE-USP, existe um dispositivo para realização de ensaio de impacto por queda livre, com altura máxima de $1,5 \mathrm{~m}$ e capacidade máxima de $20 \mathrm{~kg}$. Considerando que $V=\sqrt{2 g h}$ e $E=m g h$, este equipamento possibilita velocidade de impacto de até $5,4 \mathrm{~m} / \mathrm{s}$ e energia de até $588 \mathrm{~J}$. Desse modo, os níveis de velocidade e energia de impacto providos por esse equipamento estão dentro das necessidades do projeto do dispositivo.

Deve-se frisar que no sistema escolhido não existe controle da velocidade de solicitação do material durante o teste, assim a velocidade irá variar durante o experimento, cabendo ao operador definir se a variação obtida é relevante ou não para a validação do experimento. Uma maneira de minimizar tal efeito é operar o equipamento com excesso de energia. Assim, a energia consumida para a deformação do espécime é insignificante quando comparada com a energia total existente no sistema, não causando variação de velocidade no dispositivo e, portanto, na velocidade de tração do espécime. No caso do martelo de impacto, a energia é aumentada com o aumento da massa de impacto. 
$\mathrm{Na}$ Figura 22(a) é apresentado um esboço do equipamento projetado a ser utilizado no martelo de impacto do GMSIE-USP. O princípio de funcionamento consiste em um elemento impactante em formato de "U invertido" o qual deve-se chocar contra a parte inferior do corpo de prova. A parte superior de fixação do corpo de prova é desenhada de forma a caber na região interna do elemento impactante sem tocá-la antes da ruptura do espécime. Este dispositivo deve ser projetado de modo a ser instalado dentro do espaço livre existente na base do martelo de impacto, Figura 22(b), sendo possibilitada sua remoção quando necessário.

(a)

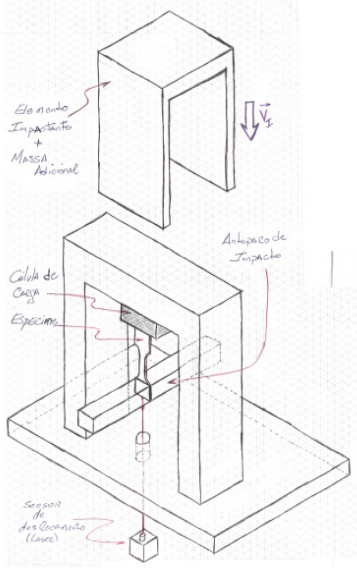

(b)

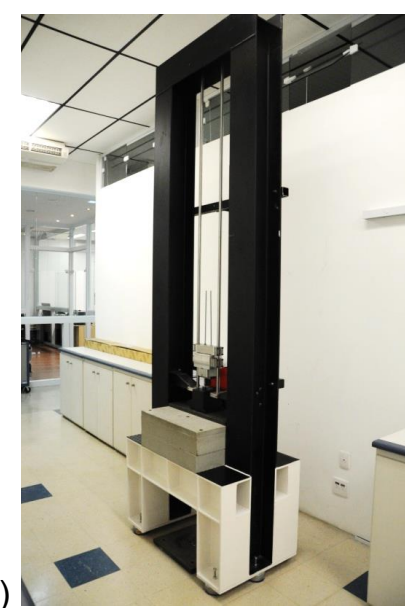

Figura 22: (a) Esboço conceitual da solução escolhida a ser utilizado no (b) martelo de impacto pertencente ao GMSIE-USP.

A análise numérica de um modelo idealizado do dispositivo a ser projetado foi realizada utilizando o software comercial LS-Dyna. Neste, um quarto do dispositivo idealizado foi modelado, utilizando um modelo de material elasto-plástico bi-linear para o alumínio aeronáutico (corpo de prova), e modelo elástico linear para um aço, utilizado na estrutura do equipamento. O elemento impactante foi modelado contendo $20 \mathrm{~kg}$ de massa total e com velocidade inicial de $1 \mathrm{~m} / \mathrm{s}$. O modelo numérico desenvolvido é apresentado na Figura 23.

A partir do modelo numérico, foi observada a ocorrência da taxa de deformação de 218 /s nos elementos centrais do corpo de prova. Tal taxa de deformação está levemente acima do inicialmente especificado, porém sendo ainda considerado taxa intermediária de deformação. Este resultado valida o projeto do dispositivo almejado. 
(a)

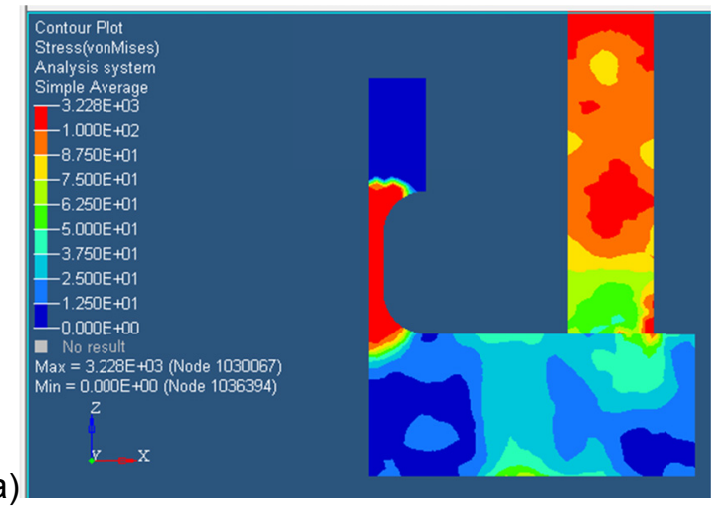

Figura 23: Simulação numérica do equipamento desenvolvido para ensaios de médias taxas de deformacão.

Oscilações foram observadas na curva tensão-deformação obtida numericamente, sendo mais perceptível no histórico de tensão do espécime. Tais efeitos foram descritos em trabalhos anteriores relacionados com dispositivos similares. Segundo (Othman et al., 2009) e conforme observado na simulação numérica, a velocidade de aplicação de força no espécime pode excitar algumas formas de vibrar do espécime ou do dispositivo. Assim, este aspecto é característico desse tipo de equipamento, devendo ser abordado diferentemente em cada caso de aplicação. Foi observado também que este efeito é altamente influenciado pela rigidez do espécime e amplificado quando cargas acima de $5 \mathrm{kN}$ são aplicadas ao espécime. Este efeito pode ser minimizado com o desenvolvimento de uma estrutura compacta e rígida, utilização de elementos macios (como borrachas e esponjas) e alteração da geometria do espécime. Vale frisar que o modelo numérico não considera efeitos dissipativos, como fricção e amortecimento. Acredita-se que estes efeitos podem ser menos significativos durante os ensaios experimentais.

A curva tensão-deformação obtida foi analisada no espectro da frequência, sendo observada a existência de componentes significantes até $15 \mathrm{kHz}$. Este parâmetro é fundamental para a seleção dos sensores a serem utilizados.

\subsection{PROJETO DETALHADO DO DISPOSITIVO}

Uma vez definidos aspectos básicos do dispositivo, o projeto detalhado do equipamento foi realizado utilizando a ferramenta CAD-3D Autodesk Inventor 2011. 
A configuração de corpo de prova adotada foi baseada no trabalho de (Othman et al., 2009) sendo um corpo de prova afinado na largura (também conhecido por "dog-bone" ou "gravata") e com comprimento efetivo de $20 \mathrm{~mm}$. A secção transversal do mesmo deve ser escolhida de forma que a carga máxima não ultrapasse $5 \mathrm{kN}$ e minimizando assim efeitos de vibrações indesejáveis.

As dimensões da região de fixação foram adotadas a fim de minimizar a concentração de tensão nestas regiões e possibilitar diversificação nas dimensões de secção transversal utilizadas. Uma região de arredondamento foi adotada a fim de evitar concentração de tensões nas extremidades do corpo de prova. Uma vista da geometria do corpo de prova está apresentada na Figura 24(a). Uma análise numérica estática do campo de tensões no corpo de prova, Figura 24(b), mostrando o satisfatório efeito de concentração de tensão na região do afilamento.

(a)

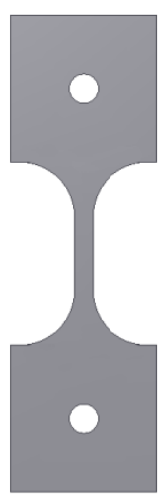

Figura 24: (a) Geometria básica adotada para o corpo de prova, (b) sistema de fixação do corpo de prova e (c) análise em elementos finitos estática do corpo de prova.

O sistema de fixação do corpo de prova consiste na utilização de garra circulares (Figura 24), que são pressionadas contra o corpo de prova pela utilização de parafusos de fixação. Uma fixação pinada foi utilizada na parte superior a fim de possibilitar a rotação e alinhamento do corpo de prova. As fixações inferiores são alongadas a fim de que sejam tracionadas durante o impacto com a massa em queda livre. Uma perspectiva do corpo de prova com os elementos de fixação está apresentada na Figura 24(c).

O elemento impactante (Figura 25) foi projetado utilizando uma configuração tipo "U invetido", ocorrendo o primeiro contato apenas com as fixações inferiores do corpo de prova. Após o rompimento do espécime, esta massa é amortecida por batedores de borracha. Este elemento impactante é integrado ao martelo de impacto 
existente no GMSIE-USP, possibilitando um movimento vertical preciso e o acréscimo de massa, se necessário. Nas laterais do elemento impactante, cunhas de $45^{\circ}$ foram projetados a fim de conduzir o alinhamento do corpo de prova durante a tração. Duas aberturas laterais foram inseridas a este, a fim de possibilitar a observação do evento e utilização de técnicas óticas de medição de deformação.

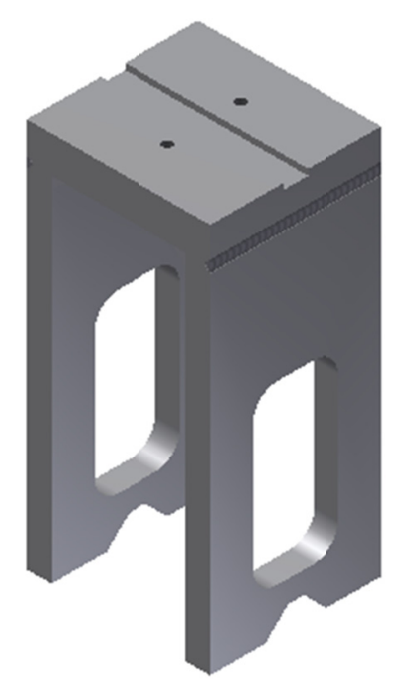

Figura 25: Elemento impactante.

As especificações de projeto e resultados de análise numérica foram considerados para seleção do conjunto de sensores a serem utilizados. A célula de carga Kister 9341B, munida do amplificador de carga Kistler 5015A1000, forram escolhidos para utilização no equipamento, possibilitando a medição de cargas de tração de até 40 kN e frequência natural de 40 kHz. Um vibrômetro a laser Polytech OFV-323 foi selecionado para medição de deslocamento do corpo de prova durante o teste de tração, possibilitando a medição de deslocamento de até $100 \mathrm{~mm}$, com precisão de até $0,004 \mu m$ e frequência máxima de $100 \mathrm{kHz}$, utilizando técnica totalmente sem contato.

Uma câmera de alta velocidade Photron APX-RS foi utilizada para observação do fenômeno, possibilitando a obtenção uma sequência de imagens de evento a velocidade de até 250.000 quadros por segundo por segundo, e munido de um sistema de iluminação específico. A utilização desde equipamento possibilita tanto a avaliação qualitativa do fenômeno como também a medição de deformação por imagens. 
A célula de carga foi instalada na parte superior do espécime, fixada entre a estrutura do dispositivo e o sistema de fixação do espécime. O vibrômetro a laser será utilizado para a medição do deslocamento da parte inferior do espécime, conforme possibilitado pelo martelo de impacto do GMSIE-USP. A fim de facilitar a medição a laser, um anteparo plano foi desenvolvido para fixação na parte inferior do corpo de prova, no qual é fixado um adesivo reflexivo. Na Figura 26 é apresentada a fixação da célula de carga e localização do anteparo de medição do vibrômetro.

(a)

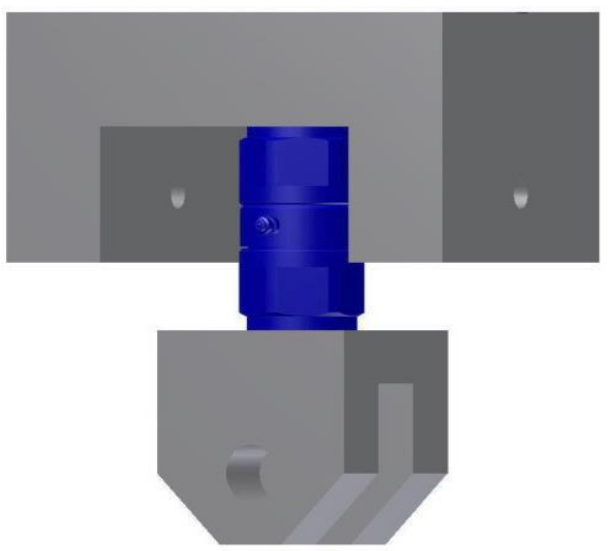

(b)

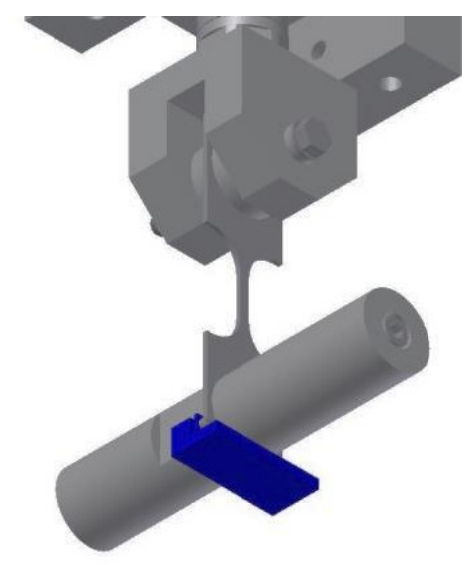

Figura 26: (a) Fixação da célula de carga e (b) anteparo de medição do deslocamento pelo sensor a laser.

(a)

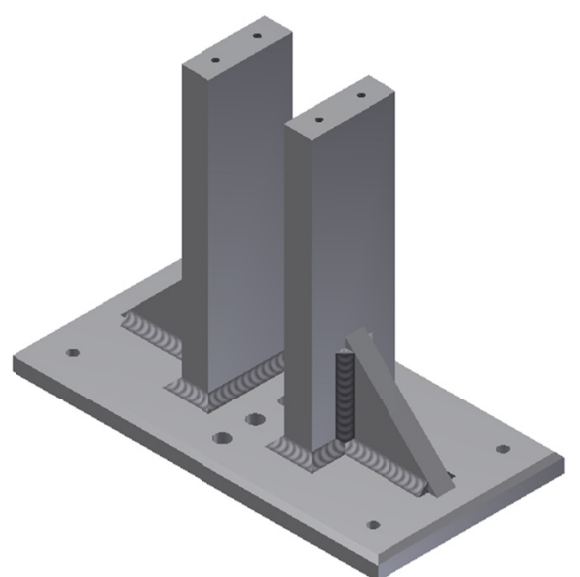

(b)

Figura 27: (a) Estrutura base do equipamento e (b) detalhe entre a massa de impacto e a estrutura da máquina.

Uma estrutura rígida foi desenvolvida para o equipamento, em concordância com o martelo de impacto utilizado, conforme apresentado na Figura 27. Observa-se 
que não há contato entre a massa de impacto e a estrutura do dispositivo, antes que o corpo de prova seja completamente tracionado.

O alumínio foi escolhido para a fabricação do anteparo de medição para o sensor de deslocamento, buscando a redução da massa móvel do dispositivo. A liga de aço ABNT 1020 foi adotada para a fabricação das demais partes do equipamento, em virtude de sua resistência, preço, usinagem e soldabilidade. Todas as peças, com exceção da estrutura base, foram submetidas ao tratamento superficial de cementação, buscando aumentar sua rigidez superficial, uma vez que são submetidas a cargas de impacto frequentemente. Os desenhos de fabricação foram gerados, sendo o equipamento fabricado por uma empresa contratada.

\subsection{AVALIAÇÃO DO DESEMPENHO DO DISPOSITIVO}

O dispositivo desenvolvido está apresentado na Figura 28, sendo o desempenho deste avaliado para a caracterização de amostras de alumínio 5052 . O corpo de prova utilizado apresenta secção transversal com largura de $5 \mathrm{~mm}$ e espessura de 2 $\mathrm{mm}$. De forma experimental, foi possível minimizar oscilações na curva tensãodeformação obtida com a utilização de mantas de borracha rígida com $2 \mathrm{~mm}$ de espessura na região de contato entre a fixação inferior do espécime e elemento impactante. Uma massa de impacto de $20 \mathrm{~kg}$ foi utilizada.

A força e deslocamento foram medidos com o uso da célula de carga piezoeléctrica e vibrômetro, conforme descritos anteriormente. O sinais oriundos de tais sensores foram adquiridos e condicionados com o uso do software comercial MatLab 7.0 e placa de aquisição National Instruments PCI-6550.

Na Figura 29 é apresentada uma sequência de imagens nas quais o dispositivo é observado em operação. Nota-se que o mesmo possibilitou a aplicação da solicitação ao espécime de forma alinhada, possibilitando a medição adequada de força e deslocamento. 


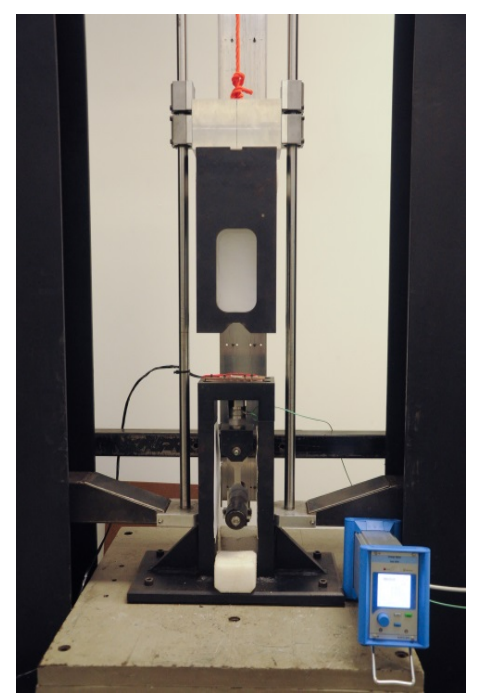

Figura 28: Dispositivo desenvolvido para ensaios de caracterização mecânica em médias taxas de deformação.
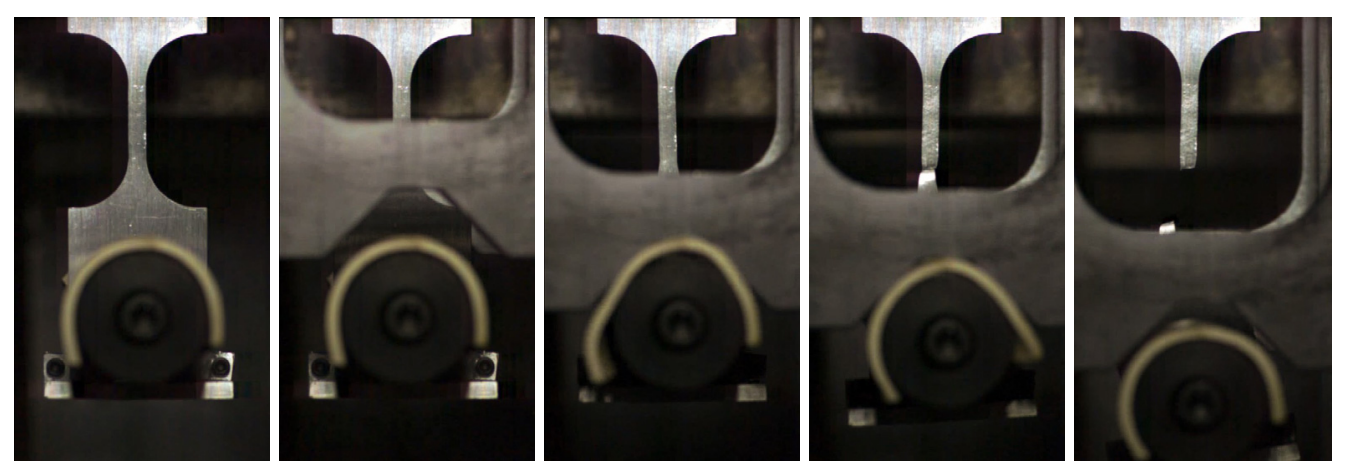

Figura 29: Avaliação qualitativa do desempenho do equipamento.

Na Figura 30 são apresentados os históricos de deslocamento e força aplicados ao espécime, assim com o a curva tensão-deformação de engenharia para o material testado. Para o cálculo da deformação de engenharia adota-se

$$
\varepsilon=\frac{\Delta l}{l_{0}}
$$

sendo $\Delta l$ a variação de comprimento do espécime $\left(\Delta l=l_{f}-l_{0}\right)$, com $l_{f}$ e $l_{i}$ os comprimentos final e inicial do espécime. Por sua vez, a tensão de engenharia é definida por 


$$
\sigma_{\text {eng }}=\frac{F}{A}
$$

sendo $F$ a força axial aplicada ao espécime e $A$ a área de secção transversal deste. Maiores detalhes sobre o embasamento teórico do processo de caracterização de materiais serão apresentado no Capítulo 6.

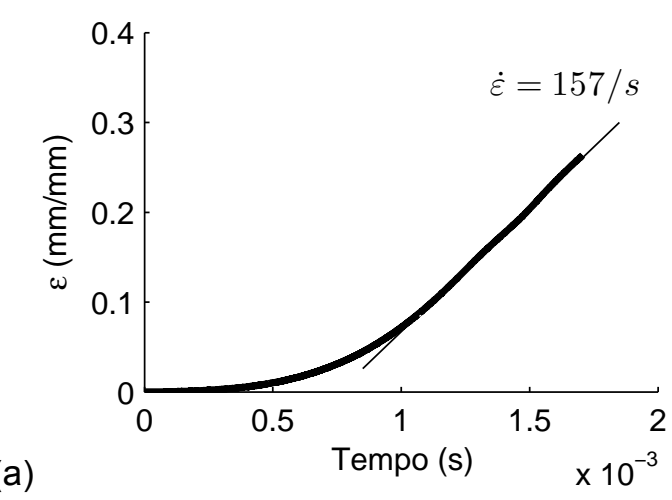

(a)

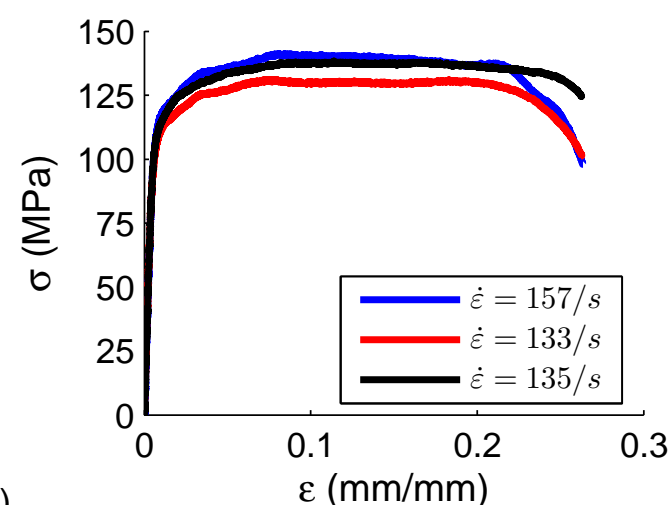

(c)

(b)

$\varepsilon(\mathrm{mm} / \mathrm{mm})$

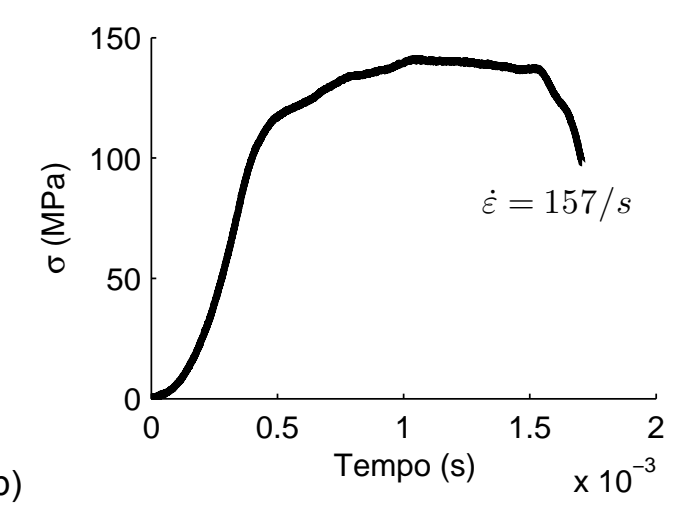

Figura 30: Histórico de (a) deformação e (b) tensão aplicada no espécime. (c) Exemplos de curva tensão-deformação de engenharia obtidas na taxa de deformação de 133 /s, 135 /s e 157 /s.

Neste caso em especial, apesar de esperado, não foram observadas oscilações na curva do material obtida. É importante enfatizar que este aspecto é específico para o ensaio aqui apresentado, devendo ser avaliado para cada configuração de material e corpo de prova utilizado. Foi observada uma boa correspondência entre as três curvas medidas do material testado, o que demostra a aparente repetibilidade dos resultados provenientes deste equipamento. 


\subsection{CONSIDERAÇÕES FINAIS}

Neste capítulo foi apresentado o desenvolvimento de um dispositivo para a caracterização de materiais em taxas intermediárias de deformação, utilizando a energia de uma massa em queda livre. A concepção deste equipamento utilizou método dos elementos finitos e ferramentas CAD. Em testes experimentais de desempenho, foi observado que o mesmo apresenta um desempenho satisfatório para caracterização em questão. Com isso, este equipamento será utilizado com uma ferramenta para o desenvolvimento desta tese, possibilitando a caracterização dos laminados fibra-metal e seus constituintes em regime de médias taxas de deformação. 



\section{FABRICAÇÃO E DESCRIÇÃO DOS MATERIAIS}

Neste capítulo, descreve-se como os laminados fibra-metal termoplásticos (TFML, do inglês, thermoplastic fibre-metal laminates) utilizados neste trabalho foram fabricados. Serão também especificados os FML com reforços termofíxos, utilizados para comparação de desempenho. Por fim, será apresentado um código de identificação desenvolvido para identificação dos materiais utilizados ao longo deste estudo.

\subsection{LAMINADOS FIBRA-METAL TERMOPLÁSTICOS}

Os TFML utilizados como base para este estudo foram fabricados utilizando liga de alumínio aeronáutico 2024-T3, material de reforço de polipropileno (PP) e adesivo na interface polímero-metal.

A liga de alumínio 2024-T3 foi utilizada na forma de chapas, com espessura de $0,3 \mathrm{~mm}$ e $0,4 \mathrm{~mm}$, sendo fornecida pela empresa ALCOA. Os principais constituintes dessa liga são cobre, magnésio e manganês nas frações 4,4\%p, 1,5\%p e $0,6 \% p$ respectivamente. Durante o processo de fabricação da chapa, este material foi submetida à solubilização, conformação plástica a frio e endurecida por envelhecimento (Callister, 2003).

A liga de alumínio 2024-T3 é considerada uma liga aeronáutica de alto desempenho, apresentando elevada resistência mecânica e à fadiga. Esta é utilizada em fuselagens, asas e reforçadores de aeronaves.

O polipropileno (PP) utilizado para a fabricação do TFML é denominado PU$\mathrm{RE}$, fabricado empresa Lankhorst Bv. Este material consiste em um tecido tipo ondaplana equilibrada formado por fitas de PP compostas. Esta fita é fabricada pelo processo de co-extrução, de modo que o PP do núcleo e do revestimento tem composições distintas. O PP utilizado para revestimento possui uma temperatura de moldegem menor do que a do PP do núcleo. Desse modo, durante a termomoldagem, apenas a camada externa do filamento é fundida com os filamentos adjacentes, fa- 
zendo com que o núcleo do filamento permaneça inalterado. Além disso, durante o processo da co-extrusão, estas fitas são estiradas resultando em um alto grau de alinhamento das moléculas, o que proporciona uma elevada resistência mecânica. Cada fita possui $4 \mathrm{~mm}$ de largura e $0,2 \mathrm{~mm}$ de espessura, sendo tramadas para a formação do tecido. Por este material ser totalmente constituído por PP, este será aqui designado por SRPP, do inglês, self-reinforced polypropylene. Um esquema de produção simplificado do material é apresentado na Figura 31 (Lankhorst, 2011).

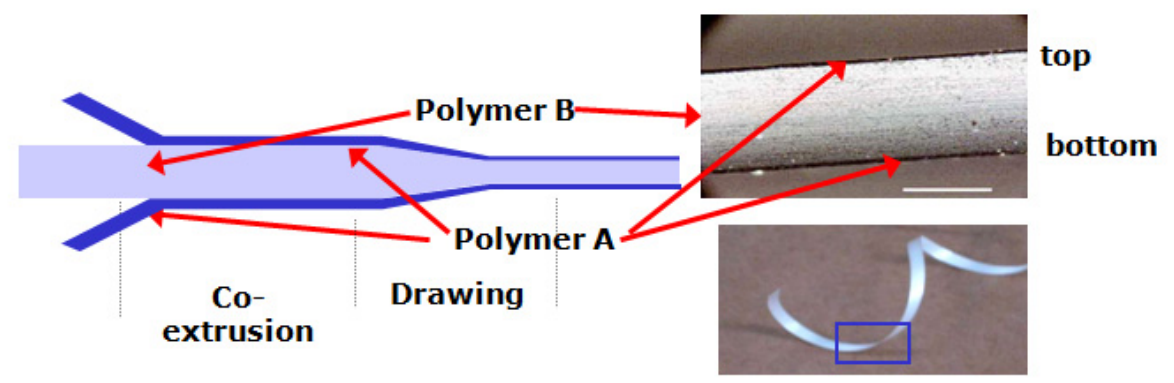

Figura 31: Esquema de fabricação do SRPP denominado PURE (Lankhorst, 2011).

Vários trabalhos (Alcock et al., 2006; Alcock, Cabrera, Barkoula, Reynolds, et al., 2007; Alcock, Cabrera, Barkoula, Spoelstra, et al., 2007) observaram que a resistência ao impacto do SRPP PURE pode ser igual ou superior a materiais como ABS, vidro/epóxi ou aramida/epóxi. Além disso, o SRPP apresenta baixo peso específico e possibilidade de reciclagem, o que o torna promissor para futuras aplicações no setor naval, aeronáutico e automobilístico. Atualmente este material apresenta uso pouco expressivo em capacetes, pás para neve, mochilas e blindagens.

Sadighi et al. (Sadighi, Alderliesten e Benedictus, 2012) relatam que os TFML usualmente apresentam fraca adesão na interface metal-polímero. Melhores adesivos para adesão PP-metal tem sido desenvolvidos, como o Xiro, um adesivo de PP com anidrido maleico fabricado por Collano Adhesives AG. Este adesivo foi utilizado para fabricação dos TFML aqui estudados, sendo apresentado na forma de lâminas de 0,04 mm de espessura. Para ainda melhorar a adesão, as chapas de liga de alumínio 2024-T3 foram submetidas à anodização sulfídrica a fim de aumentar a rugosidade superficial deste.

A consolidação dos constituintes do TFML foi realizada utilizando a técnica da termomoldagem. Inicialmente as lâminas de liga de alumínio anodizadas são cortadas em guilhotina e desengorduradas com acetona e toalhas absorventes, a fim de 
retirar qualquer camada oleosa que prejudique a adesão destas. A quantidade desejada de lâminas de SRPP e de adesivo são cortadas utilizando uma tesoura, sendo deixado um excesso de material em função do encolhimento esperado deste.

As camadas de metal, SRPP e adesivo são empilhadas na quantidade, organização e alinhamento do tecido SRPP nas direções $0^{\circ}$ e $90^{\circ}$, tendo-se como referência as direções de laminação das camadas metálicas. O TFML assim formado é posicionado entre dois moldes planos revestidos com politetrafluoretileno (PTFE ou nome comercial Teflo®) e instalados em uma pensa pneumática com aquecimento Mayer, sob pressão de 6 bar. O TFML é então aquecido até $150^{\circ} \mathrm{C}$ a uma taxa de $5^{\circ} \mathrm{C} / \mathrm{min}$, sendo esta temperatura mantida por cerca de 5 mim e então resfriado até a temperatura de $60^{\circ} \mathrm{C}$ a uma taxa de $2^{\circ} \mathrm{C} / \mathrm{min}$. Após esse processo, o TFML é retirado da pensa e o excesso de SRPP é removido com um estilete. A temperatura do TFML é monitorada com um termopar instalado diretamente neste. Os equipamentos utilizados para a fabricação do TFML são apresentados na Figura 32.

(a)

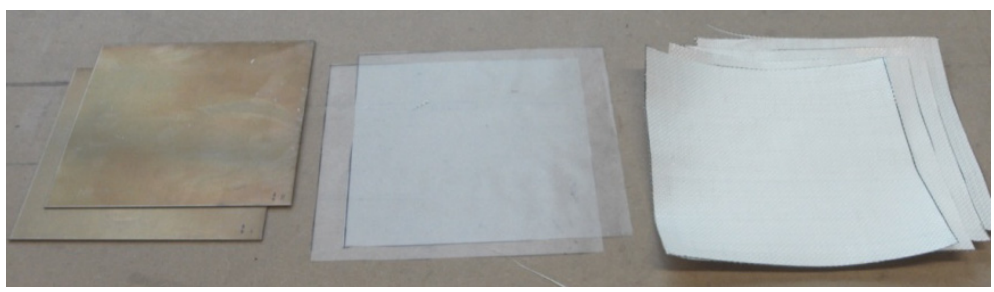

(b)

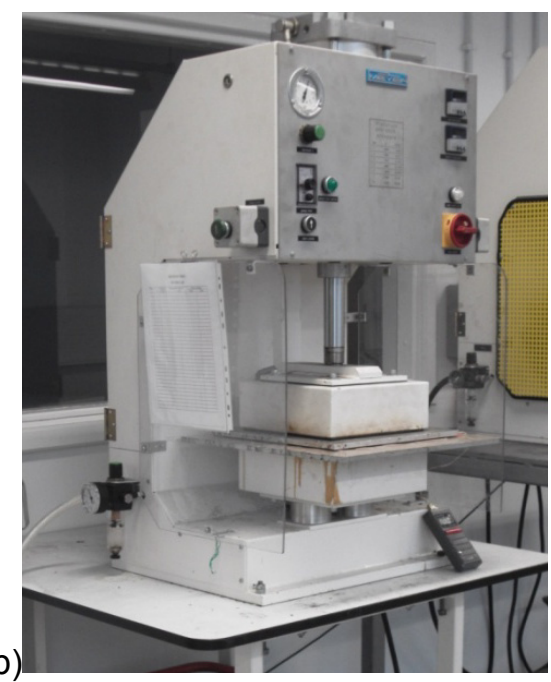

(c)

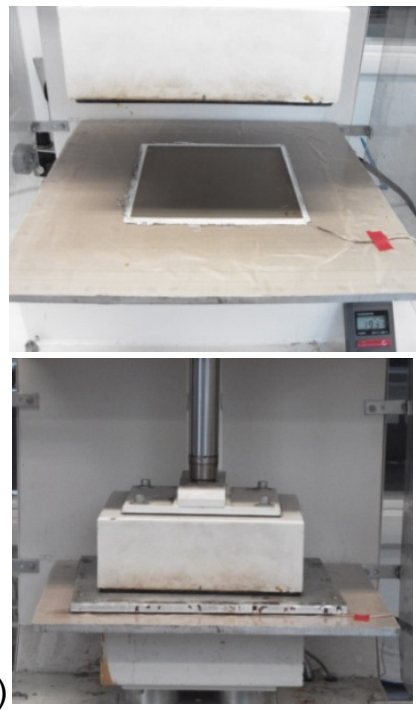

Figura 32: (a) Constituintes do FML, sendo (da esquerda para direita): camadas de alumínio, camadas de adesivos Xiro e camadas de SRPP-PURE. (b) Prensa pneumática com aquecimento Meyer e (c) TFML durante o processo de fabricação. 
Técnicas tradicionais de usinagem como furação com brocas de aço rápido, corte por serra de fita e fresamento foram utilizadas para a fabricação de corpos de prova para teste de impacto e caracterização mecânica. Cuidado especial foi tomado para que não ocorresse descolamento entre as camadas do TFML.

É importante enfatizar que, apesar do termo "fibra" na abreviatura TFML (termoplastic fibre-metal laminates), o SRPP aqui utilizado como estudo não possui fibras em sua composição. Do mesmo modo, que o material aqui estudado não é fabricado pelo processo da laminação, processo usual em materiais compósitos. Desse modo o termo TFML é utilizado neste estudo, visando uniformizar a forma com que tipo de material é referenciando em outros trabalhos, como (Abdullah, 2006), e também pela natureza ortotrópica do reforço utilizado. Além disso, o termo "laminado" é utilizado no sentido de "formar lâminas", não sendo relacionado ao processo de fabricação do material.

\subsection{LAMINADOS FIBRA-METAL TERMOFÍXOS}

FML termofíxos (aqui também denominados apenas por FML) foram utilizados para comparação do desempenho do impacto de TFML durante a realização de ensaios experimentais. Estes materiais foram fabricados de modo semelhante à FML comerciais, como o GLARE, utilizado atualmente em estruturas aeronáuticas.

O FML foi fabricado também utilizando a liga de alumínio aeronáutico 2024T3 na espessura de 0,40 mm. Lâminas unidirecionais pré-impregnados de fibra de vidro S2 e resina epóxi FM94, ambas fabricadas pela empresa Cytec, foram utilizadas para a laminação da camada de reforço do FML. A fim de garantir a adesão entre as camadas de material metálico e compósito, as chapas de liga de alumínio foram anodizadas e o adesivo epóxi FM94 foi entre estas.

O processo de fabricação dos FML tenta repetir o processo de fabricação de FML comerciais, sendo utilizada a técnica de compressão em autoclave. Inicialmente as lâminas de liga de alumínio são cortadas, limpas e submetidas à anodização fosfórica. Posteriormente, uma camada base de adesivo epoxílico é aplicada sobre estas, utilizando uma pistola pneumática de pintura. Após este processo, a quantidade de camadas de metal e compósitos são devidamente empilhadas e alinhadas, 
de forma a garantir o alinhamento das direções de laminação das lâminas de alumínio e o alinhamento das camadas de compósitos alternadamente nas direções $0^{\circ} \mathrm{e}$ $90^{\circ}$ com a direção de laminação do metal. Uma vez empilhadas todas as camadas, o FML é submetido a alta pressão e temperatura em uma autoclave. Nesta etapa, as camadas do FML são aderidas e o compósito é curado. O fabricante do material não forneceu mais informações sobre o processo de fabricação destes materiais.

Técnicas tradicionais de usinagem, como furação com brocas de aço rápido e corte com serra de fita foram utilizadas para a fabricação de corpos de prova para teste de impacto.

\subsection{AMOSTRAS DE CONSTITUINTES DO TFML PARA TESTES DE CARAC- TERIZAÇÃO MECÂNICA}

Amostras da liga de alumínio 2024-T3 foram obtidas a mesmo lote utilizado para fabricação dos TFML. Amostras de chapas planas de SRPP e TFML foram utilizadas para extração de amostras, sendo estas fabricadas utilização processo semeIhante ao descrito anteriormente.

\subsection{DEFINIÇÕES E CÓDIGO DE IDENTIFICAÇÃO DOS MATERIAIS}

É importante enfatizar que todos os TFML e FML utilizados para este estudo apresentam camada metálica na face superior e inferior. Define-se "configuração" do TFM ou FML como a quantidade de camadas metálicas e de reforços, sendo esta sempre representada na forma $n /(n-1)$. Desse modo, um TFML 5/4 apresenta 5 camadas de metais intercaladas entre 4 camadas de reforços.

O Composite Laminate Layup Code (CLLC) (Daniel e Ishai, 2006) é uma forma de identificação de propriedades da cada lâmina de um compósito. Em geral, este código é utilizado para identificação de alinhamento das fibras de cada camada, sendo representa entre colchetes e cada camada apresenta de forma sequencial 
dividida entre barras. Por exemplo, o compósito $\left[0^{\circ} / 90^{\circ} / 45^{\circ} / 0^{\circ}\right]$, apresenta quatro camadas empilhadas com alinhamento na sequencia $0^{\circ}, 90^{\circ}, 45^{\circ}$ e $0^{\circ}$.

Este código foi modificado para este estudo, sendo utilizado para representar a espessura das camadas do FML. Neste caso, este código é utilizado independentemente para as camadas metálicas e de reforços, sendo as espessuras representadas por três dígitos, em unidade de milímetros, com dois algarismos decimais, sem representação da vírgula. Assim, um FML com camadas metálicas empilhadas na forma [040/080/120] apresenta três camadas metálicas, empilhadas com espessuras na sequencia de $0,40 \mathrm{~mm}, 0,80 \mathrm{~mm}$ e $1,20 \mathrm{~mm}$.

A fim de facilitar a identificação dos materiais utilizados neste trabalho, um código de identificação foi desenvolvido. Este código segue a estrutura apresentada abaixo:

\section{Estrutura: X Y Z K}

\section{Exemplo: P5A027, G3B[027/054] ou P3[040/040/080]127}

Sendo a variáveis:

- X: Código alfabético de identificação de FML termoplástico ou termofíxo. Este pode assumir os valore "P" para TFML (referente à consoante inicial de polipropileno) ou "G" para FML (referente à consoante inicial do termo em inglês glass/epoxy).

- Y: Código numérico referente à quantidade de camadas metálicas.

- Z: Código alfabético referente à espessura das camadas metálicas e sumarizado na Tabela 4.

- $\mathrm{K}$ : Código numérico referente à espessura das camadas de reforço, em unidade de milímetros, com dois algarismos decimais e sem representação da vírgula.

Tabela 4: Código alfabético para identificação de espessuras das camadas metálicas.

\begin{tabular}{cc}
\hline Código & Espessura $(\mathbf{m m})$ \\
\hline A & 0,30 \\
B & 0,40 \\
\hline
\end{tabular}


Caso não haja uniformidade na espessura das camadas de metais ou reforços, os termos Z e K podem ser substituídos pelo CLLC modificado para identificação de espessuras de FML. A partir o código de identificação apresentado, é fácil observar que a configuração do FML é definida por $Y /(Y-1)$ e a espessura total por $Y Z+(Y-1) K$, ou a somatório dos termos da CLLC para o caso de diferentes espessuras no material.

Para o caso dos exemplos apresentados acima, tem-se:

- P5A027: TFML na configuração 5/4, com cinco camadas de metal de espessuras iguais a $0,30 \mathrm{~mm}$ e quatro camadas de reforços com espessuras iguais a $0,27 \mathrm{~mm}$.

- G3B[027/054]: FML na configuração 3/2, com três camadas de metal com espessuras iguais a $0,40 \mathrm{~mm}$ e camadas de reforços com espessura na sequência de $0,27 \mathrm{~mm}$ e $0,54 \mathrm{~mm}$.

- P3[040/040/080]127: TFML na configuração 3/2, com camadas de metal com espessuras na sequencia de $0,40 \mathrm{~mm}, 0,40 \mathrm{~mm}$ e $0,80 \mathrm{~mm}$, e reforços com espessuras iguais a 1,27 mm. 



\section{ESTUDO EXPERIMENTAL DE IMPACTO EM FML}

Neste capitulo será explorado o desempenho de FMLs em regime de impacto a diferentes velocidades. O impacto a baixa velocidade até $10 \mathrm{~m} / \mathrm{s}$, consta de ensaio de queda livre de peso em equipamento denominado martelo de impacto. No impacto de alta de $50 \mathrm{~m} / \mathrm{s}$ até $200 \mathrm{~m} / \mathrm{s}$ com projétil é acelerado por um equipamento denominado canhão pneumático ou gas-gun.

Três configurações de TFML foram consideradas para desenvolvimento do estudo experimental, o qual será comparado nos Capítulos 7 e $8 \mathrm{com}$ modelo teóricos e experimentais. Amostras de FML foram também ensaiadas a fim de comparação do comportamento do TFML com materiais similares utilizados em estruturas aeronáuticas atuais.

É importante ressaltar a importância do desenvolvimento de uma campanha experimental uma vez que esta busca embasar o estudo proposto com resultados reais do material quando ensaiado. Este aspecto é de fundamental importância para avaliação de modelos do material, assim como o alcance dos resultados esperados na tese. Além disso, a documentação detalhada dos resultados experimentais facilita o desenvolvimento de trabalhos futuros.

\subsection{IMPACTO A BAIXA VELOCIDADE}

A campanha de ensaios experimentais de baixa velocidade será apresentada neste item, sendo descritos os equipamentos e procedimento experimental adotado, materiais utilizados e resultados obtidos.

\subsubsection{Equipamentos e procedimento experimental}

O martelo de impacto do GMSIE-USP foi utilizado para o desenvolvimento de eventos de impacto de baixa velocidade em amostras de FML e TFML. Este equi- 
pamento, Figura 33, consiste em dois trilhos verticais os quais possibilitam o deslocamento vertical em queda livre de uma massa de impacto. O equipamento permite o posicionamento e lançamento remoto da massa, além de possuir dispositivos de segurança para realização do experimento. Um indentador semi-hemisférico com 20 $\mathrm{mm}$ de diâmetro foi utilizado, Figura 33, assim como massas de impacto de $4,65 \mathrm{~kg}$ e $6,73 \mathrm{~kg}$.

As amostras foram fixadas em um aparato de fixação rígido com $80 \mathrm{~mm}$ de diâmetro interno, Figura 33. Este utiliza parafusos igualmente espaçados e ranhuras internas para evitar o deslocamento do material durante o impacto e possibilitar o completo engastamento na periferia da placa. O impacto de indentador foi direcionado ao centro da amostra, sendo permitido ao primeiro impacto e evitado os contatos posteriores.

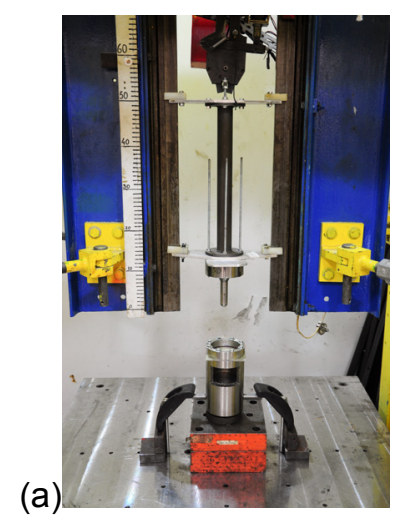

(b)

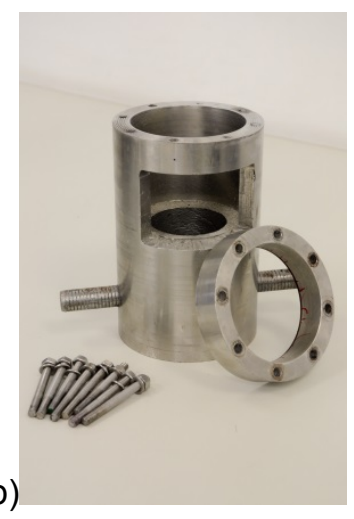

Figura 33: (a) Martelo de impacto e indentador, e (b) aparato de fixação das amostras.

Um vibrômetro a laser Polytec OFV-323 (Figura 34) foi utilizando para a medição do histórico de velocidade do indentador durante o impacto. Vale enfatizar que, com este equipamento, a medição é realizada totalmente sem contato, apresentando resolução e resposta em frequência suficientes para medição desejada. Além disso, a partir da integração e derivação do sinal, é possível obter histórico de deslocamento, aceleração e força atuante no indentador. O sinal analógico proveniente deste sensor foi adquirido por um sistema de aquisição National Instruments PCl6550, com taxa de amostragem de $100 \mathrm{kHz}$, sendo condicionado e tratado com o software comercial MatLab 7.0.

Uma câmera de alta velocidade Photron APX-RS (Figura 34) e sistema de iluminação apropriado foram utilizados para observação do evento de impacto, for- 
necendo imagens a taxas de até 10.000 quadros por segundo (fps). Após a realização do evento de impacto, o deslocamento residual central da amostra foi medido com um relógio comparador analógico, com resolução de $\pm 0,005 \mathrm{~mm}$ (Figura 34).

(a)

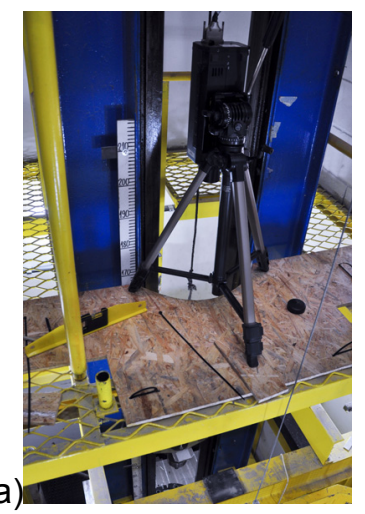

(b)

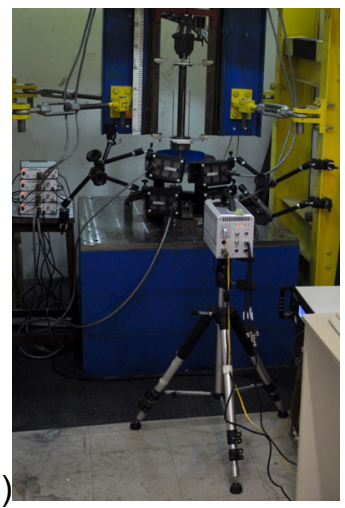

(c)

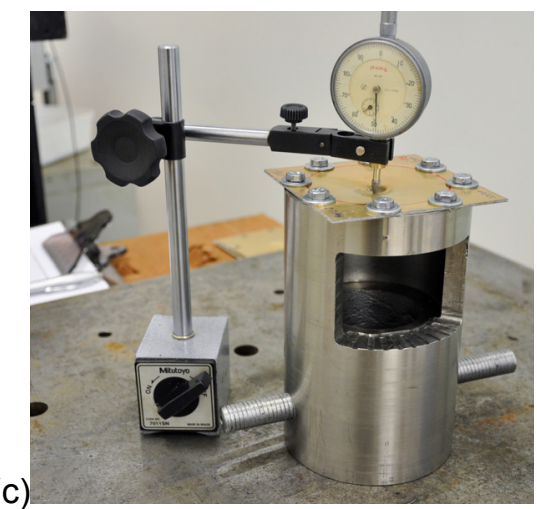

Figura 34: (a) Vibrômetro a laser, (b) câmera de alta velocidade e (c) relógio comparador.

Durante a preparação para realização do experimento, o martelo de impacto é montado utilizando a massa e indentador escolhidos, sendo devidamente alinhado para a realização do impacto na região central da amostra. Posteriormente, o vibrômetro a laser, sistema de aquisição, câmera de alta velocidade, sistema de iluminação e sistema de sincronização são instalados e previamente testados. Então, o procedimento experimental segue as etapas descritas a seguir, de forma repetitiva para cada amostra a ser testada:

1. Uma amostra de material a ser testado é escolhida ao acaso, sendo devidamente identificada.

2. A amostra é instalada no aparato de fixação com oito parafusos, apartado com mesmo torque, utilizando uma ferramenta pneumática.

3. A altura de impacto é definida e os sensores são preparados e sincronizados.

4. O ensaio é realizado, sendo o sistema de aquisição e sensores disparados automaticamente.

5. Não havendo imprevistos na realização do experimento, a velocidade incidente, residual e aspectos de comportamento do espécime são registrados.

6. A amostra é retirada do aparato de fixação. 
Após a campanha experimental, as amostras são reinstaladas no aparato de fixação, sem a utilização do disco superior de fixação, para que seja obtido o deslocamento central residual da mesma. Por fim, as amostras são devidamente fotografadas para documentação do experimento.

Os ensaios experimentais de impacto foram realizados com energias de impacto crescentes até que seja identificada a condição de ocorrência de trinca observável a olho nu. Ensaios em condições limites de ocorrência de falha ou ensaios com resultados duvidosos foram repetidos.

\subsubsection{Materiais}

A Tabela 5 sumariza os materiais utilizados para realização dos ensaios experimentais de impacto de baixa velocidade, bem como as principais características dos testes. É importante ressaltar que foram ensaiadas três configurações de TFML e duas configurações de FML similares a materiais comerciais, a fim de obter parâmetros de comparação de desempenho.

Tabela 5: Amostras utilizadas para realização de experimentais de impacto.

\begin{tabular}{cccc}
\hline Identificação & $\begin{array}{c}H \\
(\mathrm{~mm})\end{array}$ & $\begin{array}{c}\rho_{F M L} \\
\left(\mathrm{~g} / \mathrm{cm}^{3}\right)\end{array}$ & Descrição \\
\hline P3A043 & 1,76 & 1,80 & TFML 3/2 \\
P4B039 & 2,78 & 1,93 & TFML 4/3 \\
P5A044 & 3,24 & 1,70 & TFML 5/4 \\
G3B054 & 2,28 & 2,34 & FML 3/2 \\
G5B027 & 3,08 & 2,45 & FML 5/4 \\
\hline
\end{tabular}

\subsubsection{Resultados e discussões}

Nas Tabelas 6 a 10 são apresentados os perfis das amostras testadas após o impacto, sendo observado que tanto os TFMLs como os FMLs apresentam um perfil 
dúctil de deslocamento residual. Nas Tabelas 12 a 16 são apresentados resultados experimentais obtidos para as amostras testadas, sendo $V_{i n c}$, velocidade incidente, $V_{\text {res }}$, velocidade residual, $E_{a b s}$, a energia de impacto absorvida definida por

$$
E_{a b s}=\frac{G}{2}\left(\frac{V_{i n c}^{2}-V_{r e s}^{2}}{V_{i n c}^{2}}\right) \cdot 100,
$$

sendo $G$ a massa de impacto. O deslocamento central residual da placa após o impacto é definido por $W_{f}$ medido pelo relógio comparador, e a nomenclatura utilizada para a avaliação visual está apresentada na Tabela 11.

Para os níveis de energia de impacto praticados para os experimentos de impacto de baixa velocidade, foi observado que o mecanismo de dissipação de energia no material ocorre principalmente pela deformação de membrana de todo o material. Também é observada dissipação de energia na formação de uma calota central formada pelo indentador, porém com menor relevância para o comportamento global do material. Não foi observada a formação de rótulas plásticas evidentes no material.

Tabela 6: Perfil pós-impacto de P3A043.

\begin{tabular}{c:|c|}
\hline $\begin{array}{c}E_{\text {imp }} \\
(J)\end{array}$ & \multicolumn{2}{|c}{ P3A043 } \\
\hline 10,0 & \\
\hline 14,8 & \\
19,8 & \\
\hline 24,8 & \\
\hline
\end{tabular}


Tabela 7: Perfil pós-impacto de P4B039.

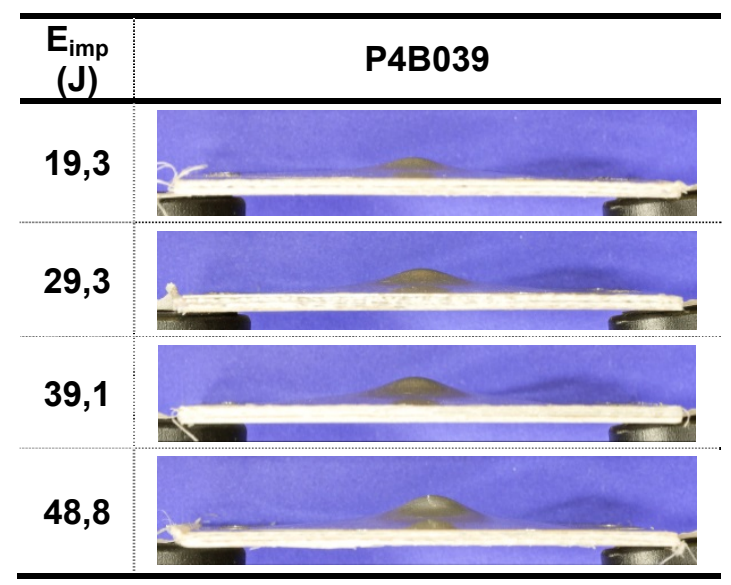

Tabela 9: Perfil pós-impacto de G3B054.

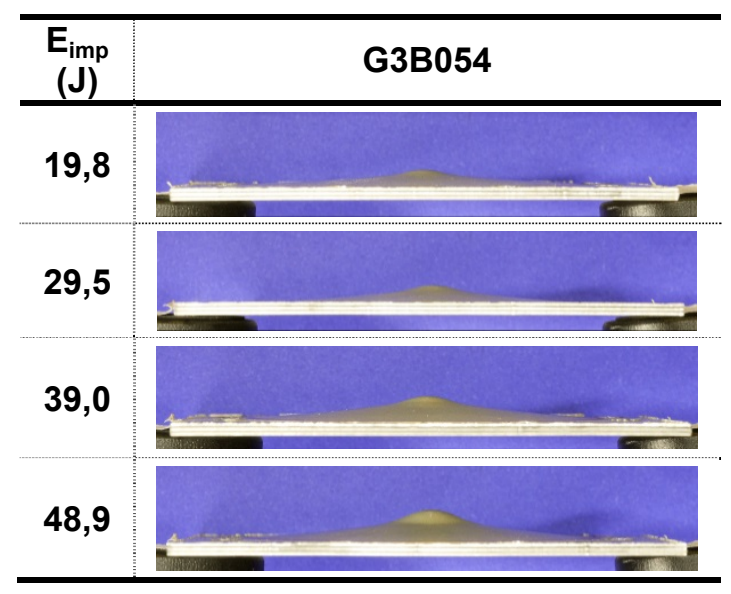

Tabela 8: Perfil pós-impacto de P5A044.

\begin{tabular}{c:c}
\hline $\begin{array}{c}E_{\text {imp }} \\
(J)\end{array}$ & P5A044 \\
\hline 19,1 & \\
\hline 29,1 & \\
38,8 & \\
46,3 & \\
\hline
\end{tabular}

Tabela 11: Código de identificação para falha no material para impacto de baixa velocidade.

\begin{aligned} & \hline SF Sem falha visual aparente \\ & FO Falha visual na face oposta à impactada \\ & FI Falha visual na face impactada \\ & DC Descolamento de camadas \\ & \hline\end{aligned}


Tabela 12: Resultados experimentais para o material P3A043.

\begin{tabular}{c|c|c|c|c|c}
\hline Material & P3A043 & $M_{i m p}(\mathrm{~kg})$ & 4,65 & & \\
\hline \hline Espécime & $\left|V_{\text {inc }}\right|(\mathrm{m} / \mathrm{s})$ & $\left|V_{\text {res }}\right|(\mathrm{m} / \mathrm{s})$ & $E_{a b s}(\%)$ & $w_{f}(\mathrm{~mm})$ & $\begin{array}{c}\text { Avaliação } \\
\text { visual }\end{array}$ \\
\hline 17 & 2,07 & 1,16 & 68,6 & 3,87 & $\mathrm{SF}$ \\
\hline 16 & 2,08 & 1,18 & 67,8 & 3,96 & $\mathrm{SF}$ \\
\hline 11 & 2,52 & 1,30 & 73,4 & 4,88 & $\mathrm{SF}$ \\
\hline 12 & 2,53 & 1,31 & 73,2 & 4,39 & $\mathrm{SF}$ \\
\hline 14 & 2,90 & 1,21 & 82,6 & 5,98 & $\mathrm{FO}$ \\
\hline 13 & 2,91 & 1,33 & 79,1 & 5,67 & $\mathrm{FO}$ \\
\hline 10 & 3,25 & 1,11 & 88,3 & 6,78 & $\mathrm{FI}+\mathrm{FO}$ \\
\hline 15 & 3,27 & 1,26 & 85,2 & 6,42 & FO \\
\hline
\end{tabular}

Tabela 13: Resultados experimentais para o material P4B039.

\begin{tabular}{c|c|c|c|c|c}
\hline Material & P4B039 & $M_{\text {imp }}(\mathrm{kg})$ & 4,65 & & \\
\hline \hline Espécime & $\left|V_{\text {inc }}\right|(\mathrm{m} / \mathrm{s})$ & $\left|V_{\text {res }}\right|(\mathrm{m} / \mathrm{s})$ & $E_{\text {abs }}(\%)$ & $w_{f}(\mathrm{~mm})$ & $\begin{array}{c}\text { Avaliação } \\
\text { visual }\end{array}$ \\
\hline 19 & 2,88 & 1,50 & 72,9 & 4,25 & $\mathrm{SF}$ \\
\hline 18 & 3,55 & 1,68 & 77,6 & 5,49 & $\mathrm{SF}$ \\
\hline 17 & 3,81 & 1,75 & 78,9 & 5,49 & $\mathrm{SF}$ \\
\hline 16 & 3,82 & 1,79 & 78,0 & 5,51 & $\mathrm{SF}$ \\
\hline 13 & 4,10 & 1,48 & 87,0 & 6,28 & $\mathrm{FI}+\mathrm{FO}$ \\
\hline 14 & 4,10 & 1,82 & 80,3 & 6,04 & $\mathrm{SF}$ \\
\hline 15 & 4,10 & 1,47 & 87,1 & 6,40 & $\mathrm{FI}+\mathrm{FO}$ \\
\hline 12 & 4,58 & 1,50 & 89,3 & 7,26 & $\mathrm{FI}+\mathrm{FO}$ \\
\hline 11 & 4,99 & 1,39 & 92,2 & 8,40 & $\mathrm{FI}+\mathrm{FO}$ \\
\hline
\end{tabular}

Tabela 14: Resultados experimentais para o material P5A044.

\begin{tabular}{c|c|c|c|c|c}
\hline Material & P5A044 & $M_{i m p}(\mathrm{~kg})$ & 4,65 & & \\
\hline \hline \multirow{2}{*}{ Espécime } & $\left|V_{\text {inc }}\right|(\mathrm{m} / \mathrm{s})$ & $\left|V_{\text {res }}\right|(\mathrm{m} / \mathrm{s})$ & $E_{a b s}(\%)$ & $w_{f}(\mathrm{~mm})$ & $\begin{array}{c}\text { Avaliação } \\
\text { visual }\end{array}$ \\
\hline 21 & 2,87 & 1,55 & 70,8 & 3,78 & $\mathrm{SF}$ \\
\hline 12 & 4,09 & 1,90 & 78,4 & 6,03 & $\mathrm{SF}$ \\
\hline 13 & 4,09 & 1,81 & 80,4 & 5,51 & $\mathrm{SF}+\mathrm{DC}$ \\
\hline 14 & 4,30 & 1,80 & 82,5 & 6,87 & $\mathrm{SF}$ \\
\hline 16 & 4,30 & 1,81 & 82,3 & 6,48 & $\mathrm{SF}$ \\
\hline 15 & 4,31 & 1,40 & 89,4 & 5,95 & $\mathrm{FI}+\mathrm{FO}+\mathrm{DC}$ \\
\hline 17 & 4,46 & 1,64 & 86,5 & 7,09 & $\mathrm{FO}+\mathrm{DC}$ \\
\hline 19 & 4,46 & 1,45 & 89,4 & 7,28 & $\mathrm{FI}+\mathrm{FO}$ \\
\hline 18 & 4,47 & 1,52 & 88,4 & 6,66 & $\mathrm{FI}+\mathrm{FO}+\mathrm{DC}$ \\
\hline 20 & 4,54 & 1,74 & 85,3 & 5,14 & $\mathrm{SF}$ \\
\hline 11 & 4,60 & 1,52 & 89,1 & 6,96 & $\mathrm{FI}+\mathrm{FO}+\mathrm{DC}$ \\
\hline 10 & 5,00 & 1,11 & 95,1 & 9,12 & $\mathrm{FI}+\mathrm{FO}$ \\
\hline
\end{tabular}


Tabela 15: Resultados experimentais para o material G3B054.

\begin{tabular}{c|c|c|c|c|c}
\hline Material & G3B054 & $M_{\text {imp }}(\mathrm{kg})$ & \multicolumn{2}{|c}{6,73} & \\
\hline \hline Espécime & $\left|V_{\text {inc }}\right|(\mathrm{m} / \mathrm{s})$ & $\left|V_{\text {res }}\right|(\mathrm{m} / \mathrm{s})$ & $E_{a b s}(\%)$ & $w_{f}(\mathrm{~mm})$ & $\begin{array}{c}\text { Avaliação } \\
\text { visual }\end{array}$ \\
\hline 18 & 2,43 & 1,39 & $67,3 \%$ & 3,2 & $\mathrm{SF}$ \\
\hline 17 & 2,62 & 1,64 & $60,8 \%$ & 3,7 & $\mathrm{SF}$ \\
\hline 13 & 3,41 & 1,79 & $72,4 \%$ & 4,52 & $\mathrm{SF}$ \\
\hline 16 & 3,63 & 1,86 & $73,7 \%$ & 5,1 & $\mathrm{SF}$ \\
\hline 14 & 3,64 & 1,78 & $76,1 \%$ & 5 & $\mathrm{FO}$ \\
\hline 15 & 3,64 & 1,87 & $73,6 \%$ & 4,88 & $\mathrm{SF}$ \\
\hline 12 & 3,81 & 1,64 & $81,5 \%$ & 5,55 & $\mathrm{FO}$ \\
\hline 11 & 4,40 & 1,56 & $87,4 \%$ & 6,98 & $\mathrm{FI}+\mathrm{FO}$ \\
\hline
\end{tabular}

Tabela 16: Resultados experimentais para o material G5B027.

\begin{tabular}{c|c|c|c|c|c}
\hline Material & G5B027 & $M_{\text {imp }}(\mathrm{kg})$ & 6,73 & \\
\hline \hline Espécime & $\left|V_{\text {inc }}\right|(\mathrm{m} / \mathrm{s})$ & $\left|V_{\text {res }}\right|(\mathrm{m} / \mathrm{s})$ & $E_{a b s}(\%)$ & $w_{f}(\mathrm{~mm})$ & $\begin{array}{c}\text { Avaliação } \\
\text { visual }\end{array}$ \\
\hline 16 & 2,43 & 1,43 & 65,4 & 2,15 & $\mathrm{SF}$ \\
\hline 15 & 3,42 & 1,81 & 72,0 & 3,60 & $\mathrm{SF}$ \\
13 & 4,01 & 2,01 & 74,9 & 4,58 & $\mathrm{SF}$ \\
14 & 4,01 & 2,00 & 75,1 & 4,64 & $\mathrm{SF}$ \\
\hline 12 & 4,21 & 2,04 & 76,5 & 4,85 & $\mathrm{FO}$ \\
11 & 4,22 & 1,96 & 78,4 & 4,53 & $\mathrm{FO}$ \\
\hline 10 & 4,55 & 1,91 & 82,4 & 5,65 & $\mathrm{FO}$ \\
\hline 9 & 5,23 & 1,68 & 89,7 & 7,05 & $\mathrm{FI}+\mathrm{FO}$ \\
\hline
\end{tabular}

Na Figura 35 são exemplificados os modos de falha obtidos durante os testes, assim com o a Figura 36 correlaciona o tipo de falha obtido como a $E_{i m p}$ para as amostras testadas.

A falha visual na face oposta ao impacto (FO) é caracterizada por uma trinca única, possível de ser identificada visualmente e originada na posição central da calota formada pelo indentador. Nos experimentos realizados, foi observado que a trinca da FO foi gerada tanto paralela como perpendicular à direção de laminação das camadas metálicas.

A falha visual na face impactada (FI) é caracterizada por uma trinca periférica à calota formada pelo indentador, apresentando uma direção circunferencial majoritariamente. Em geral, foi observado que a falha tipo FI ocorre em espécimes submetidos a níveis mais altos de energia de impacto. É importante enfatizar que nos ensaios, não se teve como objetivo a realização de eventos de impacto a baixa velocidade com perfuração ou atravessamento das amostras. 
(a)

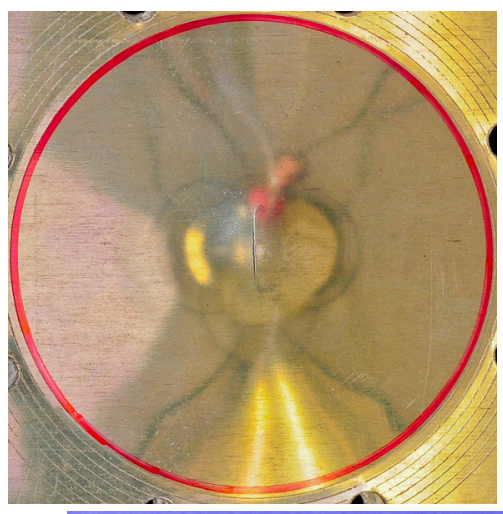

(b)

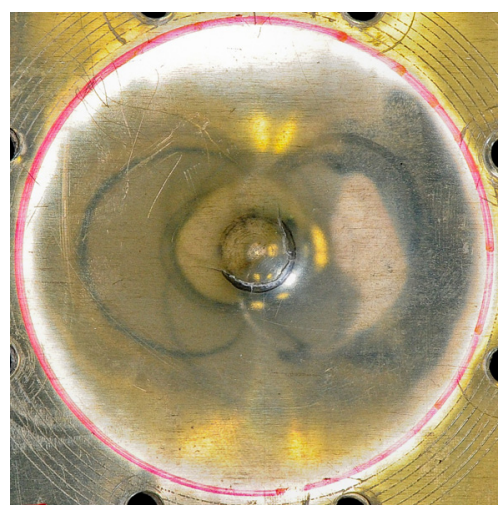

(c)

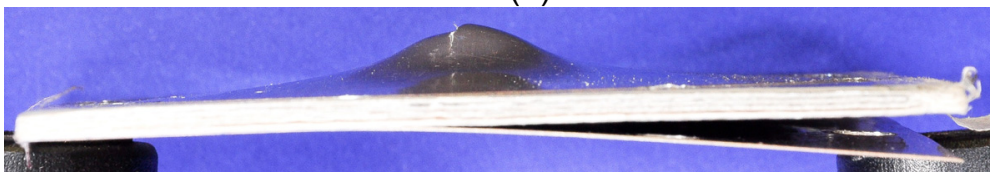

Figura 35: Modos de falha identificados: (a) falha na face oposta, (b) falha na face impactada e (c) descolamento de camadas.

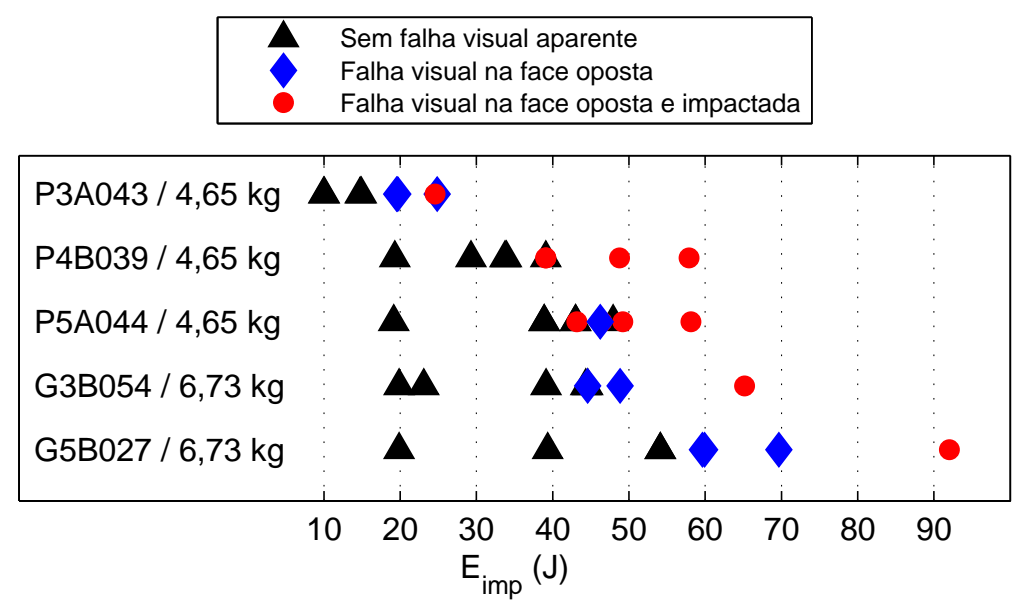

Figura 36: Ocorrência dos modos de falha nos materiais testados.

Apenas em amostras de TFML foi observado o descolamento de camadas (DC) quando o material é retirado do aparato de fixação. Este fenômeno é causado pela fraca aderência entre o reforço termoplástico e o alumínio, mesmo com o uso da anodização e camada adesiva. A ocorrência do DC é mais evidente em TFML com maior número de camadas, como o P5A044, sendo também observado em áreas periféricas P4B039 e P3A043. É importante frisar que, além do impacto, o DC também pode ser causado (ou intensificado) pelo aperto dos parafusos de fixação, em função da menor rigidez normal do TFML quando comparado ao FML. 


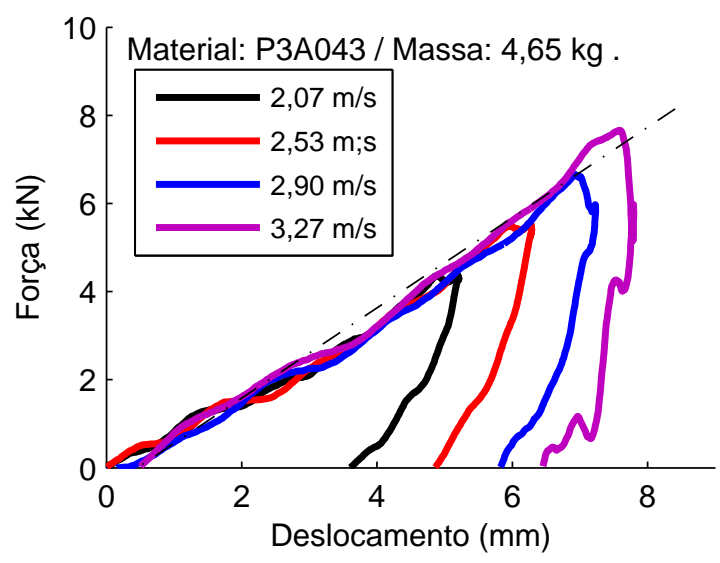

Figura 37: Comportamento do material P3A043 durante o impacto de baixa velocidade.
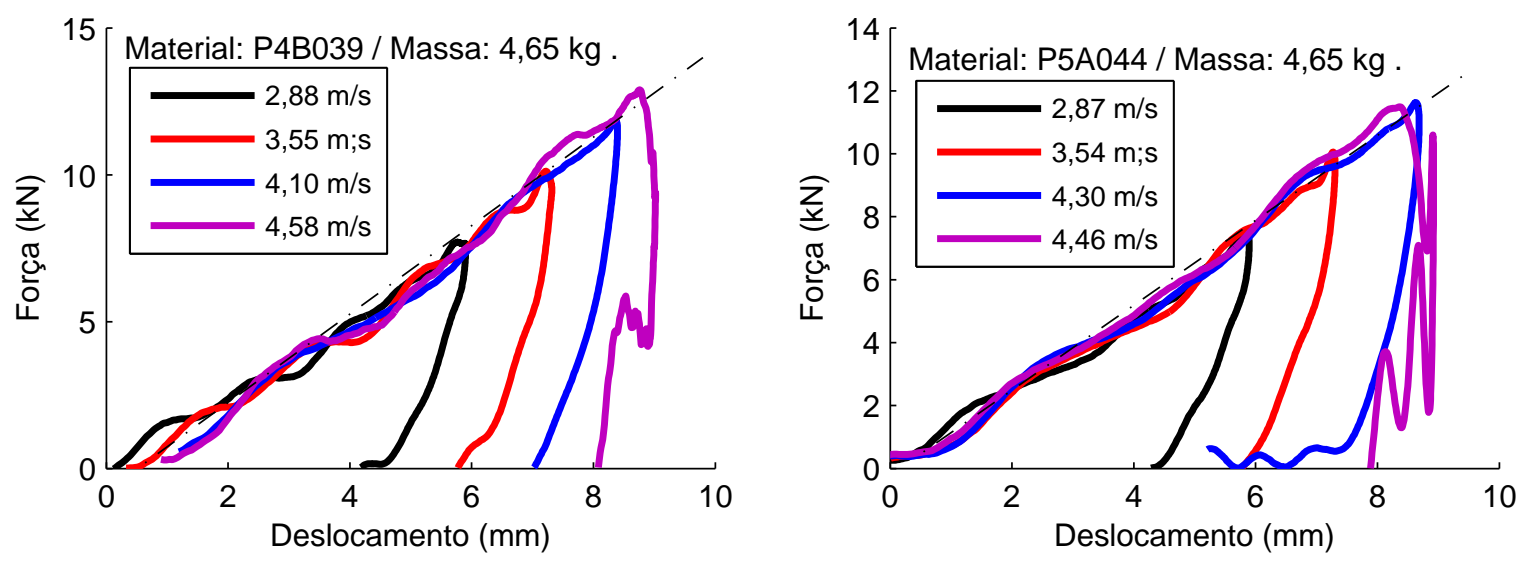

Figura 38: Comportamento dos materiais P3B039 e P5A044 durante o impacto de baixa velocidade.
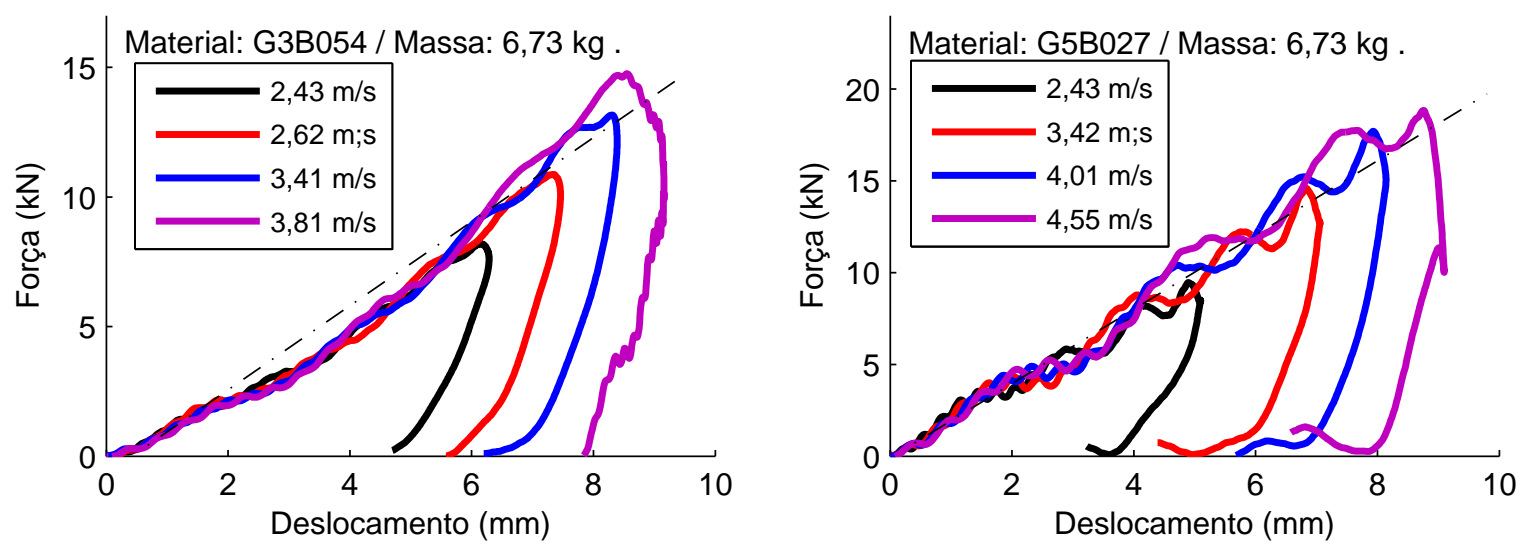

Figura 39: Comportamento dos materiais G3B054 e G5B027 durante o impacto de baixa velocidade.

O comportamento dos materiais submetidos ao impacto de baixa velocidade está apresentado nas Figuras 37 a 39. Nestas, é possível observar uma significativa 
correlação entre os comportamentos das amostras, apresentando comportamento semelhante até o início do descarregamento.

Em geral, quando não é observada falha no material, tem-se uma curva contínua, apresentando um aumento progressivo da carga até um valor máximo e o posterior retorno elástico até a condição de força nula. Por sua vez, quando é observada a ocorrência de falha na amostra, observa-se uma queda abrupta da força e ocorrência de instabilidade na curva força-deslocamento, possivelmente causada por ruptura de material e descolamento de camadas. Vale ressaltar que o deslocamento aqui apresentado é relativo ao deslocamento do indentador com a utilização do sensor de velocidade usando laser nos instantes de contato com a placa. Após a separação destes, a partir do uso de câmeras de alta velocidade, foi observado o descarregamento elástico do material. Assim, o deslocamento final apresentado nas Figuras 37 a 39, relativo ao indentador, difere o deslocamento central residual, $W_{f}$, apresentado nas Tabelas 12 a 16 , relativo à placa.

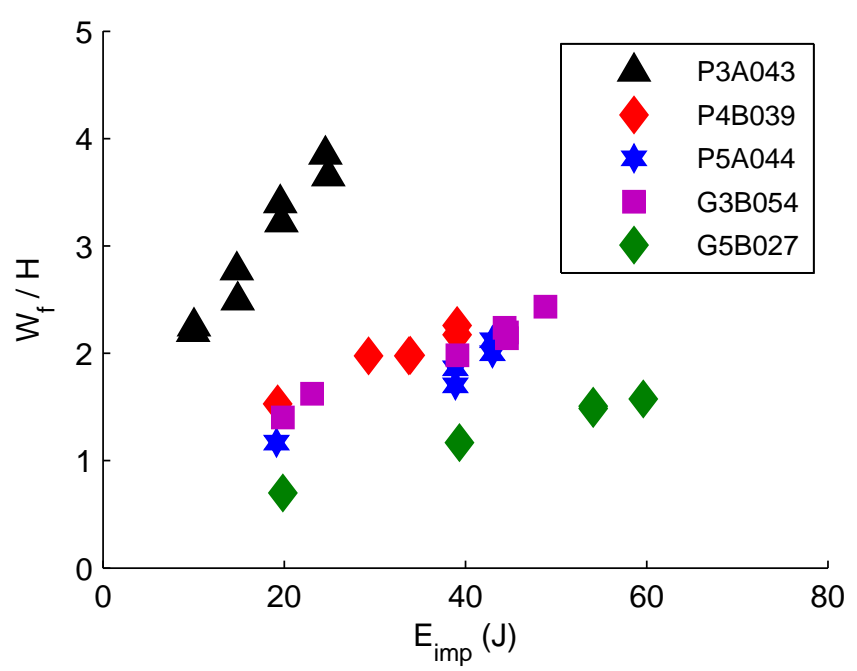

Figura 40: Deslocamento residual central adimensional para as amostras testadas sem ocorrência de falha.

$\mathrm{Na}$ Figura 40 é apresentado o deslocamento central residual adimensional das amostras de TFML e FML testadas, sem a ocorrência de falha. Observa-se que as amostras de P3A043 apresentam maior deslocamento central, suportando menores cargas de impacto. Por sua vez, a amostra G5B027 apresenta resistência a maiores níveis de tensão, apresentando menor deslocamento residual após o impacto. 
As amostras P4B039, P5A044 e G3A044 apresentam comportamentos semelhantes, com resistência sensivelmente superior para a amostra G3B054.

A Tabela 17 sumariza o desempenho das amostras testadas quando submetidas ao impacto de baixa velocidade, sendo apresentados o deslocamento residual central adimensional, $W_{f} / H$, velocidade limiar de falha, $V L F$, energia limiar de falha, $E L F$, e rigidez ao impacto, $K_{p}$. Buscando realizar o estudo comparativo, todos estes parâmetros foram também apresentados de forma relativa à densidade do material, $\rho_{F M L}$.

A Tabela 17 sumariza o desempenho das amostras testadas quando submetidas ao impacto de baixa velocidade. Observa-se que a energia limiar de falha (ELF) é maior para os FML quando comparado com os TFML. No entanto quando a ELF específica $\left(E L F / \rho_{F M L}\right)$ é avaliada, observa-se um desempenho similar entre as amostras P3B039 e G3B054, como também entre as amostras P5A054 e G5B027. Da mesma forma, observa-se que a rigidez específica ao impacto $\left(K_{p} / \rho_{F M L}\right)$ das amostras P3B039 e G3B054; e P5A054 e G5B027 também são semelhantes.

Com relação ao deslocamento central residual adimensionalizado específico $\left(W_{f, \max } / H \cdot \rho_{F M L}\right)$ das amostras testadas, observa-se um desempenho superior dos TFMLs quando comparado aos FMLs.

Tabela 17: Resultados experimentais comparativos.

\begin{tabular}{cccccc}
\hline Material & $w_{f} / H^{1}$ & $\begin{array}{c}w_{f} / H \cdot \rho_{F M L} \\
\left(\mathrm{~mm}^{2} / \mathrm{g}\right) \cdot 10^{3}\end{array}$ & $\begin{array}{c}V L F \\
(\mathrm{~m} / \mathrm{s})\end{array}$ & $\begin{array}{c}E L F \\
(\mathrm{~J})\end{array}$ & $\begin{array}{c}E L F / \rho_{F M L} \\
\left(\mathrm{~J} . \mathrm{mm}^{2} / \mathrm{g}\right) \cdot 10^{3}\end{array}$ \\
\hline TFML 3/2 (P3A043) & 2,77 & 1,54 & 2,72 & 33,90 & 18,81 \\
TFML 4/3 (P4B039) & 2,17 & 1,12 & 4,10 & 78,17 & 40,46 \\
TFML 5/4 (P5A044) & 2,12 & 1,24 & 4,35 & 85,98 & 50,46 \\
FML 3/2 (G3B054) & 2,24 & 0,96 & 3,62 & 87,22 & 37,29 \\
FML 5/4 (G5B027) & 1,49 & 0,61 & 4,11 & 129,94 & 52,96 \\
\hline
\end{tabular}

: Sem ocorrência de falha visual.

\begin{tabular}{ccc}
\hline Material & $\begin{array}{c}K_{p} \\
(\mathrm{kN} / \mathrm{mm})\end{array}$ & $\begin{array}{c}K_{p} / \rho_{F M L} \\
\left(\mathrm{kN} \cdot \mathrm{mm}^{2} / \mathrm{g}\right) \cdot 10^{3}\end{array}$ \\
\hline TFML 3/2 (P3A043) & 1,03 & 574,05 \\
TFML 4/3 (P4B039) & 1,53 & 790,58 \\
TFML 5/4 (P5A044) & 1,41 & 826,44 \\
FML 3/2 (G3B054) & 1,67 & 713,64 \\
FML 5/4 (G5B027) & 2,10 & 855,50 \\
\hline
\end{tabular}




\subsection{IMPACTO DE ALTA VELOCIDADE}

A seguir, a campanha experimental de impacto de alta velocidade será apresentada, sendo descritos os equipamentos utilizados, procedimento experimental, materiais e resultados obtidos.

\subsubsection{Equipamentos e procedimento experimental}

O canhão pneumático lançador de projéteis do GMSIE-USP foi utilizado para a realização de eventos de impacto de alta velocidade em amostras de FML e TFML. Este equipamento, Figura 41, consiste em um reservatório de ar, uma válvula de abertura rápida e um tubo de aceleração de $6 \mathrm{~m}$ de comprimento. Incialmente, o projétil é instalado no início do tubo de aceleração e o reservatório é pressurizado com ar comprimido. Quando este atinge o nível de pressão esperado, a válvula de abertura rápida é acionada, ocasionando o descarregamento do reservatório e aceleração do projétil ao longo no tubo de aceleração. Este equipamento é operado em ambiente seguro, sendo munido de sistema de acionamento remoto e dispositivos de segurança.

Um sistema óptico de medição de velocidade de projéteis, Figura 41, é utilizado na extremidade final do tubo de aceleração. Para o experimento em questão, esferas rígidas com 20 mm de diâmetro e massa de 32,5 g foram utilizadas, sendo previamente definida uma correlação entre velocidade final do projétil e pressão aplicada ao reservatório pneumático.

De maneira semelhante aos ensaios de baixa velocidade, as amostras foram fixadas em um aparato de fixação rígido com $80 \mathrm{~mm}$ de diâmetro interno, Figura 33b, descrito anteriormente. O impacto foi direcionado ao centro da placa, no entanto, houve pequena variação na posição final do impacto por característica do próprio equipamento. 
(a)

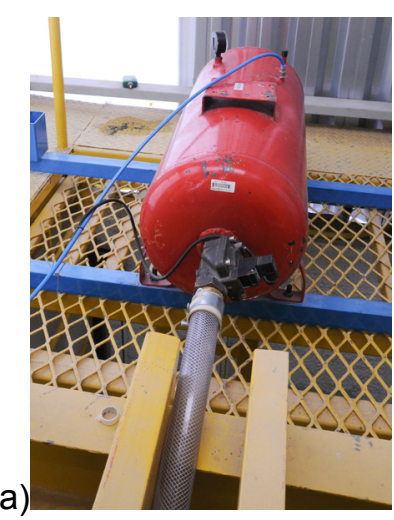

(b)

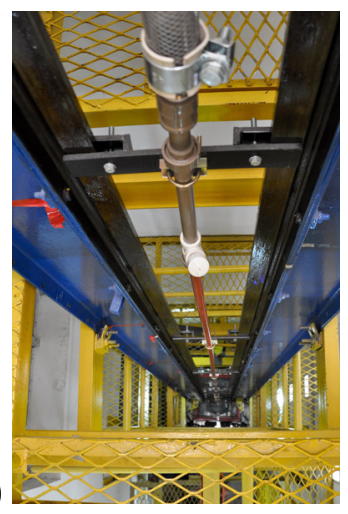

(c)

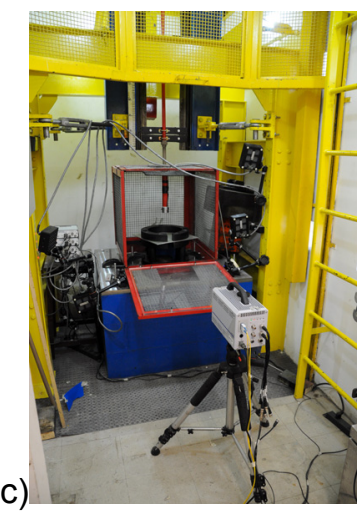

Figura 41: Canhão pneumático lançador de projéteis: (a) reservatório pneumático e válvula de abertura rápida, (b) tubo de aceleração e (c) dispositivos de proteção, sensor de velocidade e câmera de alta velocidade.

Uma câmera de alta velocidade Photron APX-RS (Figura 41) e sistema de iluminação apropriado foram utilizados para observação do evento de impacto, fornecendo imagens a taxa de até 10.000 fps. A obtenção da velocidade incidente e residual do projetil foi feita através da análise da sequência de imagens de impacto.

Para a preparação do aparato experimental, inicialmente o canhão pneumático é montado, sendo devidamente alinhado para a realização do impacto na região central da amostra. Posteriormente, a câmera de alta velocidade, sistema de iluminação e sincronização são instalados e previamente testados. Deste ponto, o procedimento experimental segue as seguintes etapas, de forma repetitiva para cada amostra a ser testada:

1. Uma amostra de material a ser testado foi escolhida ao acaso, sendo devidamente identificada.

2. A amostra é instalada no aparato de fixação com oito parafusos, apartado com mesmo torque, utilizando uma ferramenta pneumática.

3. O projétil é instalado no início do tubo aceleração e os dispositivos de segurança são acionados.

4. Uma pressão pré-definida é aplicada no reservatório pneumático do canhão e os sensores são preparados e sincronizados.

5. A válvula de esvaziamento do reservatório é acionada, sendo o projétil disparado, acionando automaticamente os sensores.

6. Não havendo imprevistos na realização do experimento, velocidade incidente e residual são registradas; assim como aspectos de comporta- 
mento do espécime, como ocorrência de falha, excentricidades e escorregamentos.

7. A amostra é retirada do aparato de fixação.

8. As amostras são devidamente fotografadas para documentação do experimento.

Os ensaios experimentais de impacto de alta velocidade foram realizados objetivando a identificação do limite balístico do material testado, sendo tomada energia de impacto crescente até que a ocorrência da perfuração completa. Ensaios em condições limites ou com resultados duvidosos foram repetidos até que uma tendência comportamento fosse definida.

\subsubsection{Materiais}

Do mesmo modo que os ensaios de baixa velocidade, foram ensaiadas três configurações de TFML e duas configuras de FML similares a materiais aeronáuticos comerciais para obtenção de parâmetros de comparação de desempenho. A Tabela 5 sumariza os materiais utilizados para realização dos ensaios experimentais de impacto de alta velocidade, assim como aspectos relevantes desses.

\subsubsection{Resultados e discussões}

Resultados qualitativos da vista lateral e face oposta das amostras testadas são apresentados nas Tabelas 6 a 16, quando submetidas à energia crescente de impacto de alta velocidade. Na Figura 42 é apresentada a secção transversal da amostra P4B039 após o impacto, sendo possível observar claramente a perfuração do material pela esfera, com ruptura do reforço e metal. Observa-se a formação de duas rótulas plásticas circulares formadas na região periférica à calota central e na região de engastamento do material. O descolamento interno do material é observado principalmente nas camadas inferiores deste. No geral, também é possível ob- 
servar que houve a conservação da integridade da amostra após a perfuração e que a imagem representa o comportamento observado na maioria das amostras testadas

Tabela 18: Perfil pós-impacto de P3A043.

\begin{tabular}{c:c}
\hline $\begin{array}{c}V_{\text {inc }} I \\
V_{\text {res }} \\
(\mathrm{m} / \mathrm{s})\end{array}$ & P3A043 \\
\hline $60,27 I$ \\
$-6,43$
\end{tabular}

Tabela 19: Perfil pós-impacto de P4B039.

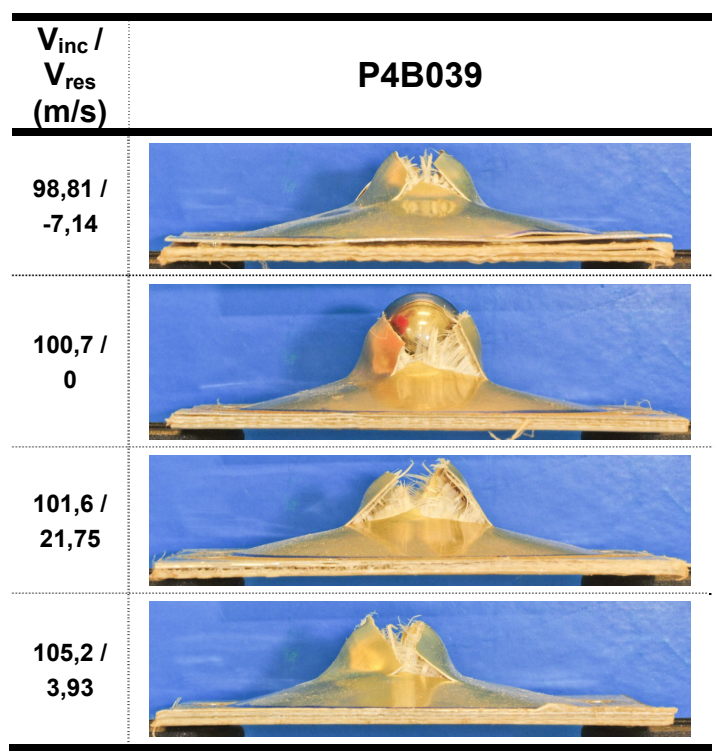
Tabela 20: Perfil pós-impacto de P5A044.

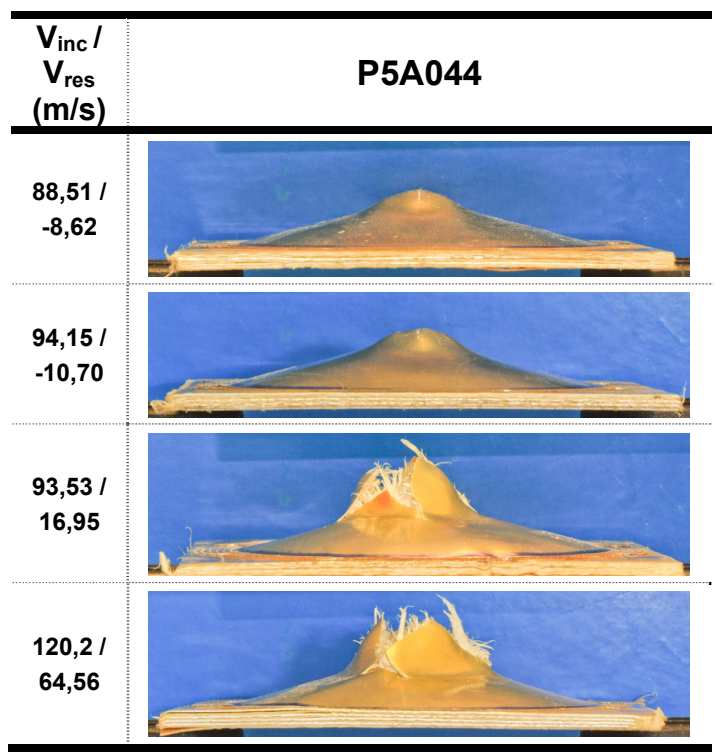


Tabela 21: Perfil pós-impacto de G3B054.

Tabela 22: Perfil pós-impacto de G5B027.

\begin{tabular}{c:c|c}
\hline $\begin{array}{c}V_{\text {inc }} l \\
V_{\text {res }} \\
(\mathrm{m} / \mathrm{s})\end{array}$ & G3B054 \\
\hline $103,2 /$ & \\
\hline$-10,07$ & \\
\hline 105,81 & \\
\hline$-9,83$ & \\
\hline $111,7 /$ & \\
\hline 12,76 & \\
\hline $124,1 /$ & \\
\hline 50,60 & \\
\hline
\end{tabular}

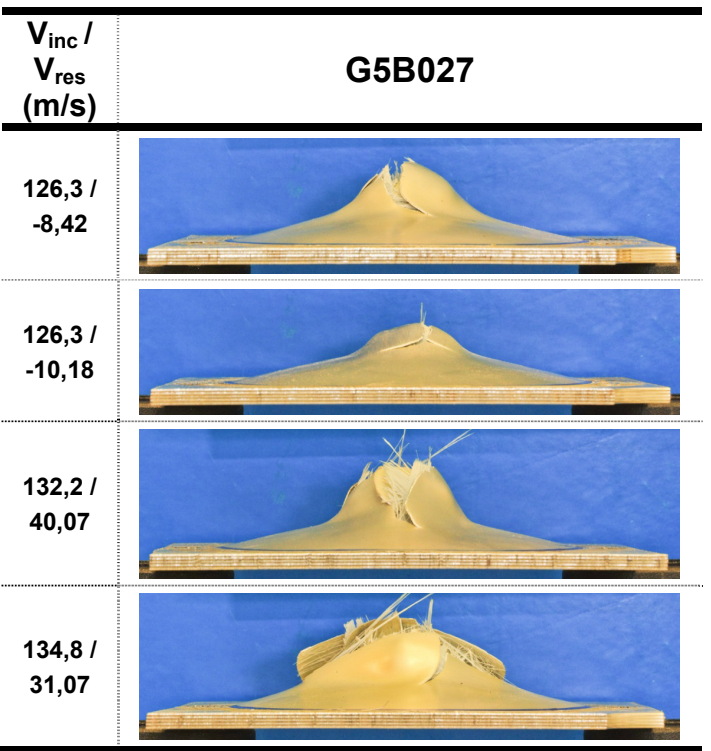

Tabela 23: Vista da face oposta a impacto, material: P3A043.

\begin{tabular}{c|c|c|c|c|c|}
\hline & \multicolumn{3}{|c|}{ P3A043 } \\
\hline $\begin{array}{c}\mathrm{V}_{\text {inc }} / \mathrm{V}_{\text {res }}(\mathrm{m} / \mathrm{s}) \\
\text { (n) }\end{array}$ & $-60,27 /+6,43$ & $-63,60 /+5,96$ & $-66,07 /-13,39$ \\
\hline
\end{tabular}

Tabela 24: Vista da face oposta a impacto, material: P4B039.

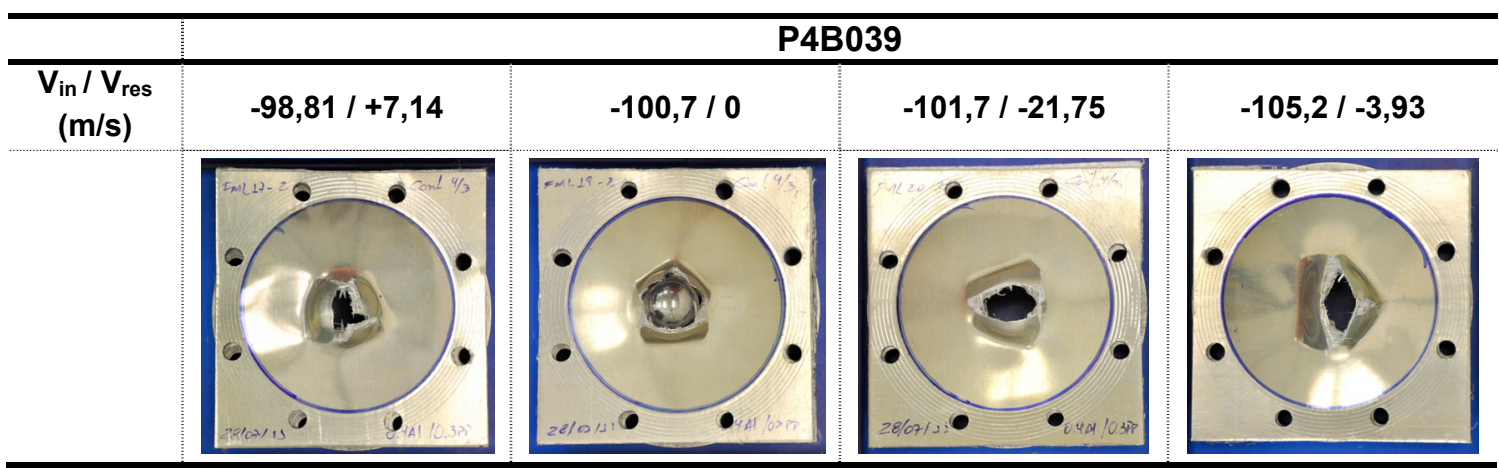


Tabela 25: Vista da face oposta a impacto, material: P5A044.

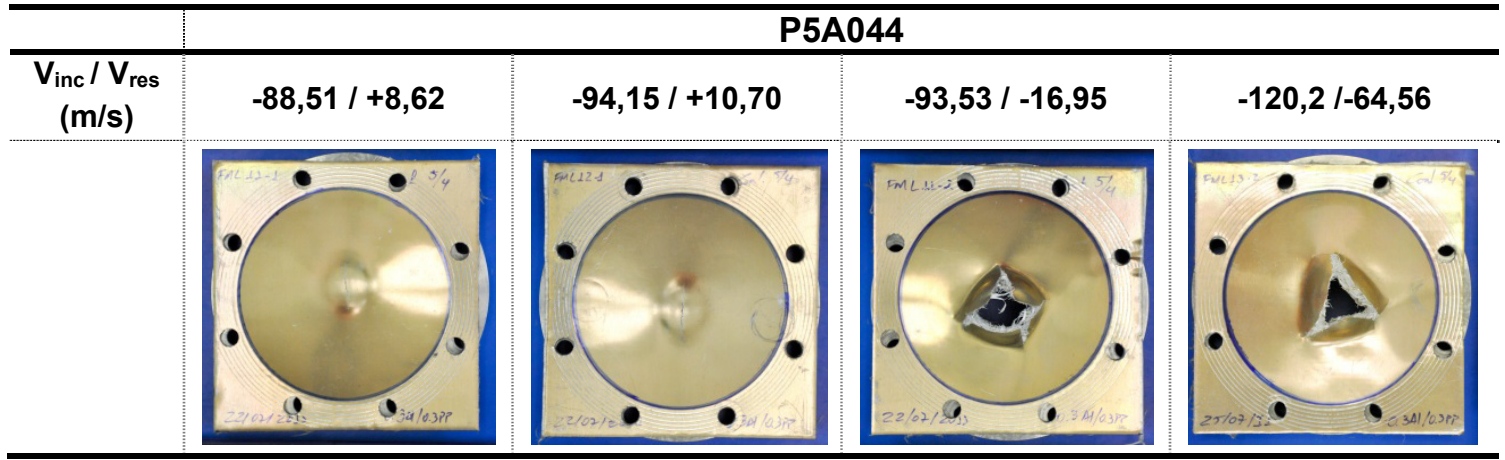

Tabela 26: Vista da face oposta a impacto, material: G3B054.

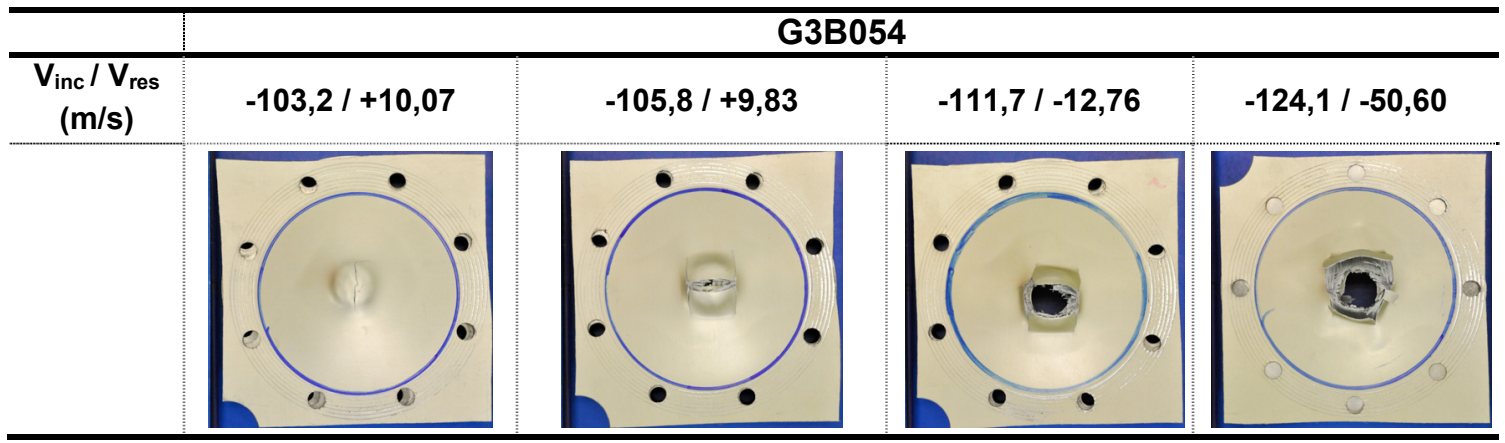

Tabela 27: Vista da face oposta a impacto, material: G5B027.

\begin{tabular}{c|c|c|c|c|c|c|}
\hline & \multicolumn{5}{|c|}{ G5B027 } \\
\hline \begin{tabular}{c}
$V_{\text {inc }} / \mathrm{V}_{\text {res }}(\mathrm{m} / \mathrm{s})$ \\
\hline
\end{tabular} & $-126,3 /+8,42$ & $-126,3 /+10,18$ & $-132,2 /-40,07$ & $-134,8 /-31,07$ \\
\hline
\end{tabular}

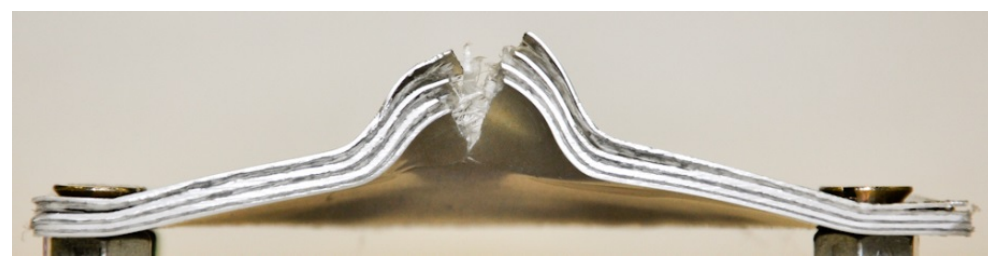

Figura 42: Secção transversal da amostra P4B039 após impacto.

Nas Tabelas 29 a 33 são relacionados resultados experimentais obtidos para as amostras testadas. As velocidades incidentes, $V_{i n c}$, e residuais, $V_{\text {res }}$, são apresen- 
tadas com base na orientação apresentada na Figura 43. A coluna "Perfuração" registra a ocorrência ou não do atravessamento completo da amostra pelo projétil. A coluna "Excentricidade" relaciona a distância entre a posição do impacto e o centro da placa circular. É importante ressaltar que, por dificuldade da definição exata da posição de impacto após a perfuração da amostra, a medição de excentricidade foi realizada utilizando medição aproximada com régua, obtendo precisão estimada de 1,0 mm. Nas colunas "Inspeção na face impactada" e "Inspeção na face oposta" descrevem a forma de ruptura observada nas faces do material, utilizando a identificação apresentada na Tabela 28. Na Figura 44 são exemplificados os diferentes modos de ruptura dos materiais observados.
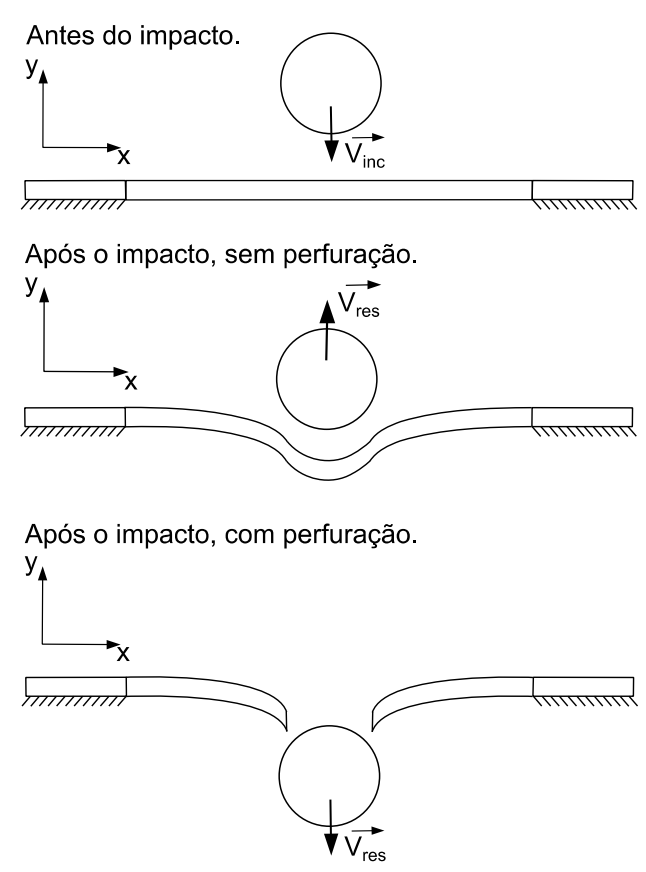

Figura 43: Orientação adotada para a direção das velocidades.

Tabela 28: Código de identificação para falha no material para impacto de alta velocidade.

\begin{tabular}{cl}
\hline SF & Sem falha visual aparente \\
$\mathbf{P}$ & Pétala \\
$\mathbf{R}$ & Rasgamento \\
$\mathbf{D F S}$ & Descolamento de camadas, com falha no suporte \\
\hline
\end{tabular}


Tabela 29: Resultados experimentais para o material P3A043.

\begin{tabular}{|c|c|c|c|c|c|c|}
\hline Material & P3A043 & & & & & \\
\hline Espécime & $\begin{array}{c}V_{i n c} \\
(\mathrm{~m} / \mathrm{s})\end{array}$ & $\begin{array}{c}V_{\text {res }} \\
(\mathrm{m} / \mathrm{s})\end{array}$ & Penetração & $\begin{array}{c}\text { Inspeção na } \\
\text { face impactada }\end{array}$ & $\begin{array}{l}\text { Inspeção na } \\
\text { face oposta }\end{array}$ & $\begin{array}{l}\text { Excentricidade } \\
(\mathrm{mm})\end{array}$ \\
\hline 8 & $-59,21$ & $+5,79$ & Não & $P$ & $\mathrm{R}$ & 6,0 \\
\hline 4 & $-60,27$ & $+6,43$ & Não & $\mathrm{P}$ & $P$ & 4,0 \\
\hline 6 & $-63,60$ & $+5,96$ & Não & $\mathrm{P}$ & $\mathrm{P}$ & 3,0 \\
\hline 9 & $-66,07$ & $-13,39$ & Sim & $\mathrm{P}$ & $P$ & 4,0 \\
\hline 5 & $-65,09$ & $-14,70$ & Sim & $\mathrm{P}$ & $\mathrm{P}$ & 1,0 \\
\hline 7 & $-64,53$ & $-11,21$ & Sim & $P$ & $P$ & 3,0 \\
\hline 3 & $-81,29$ & $-46,62$ & Sim & $\mathrm{P}$ & $\mathrm{P}+\mathrm{R}$ & 1,0 \\
\hline 2 & $-109,82$ & $-79,47$ & Sim & $\mathrm{P}$ & $P$ & 5,0 \\
\hline 1 & $-122,81$ & $-101,75$ & Sim & $\mathrm{P}$ & $P$ & 2,0 \\
\hline
\end{tabular}

Tabela 30: Resultados experimentais para o material P4B039.

\begin{tabular}{c|c|c|c|c|c|c}
\hline Material & P4B039 & \multicolumn{1}{l|}{} \\
\hline \hline Espécime & $\begin{array}{c}V_{\text {inc }} \\
(\mathrm{m} / \mathrm{s})\end{array}$ & $\begin{array}{c}V_{\text {res }} \\
(\mathrm{m} / \mathrm{s})\end{array}$ & Penetração & $\begin{array}{c}\text { Inspeção na } \\
\text { face impactada }\end{array}$ & $\begin{array}{c}\text { Inspeção na } \\
\text { face oposta }\end{array}$ & $\begin{array}{c}\text { Excentricidade } \\
(\mathrm{mm})\end{array}$ \\
\hline 10 & $-78,82$ & $+8,97$ & Não & $\mathrm{P}$ & $\mathrm{P}$ & 4,0 \\
\hline 1 & $-92,86$ & $+8,75$ & Não & $\mathrm{P}$ & $\mathrm{P}$ & 5,0 \\
\hline 6 & $-94,83$ & $+8,10$ & Não & $\mathrm{P}$ & $\mathrm{P}+\mathrm{R}$ & 6,0 \\
\hline 7 & $-98,81$ & $+7,14$ & Não & $\mathrm{P}$ & $\mathrm{P}+\mathrm{R}$ & 2,0 \\
\hline 4 & $-100,71$ & 0,00 & - & $\mathrm{P}$ & $\mathrm{P}+\mathrm{R}$ & 1,0 \\
\hline 5 & $-98,24$ & $-25,96$ & Sim & $\mathrm{P}+\mathrm{R}$ & $\mathrm{R}$ & 4,0 \\
\hline 3 & $-101,75$ & $-21,75$ & Sim & $\mathrm{P}$ & $\mathrm{R}$ & 2,0 \\
\hline 8 & $-104,39$ & $-24,56$ & Sim & $\mathrm{P}$ & $\mathrm{P}$ & 1,0 \\
\hline 9 & $-102,63$ & 0,00 & - & $\mathrm{P}$ & $\mathrm{DFS}$ & 3,0 \\
\hline 2 & $-105,17$ & $-3,93$ & Sim & $\mathrm{P}$ & $\mathrm{P}+\mathrm{R}$ & 5,0 \\
\hline
\end{tabular}

Tabela 31: Resultados experimentais para o material P5A044.

\begin{tabular}{c|c|c|c|c|c|c}
\hline Material & P5A044 & \multicolumn{1}{|c|}{} & \\
\hline \hline Espécime & $\begin{array}{c}V_{i n c} \\
(\mathrm{~m} / \mathrm{s})\end{array}$ & $\begin{array}{c}V_{\text {res }} \\
(\mathrm{m} / \mathrm{s})\end{array}$ & Penetração & $\begin{array}{c}\text { Inspeção na } \\
\text { face impactada }\end{array}$ & $\begin{array}{c}\text { Inspeção na } \\
\text { face oposta }\end{array}$ & $\begin{array}{c}\text { Excentricidade } \\
(\mathrm{mm})\end{array}$ \\
\hline 4 & $-88,51$ & $+8,62$ & Não & $\mathrm{P}$ & $\mathrm{P}$ & 2,0 \\
\hline 9 & $-94,15$ & $+10,70$ & Não & $\mathrm{P}$ & $\mathrm{P}$ & 2,0 \\
\hline 5 & $-93,56$ & $-16,95$ & Sim & $\mathrm{P}$ & $\mathrm{P}$ & 1,0 \\
\hline 6 & $-96,49$ & $+9,30$ & Não & $\mathrm{P}$ & $\mathrm{DFS}$ & 2,0 \\
\hline 7 & $-97,02$ & $+9,29$ & Não & $\mathrm{P}$ & $\mathrm{R}+\mathrm{P}$ & 3,0 \\
\hline 2 & $-102,86$ & $-25,00$ & Sim & $\mathrm{P}$ & $\mathrm{DFS}$ & 1,0 \\
\hline 3 & $-103,57$ & $-21,38$ & Sim & $\mathrm{P}$ & $\mathrm{P}$ & 1,0 \\
\hline 1 & $-120,18$ & $-64,56$ & Sim & $\mathrm{P}$ & $\mathrm{P}$ & 5,0 \\
\hline
\end{tabular}


Tabela 32: Resultados experimentais para o material G3B054.

\begin{tabular}{|c|c|c|c|c|c|c|}
\hline Material & G3B054 & & & & & \\
\hline Espécime & $\begin{array}{c}V_{i n c} \\
(\mathrm{~m} / \mathrm{s})\end{array}$ & $\begin{array}{c}V_{\text {res }} \\
(\mathrm{m} / \mathrm{s})\end{array}$ & Penetração & $\begin{array}{l}\text { Inspeção na } \\
\text { face impactada }\end{array}$ & $\begin{array}{l}\text { Inspeção na } \\
\text { face oposta }\end{array}$ & $\begin{array}{l}\text { Excentricidade } \\
(\mathrm{mm})\end{array}$ \\
\hline 5 & $-105,00$ & $+9,11$ & Não & $P$ & $P$ & 6,0 \\
\hline 6 & $-103,16$ & $+10,07$ & Não & $P+R$ & $\mathrm{P}$ & 2,0 \\
\hline 10 & $-105,75$ & $+9,83$ & Não & $P+R$ & $\mathrm{R}$ & 4,0 \\
\hline 9 & $-109,47$ & $-10,70$ & Sim & $\mathrm{P}$ & $P+R$ & 5,0 \\
\hline 7 & $-109,48$ & $-12,41$ & Sim & $\mathrm{P}$ & $P+R$ & 3,0 \\
\hline 8 & $-111,72$ & $-12,76$ & Sim & $\mathrm{P}$ & $\mathrm{R}$ & 1,0 \\
\hline 4 & $-116,49$ & $-36,40$ & Sim & $P$ & $\mathrm{R}$ & 4,0 \\
\hline 3 & $-124,11$ & $-50,60$ & Sim & $\mathrm{P}$ & $\mathrm{R}$ & 3,0 \\
\hline 1 & $-123,98$ & $-48,62$ & Sim & $P$ & $\mathrm{R}$ & 4,0 \\
\hline 2 & $-120,69$ & $-6,12$ & Sim & $P$ & $P+R$ & 2,0 \\
\hline
\end{tabular}

Tabela 33: Resultados experimentais para o material G5B027.

\begin{tabular}{c|c|c|c|c|c|c}
\hline Material & G5B027 & \multicolumn{10}{|c}{} \\
\hline \hline Espécime & $\begin{array}{c}V_{\text {inc }} \\
\mathrm{m} / \mathrm{s})\end{array}$ & $\begin{array}{c}V_{\text {res }} \\
(\mathrm{m} / \mathrm{s})\end{array}$ & Penetração & $\begin{array}{c}\text { Inspeção na } \\
\text { face impactada }\end{array}$ & $\begin{array}{c}\text { Inspeção na } \\
\text { face oposta }\end{array}$ & $\begin{array}{c}\text { Excentricidade } \\
(\mathrm{mm})\end{array}$ \\
\hline 8 & $-103,16$ & $+27,92$ & $\mathrm{Não}$ & $\mathrm{SF}$ & $\mathrm{SF}$ & 1,0 \\
\hline 5 & $-126,32$ & $+10,18$ & $\mathrm{Não}$ & $\mathrm{P}+\mathrm{R}$ & $\mathrm{P}+\mathrm{R}$ & 0,0 \\
\hline 4 & $-126,32$ & $+8,42$ & $\mathrm{Não}$ & $\mathrm{P}+\mathrm{R}$ & $\mathrm{P}+\mathrm{R}$ & 0,0 \\
\hline 2 & $-128,95$ & $+5,43$ & $\mathrm{Não}$ & $\mathrm{P}$ & $\mathrm{R}$ & 1,0 \\
\hline 3 & $-128,95$ & $-20,18$ & $\mathrm{Sim}$ & $\mathrm{P}$ & $\mathrm{P}+\mathrm{R}$ & 0,0 \\
\hline 7 & $-134,82$ & $-31,07$ & $\mathrm{Sim}$ & $\mathrm{P}$ & $\mathrm{R}$ & 1,0 \\
\hline 6 & $-132,18$ & $-40,07$ & $\mathrm{Sim}$ & $\mathrm{P}$ & $\mathrm{R}+\mathrm{P}$ & 0,0 \\
\hline
\end{tabular}

(a)

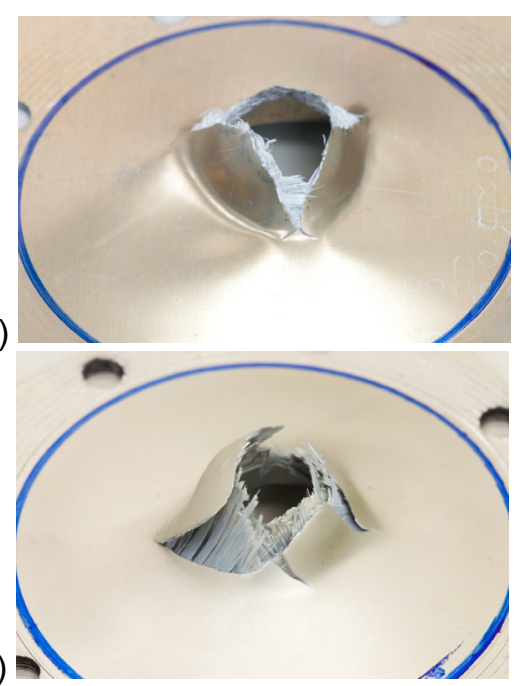

(b)

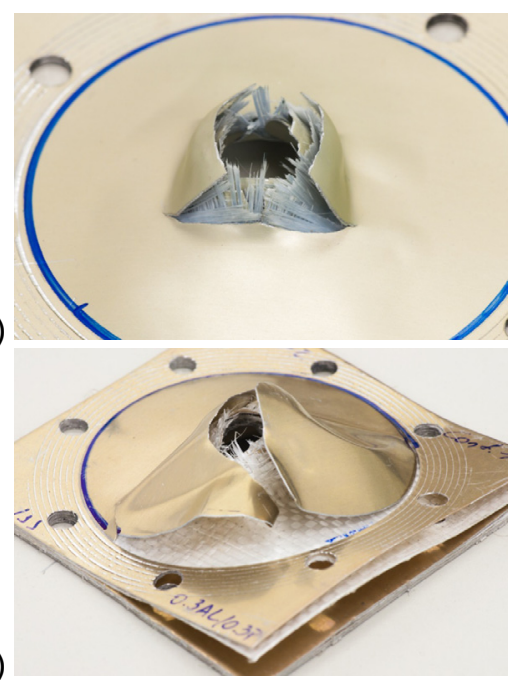

Figura 44: Formas de falha observados nas amostras testadas: (a) pétala, (b) rasgamento, (c) mista e (d) descolamento e falha no suporte.

A ruptura tipo pétala $(P)$ caracteriza-se pela formação de duas a seis faces triangulares (semelhantes a pétalas de flores) ao redor da região impactada pela 
esfera. Neste caso, observa-se que a falha do material ocorre por solicitações de membrana, com propagações de trincas nas direções radiais. Em geral, a abertura de tais pétalas coincide com o centro da calota semihemisférica formada pela esfera.

A ruptura tipo rasgamento $(R)$ é caracterizada pelo aparecimento de um a três faces rompidas de forma irregular, na qual a ruptura da camada ocorre por solicitações cisalhantes. Em geral, esta ruptura foi observada na face oposta ao impacto de materiais com maior espessura, com P4B039, G3B054 e G5B027.

A ruptura tipo mista $(P+R)$ consiste da combinação da falha tipo pétala e rasgamento, sendo observado, portanto, trincas formadas por solicitações de membrana e cisalhantes. Em três amostras de TFML foi observada a ocorrência de descolamento generalizada da camada e ruptura na região periférica, junto ao engastamento do material. Acredita-se que esta falha é decorrente de deficiências do processo construtivo, causando fraca aderência entre as camadas do TFML.

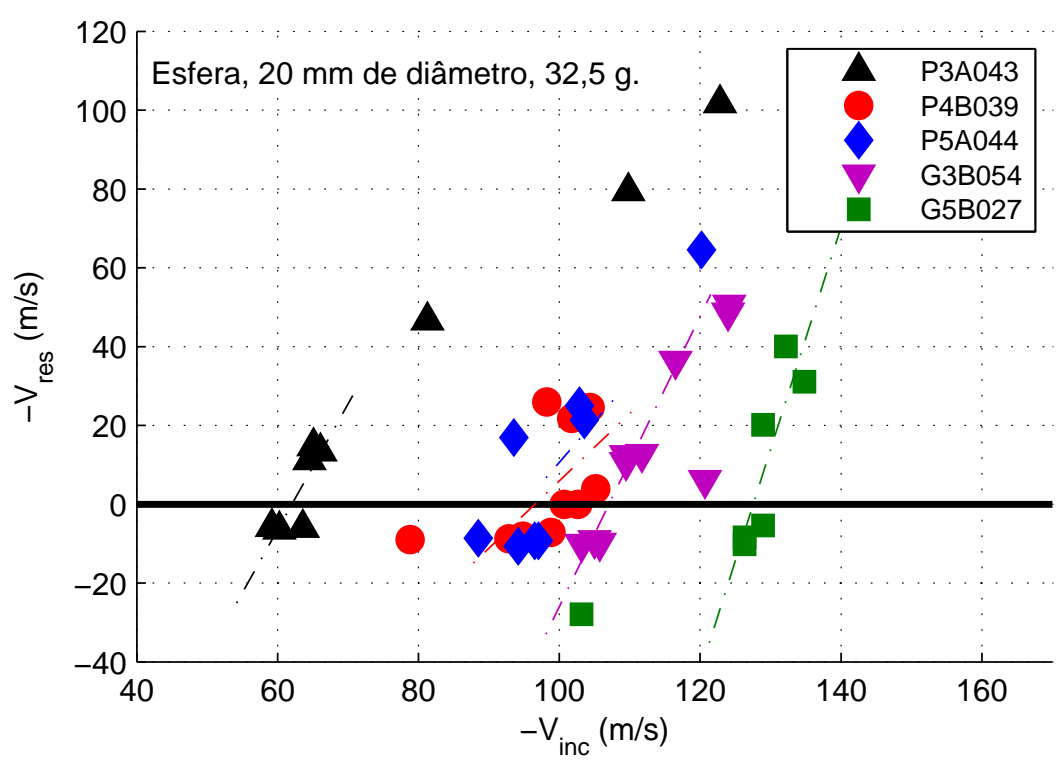

Figura 45: Diagrama de velocidades incidente e residual.

Vale ressaltar que a condição de limite balístico é difícil de ser obtida experimentalmente, sendo então adotada uma metodologia gráfica para sua definição. $\mathrm{Na}$ Figura 45 é apresentado o diagrama de velocidade dos testes realizados, sendo os experimentos representados em função de $V_{i n c}$ e $V_{\text {res }}$. É fácil observar que na condição de rebote ocorre a mudança de direção de velocidade do projétil, e tem-se $V_{\text {res }}$ positiva, conforme orientação apresentada na Figura 43. Por sua vez, na condição 
de atravessamento, a direção da velocidade é mantida, obtendo $V_{\text {res }}$ negativo. A partir da interpolação linear de ensaios no limiar às condições de rebote e perfuração, define-se o limite balístico, $V_{b}$, com a velocidade na qual a interpolação resulta $V_{\text {res }}$ nula. Na Tabela 34 são apresentados valores de $V_{b}$ obtidos para os materiais ensaios, assim como parâmetros de desempenho estruturais destes.

Observa-se que o material G5B027 apresenta maior velocidade balística dentre as amostras ensaiadas, com valor de $127,60 \mathrm{~m} / \mathrm{s}$. Dentre os TFML, o material P4B039 apresentou valor mais expressivo de 96,56 m/s. Quando o desempenho estrutural é avaliado, tomando como base a energia balística específica, observa-se também o melhor desempenho do material G5B027. Vale ressaltar também o desempenho similar entre os TFMLs P4B039 e P5A044, e o FML G3B054. Os parâmetros apresentados na Tabela 34 são de fundamental importância para avalição de resultados provenientes de modelos numéricos a serem apresentados no Capítulo 8.

Tabela 34: Resultados experimentais comparativos.

\begin{tabular}{cccc}
\hline Material & $\left|V_{b}\right|$ & $\begin{array}{c}E_{b} \\
(\mathrm{~m} / \mathrm{s})\end{array}$ & $\begin{array}{c}E_{b} / \rho_{f m l} \\
\left.(\mathrm{~J}) \mathrm{mm}^{3} / \mathrm{g}\right) \cdot 10^{-3}\end{array}$ \\
\hline TFML 3/2 (P3A043) & 62,03 & 62,53 & 34,70 \\
TFML 4/3 (P4B039) & 96,56 & 151,51 & 78,42 \\
TFML 5/4 (P5A044) & 94,97 & 146,56 & 86,01 \\
FML 3/2 (G3B054) & 107,05 & 186,22 & 79,61 \\
FML 5/4 (G5B027) & 127,60 & 264,58 & 107,83 \\
\hline
\end{tabular}

\subsection{CONSIDERAÇÕES FINAIS}

Neste capítulo, o desempenho estruturas de amostras de TFML e FML similares a materiais utilizados em estruturas aeronáuticas foram avaliados. Mesmo utilizando procedimentos para melhoria da adesão entre as camadas metálicas e de reforços termoplásticos do TFML, como anodização e elementos adesivos, foi observada uma fraca adesão entre as camadas do TFMLs, aspecto não observado nos FMLs.

As campanhas experimentais de impacto de alta e baixa velocidade possibilitaram a obtenção de parâmetros de comportamento esperado dos materiais ensaia- 
das, possíveis de serem utilizados para avaliação de modelos teóricos e numéricos de tais fenômenos, a serem apresentados nos Capítulos 7 e 8, respectivamente.

Apesar da fraca aderência entre as camadas do TFML, foi observado que o desempenho estrutural deste é equivalente ou superior a FML comerciais utilizados em elementos aeronáuticos. Sendo este, portanto, um material promissor para utilização em estruturas leves submetidas ao impacto. 


\section{CARACTERIZAÇÃO DOS MATERIAIS}

O conhecimento do comportamento mecânico dos materiais é necessário para a avaliação do desempenho de TFML, sendo uma premissa para o desenvolvimento e análise de estruturas. No tocante ao fenômeno de impacto, deve-se considerar o efeito de taxa da taxa de deformação, o qual pode influenciar consideravelmente o comportamento dos materiais metálicos e poliméricos. É importante enfatizar que a caracterização do comportamento dinâmico dos materiais, em especial para médias taxas de deformação, não é um procedimento trivial, sendo continuamente explorada pela comunidade científica.

Neste capítulo, será apresenta a caracterização mecânica da liga de alumínio 2024-T3, do material SRPP denominado PURE e das amostras de TFML tomadas como base para o estudo. Além do regime quase estático, a caracterização dinâmica foi também almejada, sendo realizados ensaios em médias e altas taxas de deformação. Para tanto, serão utilizados equipamentos comerciais combinados com o dispositivo desenvolvido no Capítulo 3 para realização de ensaios a médias taxa de deformação. Por fim, os ensaios de caracterização mecânica serão modelados buscando definir parâmetros constitutivos dos materiais a serem utilizados para a modelagem do fenômeno de impacto.

É importante ressaltar que não foram encontrados relatos na literatura a respeito da caracterização mecânica em regime dinâmico e obtenção de parâmetros constitutivos para material SRPP Pure. Este procedimento será abordado neste capítulo, sendo, portanto, uma contribuição desta pesquisa.

\subsection{METODOLOGIA}

Nesta secção serão apresentados os equipamentos utilizados para caracterização mecânica dos materiais a diferentes taxas de deformação. Posteriormente será apresentada a técnica óptica de medição de deformação por imagens utilizada e formulação para obtenção dos resultados pretendidos. 


\subsubsection{Equipamentos}

Uma máquina de ensaio universal Instron 3369, Figura 46, foi utilizada para realização de ensaios de caracterização mecânica em regime quase estático. Este equipamento utiliza um motor elétrico, com controle por malha fechada, acoplado a fusos de movimento para o deslocamento do cabeçote desta. A máquina é capaz de aplicar cargas de até $50 \mathrm{kN}$ à velocidade de até $50 \mathrm{~mm} / \mathrm{min}$. O sistema ainda possibilita a utilização de extensômetros tipo clipe (ou "clip-gauges") para medição de deformação axial e transversal do espécime, conforme apresentado na Figura 46.

Este equipamento foi utilizado para realização de ensaios de tração em amostras de ligas de alumínio 2024-T3 e TFML, assim como e ensaios de tração, compressão e cisalhamento em SRPP Pure, a taxas de deformação entre $10^{-3} / s$ a $10^{-1} / s$.

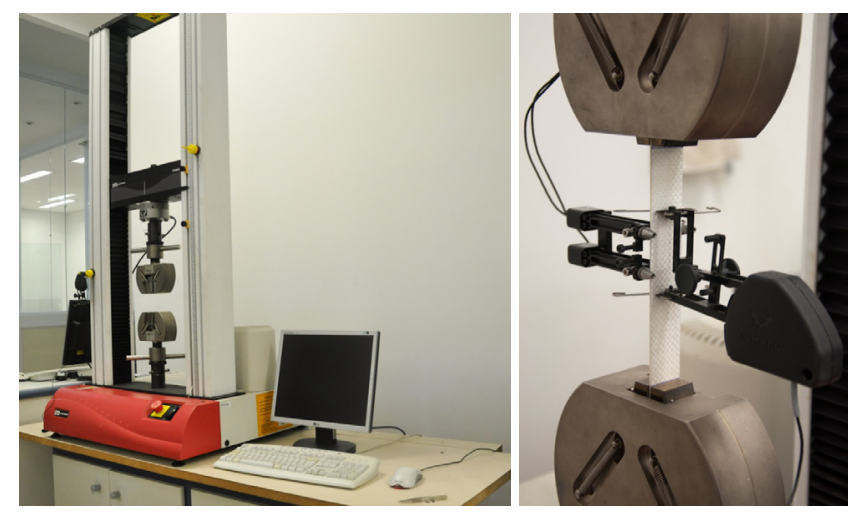

Figura 46: Máquina de ensaio universal Instron 3369.

Uma máquina Instron ElectroPuls E10000, Figura 47, foi utilizada para realização de ensaios dinâmicos de caracterização mecânica. Este equipamento possui um motor elétrico linear, capaz de aplicar esforços de tração de até $10 \mathrm{kN}$, a velocidade de até $1 \mathrm{~m} / \mathrm{s}$. Este equipamento é munido de garras pneumáticas para fixação das amostras e possui sensor de deslocamento integrado ao atuador.

A Instron ElectroPuls foi utilizada para realização de ensaios de tração em alumino 2024-T3 e SRPP Pure a taxas de deformação entre $1 / \mathrm{s}$ a $10 / \mathrm{s}$. 

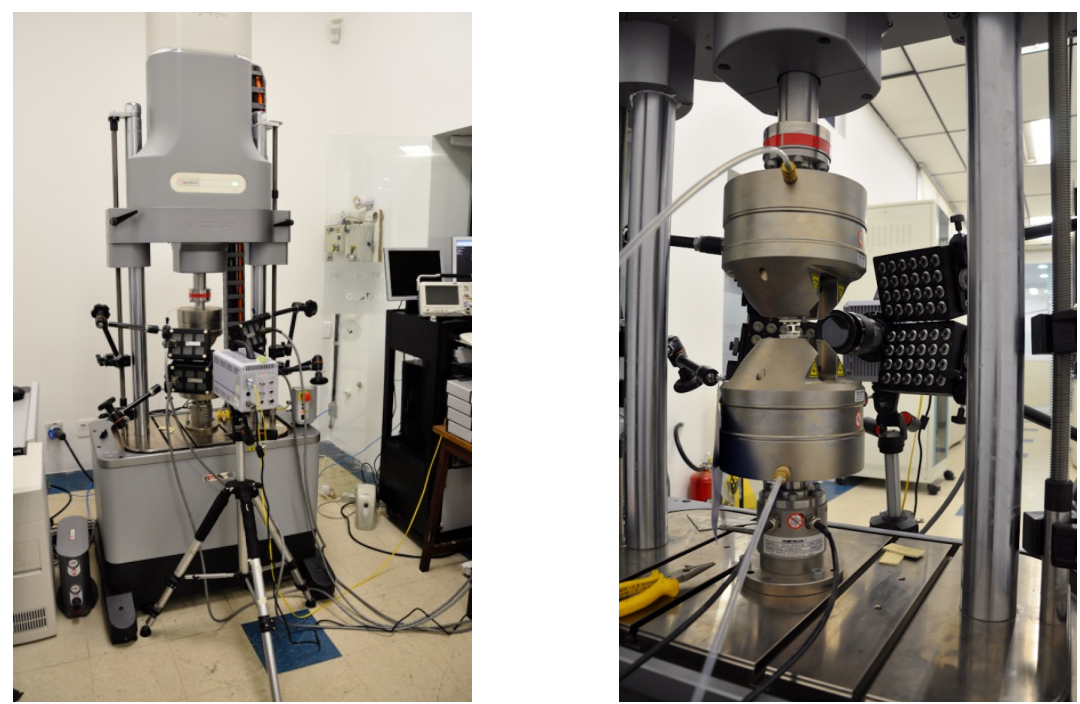

Figura 47: Máquina de ensaios dinâmicos ElectroPuls E10000.

O dispositivo para ensaios tração em médias taxas de deformação apresentado no Capítulo 3, Figura 48, foi utilizado para a caracterização dinâmica dos materiais. Este equipamento é acoplado ao martelo de impacto de baixa energia do GMSIE-USP com velocidade máxima de deslocamento de $3 \mathrm{~m} / \mathrm{s}$, sendo munido de célula de carga com capacidade máxima de $30 \mathrm{kN}$ e sensor de deslocamento a laser. Frisando que efeitos de vibrações e ressonâncias são observados durante a utilização deste equipamento, sendo utilizados materiais macios em locais de contato com o intuito de minimizar este efeito.

Este equipamento foi utilizado para realização de ensaios de tração em amostras de alumínio 2024-T3 e SRPP Pure a taxa de deformação de $10^{2} / \mathrm{s}$.

O martelo de impacto, Figura 49, foi utilizando para realização de ensaios de compressão dinâmicos, utilizando massas de $500 \mathrm{~g}$ a $10 \mathrm{~kg}$ em queda livre. Um sensor de deslocamento a laser Polytec OFV-323 e uma célula de carga PCB 200C20, com capacidade máxima de $80 \mathrm{kN}$ foram utilizados para medição de deslocamento e força, respectivamente. Os sinais de tais sensores foram adquiridos por um placa de aquisição National Instruments PCl-6550 e analisados utilizando o programa MatLab 2007.

Este equipamento está apresentado da Figura 49 e foi utilizado para a caracterização dinâmica do SRPP Pure em regime dinâmico. 


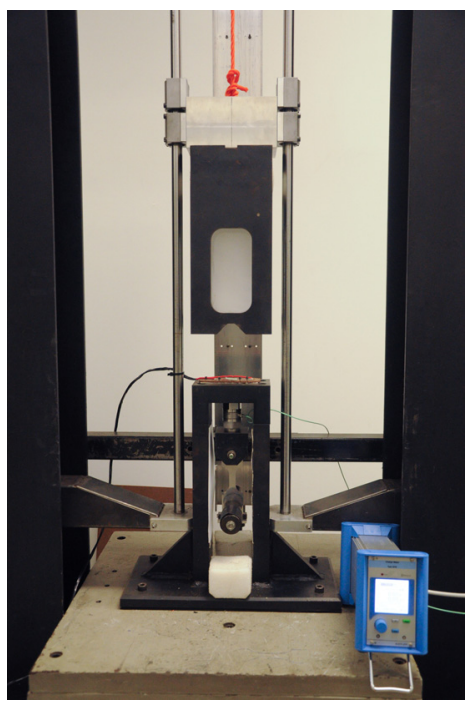

Figura 48: Máquina de ensaios em médias taxas de deformação.
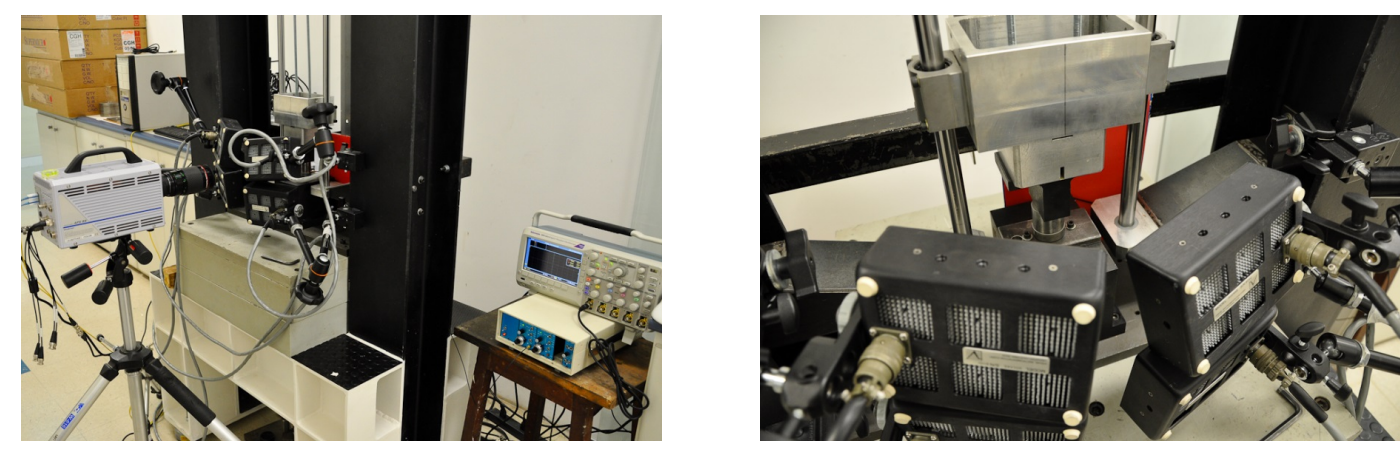

Figura 49: Martelo de impacto utilizado para ensaios de compressão dinâmico.

\subsubsection{Medição de deformação por correlação de imagens}

A técnica de correlação digital de imagem (ou do inglês, "Digital Image Correlation - DIC) foi utilizada para a medição de deformação dos espécimes, de maneira concomitante com os dispositivos de medição de deformação existentes em cada equipamento. O DIC é capaz de realizar medições bidimensionais, em regime quase estático e dinâmico, utilizando técnica totalmente sem contato. Para a realização da medição, é necessária que uma sequência de imagens seja tomada durante a realização do ensaio de caracterização, sendo posteriormente analisadas por um programa específico. Duas técnicas DIC foram utilizadas para a realização dos experimentos em questão, sendo estas a correlação digital de campo completo e acompa- 
nhamento de marcadores, utilizados conforme disponibilidade no momento do experimento.

O programa comercial 7D foi utilizado para a correlação digital de campo completo. Nesta técnica, o espécime é coberto por uma pintura difusa de gradientes preto e branco, produzido por pintura em spray. Durante o teste, uma sequência de imagens de alta resolução é tomada, de forma sincronizada com o sistema de aquisição do equipamento utilizado. O programa define regiões de interesse ao longo da área a ser analisada na configuração inicial do espécime, e busca localizar tais regiões nas imagens seguintes tomadas durante o experimento. A partir do histórico de deslocamento dessas regiões, é possível obter medições de deformações bidimensional do espécime, até a ruptura do mesmo. A Figura 50 exemplifica a utilização desta técnica.

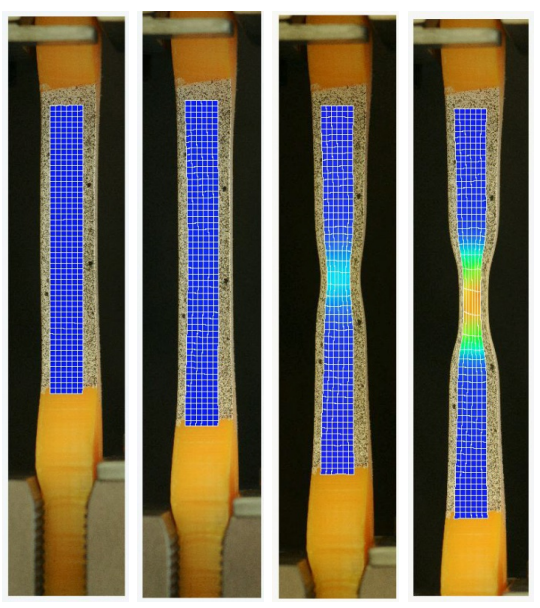

Figura 50: Exemplo de utilização de DIC de campo completo.

O programa comercial Xcitex Proanalyst foi utilizado para a realização de medição de deformação por imagens, a partir do deslocamento de marcadores. Neste caso, uma série de marcadores com posicionamento pré-definido é colada sobre a superfície do espécime e a sequencia de imagens de alta resolução é tomada de forma sincronizada com o equipamento utilizado. Esta sequencia de imagem é analizada pelo programa, que fornece o histórico de deslocamento de todos os marcadores instalados no espécime. Estes deslocamentos são tratados no programa comercial MatLab 7.0, para obtenção do histórico de deformação do espécime até sua ruptura. Um exemplo de utilização deste método é apresentado na Figura 51. 

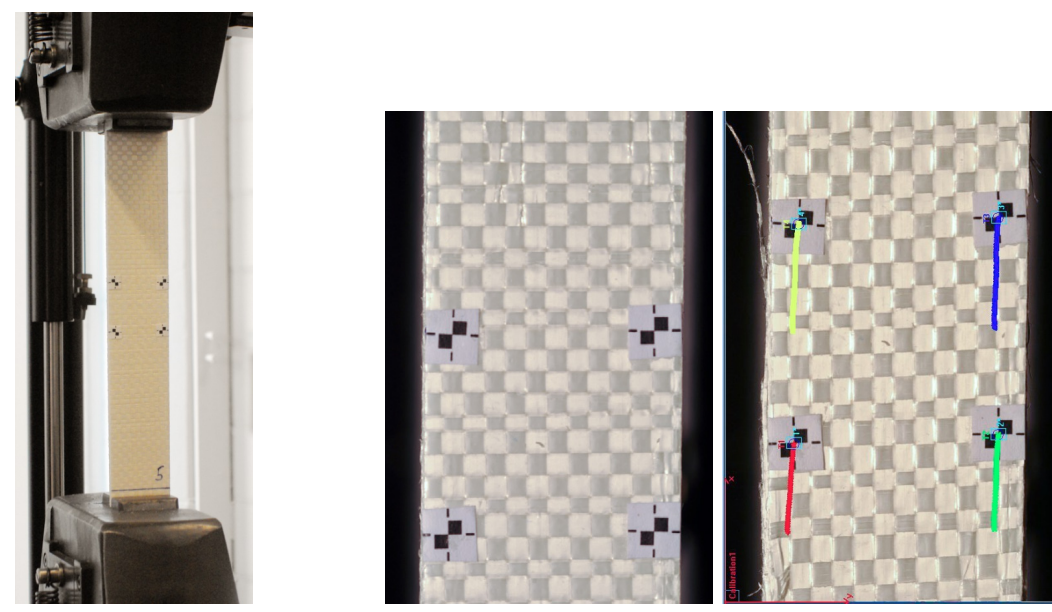

Figura 51: Exemplo de utilização de DIC com acompanhamento de marcadores.

(a)

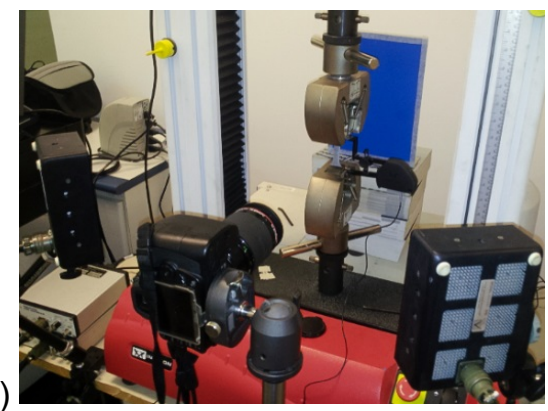

(b)

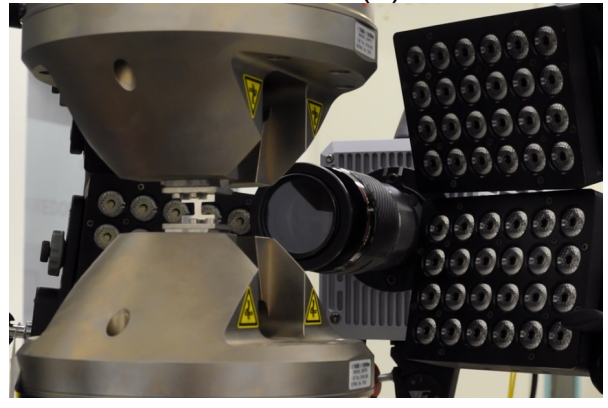

(c)

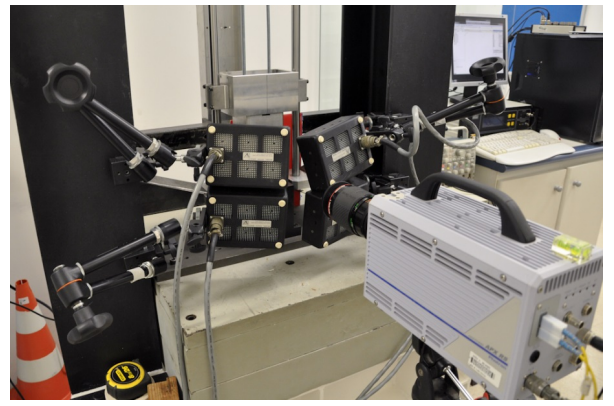

Figura 52: (a) Nikon D90 em ensaio quase estático em Instron 3369; Photron APX-RS em ensaios dinâmicos em (b) Instron ElectroPuls E10000 e (c) dispositivo desenvolvido para ensaios em médias taxas de deformação.

Uma câmera Nikon D90, Figura 52a, com resolução de até 4288x2848 pixels foi utilizada para obtenção da sequência de imagens para o DIC em ensaios com taxa de deformação de até $10^{-3} / s$, obtendo imagens a taxa de 1 quadro a cada 5 segundos. Para os ensaios com taxa de deformação maiores, uma câmera de alta velocidade Photron APX-RS foi utilizada, Figura 52b-c, fornecendo imagens de até $1024 \times 1024$ pixels, a taxa de $60 \mathrm{fps}$ a $10.000 \mathrm{fps}$ (quadros por segundo). Em ambos os casos, foi utilizada iluminação para melhoria da definição das imagens. Lentes Nokkor 50mm/f1.8, Nikkor 18-105mm/f3.5-5.6, Sigma 105mm/f2.8 e Vivitar 
105mm/f2.5 macro foram utilizadas de acordo com o tamanho da área de interesse objetivada.

\subsubsection{Análise de dados}

A seguir, será apresentado o procedimento utilizado para caracterização dos materiais em ensaios de tração, compressão e cisalhamento.

Buscando facilitar o entendimento, toma-se como base um espécime com estricção por redução de largura (tipo "dog bone" ou gravata). Inicialmente, o espécime possui largura $a_{0}$, espessura $b_{0}$, comprimento útil $l_{0}$. Quando este é solicitado pela força axial $F_{1}$, o material deforma, atingindo largura $a$, espessura $b$, comprimento útil $l$, conforme representado na Figura 53. Uma vez que a área inicial da secção transversal do espécime é $A_{0}=a_{0} \cdot b_{0}$, pode-se definir tensão de engenharia, $\sigma_{\text {eng }}$, deformação na direção $x, \varepsilon_{x}$, deformação na direção $y, \varepsilon_{y}$, e Coeficiente de Poisson no plano $x y, v_{x y}$, como
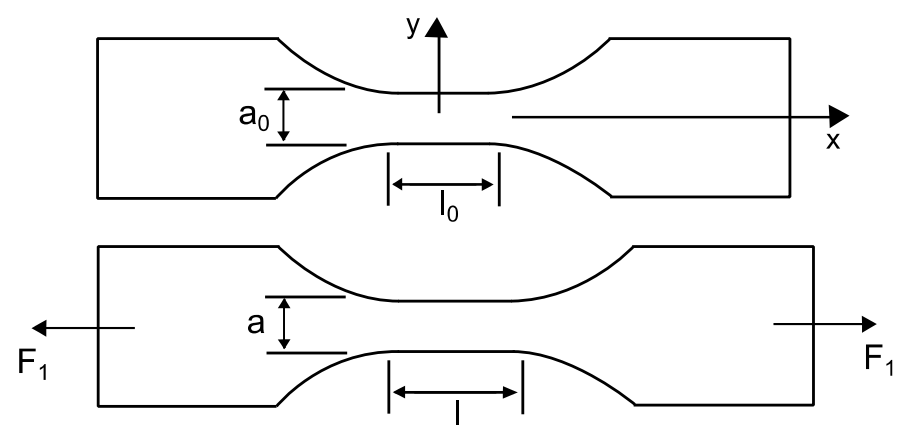

Figura 53: Esquema CDP tração.

$$
\begin{gathered}
\sigma_{e n g}=\frac{F_{1}}{A_{0}}, \\
\varepsilon_{x}=\frac{l-l_{o}}{l_{0}},
\end{gathered}
$$




$$
\varepsilon_{y}=\frac{a-a_{o}}{a_{0}}
$$

e

$$
v_{x y}=-\frac{\varepsilon_{2}}{\varepsilon_{1}}
$$

As equações (5) a (8) consideram a configuração inicial do espécime, sendo estas válidas para regime de pequenos deslocamentos e deformações. Para condições de elevadas deformações, deve-se considerar o efeito de diminuição da secção transversal.

Para a avaliação do comportamento da liga de alumínio 2024-T3 em regime de grandes deformações (acima de $5 \%$ ), é utilizada a tensão real, $\sigma_{r}$, obtida considerando a conservação de volume do material. Com nessa hipótese, tem-se

$$
A \cdot l=A_{0} \cdot l_{0},
$$

que pode ser utilizada para o cálculo da tensão

$$
\begin{gathered}
\sigma_{r}=\frac{F_{1}}{A}=\frac{F_{1}}{A_{0}} \cdot \frac{l}{l_{0}}=\frac{F_{1}}{A_{0}} \cdot \frac{l_{0}+\Delta l}{l_{0}}=\frac{F_{1}}{A_{0}} \cdot \frac{l_{0}+\left(l-l_{0}\right)}{l_{0}} \\
\sigma_{r}=\sigma_{e}\left(1+\varepsilon_{x}\right) .
\end{gathered}
$$

Nestes casos, a deformação é considerada como a somatória das deformações instantâneas ao longo dos experimentos, na seguinte forma:

$$
\begin{gathered}
\varepsilon_{r}=\int_{l_{0}}^{l} d \varepsilon=\int_{l_{0}}^{l} \frac{d l}{l}=\ln \frac{l}{l_{0}}=\ln \frac{l_{0}+\Delta l}{l_{0}}=\ln \frac{l_{0}+\left(l-l_{0}\right)}{l_{0}} \\
\varepsilon_{r}=\ln \left(1+\varepsilon_{x}\right) .
\end{gathered}
$$

Para o material SRPP Pure e TFML, a hipótese de conservação de volume não é válida em virtude da existência de vazios no interior do material. Nestes casos, 
a variação da secção transversal foi considerada a partir da correção da largura do corpo de prova medida ao longo do experimento. Considere a deformação na direção $2, \varepsilon_{2}$, definida pela equação (7), obtida com a utilização da técnica DIC. Uma vez que largura do espécime ao logo do experimento pode ser definida por $a=a_{0}\left(1+\varepsilon_{y}\right)$, a área a secção transversal do espécime é

$$
A=A_{0}\left(1+\varepsilon_{y}\right),
$$

sendo considerada espessura inicial, $b_{0}$, constante pela hipótese de estado plano de de deformação (EPD). Assim, a tensão em grandes níveis de deformação, aqui também denominada por tensão real, $\sigma_{r}$, pode ser obtida sendo considerada a variação da área da secção transversal do espécime ao longo do teste, como

$$
\sigma_{r}=\frac{F_{1}}{A}=\frac{F_{1}}{A_{0}\left(1+\varepsilon_{y}\right)}
$$

Nestes casos, a deformação na direção 1 é obtida de forma direta, a partir de medição realizada para pela DIC.

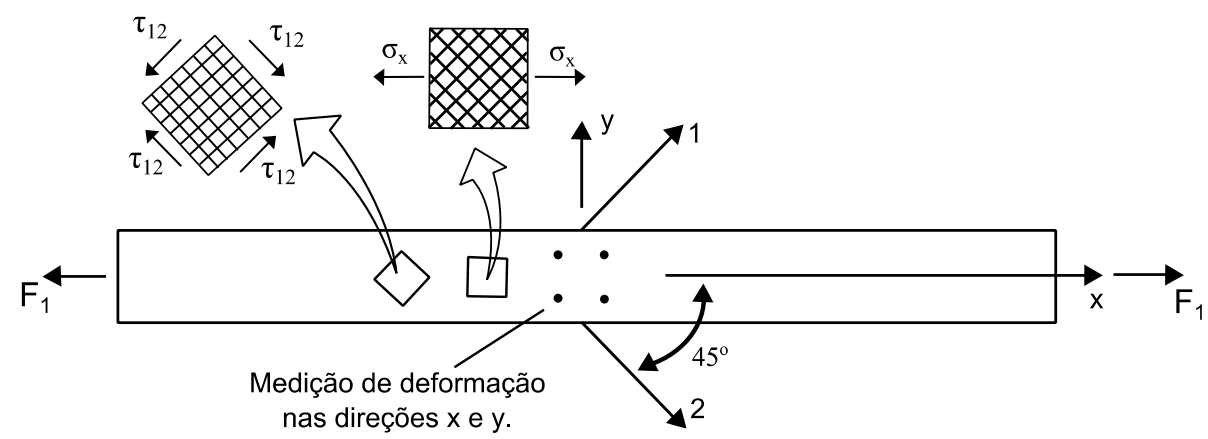

Figura 54: Esquema simplificado do ensaio de cisalhamento do SRPP Pure.

Ensaios de caracterização em cisalhamento foram realizados com o SRPP Pure, baseando-se na norma ASTM-3518 (ASTM, 2013a). Nesta, amostras do material são tracionadas uniaxialmente, com filamentos alinhados nas direções $\left[+/-45^{\circ}\right]_{\mathrm{s}}$, sendo realizada a medição de deformação nas direções axial e transversal. Com base na decomposição de tensões apresentada na Figura 54, observa-se a aplica- 
ção de cisalhamento puro nos filamentos do material, uma vez que este está angulado de $45^{\circ} \mathrm{com}$ a direção principal de solicitação.

Nesse caso, tensão de cisalhamento no plano 1-2, $\tau_{12}$, e distorção no plano 12, $\gamma_{12}$, podem ser definidas por

$$
\tau_{12}=\frac{\sigma_{x}}{2}
$$

e

$$
\gamma_{12}=\varepsilon_{x}-\varepsilon_{y} .
$$

É importante ressaltar que este ensaio é aplicável apenas para as condições de pequenos deslocamentos e deformações.

Em geral, os equipamentos utilizados para a caracterização mecânica dos materiais aqui abordados fornecem um histórico de força axial aplicada, com frequência de amostragem e resolução pertinentes com o experimento. A medição de deformação é realizada de três formas distintas: por sensores de deslocamento, que registram o deslocamento de uma das garras do equipamento (e consecutivamente da extremidade do espécime); por sensores de deformação acoplados ao espécime, que registram as deformações $\varepsilon_{x}$ e $\varepsilon_{y}$ global do comprimento útil do espécime; e pela técnica DIC, que possibilita a medição localizada das deformações $\varepsilon_{x}$ e $\varepsilon_{y}$. Assim, a medição de deformação geralmente é redundante, o que possibilita a comparação dos resultados obtidos com utilização de diferentes técnicas. A medição de deformação por técnica DIC foi priorizada na maioria dos experimentos.

\subsection{CARACTERIZAÇÃO MECÂNICA DO ALUMÍNIO 2024-T3}

A seguir, será apresentada a caracterização mecânica a diferente taxas de deformação, assim como a identificação dos parâmetros constitutivos da liga de alumínio aeronáutico 2024-T3. 


\subsubsection{Ensaios experimentais}

Três configurações de geometria espécimes foram utilizadas para a caracterização da liga de alumínio em uma ampla faixa de taxas de deformação, uma vez que diferentes equipamentos foram necessários para tanto. As configurações de corpos de provas estão apresentadas na Figura 55.

(a)

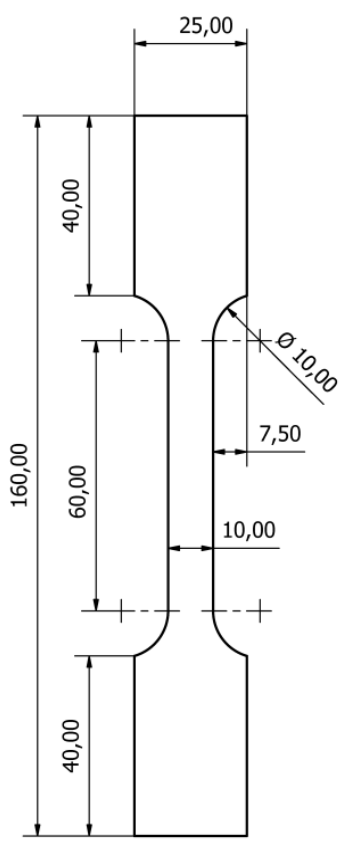

(b)

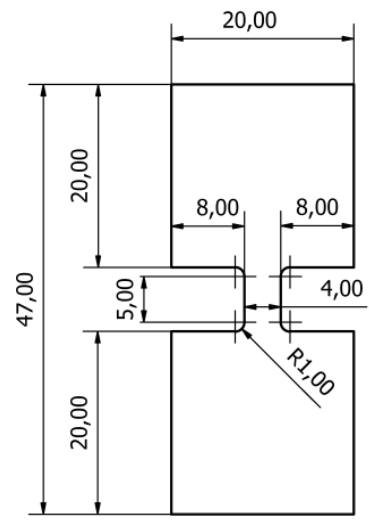

(c)

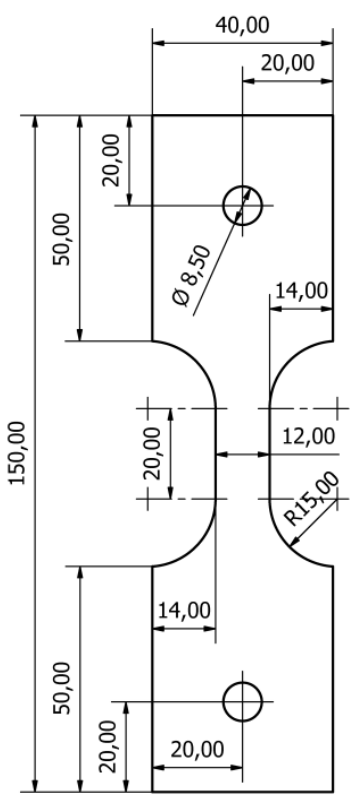

Figura 55: Configurações de espécimes utilizadas: (a) Configuração A, escala 1:2; (b) Con-

figuração B, escala 1:1 e (c) Configuração $C$, escala 1:2 (Dimensões em milímetros).

A configuração A (Figura 55a) é baseada na norma ASTM-E8 (ASTM, 2013b), apresentando comprimento útil de $60 \mathrm{~mm}$ e destinada à realização de testes a taxa de deformação de $10^{-4} / s$ a $10^{-2} / s$ em máquina de ensaios universal Instron 3369, além de embasar o comportamento esperado do material usando geometria normativa. A configuração B é baseada em (Slycken et al., 2006), sendo desenvolvida para ensaios de caracterização dinâmicos de materiais metálicos. Esta apresenta comprimento útil de $5 \mathrm{~mm}$, sendo utilizado na máquina para ensaios dinâmicos Instron ElectroPuls E10000, a taxas de deformação de $1 / s$ a $10 / s$. A configuração C é a geometria de corpo de prova desenvolvida para utilização no dispositivo projetado para ensaios a médias taxas de deformação, explanado no Capítulo 3. Esta apre- 
senta comprimento útil de $20 \mathrm{~mm}$, sendo utilizada para ensaios em taxas de deformação de $100 / \mathrm{s}$ a $300 / \mathrm{s}$.

Buscando identificar a geometria de espécime utilizada em cada experimento, uma letra "A", "B" ou "C" foi utilizada no primeiro algarismo de identificação dos espécimes, sendo esta relacionada com a configuração de espécime utilizada. Todas as amostras utilizadas foram extraídas de uma mesma chapa do material, com 0,40 $\mathrm{mm}$ de espessura, sendo fabricadas utilizando uma máquina de corte a laser com velocidade de corte constante e início de corte fora da área útil do espécime. Foram ensaiadas cerca de cinco amostras para cada taxa de deformação almejada, sendo excluídas duas curvas com comportamento muito distinto das demais.
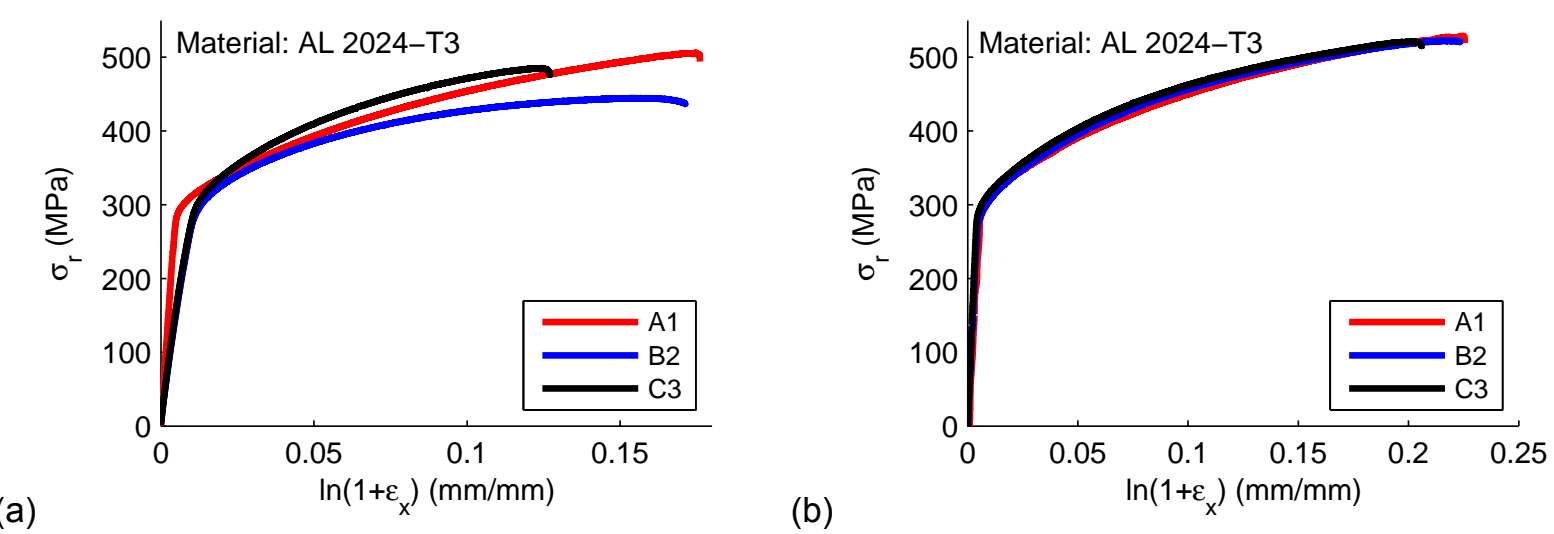

Figura 56: Curva tensão-deformação quase estática do alumínio 2024-T3 utilizando diferentes configurações de espécimes: (a) deformações medidas por extensômetro ou sensores de deslocamento e (b) deformação medidas utilizando técnica DIC.

A influência da geometria do espécime na curva tensão-deformação foi analisada comparado a curva tensão-deformação obtida para cada uma das três configurações, em regime quase estático. Nestes experimentos, a deformação foi medida concomitantemente com o sistema de medição existente nos equipamentos (sensores de deslocamento ou extensômetros de clipe), assim como utilizando técnica DIC de campo completo. A Figura 56 compara os resultados obtidos.

Observa-se uma substancial diferença entre as curvas tensão-deformação quando a deformação é medida utilizando extensômetros de clipe ou sensores de deslocamento. Por outro lado, observa-se uma substancial semelhança entre o comportamento das mesmas amostras quando a medição de deformação é realizada utilizando técnicas DIC. Isto se deve ao fato de que a medição no primeiro caso 
considera o comportamento global do espécime, sendo este influenciado por concentradores de tensão ou imperfeições. Com a utilização do DIC, a medição é realizada de forma localizada na região útil do espécime, considerando o comportamento deste exatamente na região onde foi observada a ruptura do mesmo. Desse modo, apenas o processo de medição de deformação por DIC será utilizado para medição da deformação do material, sendo os demais procedimentos existes utilizados apenas como parâmetros de comparação de resultados.

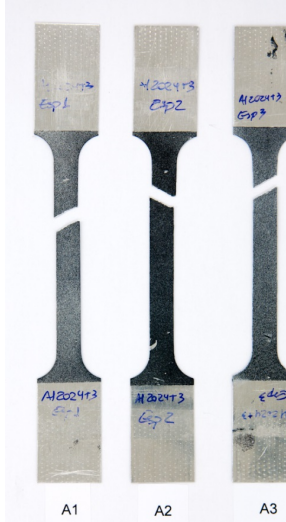

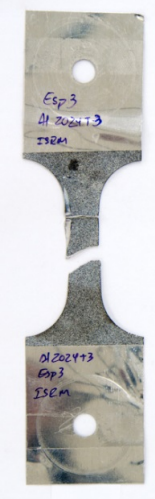

c8

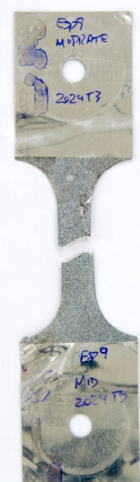

c9

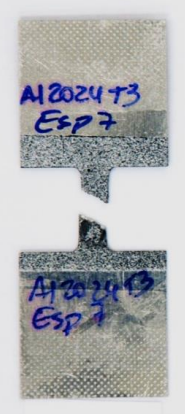

B7

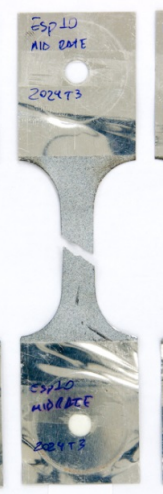

$\mathrm{C} 10$

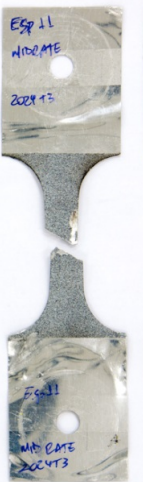

$\mathrm{C} 11$

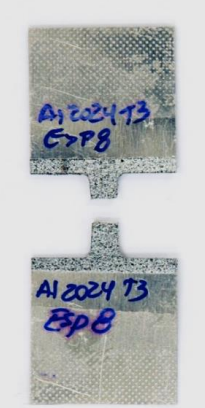

B8

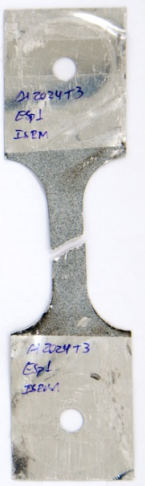

$\mathrm{C} 12$

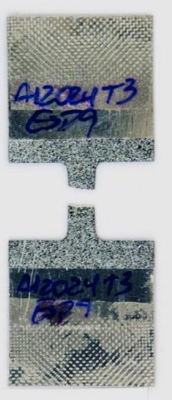

B9

Figura 57: Ruptura dos espécimes da liga de alumínio 2024-T3.

Na Figura 57 são apresentados os espécimes após a realização do experimento. Observa-se que a ruptura do material ocorreu dentro da área útil do espécime, de forma abrupta e sem a observação de empescoçamento. Foi observada que a ruptura do material ocorreu na direção perpendicular ou angulada de até $30^{\circ} \mathrm{com} 0$ eixo principal do espécime. No entanto, não foi observada diferenciação significativa da resposta do material com relação ao modo de ruptura do espécime obtido. Acredita-se que a utilização da técnica DIC contribuiu para este fato. O estudo aprofundado da ruptura do material não é escopo deste trabalho. 
A Figura 58 apresentam curvas tensão-deformação para o alumínio 2024-T3 realizada a diferentes taxas de deformação. É possível concluir que o material apresenta comportamento elasto-plástico, uma vez que foi observado um comportamento elástico-linear reversível até a condição de escoamento e, após esta, tem-se o comportamento plástico não-linear, com deformações permanentes.
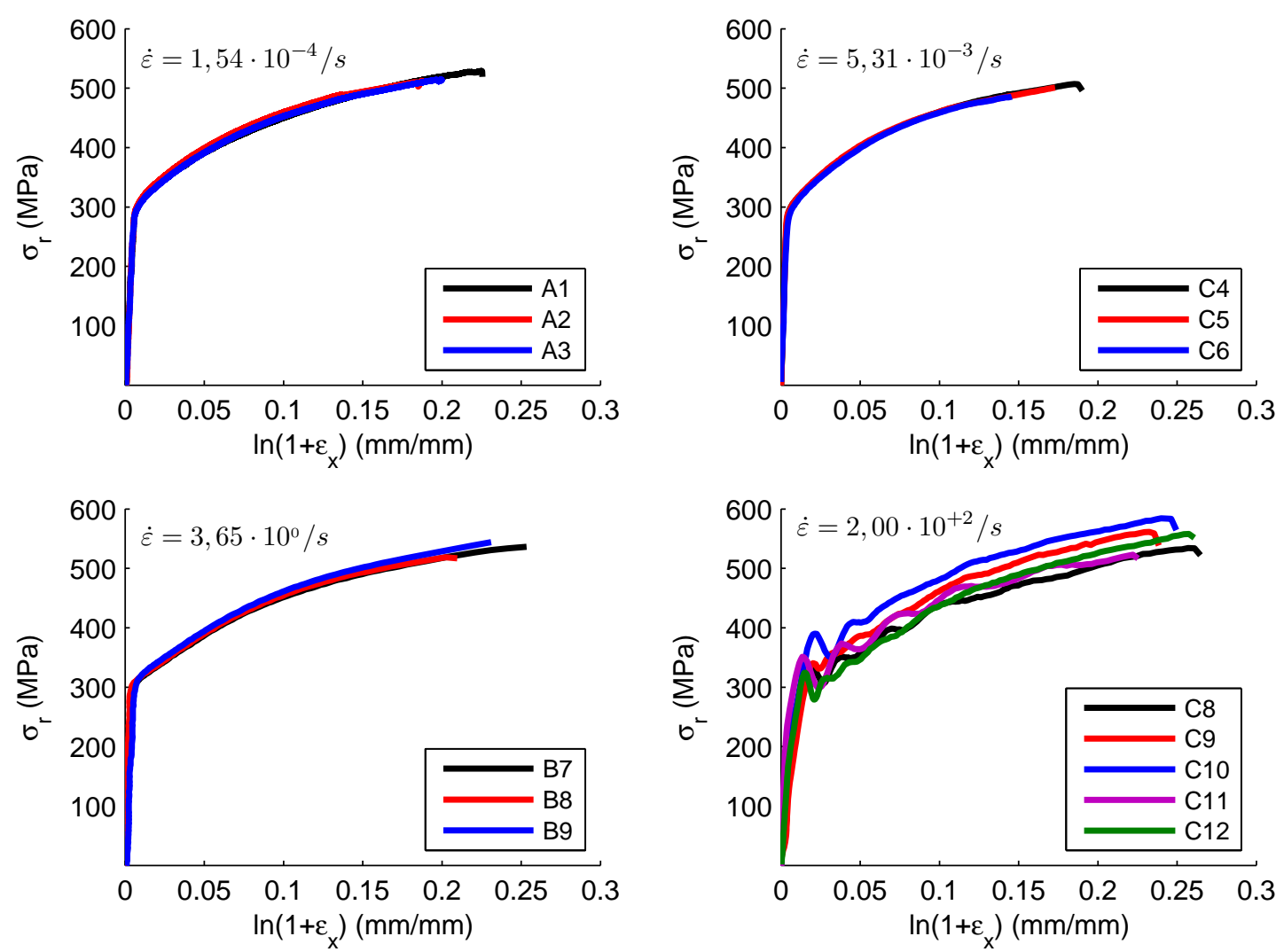

Figura 58: Curvas tensão-deformação do alumínio 2024-T3 realizada em diferentes taxas de deformação.

Foi observada uma boa correlação na resposta do material nas diferentes taxas de deformação, com ressalva apenas para os experimentos realizados a taxas de deformação de 200 /s, no qual foi possível notar maior dispersão, porém com definição de uma tendência para seu comportamento. Vale ressaltar que nestes experimentos são observadas oscilações na porção inicial da curva oriundas da falta de equilíbrio dinâmico do espécime, em função da dinâmica.

A Figura 59 compara a influência da taxa de deformação no comportamento do material, sendo consideradas apenas as curvas que melhor representam o comportamento médio do material em cada taxa de deformação ensaiada. Foi observado 
que o efeito da taxa de deformação pouco influencia no comportamento plástico do material.

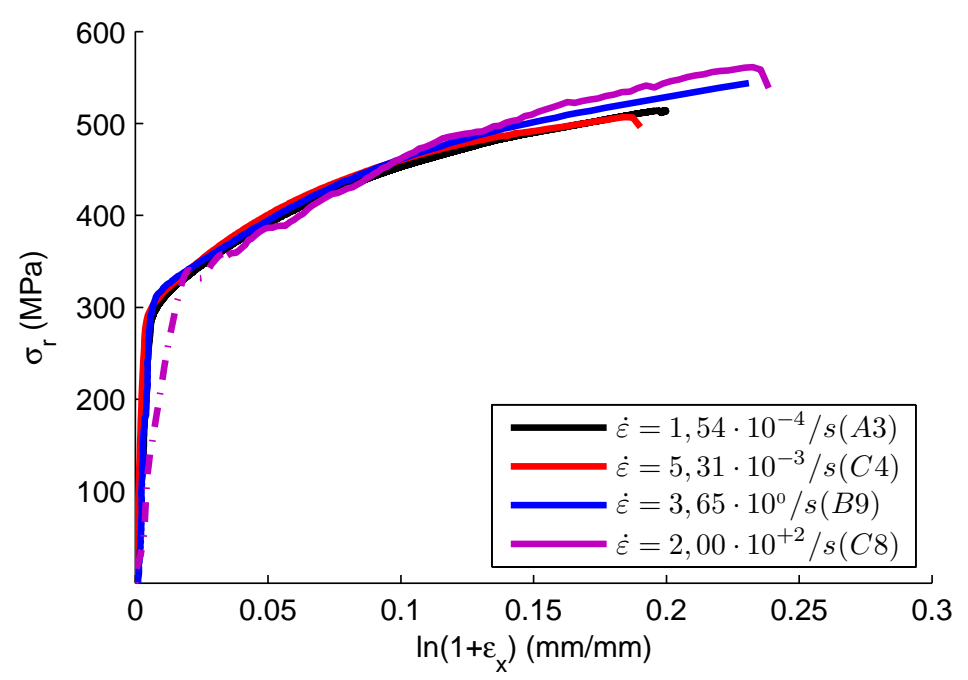

Figura 59: Comparação da curva tensão-deformação do alumínio 2024-T3 em diferentes taxas de deformação.

A Tabela 35 sumariza influência da taxa de deformação na tensão de escoamento, $\sigma_{0}$, tensão real em deformação de $\varepsilon=0,15, \sigma_{15 \%}$, tensão última, $\sigma_{u}$, e deformação última $\varepsilon_{u}$. Vale ressaltar que a tensão de escoamento foi definida graficamente como condição onde fora observado o início do comportamento não linear do material.

Tabela 35: Efeito da taxa de deformação no comportamento da liga de alumínio 2024-T3.

\begin{tabular}{ccccc}
\hline $\begin{array}{c}\dot{\varepsilon} \\
\left(\mathrm{s}^{-1}\right)\end{array}$ & $\begin{array}{c}\sigma_{0} \\
(M P a)\end{array}$ & $\begin{array}{c}\sigma_{15 \%} \\
(M P a)\end{array}$ & $\begin{array}{c}\sigma_{u} \\
(M P a)\end{array}$ & $\begin{array}{c}\varepsilon_{u} \\
(\mathrm{~mm} / \mathrm{mm})\end{array}$ \\
\hline $\mathbf{0 , 0 0 0 1 5}$ & $279,67 \pm 1,9 \%$ & $491,60 \pm 0,4 \%$ & $517,40 \pm 2,0 \%$ & $0,2021 \pm 10,3 \%$ \\
$\mathbf{0 , 0 0 5 3}$ & $274,67 \pm 2,2 \%$ & $489,77 \pm 0,4 \%$ & $497,97 \pm 2,2 \%$ & $0,1680 \pm 12,0 \%$ \\
$\mathbf{3 , 5 6}$ & $300,53 \pm 1,7 \%$ & $494,30 \pm 1,0 \%$ & $494,30 \pm 1,7 \%$ & $0,2290 \pm 11,2 \%$ \\
$\mathbf{2 0 0 , 1 2}$ & - & $495,80 \pm 4,3 \%$ & $495,80 \pm 4,3 \%$ & $0,2463 \pm 6,8 \%$ \\
\hline
\end{tabular}

A identificação do coeficiente de Poisson foi realizada a partir da interpolação linear da curva $\varepsilon_{x}-\left(-\varepsilon_{y}\right)$, conforme apresentado na Figura 60, sendo obtido o valor de $0,2958 \pm 1,9 \%$ para este. 


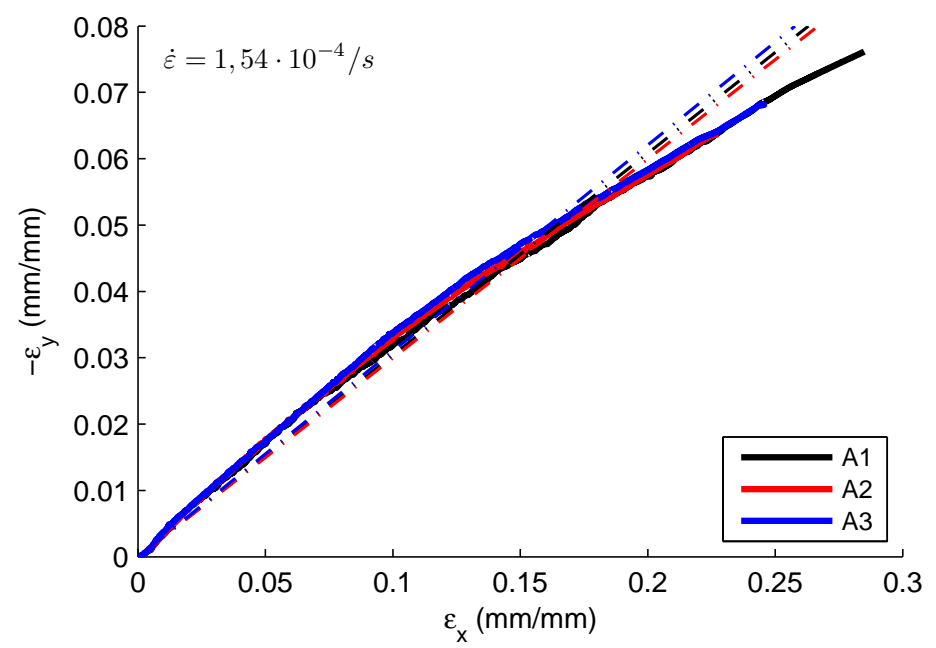

Figura 60: Obtenção do coeficiente de Poisson para a liga de alumínio 2024-T3.

\subsubsection{Definição de parâmetros constitutivos}

A modelagem numérica do comportamento elasto-plástico da liga de alumínio 2024-T3 foi realizada utilizando o modelo de material MAT-15 “Johson-Cook", disponível no programa comercial LS-Dyna v.971 (Hallquist, 2006; Lstc, 2012a; b). Neste, o material apresenta comportamento elástico-linear até atingir o limite de escoamento, $\sigma_{0}$. Após esta condição, o material atinge o regime plástico definido pela lei constitutiva de Jonhson-Cook

$$
\sigma_{p}=\left[A+B\left(\varepsilon_{p}\right)^{n}\right]\left[1+C \ln \left(\frac{\dot{\varepsilon}_{p}}{\dot{\varepsilon}_{p, q s}}\right)\right]\left[1-\left(\frac{T-T_{a m b}}{T_{m}-T_{a m b}}\right)^{m}\right]
$$

sendo a deformação plástica $\left(\varepsilon_{p}\right)$ definida pela diferença da deformação total $(\varepsilon)$ e deformação elástica $\left(\varepsilon_{e l}\right)$, como $\varepsilon_{p}=\varepsilon-\varepsilon_{e l}$.

Os termos dentro dos primeiros colchetes representam a curva tensãodeformação quase estática do material, modelada por um comportamento exponencial com os parâmetros $A, B$ e $n$. Os termos dentro dos segundos colchetes modelam a influência da taxa de deformação no comportamento do material. Este é feito é considerado pelo logaritmo natural da taxa de deformação adimensionalizada, multi- 
plicada pelo parâmetro $C$. Os termos dentro do terceiro colchete definem a influência da temperatura no comportamento do material, a partir do expoente $m$.

O modelo de material MAT-15 define as condições de ruptura do material a partir do critério de dano de Jonhson-Cook (Hallquist, 2006), o qual é define uma formulação acumulativa

$$
D=\sum \frac{\Delta \varepsilon_{f}}{\varepsilon_{f}}
$$

sendo a deformação plástica efetiva definida por

$$
\varepsilon_{f}=\left[D_{1}+D_{2} e^{D_{3} \sigma^{*}}\right]\left[1+D_{4} \ln \left(\frac{\dot{\varepsilon}_{p}}{\dot{\varepsilon}_{p, q s}}\right)\right]\left[1+D_{5}\left(\frac{T-T_{a m b}}{T_{m}-T_{a m b}}\right)\right]
$$

onde $\Delta \varepsilon$ é o incremento de deformação plástica obtido de um incremento de solicitação aplicado sobre o material. O termo $\sigma^{*}$ define a tensão média normalizada pela tensão equivalente $\left(\sigma^{*}=p / \sigma_{e q}=\left(\sigma_{1}+\sigma_{2}+\sigma_{3}\right) /\left(2 \sigma_{e q}\right)\right)$, também denominado triaxialidade. Os termos $D_{1}, D_{2}, D_{3}, D_{4}$ e $D_{5}$ são constantes do critério de dano. A falha do elemento é definida quando $D=1$ é atingido, sendo então eliminados por um algoritmo de exclusão de elementos.

Os termos $A, B$ e $n$ foram obtidos a partir da interpolação dos resultados experimentais de caracterização quase estática do material (Figura 58 e Tabela 35). Uma vez que não foram identificados efeitos de taxa de deformação significativos, o termo constitutivo $C$ foi extraído da literatura, na qual este é obtido em taxas de deformação mais elevadas do que as utilizadas nos ensaios experimentais aqui realizados (Buyuk, Loikkanen e Kan, 2008). Os termos de dano $D_{1}, D_{2}, D_{3}, D_{4}$ e $D_{5}$ foram extraídos da mesma referência.

Buscando avaliar o desempenho dos parâmetros constitutivos definidos, um modelo numérico de um ensaio de tração quase estático foi desenvolvido, utilizando o programa comercial LS-Dyna v.971. Neste, o espécime de configuração B, Figura 61, foi modelado utilizando elementos sólidos com modelo de material MAT-15. A Figura 62 apresenta a comparação numérico-experimental da curva tensãodeformação obtida, sendo observada uma boa correlação entre estas, no tocante do 
comportamento elástico, plásticos e ruptura. No Anexo 1 estão apresentados os parâmetros utilizados nesta análise, os quais serão utilizados para a simulação do TFML a ser apresentada no Capítulo 8.
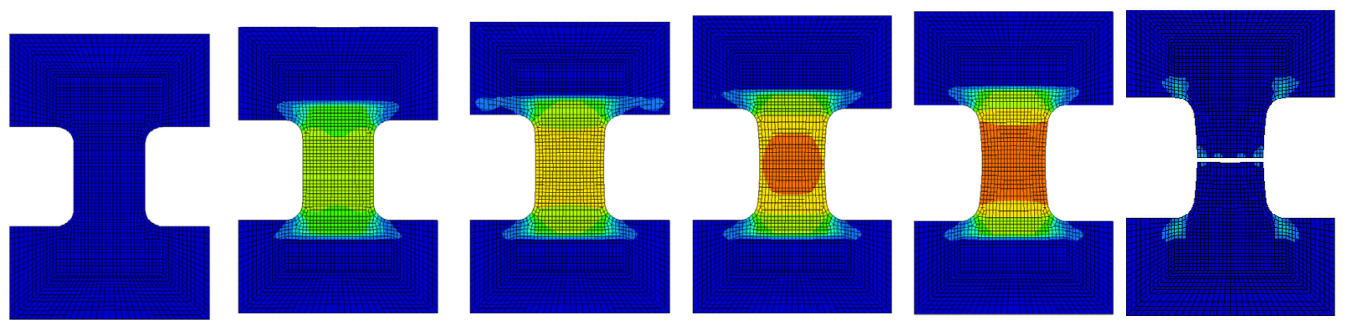

Figura 61: Modelo numérico do ensaio de tração do alumínio 2024-T3.

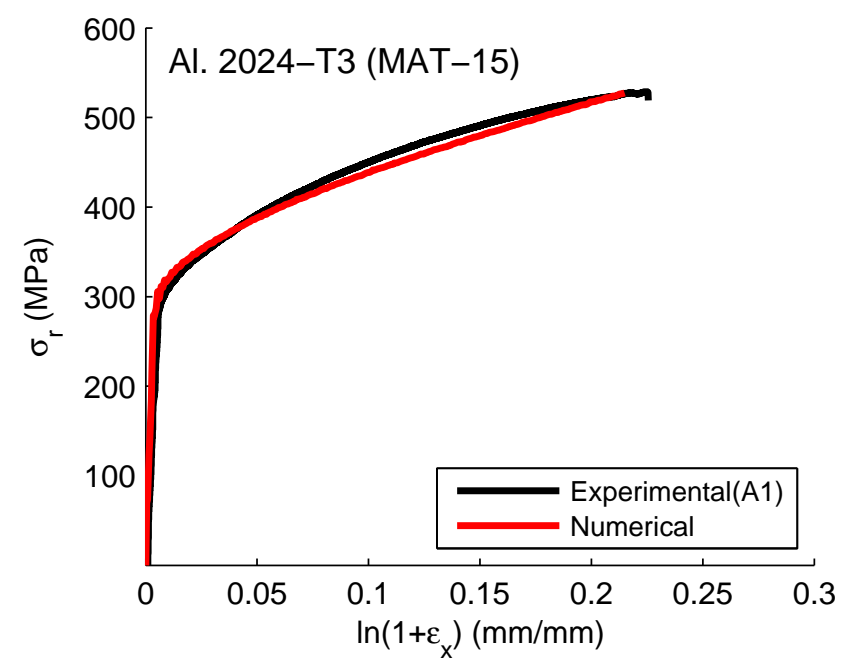

Figura 62: Comparação numérico-experimental da curva tensão-deformação para o alumínio 2024-T3.

\subsection{CARACTERIZAÇÃO DO MATERIAL AUTOREFORÇADO DE POLIPROPI- LENO}

Neste item, o SRRP denominado Pure será caracterizado em ensaios de tração, cisalhamento e compressão, assim como em regime quase estático e dinâmico. Por fim, parâmetros constitutivos destes serão identificados, sendo comparados com resultados experimentais. 


\subsubsection{Ensaios experimentais}

Cinco configurações de espécimes foram utilizados para a carcaterização do SRPP Pure, sendo objetivada a caracterização deste em uma ampla faixa de deformação, assim como em diferentes formas de solicitação, como tração compressão e cisalhamento. As configurações estão apresentadas na Figura 63.

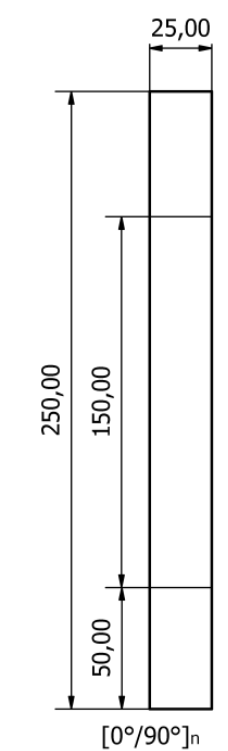

(a)

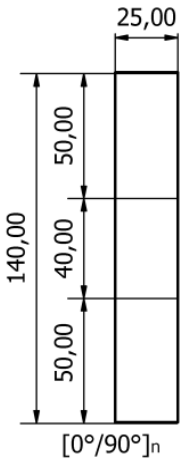

(b)

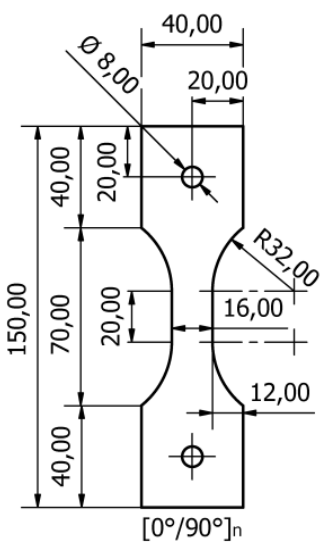

(c)

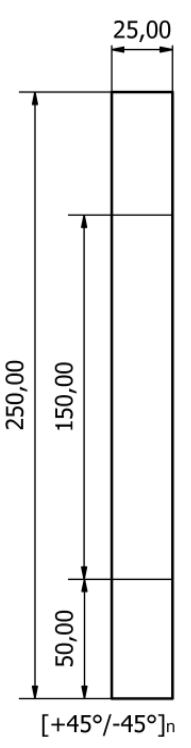

(d)

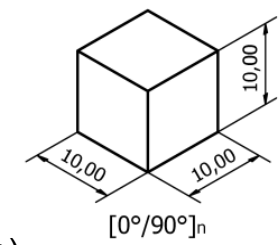

(e)

Figura 63: Configurações de espécimes de SRPP utilizadas: (a) configuração $D$, escala 1:4; (b) configuração $E$, escala 1:4; (c) configuração $F$, escala 1:4; (d) configuração $G$, escala 1:4; e (e) configuração $\mathrm{H}$, escala 2:1 (Dimensões em milímetros).

A configuração D é definida pela norma ASTM-3039 (ASTM, 2008), com comprimento útil de $150 \mathrm{~mm}$ e sendo utilizada para ensaios em taxa de deformação em torno de $10^{-4} / \mathrm{s}$. A configuração $E$ é baseada na configura $\mathrm{D}$, porém com comprimento útil reduzido a $40 \mathrm{~mm}$, sendo, utilizada para ensaios em taxa de deformação em torno de $10^{-2} / \mathrm{s}$. A configuração $\mathrm{F}$ é utilizada em ensaios de caracterização mecânica utilizando o dispositivo de queda de peso para ensaios em taxas intermediárias de deformação. A configuração $G$ foi utilizada para ensaios de cisalhamento, definida pela norma ASTM-D3518 (ASTM, 2013a), apresentando fibras anguladas de $45^{\circ} \mathrm{com}$ a direção principal do espécime. Por fim, a configuração $\mathrm{H}$ é utilizada para ensaios de compressão em regime estático e dinâmico. Buscando identificar a geometria de espécime utilizada em cada experimento, uma letra "D", "E", "F", "G" e 
"H" foi utilizada no primeiro algarismo de identificação dos espécimes, sendo esta relacionada com a configuração de espécime utilizada.

Os espécimes do material de reforço foram extraídos de chapas planas do material. Os cortes das configurações $D, E$ e $G$ foram realizados utilizando-se um guilhotina convencional. Uma faca de corte específica foi fabricada para a extração da geometria $\mathrm{F}$. A configuração $\mathrm{H}$ foi fabricada utilizando processos de corte e fresamento, a partir de uma chapa do material com $10 \mathrm{~mm}$ de espessura.

A caracterização do material SRPP Pure foi realizada utilizando a técnica DIC de medição de deformação, por acompanhamento de marcadores, através do software Pro Analyst Professional. Vale enfatizar que a distribuição dos marcadores adotada depende da propriedade a ser medida no experimento, objetivando aprimorar a resolução do sistema de medição.

A medição bidirecional de deformação foi feita em uma série de ensaios quase estáticos de tração. Nestes experimentos foram utilizados quatro marcadores formando um quadradro com $20 \mathrm{~mm}$ de aresta, na região central do espécime de configuração D, conforme apresentado na Figura 64. Lentes de alta magnificação foram utilizadas para a observação do experimento. As curvas tensão-deformação de tais amostras estão apresentas na Figura 65.

(a)

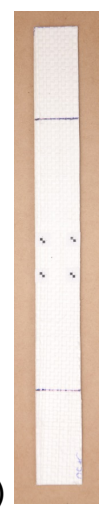

(b)

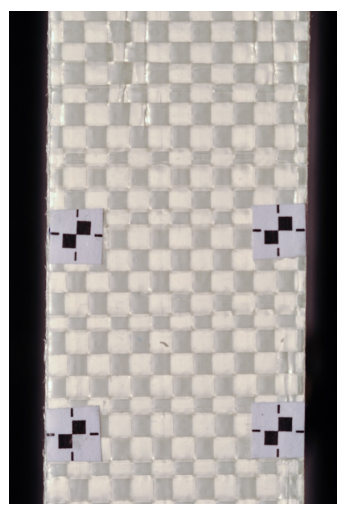

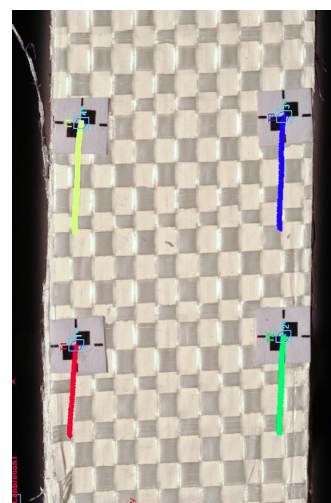

Figura 64: (a) Distribuição de marcadores para medição bidirecional de deformação e (b) medição de deformação utilizando técnica DIC. 

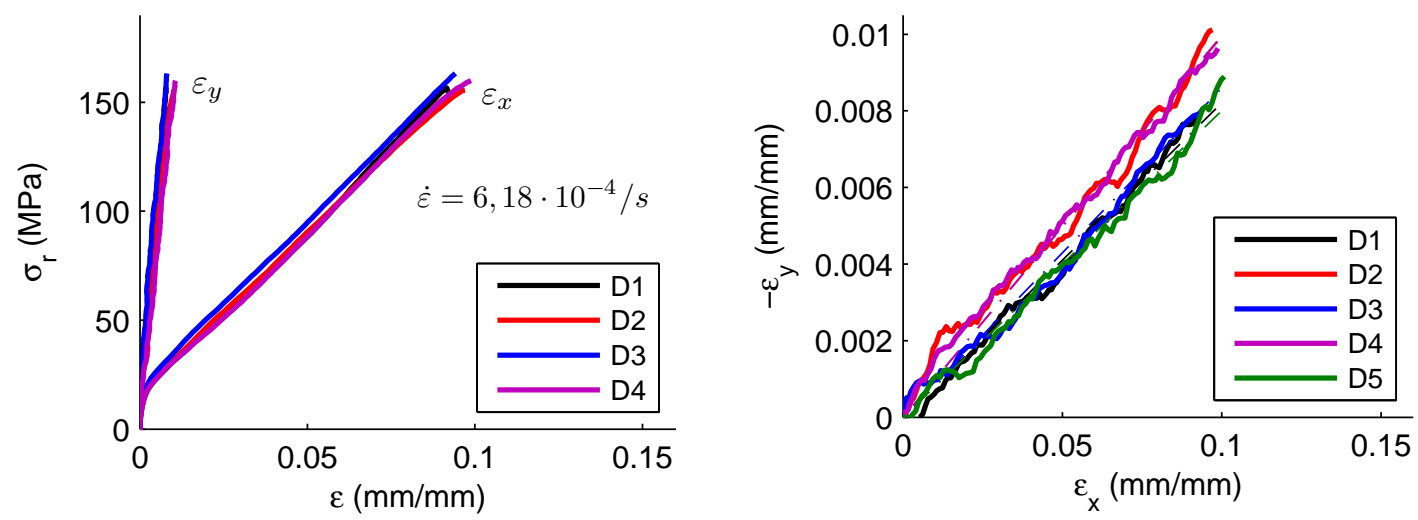

Figura 65: Curvas tensão-deformação para o SRPP Pure com medição bidirecional de deformação.

Nos experimentos apresentados acima, foi observado um comportamento majoritariamente visco-elástico linear, mesmo quando submetido a altos níveis de deformação. Além disso, foi identificada uma mudança no comportamento do material na porção inicial da curva.

Deve-se frisar que, apesar do tecido do material ser do tipo onda plana equilibrada, os espécimes foram extraídos das direções paralela e perpendicular à direção de enrrolamento do tecido, sendo mantidos os filamentos alinhados nas direções $\left[0^{\circ} / 90^{\circ}\right]$. Nestes experimentos não foi observada diferenciação no comportamento dos espécimes. Desse modo, foi considerado que as propriedades do tecido em ambas as direções são iguais.

A partir dos experimentos, foi observado que o material apresenta coeficiente de Poisson, $v_{12}=0,0894 \pm 10,6 \%$. Nota-se que o comportamento último do material não é escopo destes experimentos.

O comportamento do material até a condição de ruptura foi mensurado utilizando marcadores alinhados com a direção principal do espécime, Figura 66, sendo a deformação obtida pelo deslocamento dos marcadores entre os quais foi observada a falha do material. Buscando identificar o comportamento do material em diferentes taxas de deformação, foram utilizado espécimes de configuração D, E e F. 


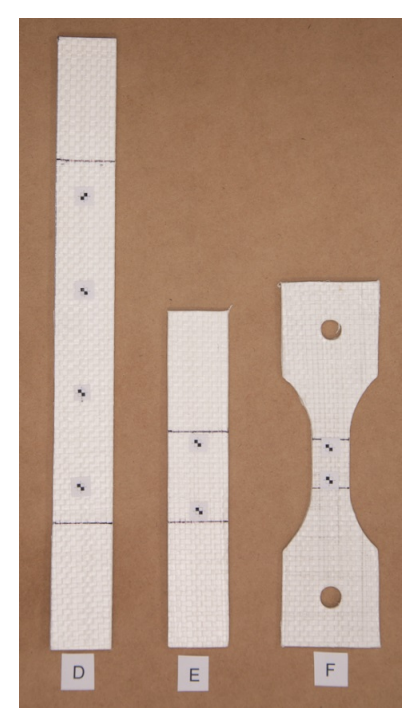

Figura 66: Espécimes com configuração (a) D, (b) E e (c) F, com os marcadores alinhados ao lonqo da direcão principal.

Foi observado que a falha do material ocorre com o rasgamento abrupto ao longo da secção transversal, com descolamento e deslizamento dos filamentos constituintes do material. Também foi observada que o mesmo apresenta elevada restituição elástica, com retorno à configuração similar a condição inicial em regiões onde não foi observada ruptura. Um sequencia de imagens apresentadas na Figura 67 exemplifica a forma de ruptura observada no material.

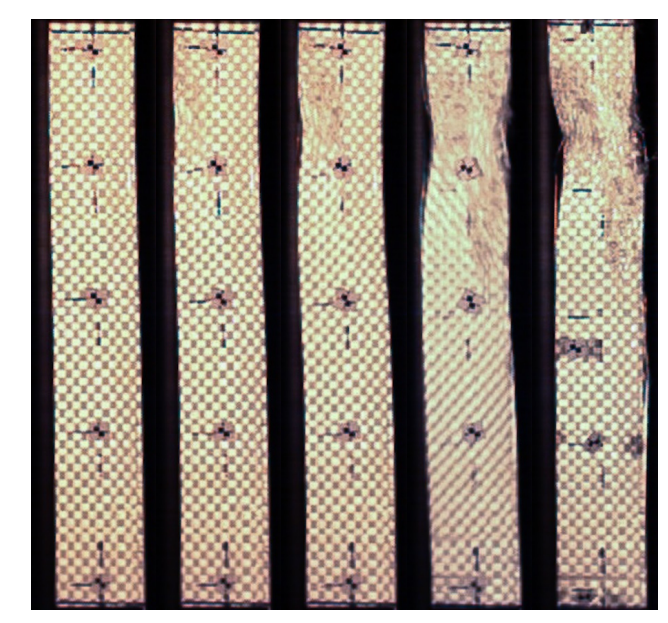

Figura 67: Sequência de imagens exemplificado o modo de ruptura observado no SRPP Pure.

Na Figura 68 são apresentados os espécimes após a realização do ensaio de tração. Nota-se que todos os espécimes apresentaram ruptura com rasgamento 
completo da seção transversal, sendo que, na maioria dos espécimes considerados, a falha ocorreu dentro da região de interesse.

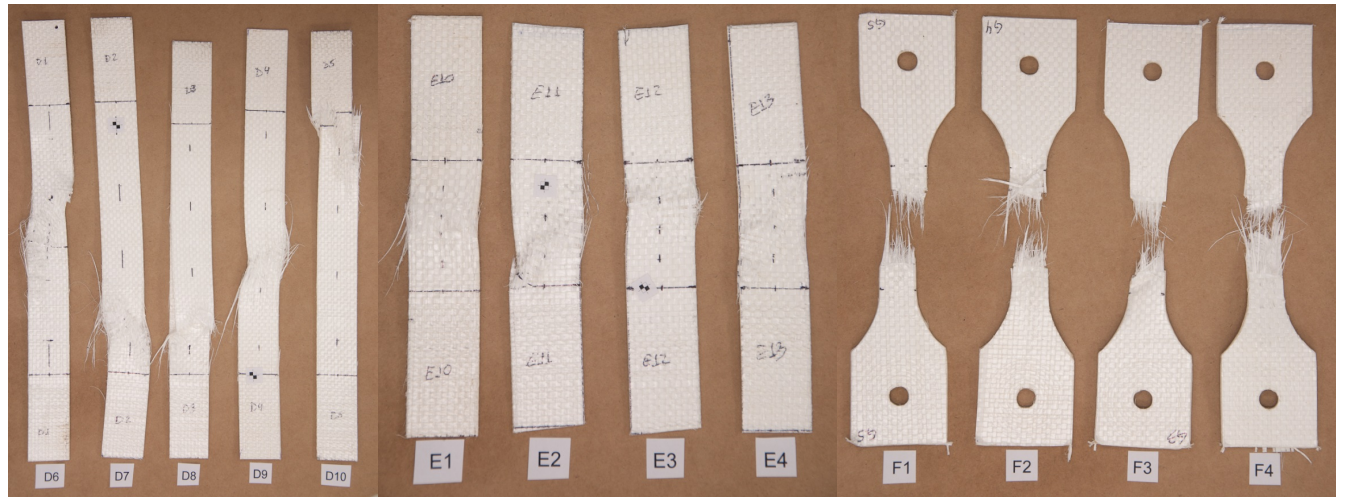

Figura 68: Espécimes de configuração (a) D, (b) E e (c) F após a realização dos experimentos.
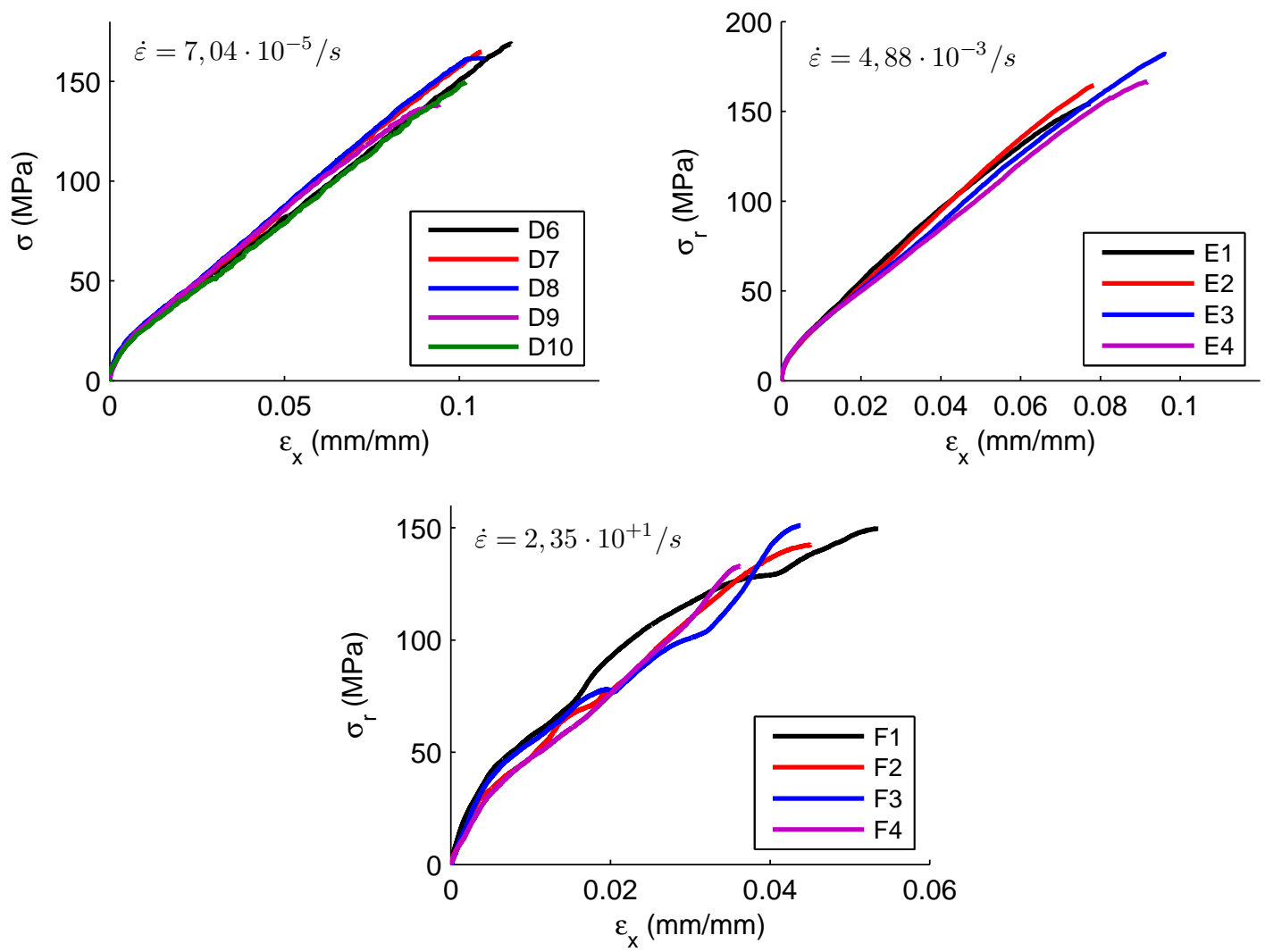

Figura 69: Curvas tensão-deformação do SRPP Pure, realizada a diferentes taxas de deformação.

Na Figura 69 é apresenta a curva tensão-deformação para o SRPP Pure até condição de ruptura em diferentes taxas de deformação. O material foi ensaiado a taxas de deformação de $10^{-5} / s$ a $10^{1} / s$, apresentando boa correlação dentre as 
amostras ensaiadas. Parâmetros obtidos no experimento estão apresentados na Tabela 36.

Observa-se que o material apresenta um aumento do módulo aparente proporcional à taxa de deformação. Neste caso, o módulo aumenta em cerca de $126 \%$ quando a taxa de deformação é alterada de $10^{-5} / \mathrm{s}$ para $10^{1} / \mathrm{s}$. De forma semelhante, observa-se redução de $55 \%$ na deformação de ruptura do material. A tensão máxima suportada pelo material é menos influenciada, com uma sensível redução quando solicitado à taxa de deformação de $10^{1} / \mathrm{s}$. A Figura 70 compara o comportamento do material em diferentes taxas de deformação e apresenta a interpolação média de comportamento deste para cada condição.

Tabela 36: Efeito da taxa de deformação no comportamento do SRPP Pure.

\begin{tabular}{cccc}
\hline$\dot{\varepsilon}$ & $E_{a p}$ & $\sigma_{u}$ & $\varepsilon_{u}$ \\
$\left(\mathrm{~s}^{-1}\right)$ & $(M P a)$ & $(M P a)$ & $(m m / m m)$ \\
\hline $\mathbf{7 , 0 3} \cdot 10^{-5}$ & $1602,82 \pm 3,8 \%$ & $156,32 \pm 8,2 \%$ & $0,1033 \pm 8,0 \%$ \\
$\mathbf{4 , 8 8} \cdot 10^{-3}$ & $2120,18 \pm 6,4 \%$ & $166,65 \pm 6,8 \%$ & $0,0861 \pm 11,1 \%$ \\
$\mathbf{2 , 3 5} \cdot \mathbf{1 0}^{+1}$ & $3628,08 \pm 2,1 \%$ & $143,96 \pm 5,8 \%$ & $0,0460 \pm 11,4 \%$ \\
\hline
\end{tabular}

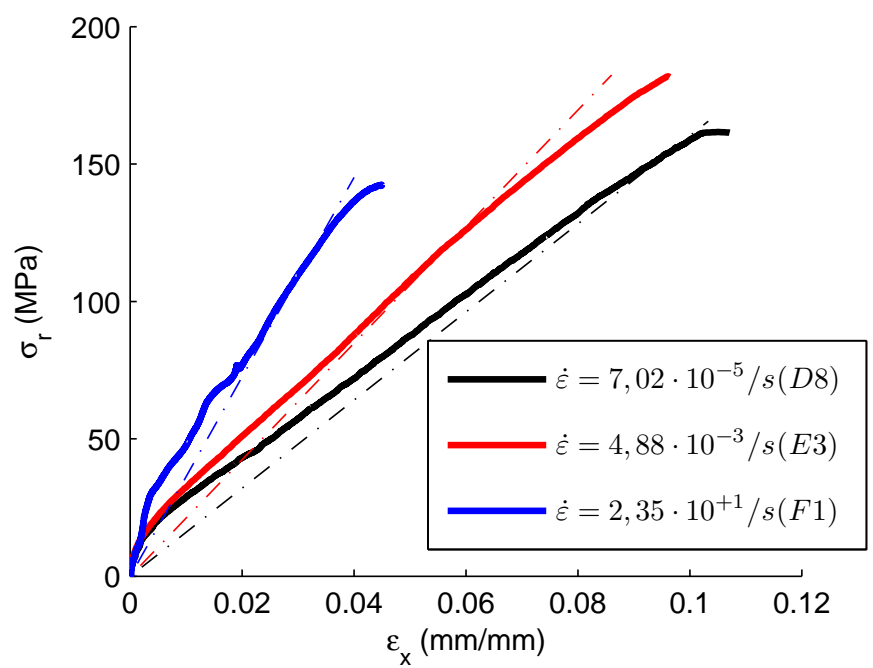

Figura 70: Comparação do comportamento do SRPP Pure em diferentes taxas de deformação.

Espécimes de configuração $G$ foram utilizados para realização de ensaios de cisalhamento no SRPP Pure, baseado na norma ASTM-3518. Quatro marcadores distribuídos na porção central dos espécimes, formando um quadrado com $20 \mathrm{~mm}$ de lado, foram utilizados para a medição bidirecional da deformação. Os espécimes 
foram solicitados em regime quase estático, a velocidade de $2 \mathrm{~mm} / \mathrm{min}$, sendo utilizada técnica DIC para medição de deformações $\varepsilon_{x}$ e $\varepsilon_{y}$. A Figura 71 apresenta a distribuição de marcadores na porção central do espécime e o processo de medição de deformação.
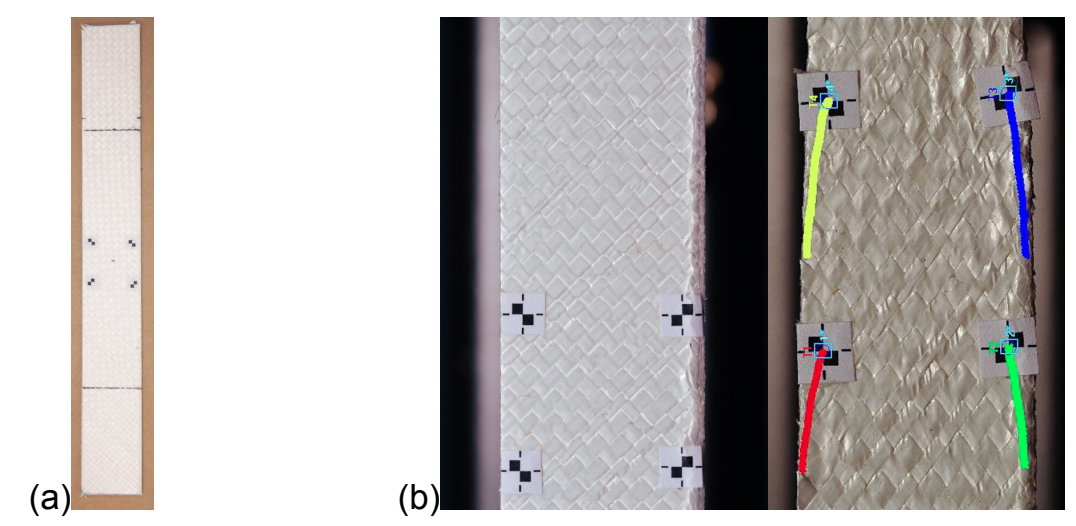

Figura 71: (a) Distribuição de marcadores para medição e (b) medição de deformações em ensaio de caracterização em cisalhamento.

A Figura 72 apresenta o comportamento do material no ensaio de cisalhamento, sendo observado o comportamento não-linear do material quando solicitado na direção [+/-45 $]$. Foi observada uma boa correção entre o comportamento das amostras ensaiadas, mesmo até elevados níveis de distorção, apresentado maior dispersão para a condição de ruptura das amostras.

Segundo (ASTM, 2013a), o ensaio de cisalhamento aqui apresentado tem validade até $\gamma_{12}=5 \%$, podendo ser aplicável para identificação de $G_{12}$ e início do comportamento não-linear. No entanto, o experimento foi realizado até a condição de ruptura da amostra para fins de comparação numérico-experimentais do comportamento do material.

A Figura 73 apresenta os espécimes após a realização do experimento, sendo também apresentado detalhe da ruptura dos mesmos. A adesão entre os filamentos é claramente avaliada nestes experimentos. Foi observado que houve a separação lenta e progressiva do espécime, com descolamento de grande quantidade de filamentos e com acentuado estiramento e estreitamento da amostra. 


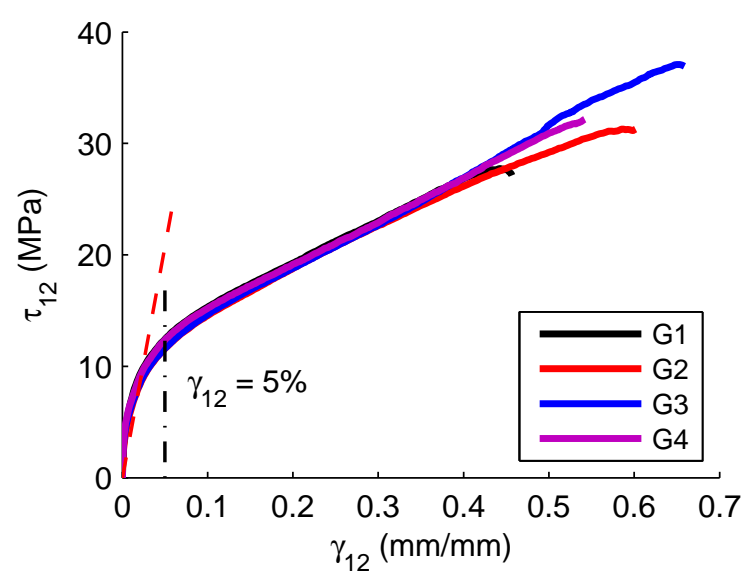

Figura 72: Comportamento do material SRPP Pure quando solicitado à direção [+/-45].

(a)

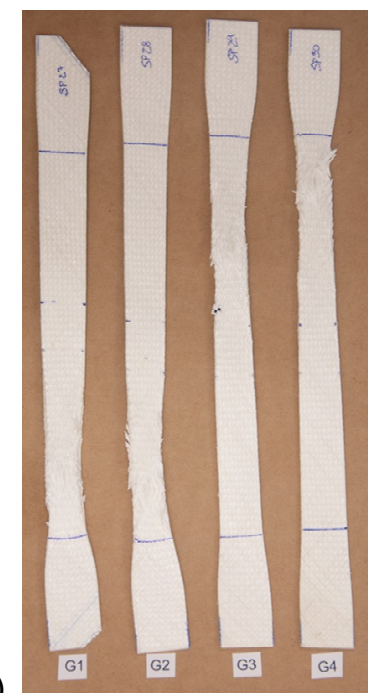

(b)

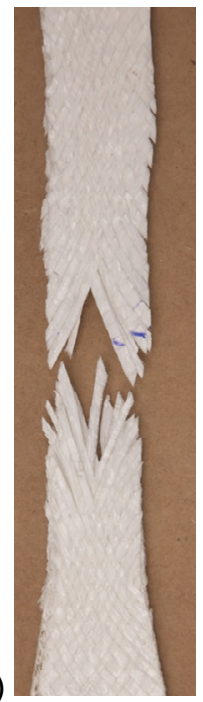

Figura 73: (a) Espécimes utilizando para a caracterização mecânica do material em cisalhamento. (b) Detalhe da ruptura do material.

Tabela 37: Parâmetros do SRPP Pure obtidos do ensaio de cisalhamento.

\begin{tabular}{cc}
\hline$G_{12}(M P a)$ & $415,53 \pm 6,7 \%$ \\
$\tau_{12, \text { rup }}(M P a)^{1}$ & $31,96 \pm 12,2 \%$ \\
$\gamma_{12, \text { rup }}(m m / m m)^{1}$ & $0,5488 \pm 16,3 \%$ \\
\hline : Condição de ruptura para o ensaio proposto.
\end{tabular}

Segundo Alcock (Alcock, Cabrera, Barkoula, Spoelstra, et al., 2007), o comportamento do material neste experimento é altamente influenciado pela pressão de consolidação utilizada durante o processo de termomoldagem do material. Segundo este estudo, a pressão de consolidação utilizada, 6 bar, não resulta na capacidade 
máxima de adesão entre os filamentos do material, causando o tipo de falha observado. Quando o material é termomoldado a pressões mais elevadas, como 10 bar ou 15 bar, a adesão entre os filamento é aumentada, aumentando sua resistência ao cisalhamento e causando ruptura repentina e localizada do mesmo. As amostras de SRPP Pure ensaiadas foram fabricadas de maneira semelhante à adotada para fabricação das amostras de TFML. Assim, o comportamento aqui obtido é relevante para o estudo proposto, mesmo que não representando o comportamento ótimo do material. A Tabela 37 sumariza parâmetros de comportamento do material.

Ensaios de caracterização em compressão foram conduzidos utilizando a máquina de ensaio universal Instron 3369 e martelo de impacto de baixa energia. Espécimes de configuração $\mathrm{H}$ foram utilizandos, sendo a solicitação aplicada na direção dos filamentos do material, conforme apresentado na Figura 74 . Os ensaios foram realizados nas velocidades de $0,002 \mathrm{~mm} / \mathrm{s}, 1 \mathrm{~mm} / \mathrm{s}$ e $500 \mathrm{~mm} / \mathrm{s}$, buscando identificar o comportamento do material em diferentes taxas de deformação. Não foi utilizado lubrificante entre as amostras e a superfície de compressão.

A sequência de imagens apresentada na Figura 75 exemplifica qualitativamente o histórico de deformação dos espécimes e exemplifica o resultado obtido após a realização dos experimentos. Todos os ensaios apresentaram falha causada por flambagem de filamentos e separação de camadas. Devido à incerteza na definição da secção transversal do material após a falha do espécime, todos os experimentos foram avaliados até o nível de $5 \%$ de deformação.

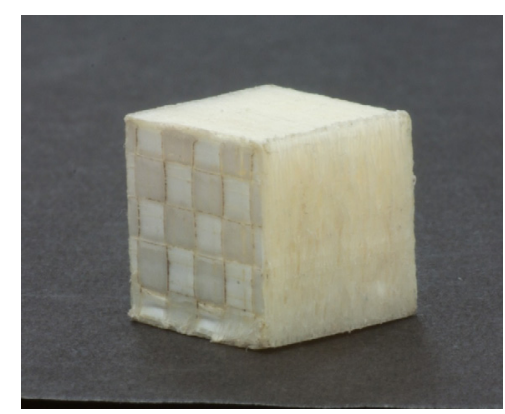

Figura 74: Espécimes de configuração H utilizados para caracterização do SRPP Pure em compressão. 
(a)

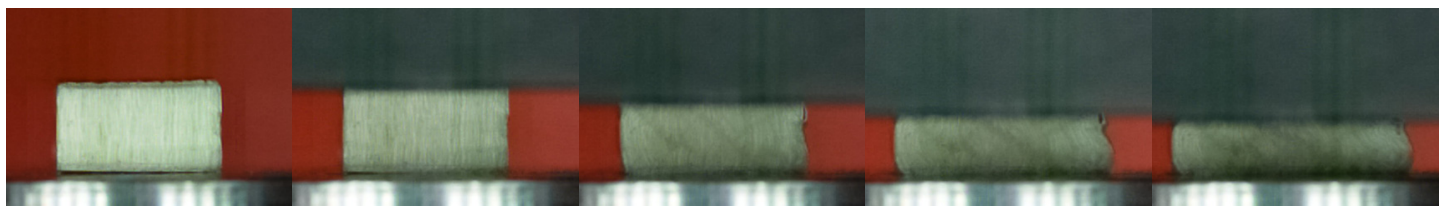

(b)

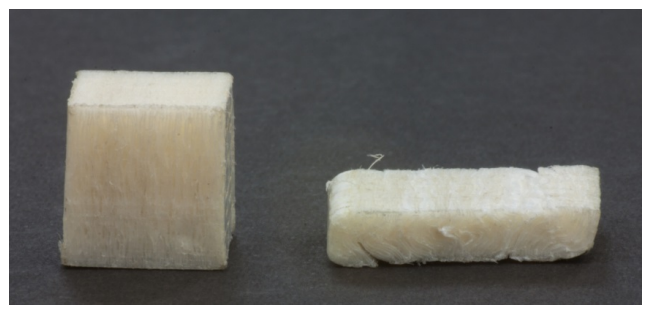

Figura 75: (a) Sequencia de imagens obtidas durante o ensaio de compressão do SRPP Pure e (b) espécimes antes e após a realizacão do experimento.

Na Figura 76 são apresentadas as curvas-tensão deformação em compressão obtidas do SRPP Pure em taxas de deformação de $-1,92 \cdot 10^{-4} / \mathrm{s},-1,17 \cdot 10^{-1} / \mathrm{s}$ e $-3,47 \cdot 10^{1} / s$. Em todas as curvas foi obtido um perfil quase linear na porção inicial da curva, sendo, posteriormente, observada a formação de um patamar quando o processo de separação de camadas é iniciado.

A Figura 77 compara o comportamento do material nas taxas de deformação avaliadas. Semelhantemente quando solicitado em tração, foi observado o aumento do módulo elástico aparente de compressão, $E_{a p}^{c}$, com o aumento da taxa de deformação. Quando a taxa de deformação é aumentada de $-1,92 \cdot 10^{-4} / \mathrm{s}$ para $-3,47 \cdot 10^{1} / s$, observa-se um aumento de aproximadamente $55,1 \%$ no $E_{a p}^{c}$.

Também foi observado o aumento da tensão na qual é iniciada a flambagem dos filamentos e separação de camadas, $\sigma_{f}^{c}$. Quando a taxa de deformação é aumentada de $-1,92 \cdot 10^{-4} / \mathrm{s}$ para $-3,47 \cdot 10^{1} / \mathrm{s}$, observa-se um aumento de $\sigma_{f}^{c}$ em $78,6 \%$. Este parâmetro representa a característica de falha de corpo de prova do material termomoldado especificamente, não representando a característica de ruptura do filamento em compressão. De fato, a dependência do $\sigma_{f}^{c}$ com a taxa de deformação demostra que a separação entre as camadas e flambagem dos filamentos do SRPP Pure são influenciadas com a velocidade de soliciticação. A Tabela 38 sumariza parâmetros do SRPP Pure obtidos no experimento. 
$\varepsilon_{\mathrm{x}}(\mathrm{mm} / \mathrm{mm})$

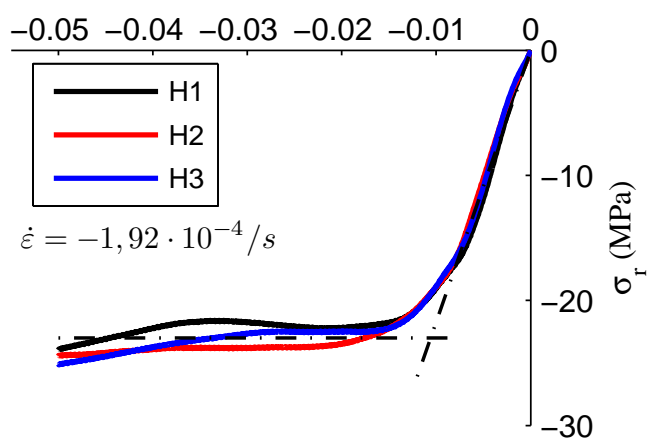

$\varepsilon_{\mathrm{x}}(\mathrm{mm} / \mathrm{mm})$

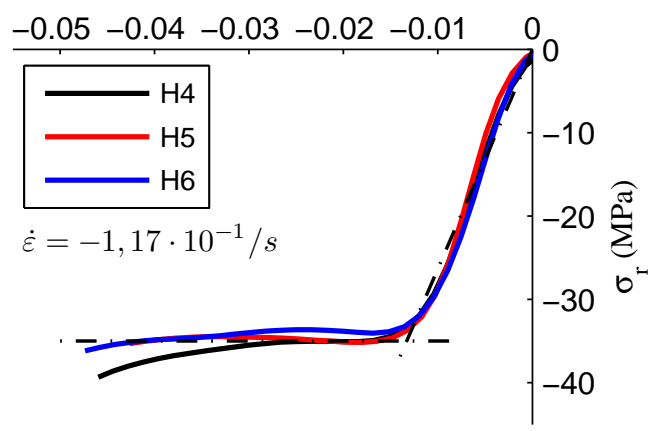

$\varepsilon_{\mathrm{x}}(\mathrm{mm} / \mathrm{mm})$

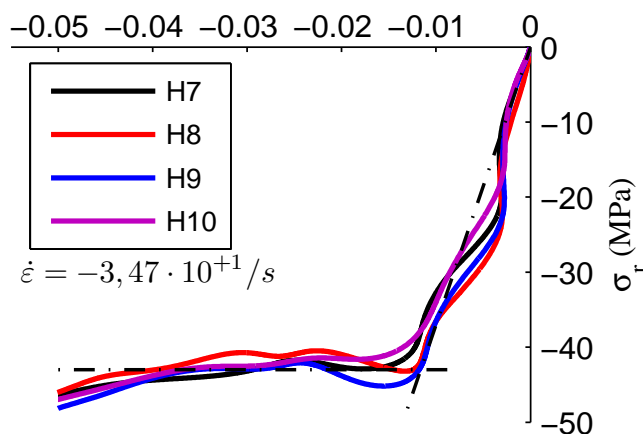

Figura 76: Curvas tensão-deformação do SRPP Pure em compressão, realizada em diferentes taxas de deformação.

$\varepsilon_{\mathrm{x}}(\mathrm{mm} / \mathrm{mm})$

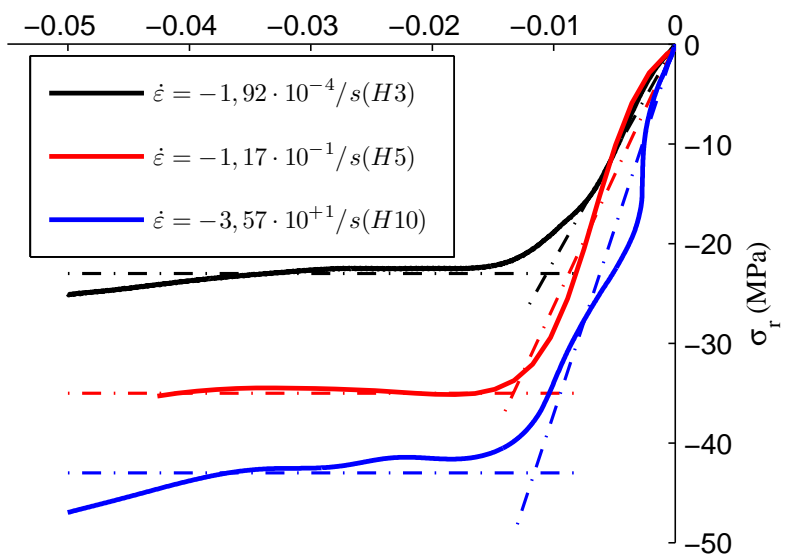

Figura 77: Comparação do comportamento do SRPP Pure em compressão a diferentes taxas de deformação. 
Tabela 38: Efeito da taxa de deformação no comportamento do SRPP Pure em compressão.

\begin{tabular}{ccc}
\hline$\dot{\varepsilon}$ & $E_{a p}^{c}$ & $\sigma_{f}^{c}$ \\
$\left(\mathrm{~s}^{-1}\right)$ & $(M P a)$ & $(M P a)$ \\
\hline$-\mathbf{1}, \mathbf{9 2} \cdot \mathbf{1 0}^{-4}$ & $2173,67 \pm 8,1 \%$ & $23,26 \pm 7,2 \%$ \\
$-\mathbf{- 1 , 1 7} \cdot \mathbf{1 0}^{-1}$ & $2630,47 \pm 7,1 \%$ & $36,43 \pm 2,2 \%$ \\
$-\mathbf{3 , 4 7} \cdot \mathbf{1 0}^{+1}$ & $3704,50 \pm 11,1 \%$ & $43,78 \pm 5,1 \%$ \\
\hline
\end{tabular}

\subsubsection{Definição de parâmetros constitutivos}

Conforme observados nos ensaios experimentais de caracterização realizado no SRPP Pure, foi observado que o mesmo apresenta um comportamento viscoelástico linear com sensibilidade a taxa de deformação, quando solicitado na direção [0\% $\left./ 90^{\circ}\right]$ em tração ou compressão, e um comportamento não-linear quando solicitado a $\left[-45^{\circ} / 45^{\circ}\right]$. Lembrando que a diferenciação no comportamento do material quando solicitado em diferentes direções é característica de materiais compósitos (ou ortotrópicos). A sensibilidade à taxa de deformação é esperado em virtude do material ser constituído por um polímero termoplástico de PP.

Foram realizadas buscas dentre os modelos de materiais disponíveis no programa comercial LS-Dyna v.971, não sendo possível identificar um modelo que combinasse características ortotrópicas do material com o efeito de taxa de deformação observado. Assim, optou-se por utilizar duas formas distintas de modelagem deste. Uma abordagem consiste na utilização do material MAT-58, destinado para modelagem de tecidos ou laminados completos, onde é disponibilizada comportamento ortotrópico, sem efeitos de taxa de deformação. A outra abordagem consiste na utilização do modelo de material MAT-24, o qual possibilita a definição do comportamento tabelado do material, considerando efeitos de taxa de deformação e desconsiderando efeitos ortotrópicos.

O modelo de material MAT-58 "Laminated Composite Fabric" pode ser implementado com elementos de casca ou elementos de casca com espessura ("Tick Shell'). Este modelo considera um comportamento elástico linear do material, com propriedades ortotrópicas, da seguinte forma 


$$
\begin{aligned}
\sigma_{a} & =(e a) \varepsilon_{a}+(\text { prab }) \varepsilon_{a} \\
\sigma_{b} & =(e b) \varepsilon_{b}+(\text { prab }) \varepsilon_{a}
\end{aligned}
$$

até a tensão ultima definida para cada direção principal do material. O modelo de material, possibilidade a inclusão de efeitos não-lineares no comportamento do material em cisalhamento, a partir do termos gab, TAU1, GAMMA1 SC e GMS, conforme apresentados na Figura 78.

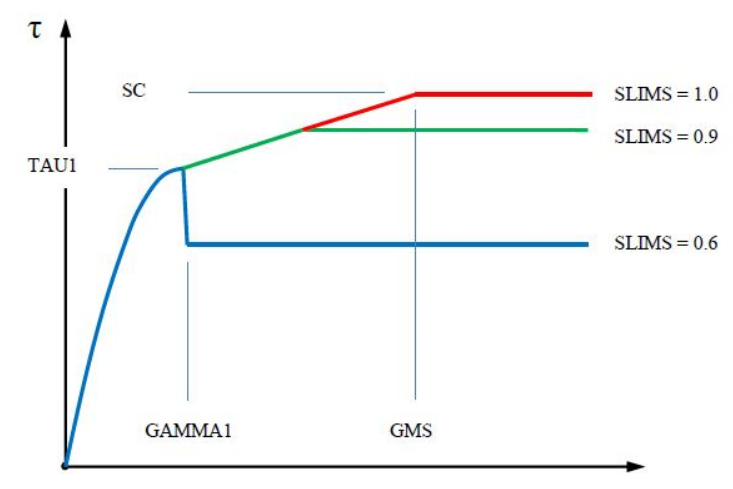

$\gamma$

Figura 78: Representação gráfica dos parâmetros para definição do comportamento não-linear do material em cisalhamento (Hallquist, 2006).

O modelo possibilita a definição dos termos $X C, X T, Y C, Y T$ e $G M S$ que definem as condições ultimas de tensão e cisalhamento no comportamento do material sob tração e compressão, em ambas direções principais. As interações entre as direções são definidas por uma superfície facetada de falha (critério de Tresca), sendo que, atingida a condição de falha, o modelo de material disponibiliza o efeito de amaciamento ("softening"), no qual a tensão do material é decaída para

$$
\sigma=S_{\lim , x x} \sigma_{f}
$$

sendo SLIM, xx definido para as condições de tração e compressão, em cada direção principal, e cisalhamento. Após esta condição, os elementos são excluídos do modelo ao atingirem uma condição de deformação limite, definida por e11c,e11t,e22c,e22t e GAMMA. Como indicado o modelo de material MAT-58 não considera efeitos de taxa de deformação do comportamento do material. 
Os parâmetros ea, eb, prab, gab, TAU1, GAMMA1,XC,XT ,YC, YT, GMS, $e 11 c, e 11 t, e 22 c, e 22 t$ e GAMMA foram obtidos a partir dos ensaios experimentais apresentados no Item 6.3.1. Os parâmetros $S L I M, x x$ foram definidos conforme sugerido pela referência (Hallquist, 2006), assumindo valores de 1,0 para solicitações de compressão e 0,1 para solicitações de tração e cisalhamento.

A fim de avaliar o desempenho dos parâmetros constitutivos obtidos do material, um ensaio de caraterização quase estático foi modelado numericamente utilizando o programa LS-Dyna v.971, considerando espécimes de configuração $E$ e G, Figura 79. A Figura 80 apresenta a comparação numérico-experimental da resposta do material. Uma boa correlação foi obtida quando o material é solicitado na direção [0\% $\left./ 90^{\circ}\right]$, no tocante de comportamento global e ruptura.

Quando o material é solicitado a $\left[+/-45^{\circ}\right]$, foi possível representar o comportamento não-linear apresentado por este com boa correlação, com pequena diferenciação na região final da curva. Tal diferenciação está na superestimação da deformação em até 15\%. Porém, o ensaio experimental também apresentou maior dispersão na condição de ruptura e, de maneira geral o modelo numérico pode representar o comportamento do SRPP neste regime. Assim, a modelagem foi considerada como válida, sendo utilizada para análises do TFML apresentadas no Capítulo 8. No Anexo 1 estão apresentados os parâmetros utilizados para modelagem do TFML.

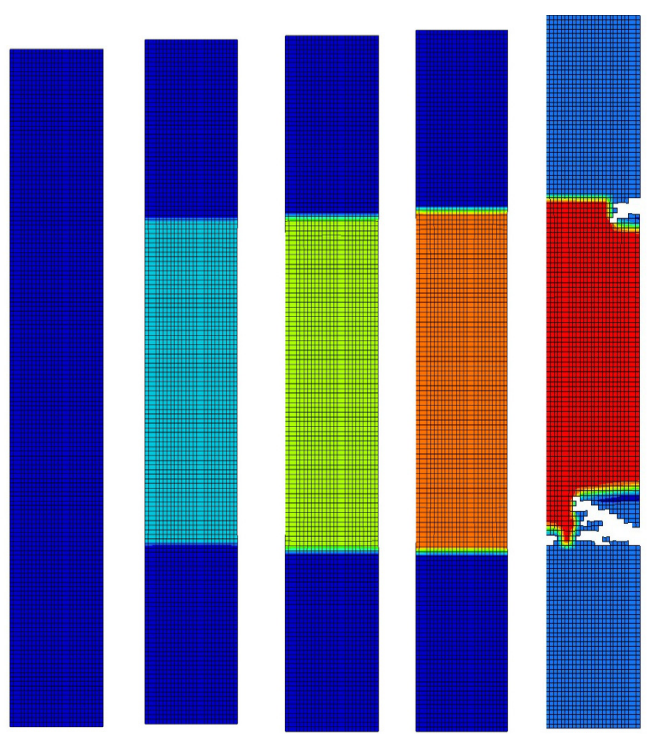

Figura 79: Modelagem numérica do ensaio de tração do SRPP Pure. 

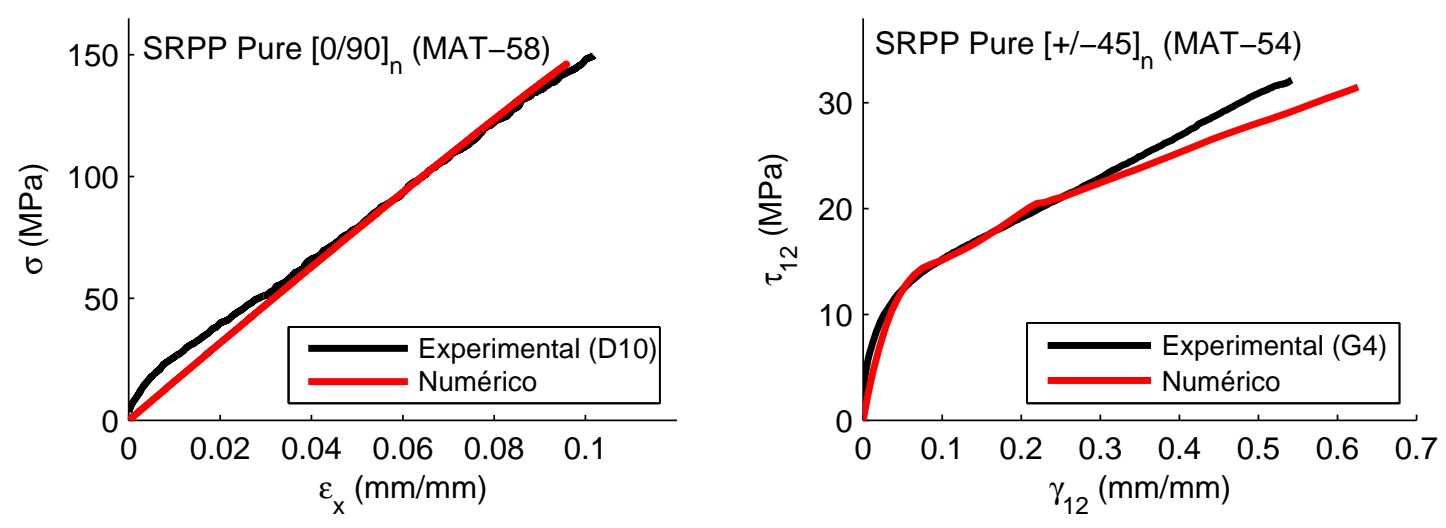

Figura 80: Modelagem numérica do ensaio de tração do SRPP Pure, utilizando modelo de material MAT-58.

O modelo de material MAT-24 "Piecewise Linear Plasticity" possibilita a entrada de curvas tensão-deformação do material a diferentes taxas de deformação. Para fins de modelagem numérica, foi assumido que o comportamento plástico do material é iniciado após o estágio inicial não-linear observado nas curvas tensãodeformação apresentadas na Figura 65. Este comportamento não fora observado em ensaios experimentais, porém é satisfatório para fins de modelagem numérica. Buscando representar as curvas tensão-deformação com efeitos de taxa de deformação obtidas experimentalmente (Figura 70), foram considerados apenas o critério de falha por tensão máxima principal.

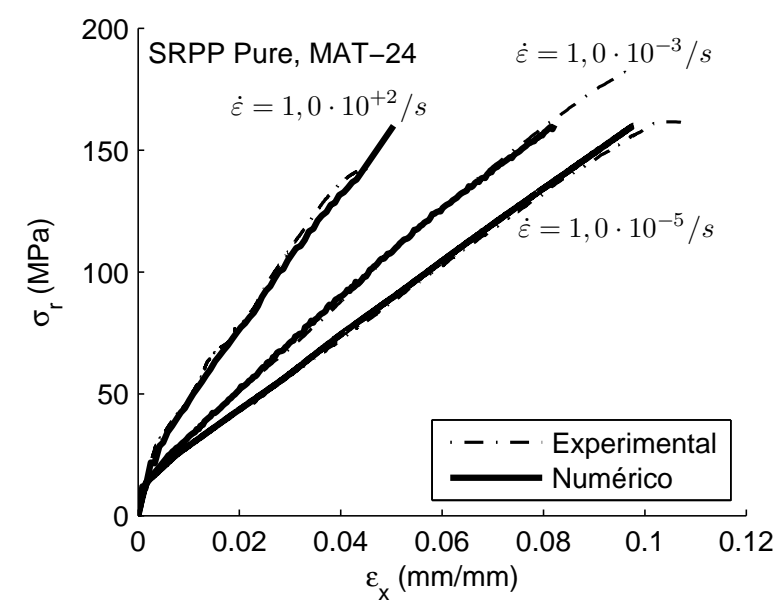

Figura 81: Modelagem numérica do ensaio de tração do SRPP Pure, utilizando modelo de material MAT-24. 
A avaliação do desempenho deste modelo de material foi realizada com a modelagem numérica de um ensaio de caracterização do SRPP Pure, utilizando espécimes de configuração $\mathrm{E}$, em diferentes taxas de deformação. A Figura 81 apresenta a comparação numérico-experimental dos resultados obtidos, sedo observada boa correção entre estas em todas as taxas de deformação consideradas. Os parâmetros utilizados neste modelo de material estão apresentado em Anexo 1, sendo inseridos resultados experimentais tabelados para as taxas de deformações ensaiadas.

\subsection{CARACTERIZAÇÃO MECÂNICA DOS TFMLS}

Amostras de materiais TFMLs foram caracterizadas em regime quase estático utilizando a máquina de ensaios universal Instron 3369. Nestes experimentos a medição da deformação destes foi realizada apenas com a utilização de um extensômento de clipe, com $25 \mathrm{~mm}$ de comprimento inicial. A configuração de corpos de prova utilizada está apresentada na Figura 83, possuindo comprimento útil de 30 $\mathrm{mm}$ e largura de $15 \mathrm{~mm}$. Foram extraídas amostras dos materiais P3A044, P4B039 e P5A043, todos alinhados com a direção principal de laminação da liga de alumínio e filamentos dos reforços. Estes espécimes foram usinados utilizando processos de corte com guilhotina e fresamento, dando atenção para que o processo não danificasse a integridade destes.

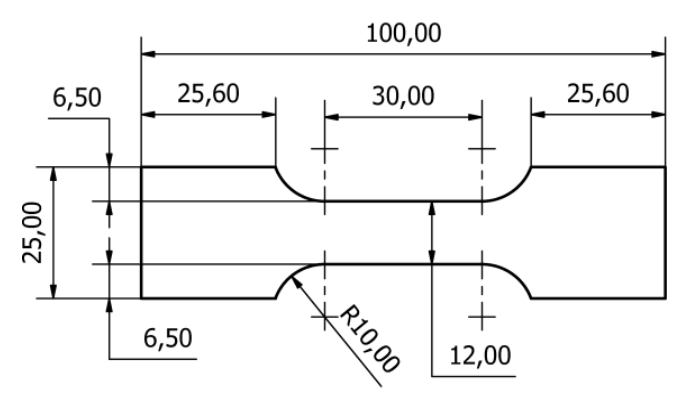

Figura 82: Configuração I de espécimes de TFML utilizada, escala 2:1 (dimensões em milímetros). 


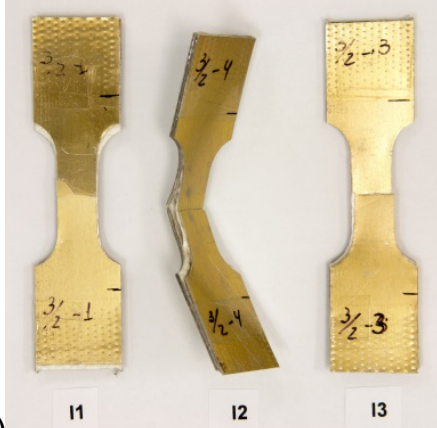

(a)

12

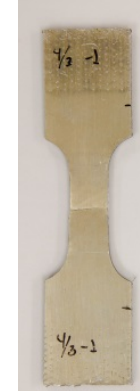

(b)

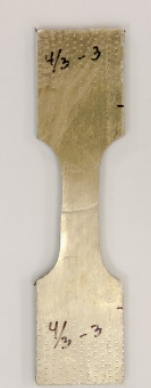

15

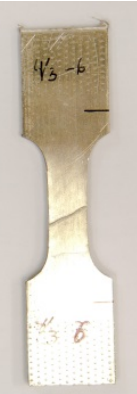

16

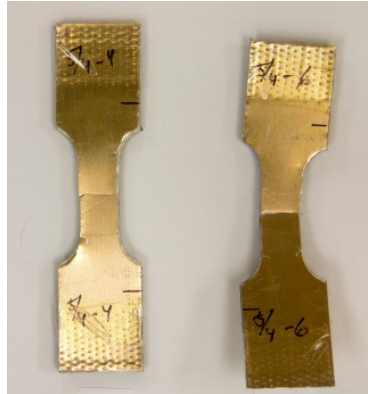

(c)

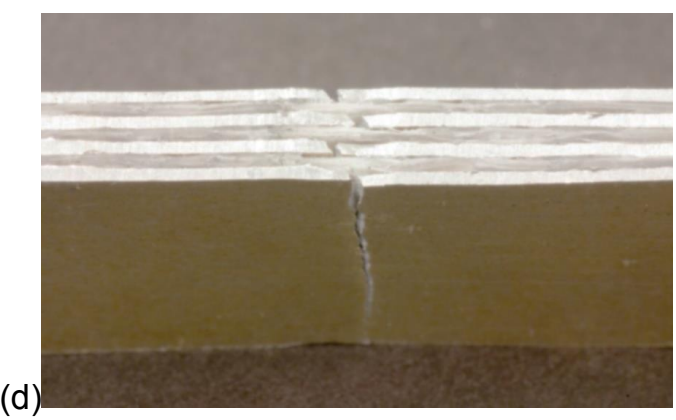

Figura 83: Especimes de TFML após a realização do ensaio de tração: (a) P3A044, (b) P4B039 e (c) P5A043. (d) Detalhe a ruptura de uma amostra P4B039.

Na Figura 83 são apresentados os espécimes utilizados após a realização dos experimentos. Na maioria dos espécimes ensaiados, a ruptura ocorreu dentro da região central do espécime, de forma perpendicular com o comprimento maior deste ou levemente inclinada. Na maioria dos casos, foi observada a ruptura de todas as camadas do material, conforme é possível observar na Figura 83d. Alguns espécimes apresentaram uma camada de metal sem ruptura após o teste, o que causa uma aparente flexão residual após a retirada deste do equipamento, como o caso das amostras H2 e H8. Apesar deste fato, não foram observadas diferenciações significativas da curva obtida do material. Três espécimes apresentaram descolamento prematuro de uma camada completa de metal (geralmente uma camada externa) durante o teste. Neste caso, estas amostras foram desconsideradas. 

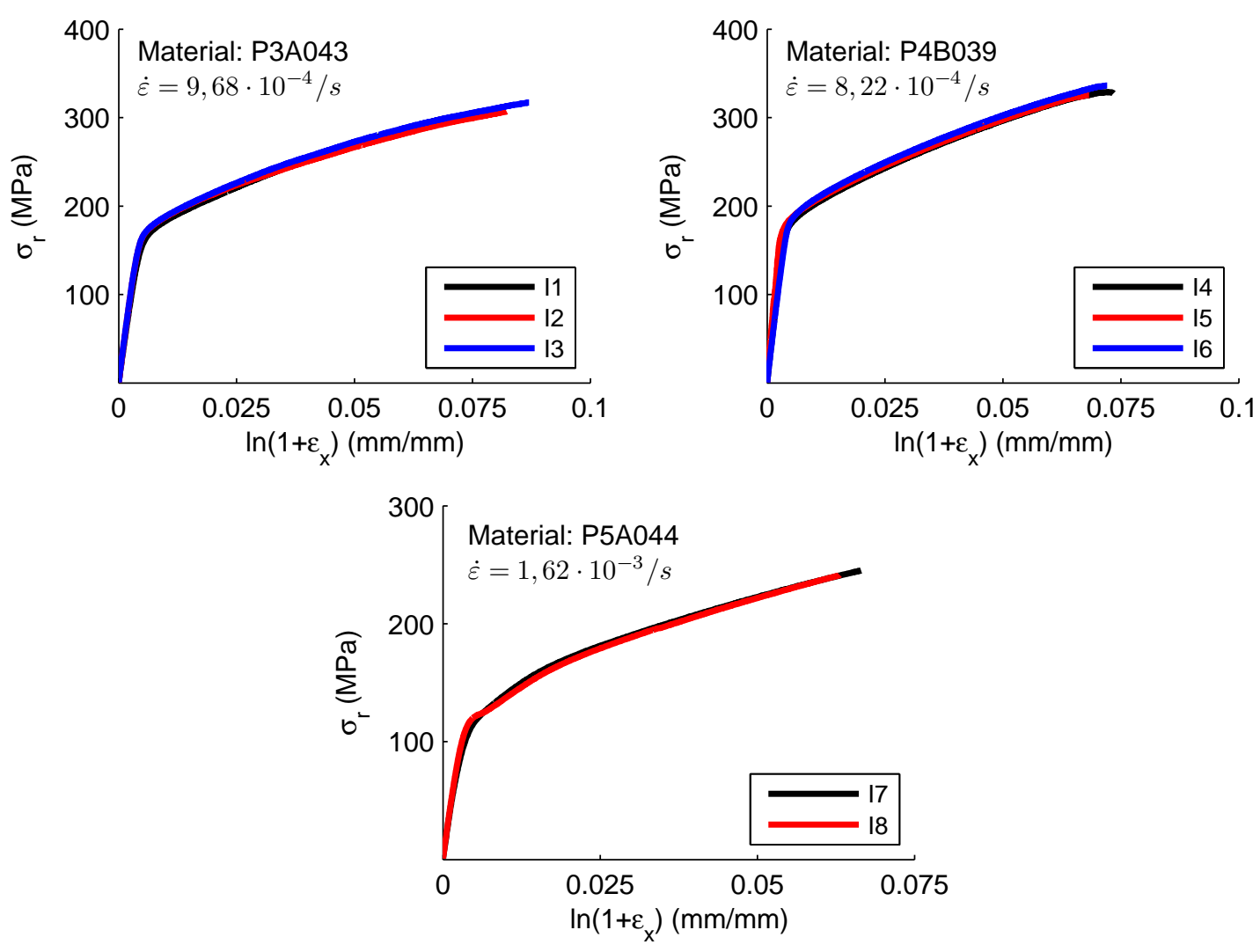

Figura 84: Curvas tensão-deformação para as amostras de TFML ensaiadas.

As curvas tensão-deformação para os materiais em questão estão apresentadas na Figura 84, sendo observada uma boa repetibilidade no comportamento das amostras ensaiadas. O material apresenta uma curva tensão-deformação característica de materiais metálicos, com comportamento linear no início desta e, após uma determinada condição, esta passa a apresentar um comportamento não linear, provavelmente relacionado com ocorrência ou não de deformações permanentes.

Na Figura 85 é possível observar que o TFML apresenta um comportamento intermediário entre o alumínio 2024-T3 e SRPP Pure. Observa-se uma aparente concordância com a Regra das misturas até níveis de deformação onde ocorre a ruptura do SRPP. Uma vez que o TFML apresenta ruptura em torno de $8 \%$, menor que o limite de ruptura da liga de alumínio 2024-T3 e próximo ao limite do SRPP PURE, acredita-se que este fato seja o motivo da ruptura do reforço. Quando o material chega à condição de ruptura do SRPP, esta camada perde resistência, induzindo o aumento da tensão de forma localizada nas camadas remanescentes, em sua maioria, metálicas. Uma vez que o aumento da tensão é localizado, o metal atinge altos níveis de deformação, o que causa a ruptura deste. Assim, apesar de 
haver ainda uma existência de camadas de reforços ligando as duas partes dos corpos de prova ao fim do teste, estas estão rompidas e sem função estrutural. As ligações entrem as partes são dadas por filamentos que, apesar de rompidos, ainda estão aderidos a outros e ao metal.

Na Figura 85 é realizada a comparação do comportamento das diferentes configurações de TFML ensaiadas. Nota-se a maior resistência mecânica da configuração P4B039, o que justifica o seu melhor desempenho em testes experimentais de impacto. Vale frisar que esta configuração possui camadas metálicas mais espessas que as demais. A configuração P5A044 apresentou a menor resistência mecânica, quando comparada com as demais.
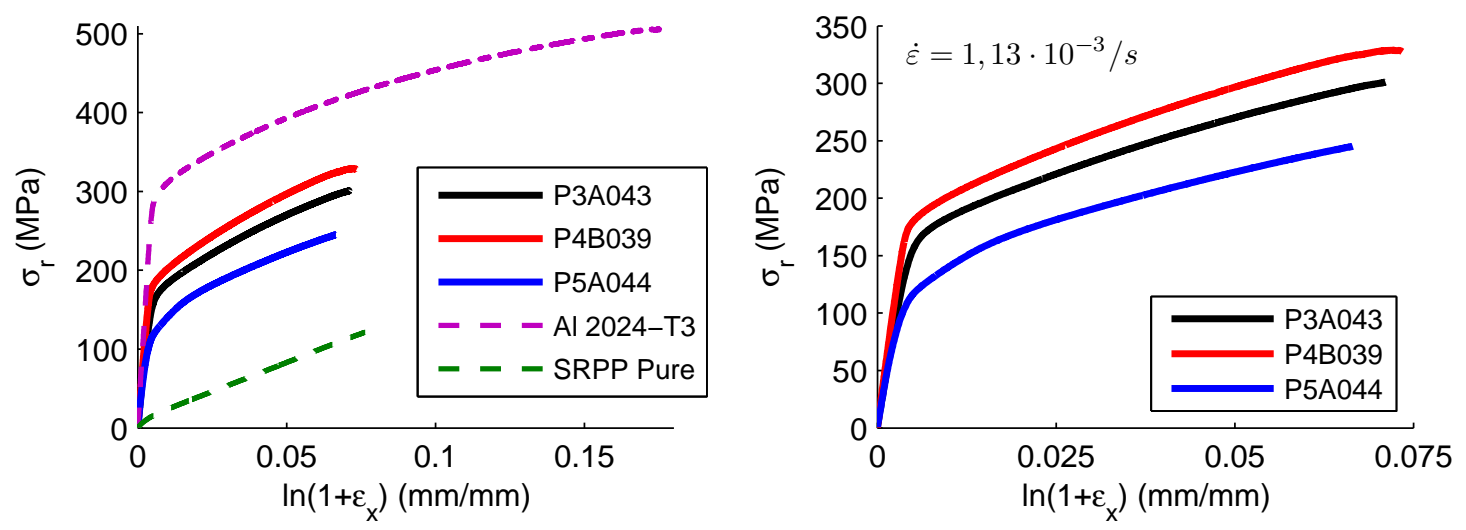

Figura 85: Comparação do comportamento do das amostras de TFMLs ensaiadas.

$\mathrm{Na}$ Tabela 39 são apresentados parâmetros de comportamento dos materiais ensaiados. A tensão $\sigma_{0}$ define uma condição limite para a transição entre comportamentos linear e não-linear, não sendo utilizado com a finalidade de definição de comportamento plástico, uma vez que este não é aplicável a materiais híbridos.

Tabela 39: Parâmetros de comportamento das amostras de TFMLs.

\begin{tabular}{ccccc}
\hline Material & $\begin{array}{c}E \\
(G P a)\end{array}$ & $\begin{array}{c}\sigma_{0} \\
(M P a)\end{array}$ & $\begin{array}{c}\sigma_{u} \\
(M P a)\end{array}$ & $\begin{array}{c}\varepsilon_{u} \\
(\mathrm{~mm} / \mathrm{mm})\end{array}$ \\
\hline P3A043 & $37,44 \pm 5,4 \%$ & $163,97 \pm 0,8 \%$ & $308,07 \pm 2,6 \%$ & $0,0799 \pm 10,3 \%$ \\
P4B039 & $46,12 \pm 8,2 \%$ & $172,33 \pm 3,8 \%$ & $329,83 \pm 1,7 \%$ & $0,0713 \pm 3,8 \%$ \\
P5A044 & $34,19 \pm 0,7 \%$ & $108,30 \pm 5,4 \%$ & $243,00 \pm 1,2 \%$ & $0,0648 \pm 3,8 \%$ \\
\hline
\end{tabular}




\subsection{CONSIDERAÇÕES FINAIS}

Neste capítulo foi realizada a caracterização mecânica dos seguintes materiais:

- Liga de alumínio 2024-T3, solicitado em tração em taxas de deformações quase estáticas e dinâmicas;

- SRPP Pure, solicitado em tração e compressão em taxas de deformações quase estáticas e dinâmicas, e em cisalhamento em taxas de deformação quase estática.

- Três amostras de TFML, solicitadas em tração em taxas de deformações quase estáticas.

Análises estatísticas foram desenvolvidas para todos os experimentos realizados, obtendo-se, de maneira geral, desvio padrão menores que $10 \%$, o que forneceu embasamento para as conclusões obtidas.

Por fim, parâmetros constitutivos foram identificados para o alumínio 2024-T3 e SRPP Pure, utilizando modelos de materiais disponíveis na biblioteca do programa comercial LS-Dyna V.971. Os resultados desse modelamento foram confrontados com resultados experimentais de forma satisfatória. Os parâmetros aqui identificados serão utilizados para a simulação numérica do TFML em regime de impacto, apresentada no Capítulo 8. 


\section{ANÁLISE TEÓRICA DO IMPACTO EM FML TERMOPLÁSTICO}

Neste capítulo será apresentada a análise teórica do impacto mecânico em TFMLs. A abordagem teórica do fenômeno possibilita o entendimento básico (e fundamental) do evento em questão. Além disso, o estudo de modelos teóricos possibilita a avaliação dos resultados proveniente dos modelos numéricos a serem desenvolvidos no Capítulo 8. Por fim, os modelos teóricos também possibilitam a identificação parâmetros básicos de desempenho do material, como o deslocamento residual e o limite balístico, de forma simples, rápida e substancialmente crível.

O impacto mecânico é um fenômeno complexo, sendo influenciado por diversos aspectos, entre estes (Jones, 1997) :

- Inércia dos elementos envolvidos: o evento de impacto é um fenômeno dinâmico com movimentação de elementos com massas e inércias específicas.

- Condição de contorno: Sabe-se que diferentes geometrias de elementos impactantes ou mesmo diferentes condições de engastamento podem gerar resultados substancialmente distintos.

- Propagações de onda: Durante o impacto mecânico ondas de deslocamento elástico e plástico são geradas ao longo do material. Estas podem ser refletidas e combinadas, influenciando substancialmente no comportamento da estrutura.

- Comportamento dinâmico dos materiais: É sabido que os materiais podem apresentar comportamento distinto quando solicitados em regime quase-estático e dinâmico.

- Ocorrência de grandes deslocamentos e deformações: os eventos de impacto podem resultar grandes deslocamentos e deformações dos elementos, condições onde formulações tradicionais não são aplicaveis.

- Ocorrência de falha: dependendo da magnitude de impacto, podem ser observadas trincas e ruptura de elementos.

- Efeitos termodinâmicos: o evento de impacto pode ser substancialmente rápido, impossibilitando a troca de calor (evento adiabático) e cau- 
sando o aquecimento local devido à fricção e deformação do material. Tal aquecimento pode influenciar no comportamento do material.

Tendo em vista a complexidade de tais efeitos, é aceitável que o modelo teórico considere hipóteses para a simplificação do fenômeno. Este capítulo visa o embasamento teórico do impacto em chapas planas e circulares de materiais híbrido, como os TFMLs. Assim o estudo profundo do fenômeno de impacto não é escopo deste estudo.

Os aspectos básicos do modelo teórico serão apresentados, tomando como base o estudo de vigas e placas. Posteriormente duas metodologias de homogeneização de propriedades de materiais híbridos serão apresentadas: a teoria das misturas, proveniente da análise micromecânica de materiais compósitos (Daniel e Ishai, 2006) e outra, aqui desenvolvida, que considera efeitos geométricos da configuração do material.

O modelo plástico desenvolvido em (Jones, 2003) foi adaptado e utilizado para a identificação do deslocamento residual das amostras de TFML submetidas ao impacto de baixa velocidade. Adaptação semelhante foi aplicada ao modelo teórico de Reid-Wen (Reid e Wen, 2000), utilizado para identificação do limite balístico de TFML submetidos ao impacto de alta velocidade.

\subsection{FORMULAÇÃO BÁSICA DE VIGAS E PLACAS SUBMETIDAS AO IMPACTO MECÂNICO}

Uma vez que o fenômeno de impacto resulta em grandes deslocamentos e deformações permanentes, tem-se a necessidade de utilizar modelos constitutivos aplicáveis nestas condições. Segundo (Jones, 1997), uma aproximação rígidoplástica do comportamento do material pode ser adotada, sendo a curva tensãodeformação simplificada por uma tensão $\sigma_{0}$ constante, conforme apresentada na Figura 86. Tal aproximação é válida para materiais com comportamento majoritariamente dúctil, como os metais. No caso do TFML, apesar deste não ser complementarmente constituído por materiais dúcteis, foi observado um comportamento dúctil 
do TFML quando submetido a ensaios experimentais de impacto (Capítulo 5), o que justifica a utilização desta abordagem.

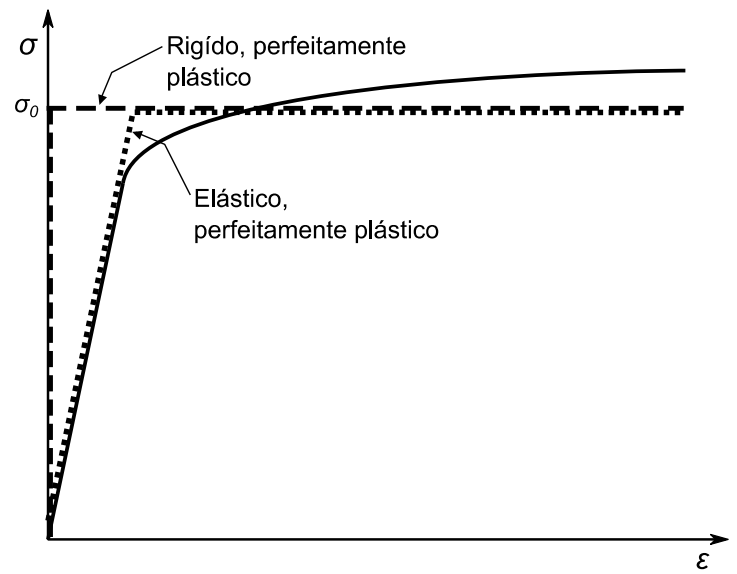

Figura 86: Aproximações rígido-plástico e elasto-plástico perfeito para a curva tensão-deformação de um material dúctil.

Considere uma viga completamente engastada com comprimento $l$ e secção transversal retangular de altura $H$ e largura $B$, sendo submetida ao momento externo $M$. Buscando facilitar o entendimento, adota-se um comportamento elástoplástico (Figura 86) no qual o material possui um comportamento elástico linear até a condição de escoamento definida por $\sigma_{0}$, e após esta condição este assume um comportamento plástico-perfeito.

Considere a sequência de distribuição de tensão ao longo da altura da viga, quando submetida a momento externo crescente, apresentada na Figura 87. Uma vez que a viga esteja em regime elástico-linear $\left(M=M_{1}\right)$, tem-se um perfil linear de tensão ao longo da espessura da viga, regido por

$$
\sigma_{x}=-\frac{M y}{I}=-\frac{12 M y}{B H^{3}} .
$$




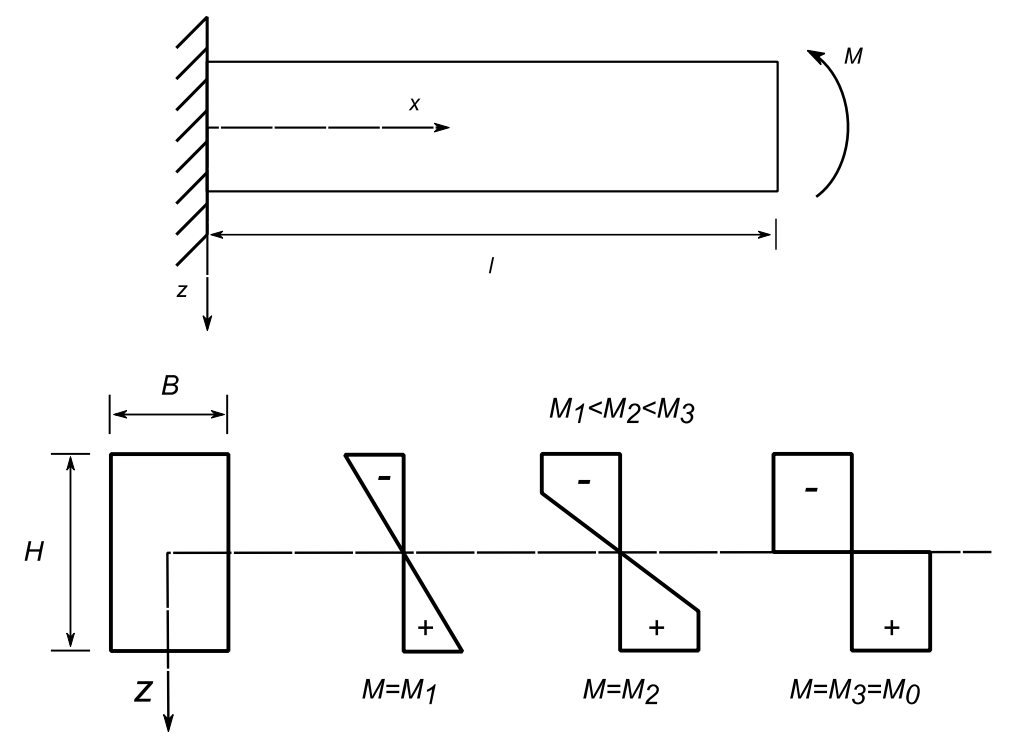

Figura 87: Perfil de tensão de uma viga submetida à flexão.

Quando o momento externo é aumentado, o regime plástico do material é atingido inicialmente nas regiões extremas ao longo da altura da viga. Nestes locais é observada a formação de zonas plásticas com patamares $\sigma= \pm \sigma_{0}$. Em uma condição limite, atinge-se a condição de plastificação total da secção transversal da viga, definida por

$$
M_{0}=2\left(\sigma_{0} B \frac{H}{2}\right)\left(\frac{H}{4}\right)=\frac{\sigma_{0} B H^{2}}{4},
$$

ou, de forma genérica

$$
M_{0}=\int_{A} \sigma_{0} z d A
$$

sendo $M_{0}$ denominado por momento limite ou momento de colapso, uma vez que toda a secção transversal da viga está em regime de deformações plásticas. $\mathrm{Na}$ maioria das aplicações de impacto, o regime elástico linear é pouco significativo quando comparado ao regime plástico. Assim, é aceitável que o regime elástico seja ignorado e uma abordagem rígido-plástica seja adotada. 
Tendo em vista o estudo do impacto em questão, busca-se identificar o momento limite para uma placa plana. Considere uma placa plana circular, com raio $R$, completamente engastada nas extremidades. De forma análoga, considera-se apenas os momento externos radial, $M_{r}$, e circunferencial, $M_{\theta}$, conforme apresentado na Figura 88.

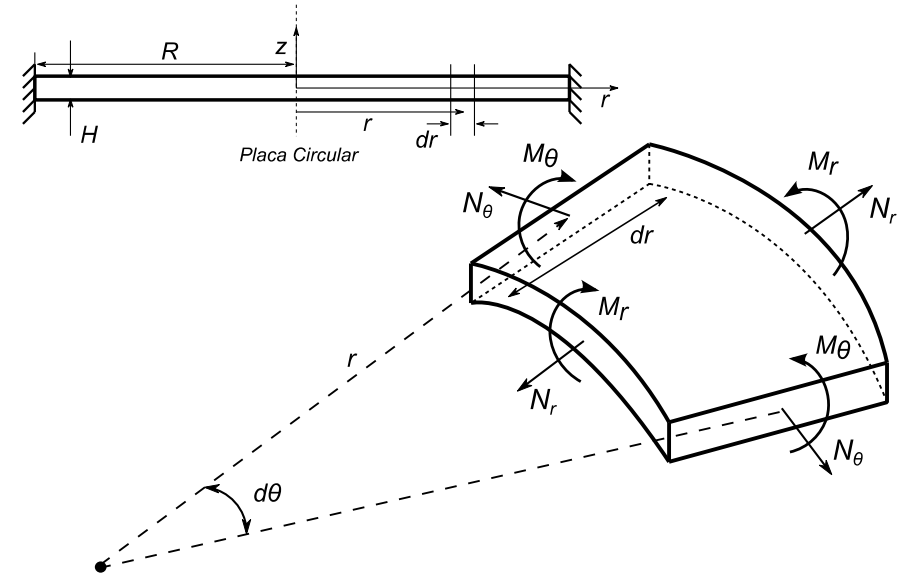

Figura 88: Esforços considerados em um elemento infinitesimal da placa circular.

Com base em (Jones, 1997), para aplicações de impacto em placas circulares, define-se o momento limite ou momento plástico por unidade de comprimento, $M_{0}^{\prime}$, definido por

$$
M_{o}^{\prime}=\int \sigma_{0} z d z
$$

o qual pode ser definido de forma análoga para a direção radial, $M_{r, 0}^{\prime}$, e circunferencial, $M_{\theta, 0}^{\prime}$.

É importante frisar que o mesmo procedimento adotado para definição do momento limite para vigas e placas pode ser aplicado para identificação de condições limites para tensões normais e cortantes.

Em uma condição de solicitação combinada ou multiaxial, uma vez que o material encontra-se em regime plástico, a combinação entre as solicitações deve satisfazer uma condição de escoamento, como por exemplo, o critério de escoamento de Tresca ou Von-Misses. Este procedimento será melhor abordado no Item 7.3, 
quando o desenvolvimento do modelo teórico para impacto de baixa velocidade é apresentado.

\subsection{MÉTODOS DE HOMOGENIZAÇÃO DE PROPRIEDADES EM MATERIAIS HÍBRIDOS}

Buscando realizar a modelagem teórica do comportamento do TFML com a utilização de aproximação rígido-plástica, tem-se a necessidade da identificação de uma tensão de escoamento equivalente para o TFML, ou $\sigma_{0}^{e q}$.

A Regra das misturas (Daniel e Ishai, 2006) é utilizada para obtenção de propriedades equivalentes de compósito, a partir de uma análise micromecânica.Apesar de sua aparente simplicidade, esta abordagem possibilita uma boa aproximação para propriedades não-lineares de compósitos. No tocante de materiais híbridos, em (Reyes e Cantwell, 2000) a Regra das misturas foi utilizada para a identificação de condições limites da curva tensão-deformação de FML a partir das propriedades de seus constituintes em separado. Neste caso, está regra é aplicada de forma macroscópica, de forma distinta do utilizado usualmente em análise de materiais compósitos.

Esta abordagem considera a fração volumétrica, $V_{i}$, e a propriedade em questão de cada constituinte em separado, $P_{i}$, para a definição de uma propriedade equivalente, $P_{e q}$, da seguinte forma

$$
P_{e q}=P_{1} V_{1}+P_{2} V_{2},
$$

com $V_{1}+V_{2}=1$, idealmente.

Com relação à identificação da tensão de escoamento equivalente para o TFML, a equação (25) toma a seguinte forma

$$
\sigma_{0}^{e q}=\sigma_{0}^{a l} V_{a l}+\sigma_{0}^{s r p p} V_{s r p p} .
$$


Uma vez que todas as camadas do TFML possuem mesma área, a fração volumétrica está diretamente relacionada com a espessura dos constituintes, $h_{i}$, e total, $H$ da placa. Assim, considerando um TFML com $i$ camadas de alumínio e $j$ camadas de SRPP, a equação (26) pode ser reescrita na forma

$$
\sigma_{0}^{e q}=\frac{\sigma_{0}^{a l} \sum h_{i}^{a l}+\sigma_{0}^{s r p p} \sum h_{j}^{s r p p}}{H} .
$$

É importante frisar que a lei da mistura não considera a distribuição das camadas ao longo da espessura do material. Assim não há uma diferenciação entre diferentes configurações de TFML.

Buscando considerar a distribuição dos constituintes do TFML, uma formulação para homogeneização de propriedades deste foi desenvolvida, baseando-se Teoria Clássica da Laminação, buscando equivalência no momento plástico limite por unidade de largura $M_{0}^{\prime}$.

(a)

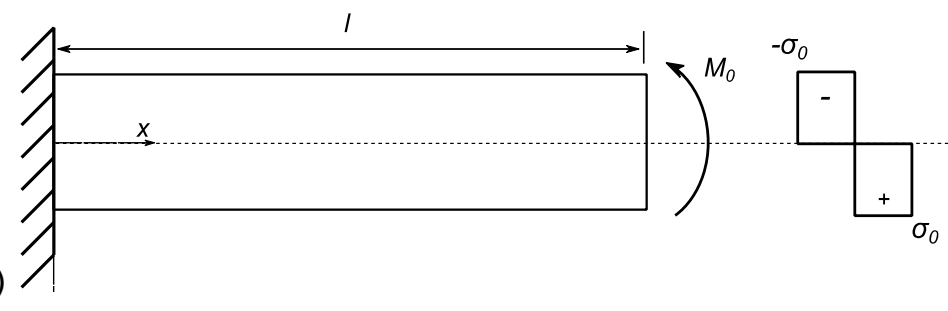

(b)

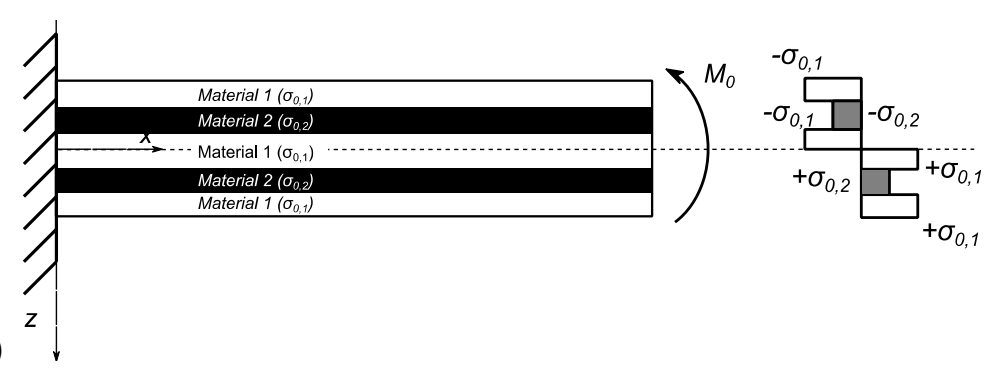

Figura 89: Perfil de tensão em uma placa monolítica e laminada híbrida.

A Figura 89(a) representa a distribuição de tensões ao longo da altura de uma viga constituída por material monolítico em condição de escoamento completo da secção transversal. Conforme apresentado anteriormente, com a hipótese de mate- 
rial rígido-plástico, o perfil de tensão apresenta valores de $+\sigma_{0}$ e $-\sigma_{0}$ para as faces em tensão e compressão, respectivamente.

Por sua vez a Figura 89(b) apresenta o perfil de tensão ao longo da altura para uma viga de TFML de configuração 3/2. Neste caso, uma vez que a viga esteja em regime plástico, o mesmo comportamento pode ser observado, no entanto a tensão apresenta valores alternado de $+\sigma_{o}^{a l}$ e $+\sigma_{o}^{\text {srpp }}$ para a face em tensão, e valores alternado de $-\sigma_{o}^{a l} \mathrm{e}-\sigma_{o}^{\text {srpp }}$ para a face em compressão.

Para o caso de a viga de TFML, o momento plástico limite por unidade de largura pode ser obtido a partir de

$$
M_{0}^{\prime}=\int \sigma_{0}^{i} z d z .
$$

Considerando um material equivalente, com mesma espessura $H$ e mesmo momento plástico limite $M_{0}^{\prime}$, tem-se

$$
M_{0}^{\prime}=\int \sigma_{0}^{e q} z d z .
$$

Assim, as equações (28) e (29) podem ser igualadas, de forma que

$$
\int \sigma_{0}^{e q} z d z=\int \sigma_{0}^{i} z d z .
$$

Com a aplicação da equação (30) é possível identificar uma tensão de escoamento equivalente, $\sigma_{0}^{e q}$, a partir da conservação do momento plástico limite por unidade de largura do material, $M_{0}^{\prime}$. É importante enfatizar que neste caso, as características geométricas do TFML são consideradas para a identificação da propriedade equivalente. O cálculo da integral definida na equação (30) é aplicado especificamente para cada configuração de material, podendo ser utilizadas simplificações e procedimentos cabíveis para cada caso. 


\subsection{OBTENÇÃO DE PROPRIEDADES PARA OS MATERIAIS ESTUDADOS}

Após extensa pesquisa bibliográfica, não foi encontrado um procedimento para a definição de uma aproximação rígido-plástica a partir da curva tensãodeformação. Apesar da aparente simplicidade do procedimento, foram observadas que pequenas variações nesta aproximação podem causar significativas diferenças no resultado obtido. Além disso, o reforço utilizado no TFML não é um material dúctil, o que torna este procedimento menos preciso.

Uma vez que não há uma definição exata de um procedimento para tanto, três cenários foram definidos, considerando propriedades máximas, mínimas e intermediárias. Tomando como base as curvas tensão-deformação do alumínio 2024T3 e SRPP Pure, ambas apresentadas Figura 90, nestas foram definidos três possíveis níveis da tensão $\sigma_{0}$ : um valor máximo, $\sigma_{0,3}$; mínimo, $\sigma_{0,1}$; e intermediário, $\sigma_{0,2}$. Com relação ao SRPP Pure, por este não apresentar um comportamento dúctil, o valor de $\sigma_{0,1}$ foi definido como o final do comportamento não-linear obtido na porção inicial da curva. Os valores de tensão definidos para cada material estão apresentados na Tabela 40.
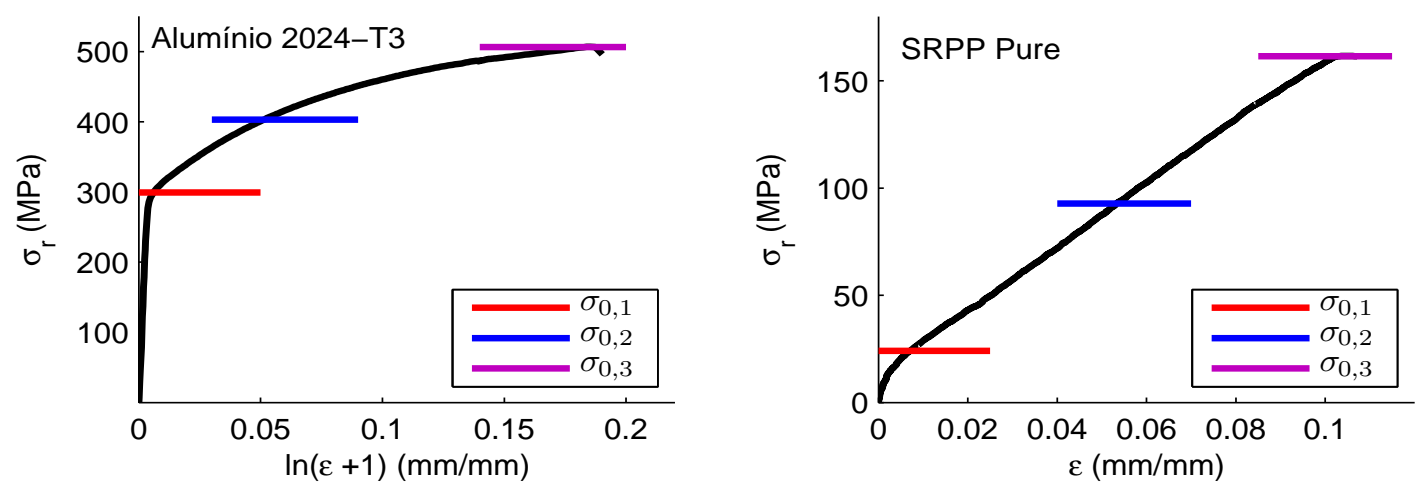

Figura 90: Definição de tensão $\sigma_{0}$ para (a) alumínio 2024-T3 e (b) SRPP Pure. 
Tabela 40: Valores de tensão plástica perfeita definidas para o Alumínio 2024-T3 e SRPP Pure.

\begin{tabular}{cc}
\hline \multicolumn{2}{c}{ Alumínio 2014-T3 } \\
\hline$\sigma_{0,1}^{a l}$ & $229,40 \mathrm{MPa}$ \\
$\sigma_{0,2}^{a l}$ & $402,93 \mathrm{MPa}$ \\
$\sigma_{0,3}^{a l}$ & $506,50 \mathrm{MPa}$ \\
\hline
\end{tabular}

\begin{tabular}{cc}
\hline \multicolumn{2}{c}{ SRPP Pure } \\
\hline$\sigma_{0,1}^{s r p p}$ & $24,12 \mathrm{MPa}$ \\
$\sigma_{0,2}^{s r p p}$ & $92,81 \mathrm{MPa}$ \\
$\sigma_{0,3}^{s r p p}$ & $161,50 \mathrm{MPa}$ \\
\hline
\end{tabular}

Com base nos valores de tensão definidos na Tabela 40 e parâmetros geométricos dos TFMLs apresentados nos Capítulos 4 e 5, foram definidas as aproximações rígido-plásticas para os materiais a partir da lei da misturas (LM) e conservação do momento plástico equivalente (CMPE). Em ambos os casos, foram definidos três cenários, sendo considerados valores mínimos, máximos e intermediários de tensão. Os resultados estão apresentados nas Tabelas 41 a 43.

Tabela 41: Valores de tensão plástica equivalente para a amostra P3A043.

\begin{tabular}{ccc}
\hline & \multicolumn{2}{c}{ P3A043 } \\
\hline $\begin{array}{c}\text { Regra das mis- } \\
\text { turas (MPa) }\end{array}$ & $\begin{array}{c}\text { Conservação do } \\
\text { momento plástico (MPa) }\end{array}$ \\
\hline$\sigma_{0,1}^{e q}$ & 164,79 & 187,83 \\
$\sigma_{0,2}^{e q}$ & 251,27 & 277,22 \\
$\sigma_{0,3}^{e q}$ & 337,80 & 366,67 \\
\hline
\end{tabular}

Tabela 42: Valores de tensão plástica equivalente para a amostra P4B039.

\begin{tabular}{ccc}
\hline & \multicolumn{2}{c}{ P4B039 } \\
\hline & $\begin{array}{c}\text { Regra das mis- } \\
\text { turas (MPa) }\end{array}$ & $\begin{array}{c}\text { Conservação do } \\
\text { momento plástico (MPa) }\end{array}$ \\
\hline$\sigma_{0,1}^{e q}$ & 183,23 & 205,53 \\
$\sigma_{0,2}^{e q}$ & 272,04 & 297,16 \\
$\sigma_{0,3}^{e q}$ & 360,91 & 388,86 \\
\hline
\end{tabular}


Tabela 43: Valores de tensão plástica equivalente para a amostra P5A044.

\begin{tabular}{ccc}
\hline \multicolumn{2}{c}{ P5A044 } \\
\hline & $\begin{array}{c}\text { Regra das mis- } \\
\text { turas (MPa) }\end{array}$ & $\begin{array}{c}\text { Conservação do } \\
\text { momento plástico (MPa) }\end{array}$ \\
\hline$\sigma_{0,1}^{e q}$ & 150,75 & 164,51 \\
$\sigma_{0,2}^{e q}$ & 235,45 & 250,96 \\
$\sigma_{0,3}^{e q}$ & 320,20 & 337,45 \\
\hline
\end{tabular}

\subsection{MODELO TEÓRICO PARA IMPACTO DE BAIXA VELOCIDADE}

O modelo teórico desenvolvido Jones (Jones, 1997; Jones, Kim e Li, 1997; Jones, 2003) foi utilizado para a predição do deslocamento residual central de placas circulares de materiais dúcteis submetidos ao impacto central de baixa velocidade. Nesta tese, este modelo será utilizado para o estudo de TFML em impacto de baixa velocidade. $\mathrm{O}$ modelo considera uma placa circular completamente engastada com diâmetros $2 R$ e espessura $H$, sendo impactada na região central por um elemento de massa $G$ e velocidade $V_{0}$, conforme apresentado na Figura 91.

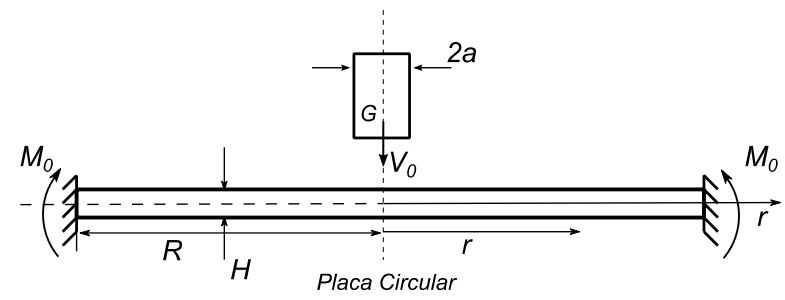

Figura 91: Modelo teórico para impacto de baixa velocidade em chapas planas circulares.

Considerando que a taxa de trabalho externo deve ser igual à taxa de dissipação interna de energia com deformações plásticas, tem-se 


$$
\begin{aligned}
& -G \ddot{W}_{0} \dot{W}_{0}-\int_{A} \mu \ddot{w} \dot{w} d A= \\
& \quad=\int_{A}\left[\left(M_{r}+w N_{r}\right) \dot{\kappa}_{r}+\left(M_{\theta}+w N_{\theta}\right) \dot{\kappa}_{\theta}\right] d A+ \\
& \quad+\sum_{m=1}^{n} \int_{C_{m}}\left(M_{r}+w N_{r}\right)(\partial \dot{w} / \partial r)_{m} d C_{m}+ \\
& \quad+\sum_{u=1}^{v} \int_{C_{u}} Q_{r}(\dot{w})_{u} d C_{u}
\end{aligned}
$$

Os termos do lado esquerdo da equação (31) definem a taxa de trabalho externo oriundo de efeitos de inércia da massa de impacto e chapa. Por sua vez, o primeiro termo do lado direito define a taxa de energia dissipada por deformações axissimétricas de flexão e forças de membrana. O segundo termo define a taxa de dissipação de energia associada às $n$ rótulas plásticas de flexão formadas da chapa durante 0 impacto, do mesmo modo que o terceiro termo define a taxa de energia dissipada nas $v$ rótula plásticas de cisalhamento.

O fenômeno de impacto deve ser dividido em duas fases de movimento: a primeira, dominada por momentos fletores e forças de cisalhamento, e segunda fase, onde os momentos fletores e forças de membranas são dominantes. Segundo (Jones, 1997; Jones, Kim e Li, 1997), a primeira fase do movimento é pouco significativa para eventos onde grandes deformações são observadas. As seguintes hipóteses foram tomadas para o estudo em questão:

- A massa de impacto considerada possui formato cilíndrico de raio $2 a$;

- Apenas o deslocamento vertical da chapa é considerado $\left(\vec{w}(r)=w_{z}(r)\right)$;

- O material da chapa de impacto é considerado rígido-plástico;

- A primeira fase do movimento é desconsiderada $\left(Q_{r}=0\right)$;

- Um perfil linear de velocidade da placa durante o impacto é considerado, de modo que o deslocamento vertical da chapa impactada, $w$, seja

$$
\begin{aligned}
& \dot{w}=\dot{W}_{0}, \text { para } 0<\mathrm{r} \leq \mathrm{a} \\
& \dot{w}=\dot{W}_{0}\left(\frac{R-r}{R-a}\right), \text { para } \mathrm{a}<\mathrm{r}<\mathrm{R}
\end{aligned}
$$


- O perfil da placa após o impacto está apresentado na Figura 92, sendo considerada a formação de quatro rótulas plásticas axissimétricas de flexão;

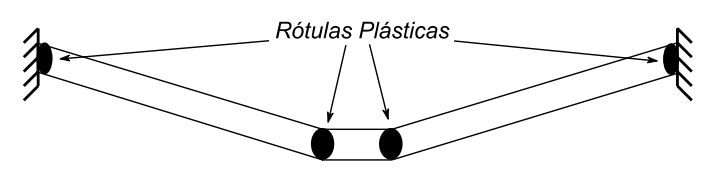

Figura 92: Perfil da placa após o impacto.

Uma abordagem adimensional foi adotada para o desenvolvimento do modelo teórico. Assim, a razão de raios $\rho=a / R$ relaciona o raio da massa $a$ com o raio da chapa $R$; a razão de massas $\gamma=G / \mu \pi R^{2}$ relaciona a massa de impacto $G$ com a massa da placa com densidade superficial $\mu$; e o adimensional de energia cinética $\lambda=\left(\mu V_{0}^{2} R^{2}\right) / M_{0}^{\prime} H$ relaciona a energia cinética inicial com a energia de deformação da placa, sendo $M_{0}=\left(\sigma_{o} H^{2}\right) / 4$.

Buscando facilitar a continuidade do desenvolvimento do modelo teórico aqui apresentado, algumas etapas foram suprimidas, sendo apresentadas em detalhes em Anexo 1. A partir da conservação do momento linear dos instantes anterior e posterior o contato entre a massa e o chapa, obtém-se

$$
\frac{\dot{W}_{0}}{V_{0}}=\left[1+\frac{\left(1+\rho+\rho^{2}\right)}{3 \gamma}\right]^{-1}
$$

Considerando o perfil de velocidade definido pela equação (32), define-se a condição de deslocamento, velocidade e aceleração ao longo da chapa engastada como

$$
\left.\begin{array}{l}
w=W_{0} \\
\dot{w}=\dot{W}_{0} \\
\ddot{w}=\ddot{W}_{0}
\end{array}\right\} \text { para } 0<\mathrm{r} \leq \mathrm{a}
$$




$$
\left.\begin{array}{l}
w=W_{0}\left(\frac{R-r}{R-a}\right) \\
\dot{w}=\dot{W}_{0}\left(\frac{R-r}{R-a}\right) \\
\ddot{w}=\ddot{W}_{0}\left(\frac{R-r}{R-a}\right)
\end{array}\right\} \text { para } \mathrm{a}<\mathrm{r}<\mathrm{R} .
$$

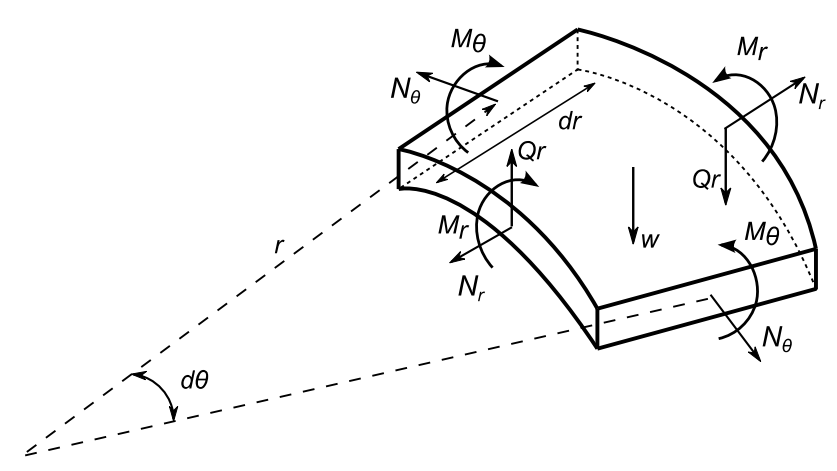

Figura 93: Esforços atuantes em um elemento infinitesimal da placa.

A Figura 93 define os esforços atuantes em um elemento infinitesimal axissimétrico da placa impactada. De acordo com a Teoria de Placas Finas (Timoshenko, 1934), a curvatura circunferencial, $\kappa_{\theta}$, é definida como

$$
\kappa_{\theta}=-\frac{1}{r}\left(\frac{\partial w}{\partial r}\right) \quad \mathrm{e} \dot{\kappa}_{\theta}=-\frac{1}{r}\left(\frac{\partial \dot{w}}{\partial r}\right)
$$

assim $\dot{\kappa}_{\theta}=0$ para $o<r<a$ e $\dot{\kappa}_{\theta}=\dot{W}_{0} /[r(R-a)]$ para $a<r<R$. Por sua vez, a curvatura radial, $\kappa_{r}$, é definida por

$$
\kappa_{r}=-\left(\frac{\partial^{2} w}{\partial r^{2}}\right) \text { e } \dot{\kappa}_{r}=-\left(\frac{\partial^{2} \dot{w}}{\partial r^{2}}\right),
$$

sendo $\dot{\kappa}_{r}=0$ para $0<r<a$ e $a<r<R$.

A deformação radial, $\varepsilon_{r}$, é definida por:

$$
\varepsilon_{r}=\frac{1}{2}\left(\frac{\partial w}{\partial r}\right)^{2} \text { e } \dot{\varepsilon}_{r}=\frac{\partial w}{\partial r} \cdot \frac{\partial \dot{w}}{\partial r},
$$


concluindo-se que $\dot{\varepsilon}_{r}=0$ para $0<r<a$, e $\dot{\varepsilon}_{r}=\left(W_{0} \dot{W}_{0}\right) /(R-a)^{2}$ para $a<r<R$. Em função do perfil de velocidade da placa adotado (equação (32)), pode-se concluir que $\varepsilon_{\theta}=0$. Considerando as singularidades onde a Teoria de Placas Finas não é aplicável, para $r=a$ tem-se $\dot{\kappa}_{r}>0, N_{r}=N_{0}$ e $M_{r}=M_{0}$. Assim como em $r=R$ temse $\dot{\kappa}_{r}<0, N_{r}=N_{0}$ e $M_{r}=-M_{0}$.

É importante enfatizar que, pelo motivo da formulação considerar um modelo de material rígido-plástico, este se encontra permanentemente em condição regime plástico, devendo o acoplamento entre as diferentes solicitações satisfazer uma condição de escoamento. Para o estudo em questão, a condição de escoamento adotada foi definida por (Jones, Kim e Li, 1997), a qual relaciona o momento fletor $M$ e esforços cortantes $N$ como

$$
\frac{M_{r}^{\prime}}{M_{0}^{\prime}}+\left(\frac{N_{r}}{N_{0}}\right)^{2}=1
$$

e

$$
\frac{M_{\theta}^{\prime}}{M_{0}^{\prime}}+\left(\frac{N_{\theta}}{N_{0}}\right)^{2}=1
$$

ou simplesmente

$$
\frac{M^{\prime}}{M_{0}^{\prime}}+\left(\frac{N}{N_{0}}\right)^{2}=1
$$

Buscando simplificar a implementação analítica da condição de escoamento, a equação (38) foi utilizada, sendo considerado o quadrado circunscrito a esta, conforme apresando na Figura 94. Assim, com base nas considerações apresentadas anteriormente e simplificação da condição de escoamento, tem-se $M_{\theta}=M_{0}$, $-N_{0}<N_{\theta}<N_{0},-M_{0}<M_{r}<M_{0}$ e $N_{r}=N_{0}$ para $a<r<R$. 


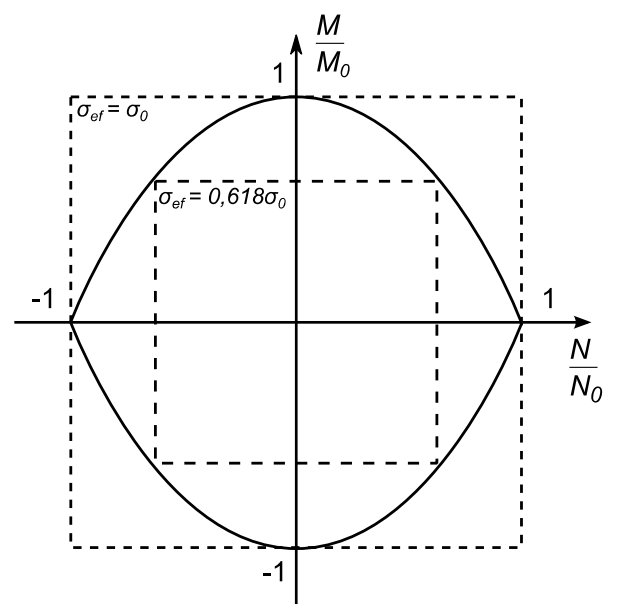

Figura 94: Condição de escoamento definindo o acoplamento entre momento fletor e tensão de membrana.

Com base nas considerações acima apresentadas, a equação (31) pode ser desenvolvida, obtendo a expressão

$$
\frac{W_{\max }}{H}=\frac{1}{(1+\rho)}\left\{\left[1+\frac{3 \gamma^{2} \lambda\left(1-\rho^{2}\right)\left(6 \gamma+1+2 \rho-3 \rho^{2}\right)}{8\left(3 \gamma+1+\rho+\rho^{2}\right)^{2}}\right]^{1 / 2}-1\right\},
$$

a qual define o deslocamento central adimensionalizado $W_{\max } / H$ em função de aspectos geométricos do placa, condições iniciais e propriedade do material. O procedimento detalhado para a obtenção da equação (39) é apresentado em ANEXO 2.

Em função da abordagem adotada para simplificação da condição de escoamento apresentada na Figura 94, dois cenários devem ser avaliados na equação (39). Em uma primeira condição, considera-se o quadrado circunscrito a relação de escoamento, no qual se tem $\sigma_{0}^{\text {eff }}=\sigma_{0}$. Por sua vez, a segunda condição considera o quadrado inscrito, cuja relação é $\sigma_{0}^{e f f}=0,618 \sigma_{0}$. Desse modo, o modelo teórico fornece limite superior e inferior entre os quais o deslocamento central é esperado.

Deve-se frisar que critérios de falha não são considerados neste modelo teórico, assim este é aplicável para grandes deformações plásticas, sem ocorrência de falha no material. 
Com relação ao estudo do impacto em chapas de TFML, para este modelo teórico proposto, a propriedade do material é considerada a partir parâmetro $\sigma_{0}^{e q}$, conforme procedimento descrito no Item 7.3.

\subsubsection{Resultados e discussões}

Considerando a equação (39), aspectos geométricos dos TFML estudados apresentados no Capítulo 4 e as propriedades plásticas equivalentes definidas no Item 7.3, pode-se obter o deslocamento residual central da placa após o impacto.

Na Figura 95 são apresentados os resultados para tais materiais, sendo considerada a Regra das misturas para obtenção da propriedade equivalente. A Figura 96 é apesenta a mesma análise, sendo utilizado o procedimento de conservação de $M_{0}$. Em tais figuras são apresentados os limites superiores e inferiores definidos pelo modelo teórico, sendo considerados tensões equivalentes mínimas, médias e máximas; definidas por $\sigma_{0,1}^{e q}, \sigma_{0,2}^{e q}$ e $\sigma_{0,3}^{e q}$ respectivamente. O comportamento do material obtido experimentalmente foi apresentado pelo deslocamento central residual após o impacto adimensional, $W_{f, r e s} / H$, assim como deslocamento central máximo durante $\mathrm{o}$ impacto, $W_{f, \max } / H$. 

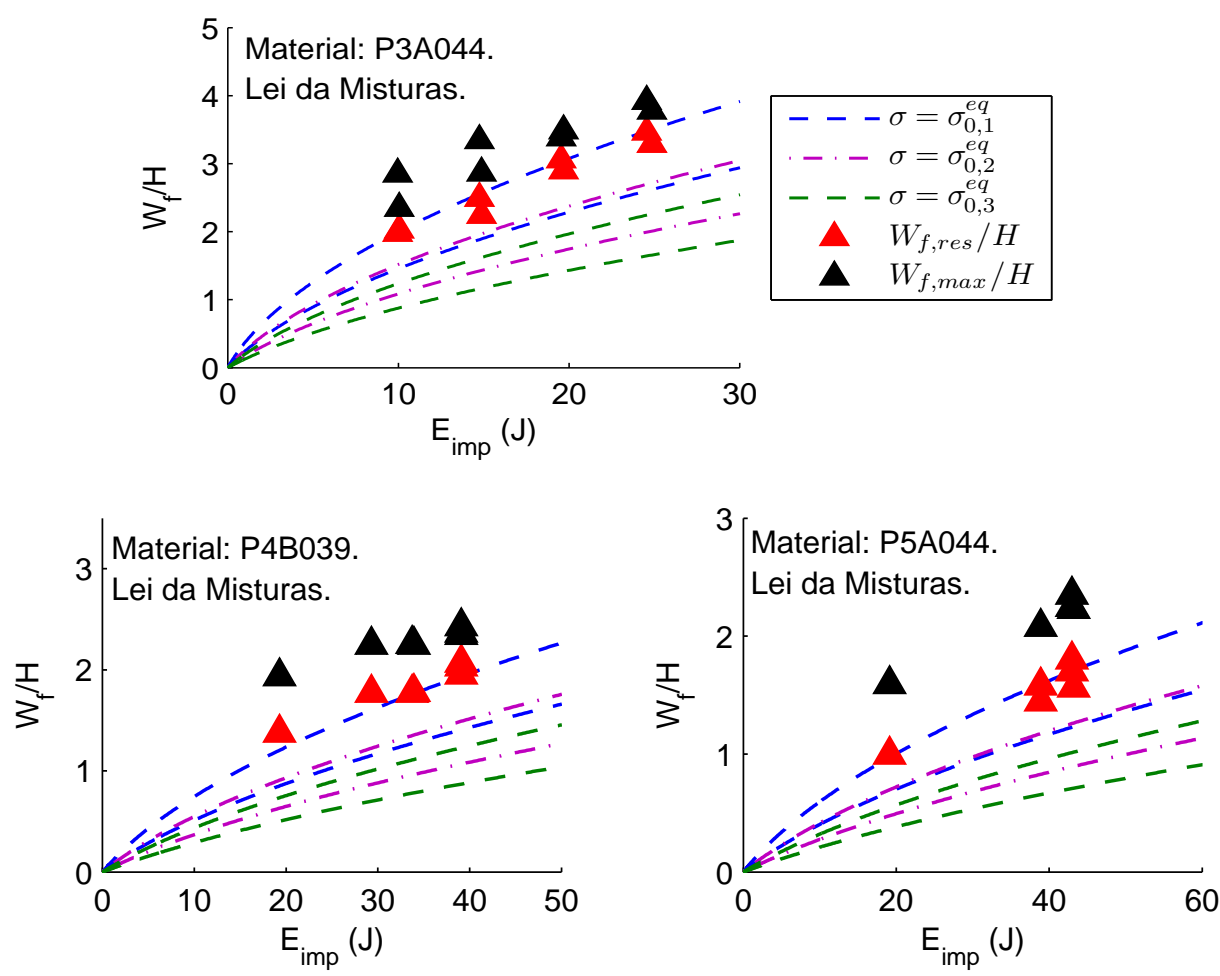

Figura 95: Predição do deslocamento residual para placas circulares de TFML submetidas ao impacto central, utilizando Regra das misturas para obtenção de propriedades equivalentes.
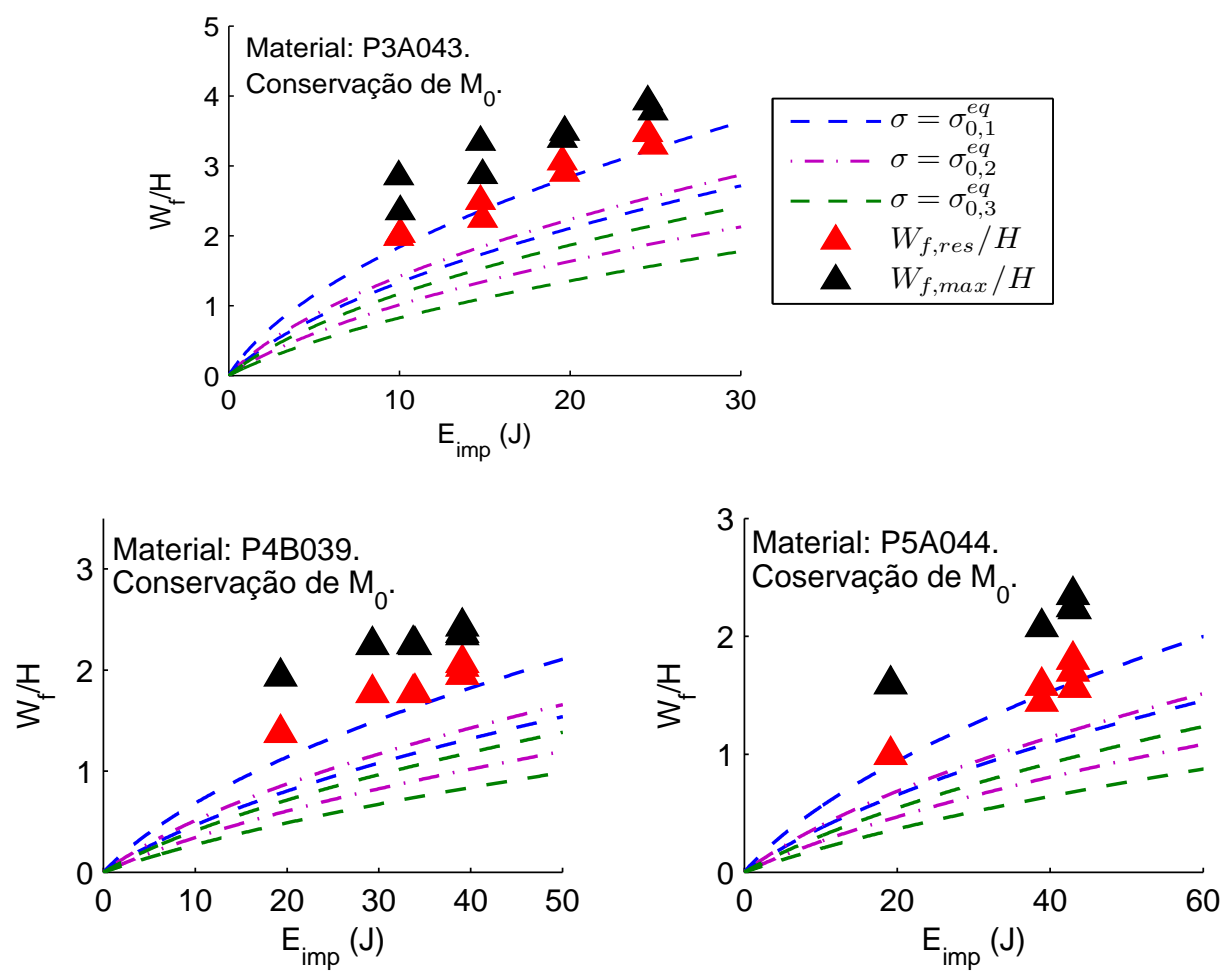

Figura 96: Predição do deslocamento residual para placas circulares de TFML submetidas ao impacto central, utilizando Técnica da Conservação de $M_{0}$ para obtenção de propriedades equivalentes. 
Com base nos resultados obtidos, foi observado que tanto a Regra das misturas como a Conservação de $M_{0}$ fornecem resultados semelhantes, sendo que a primeira apresenta resultados levemente mais concordantes com resultados experimentais obtidos.

Não foi observada uma boa correlação para os resultados de deslocamento residual máximo durante o impacto, $W_{f, \max } / H$. Este aspecto é previsível, uma vez que o modelo teórico considera uma aproximação rígido-plástica para o material e o deslocamento máximo está diretamente relacionado ao comportamento elástico deste durante o impacto.

Em todos os casos, foi observado que a melhor correlação com resultados experimentais foi obtida quando $\sigma_{0,1}^{e q}$ é considerado, ou seja, quando os menores níveis de tensão dos materiais são considerados. A consideração do valor inferior para tensão de escoamento do material é justificada pelo motivo do modelo considerar um comportamento médio para todo o material da placa, sendo que visualmente e numericamente (conforme a ser apresentado com o Capítulo 8) é observado que os maiores níveis de tensão (e deformação) ocorrem apenas nas regiões periféricas e centrais da placa. Assim, apenas nestas regiões seriam observados maiores níveis de tensão dentro do regime plástico, diferentemente das demais regiões do espécime.

Foi observado que todos os resultados experimentais estão localizados próximos à condição de limite superior definido pelo modelo $\left(\sigma^{e f}=0,618 \sigma_{0}\right)$. Um possível motivo para este fato seria a existência de materiais poliméricos no interior do TFML, o que reduz a resistência e favorece a plasticidade deste.

De maneira geral foi observado que o modelo teórico de Jones é capaz de prever o deslocamento central residual de uma placa de TFML após o impacto de baixa velocidade, uma vez que níveis mínimos de tensões plásticas sejam considerados e que a Regra das misturas seja utilizada para a homogeneização das propriedades do material. 


\subsection{MODELO TEÓRICO PARA IMPACTO DE ALTA VELOCIDADE}

O modelo teórico apresentado em por Reid e Wen (Reid e Wen, 2000) foi desenvolvido com base de observações de resultados experimentais de impacto em estruturas sanduiches. O aspecto diferencial deste modelo está em considerar efeitos não localizados para o cálculo de limite balístico, ou seja, as condições de contorno. Com base em (Jones, 1997) e outros estudos como (Karagiozova et al., 2010) e (Mott et al., 2007), os efeitos de bordas não são considerados para o cálculo do comportamento do material em impacto de alta velocidade. Nestes casos, considera-se que não há tempo suficiente para que ocorra a propagação de ondas ao longo do material até o contorno, sendo considerados apenas efeitos localizados à região de impacto. Este hipótese é satisfatória em condições de impacto em chapas finas, com tamanho da placa substancialmente maior que o do projétil e em condições de impacto de velocidade elevadas (usualmente acima de $200 \mathrm{~m} / \mathrm{s}$ ) ou explosões.

Apesar disso, esta hipótese pode se questionada em condições de impacto em velocidade moderadamente alta, durante eventos de perfuração ou condições onde as dimensões da placa não são substancialmente maiores que o projétil. Para o estudo experimental de impacto apresentado no Capítulo 4 as velocidades de impacto estão em torno de $80 \mathrm{~m} / \mathrm{s}$ a $150 \mathrm{~m} / \mathrm{s}$, com projéteis de $20 \mathrm{~mm}$ de diâmetro em placas com $80 \mathrm{~mm}$ de diâmetro. Além disso, visualmente foi observado que a periferia da chapa (condição de contorno) influenciou o comportamento do material. Por este motivo, o modelo teórico de Reid e Wen em questão foi adotado para o estudo do comportamento do TFML, uma vez que este possibilita considerar o comportamento global da chapa para cálculo do limite balístico.

Com base no procedimento apresentado em (Wen, Jones e Bulson, 1992), a energia dissipada durante o impacto por ser dividida em duas partes: uma relacionada com a energia dissipada por deformações locais, $E_{l}$, e outra associada com deformações globais, $E_{g}$, da seguinte forma

$$
E_{f}=E_{l}+E_{g}
$$


onde $E_{f}$ é a energia total absorvida pela placa durante a penetração.

É assumido que a energia localizada dissipada pela perfuração de indentadores semi-hemisféricos pode ser definida por

$$
E_{l}=\frac{\pi D^{2} H \sigma_{u} \varepsilon_{u}}{8}
$$

ou na forma adimensionalizada pelo termo $\sigma_{u} D^{3}$ como

$$
\frac{E_{l}}{\sigma_{u} D^{3}}=\frac{\pi \varepsilon_{u}}{8}\left(\frac{H}{D}\right)
$$

no qual $\sigma_{u}$ e $\varepsilon_{u}$ são tensão ultima e deformação ultima, respectivamente.

Sendo adotado o diâmetro do projétil $D$ (sendo $D=2 r$ ) como base para a adimensionalização de comprimento, experimentalmente foi observado que a energia dissipada associada a deformações globais pode ser definida por

$$
\frac{E_{g}}{\sigma_{u} D^{3}}=A\left(\frac{L}{D}\right)^{\beta_{1}}\left(\frac{H}{D}\right)
$$

sendo $L$ a largura da chapa quadrada impactada e os termos $A$ e $\beta_{1}$ são definidos a partir de resultados experimentais.

Substituindo $E_{l}$ e $E_{g}$ nas equações (42) e (43) na equação (40), tem-se

$$
\frac{E_{f}}{\sigma_{u} H D^{2}}=\frac{\pi \varepsilon_{u}}{8}+A\left(\frac{L}{D}\right)^{\beta_{1}}
$$

Com base em observações experimentais, Reid e Wen definem o fator intensificador dinâmico

$$
E_{f d}=\phi E_{f}
$$


sendo

$$
\begin{array}{ll}
\phi=1+\beta_{2}\left(\frac{V_{i}}{V_{0}}\right), & \left(\mathrm{V}_{i}<V_{0}\right) \\
\phi=1+\beta_{2}, & \left(\mathrm{~V}_{i}>V_{0}\right)
\end{array}
$$

onde $\beta_{2}$ é uma constante empírica, $V_{i}$ a velocidade de impacto e $V_{0}$ velocidade de transição definida por

$$
V_{0}=\sqrt{\frac{E^{e q}}{\rho^{e q}}} \varepsilon_{f} .
$$

Neste, nota-se que o parâmetro $\sqrt{E / \rho}$ define a velocidade de propagação de ondas elásticas no interior do material, sendo $E^{e q}$ e $\rho^{e q}$ o módulo elástico na direção da lâmina e densidade volumétrica equivalentes do material. Assim, é fácil observar o parâmetro $\phi$ é diretamente relacionado com a influência dos efeitos de propagação de onda no comportamento do material, ou seja, a influência de efeitos localizado e não-localizados no comportamento do material. Vale ressaltar que, quando o material é solicitado acima da velocidade crítica $V_{0}$, os esforços transmitidos além da região central do impacto são pequenos.

Combinando as equações (45) e (46), com a equação (44), tem-se

$$
\frac{E_{f d}}{\phi \sigma_{u} H D^{2}}=\frac{\pi \varepsilon_{u}}{8}+A\left(\frac{L}{D}\right)^{\beta_{1}}
$$

Finalmente, considerando a expressão da energia cinética $E=m v^{2} / 2$, tem-se uma expressão para o limite balístico como

$$
V_{b}=\sqrt{\left(\frac{2 \phi \sigma_{u} H D^{2}}{G}\right)\left[\frac{\pi}{8} \varepsilon_{u}+A\left(\frac{L}{D}\right)^{\beta_{1}}\right]} .
$$


Com base em (Reid e Wen, 2000), para $H / D<2$, deve-se adotar $A=0,05, \beta_{1}=1 / 3 \mathrm{e}$ $\beta_{2}=4,5$.

\subsubsection{Resultados e discussões}

O modelo teórico de Reid-Wen para limite balístico (equação (49)) foi aplicado para as amostras de TFML estudadas, sendo considerados aspectos geométricos (Capítulo 4), resultados experimentais (Capítulo 5) e propriedades de tais constituintes (Capítulo 6). Conforme apresentado no Item 7.2, a Regra das misturas foi utilizada no cálculo de tensão ultima equivalente, $\sigma_{u}^{e q}$, e deformação ultima equivalente, $\varepsilon_{u}^{e q}$

. O método de homogeinização de propriedades pela Conservação do Momento Plástico não foi utilizado, pelo motivo deste modelo não realizar uma abordagem plástica para estudo do fenômeno de impacto. Uma vez que o modelo apresentado considera uma placa quadrada, foi definida uma dimensão lateral equivalente como $L=\sqrt{\pi R^{2}}$, a fim de que seja mantida a área total da placa impactada.

É importante ressaltar que a utilização de um modelo teórico que considera efeitos não localizados para a predição do limite balístico é fundamental para análise proposta, uma vez que existe certa proximidade entre o diâmetro do projétil e diâmetro da placa $(R=4 a)$. Assim, apesar da alta velocidade do fenômeno, os efeitos globais de comportamento da chapa e efeitos de borda são relevantes para a definição do limite balístico. Este aspecto também foi observado nos resultados experimentais de impacto de alta velocidade.

A comparação dos resultados provenientes do modelo teórico e resultados experimentais estão apresentados na Tabela 44. Foi possível observar um boa correção entre resultados teóricos e experimentais para todas as configurações de TFML estudadas, apresentando diferenciação de resultados com erro médio de $7,56 \%$. Todos os resultados estimados apresentaram valores menores que os resultados experimentais, com exceção apenas para o material P3A039. Assim, de maneira geral, os resultados fornecidos pelo modelo teórico são em prol da segurança, subestimando a resposta do material. 
Tabela 44: Predição do limite balístico utilizando o modelo teórico de Reid-Wen.

\begin{tabular}{cccc}
\hline Material & $\begin{array}{c}V_{b} \text { Teórico } \\
(\mathbf{m} / \mathbf{s})\end{array}$ & $\begin{array}{c}V_{b} \text { Experimental } \\
(\mathbf{m} / \mathbf{s})\end{array}$ & Erro \\
\hline P3A043 & 61,19 & 62,03 & $-1,36 \%$ \\
P4A044 & 79,42 & 96,56 & $-16,37 \%$ \\
P5B039 & 81,04 & 94,97 & $-16,10 \%$ \\
\hline
\end{tabular}

A partir da análise dos resultados obtidos, foi possível observar que o modelo teórico de Reid-Wen pôde prever substancialmente bem o limite balístico das amostras de TFML em questão.

\subsection{CONSIDERAÇÕES FINAIS}

Neste capítulo foi analisado o desempenho dos modelos teóricos de Jones (Jones, 2003) e Reid-Wen (Reid e Wen, 2000) para a predição do comportamento de TFMLs ao impacto de baixa e alta velocidade, respectivamente.

O modelo de Jones foi capaz de prever o deslocamento central residual da placa de TFML após o fenômeno de impacto de baixa velocidade, uma vez que sejam considerados os menores níveis de tensão dentro do regime plástico do material. A Regra das misturas e Conservação do Momento Plástico Equivalente foram utilizados para identificação de propriedades equivalentes do material, apresentado resultados semelhantes.

O modelo empírico de Reid-Wen, considerando efeitos localizados e nãolocalizados da placa, foi capaz de prever substancialmente bem o limite balístico das amostras testadas, apresentado erro médio de 11,28\%.

Vale frisar que a aplicação destes modelos é satisfatoriamente simples. Os resultados provenientes destes são substancialmente próximos aos resultados experimentais, sendo, portanto, ferramentas poderosas para uma análise preliminar, ou mesmo estudos aprofundados, do comportamento de TFMLs. 


\section{ANÁLISE NUMÉRICA DO IMPACTO EM TFML}

Os programas de elemento finito são ferramentas importantes para o projeto e desenvolvimento de elementos estruturais, uma vez que estes possibilitam reduzir a quantidade necessária de experimentos, os quais demandam tempo, recursos humanos e financeiros. Impulsionado pelo desenvolvimento de supercomputadores e, consecutivamente, o aumento da capacidade de processamento, estes programas têm sido cada vez mais desenvolvidos, possibilitando análises realmente complexas de um determinado fenômeno. Aspectos termodinâmicos, analises de interações fluído-estruturas, plasticidade, grandes deslocamento e deformações, e complexos critérios de falha são frequentemente encontrados em programas de análise computacional.

Apesar disso, não se deve esquecer que uma análise de elementos finitos não deixa de ser um processo matemático, e a facilidade de implementação de modelos complexos pode gerar uma excessiva confiança nos resultados. Assim, cabe ao pesquisador uma análise crítica dos resultados provenientes deste, descartando aqueles duvidosos e não fundamentados.

Em uma análise numérica ocorrem fenômenos como hourglass (modos espúrios de energia), shear-locking (travamento por cisalhamento transversal), e instabilidades numéricas que não possuem uma representação física, mas influenciam substancialmente os resultados obtidos. Desse modo, uma fundamentação teórica é imprescindível.

No intuito de lidar com a incerteza inerente dessa abordagem, o estudo aqui apresentando visa realizar a comparação dos resultados numéricos com o comportamento experimental observado em eventos de impacto e modelos teóricos desenvolvidos.

Neste capítulo será apresentado o desenvolvimento de um modelo numérico para a representação do comportamento do TFML em eventos de impacto de alta e baixa velocidade. Para isso, serão utilizados resultados experimentais apresentado no Capítulo 5 e parâmetros constitutivos identificados no Capítulo 6. Três configurações diferentes de modelos numéricos serão avaliadas com base no comportamento 
esperado das amostras de TFML 4/3 (P4B039), sendo escolhida a melhor configuração entre estas.

\subsection{DESCRIÇÃO DO MODELO NUMÉRICO}

Incialmente os programas comerciais Ls-Dyna, Abaqus e PamCrash foram avaliados para o desenvolvimento do modelo numérico. Com base em resultados obtidos em trabalhos similares desenvolvidos anteriormente, disponibilidade de biblioteca de materiais, possibilidade de controle de parâmetros numéricos, possibilidade de processamento paralelo e conhecimento prévio do autor, o programa Ls-Dyna v.971 foi adotado para o desenvolvimento deste estudo. O pacote comercial Altair HyperWorks 7.0 e Ls-PrePost foram utilizados para pré e pós processamento do modelo.

Uma placa plana circular com $80 \mathrm{~mm}$ de diâmetro foi modelada numericamente com engastamento total da região periférica, sendo considerado a quantidade de camadas e espessuras relativas ao TFML 4/3 (P4B039). Uma esfera rígida com 20 $\mathrm{mm}$ de diâmetro foi modelada utilizando elementos de casca com espessura mínima e a velocidade inicial. Para fins de cálculos de contato, propriedades elásticas de aço carbono ABNT-1020 foram consideradas, assim como características de massa e inércia relativas ao elemento impactante utilizado no evento em análise.

Para simulação de eventos de baixa velocidade de impacto, uma esfera foi modelada numericamente com velocidade inicial e direcionada à parte central da placa circular. A esta foi possibilitada apenas deslocamento perpendicular à placa, de maneira semelhante ao ensaio experimental em martelo de impacto. Por sua vez, no caso de impacto de alta velocidade, o desalinhamento médio observado nos ensaios experimentais é considerado, não são implementadas limitações de deslocamento ou rotações à esfera, mimetizando os ensaios experimentais realizados no canhão lançador de projéteis.

A análise de sensibilidade da malha foi conduzida com as configurações de esfera e chapa descrita anteriormente, tendo em mente a espessura média das camadas que compõem o TFML. Foi considerada uma chapa monolítica com 0,4 mm de espessura e 2 elementos ao longo desta, com parâmetros constitutivos relativos 
ao alumínio 2024-T3, definidos no Capítulo 6. Fora considerada o impacto de 9,0 $\mathrm{m} / \mathrm{s}$, capaz de causar ruptura e transpassando o material. A análise de sensibilidade da malha foi conduzida utilizando o tamanho médio dos elementos centrais de 1,10 $\mathrm{x}$ $1,10 \mathrm{~mm}^{2}$ a $0,17 \times 0,17 \mathrm{~mm}^{2}$, Figura 97 , simulada utilizando a mesma versão do programa e capacidade computacional. O refino fora considerado de forma concomitante nos elementos da chapa e esfera buscando melhor estabilidade numérica no contato. Resultados de velocidade residual e tempo de processamento foram levados em conta para a escolha do tamanho de elemento a ser utilizado. Na Figura 98 são apresentados os resultados obtidos nesta análise.

(a)

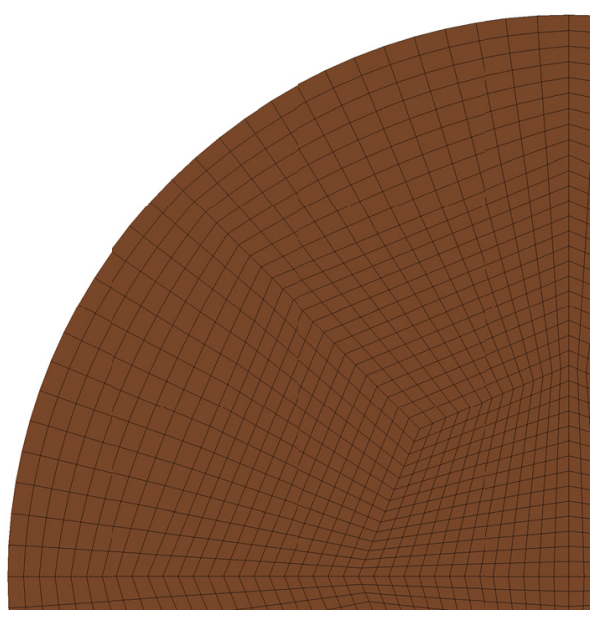

(b)

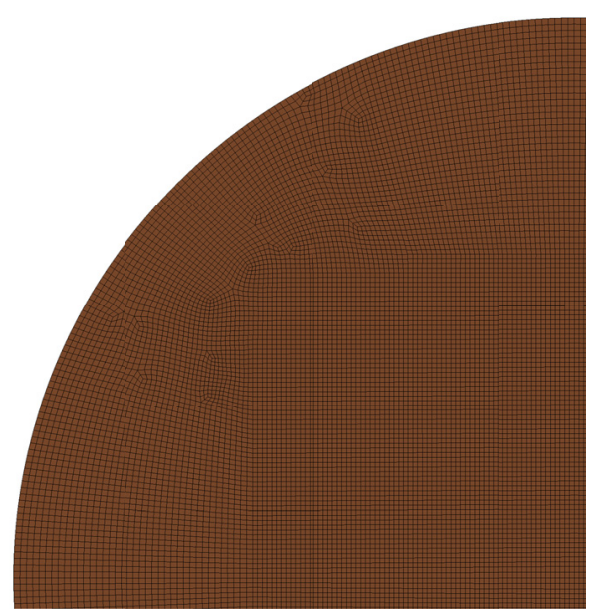

Figura 97: Exemplos de malhas com diferentes tamanhos de elementos: área média dos elementos centrais de (a) $1,10 \times 1,10 \mathrm{~mm}^{2}$ e (b) 0,32 $\times 0,32 \mathrm{~mm}^{2}$.

A partir da análise dos resultados apresentado na Figura 98, elementos de $0,34 \times 0,34 \mathrm{~mm}^{2}$ foram considerados como a melhor combinação entre resultado e tempo de simulação, sendo estes utilizados como base para o estudo de impacto no TFML. A malha utilizada para o estudo está apresentada na Figura 99.

Elementos sólidos hexaédricos de 8 nós, com integração seletivamente reduzida (quatro pontos de integração no volume) foram utilizados para a modelagem do metal e reforços, quando utilizado modelo de material MAT-15 e MAT-24, respectivamente. Nos casos onde foi utilizado o modelo de material MAT-58 para o reforço, por limitação do modelo, foram utilizados elementos tipo sólido degenerado, ou "thick-shell", hexaédricos de 8 nós, nos quais é considerada a formulação de ele- 
mentos de casca, com a existência de espessura. Para cada camada do TFML foram utilizados 2 elementos ao longo da espessura.

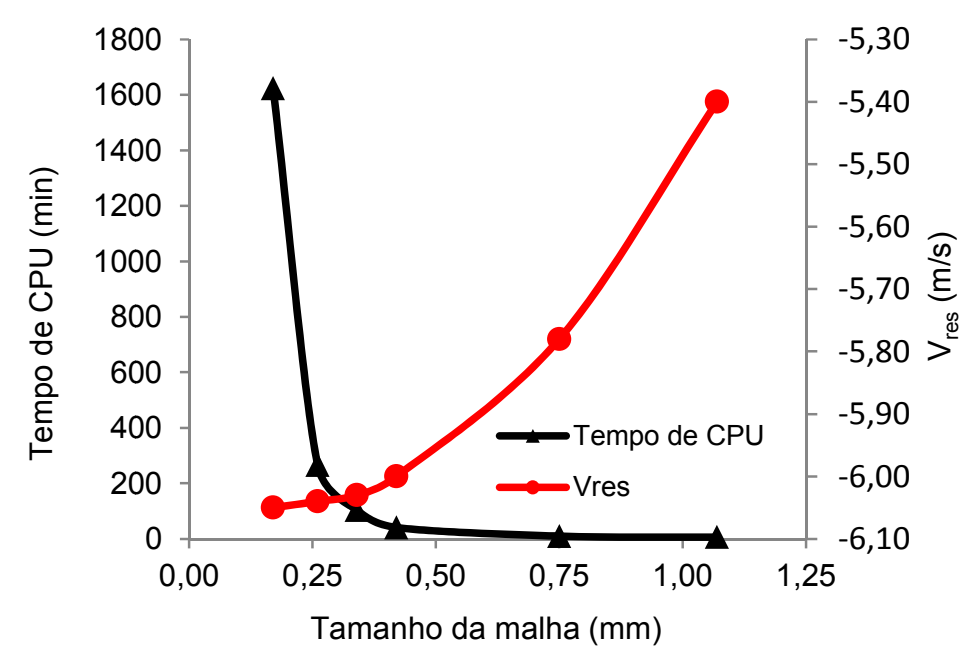

Figura 98: Análise de sensibilidade de malha.
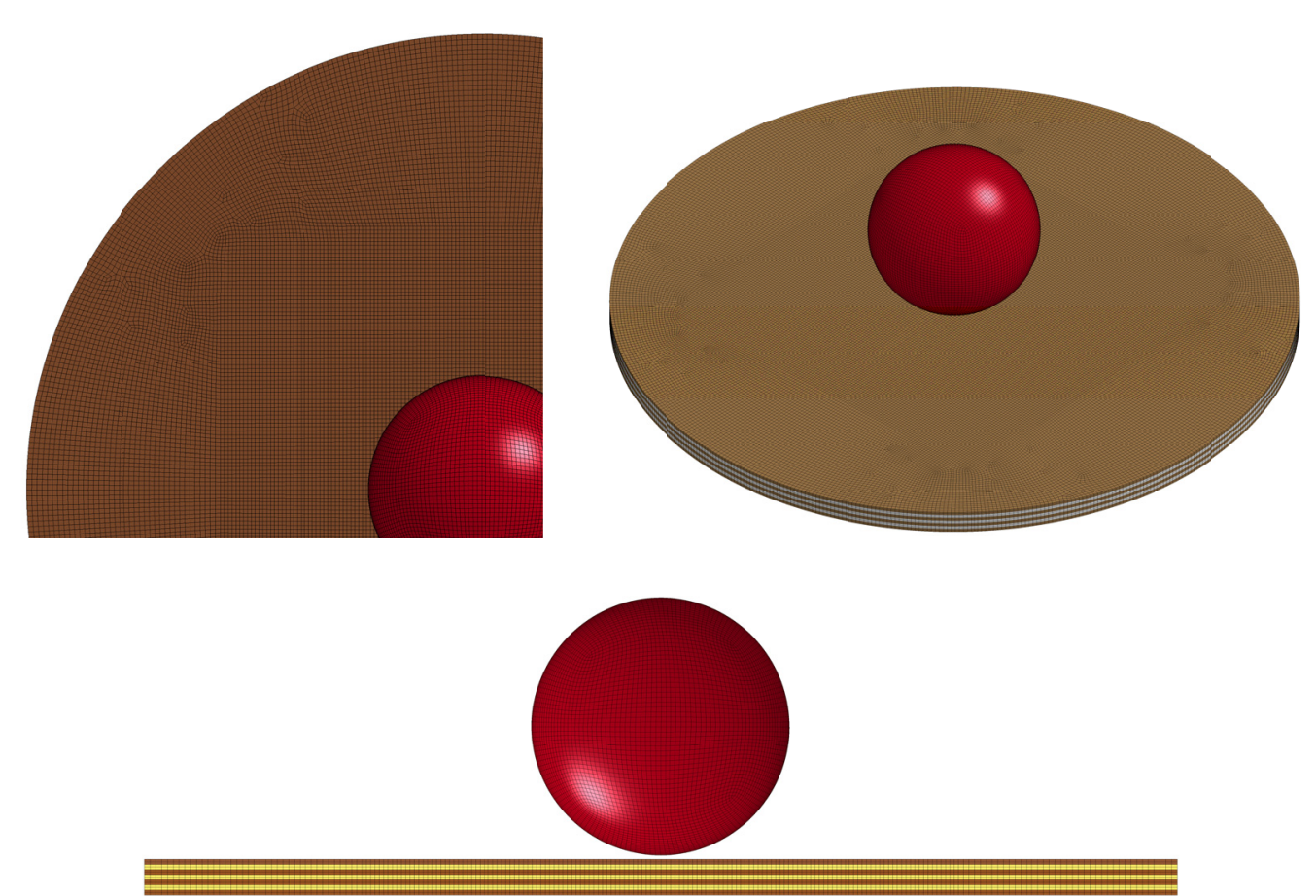

Figura 99: Malha utilizada para análise numérica.

O contato entre a esfera e todas as camadas da placa foi definido pelo tipo ERODING_NODES_TO_SURFACE, o qual possibilita o contato mutuo entra as partes, mesmo na ocorrência de falha e exclusão de elementos. 
A condição de contato entre as camadas do TFML fora definida de duas formas, utilizadas de forma oportuna. Uma forma adotada considera elementos perfeitamente aderidos entre as camadas, havendo compartilhamento de nós. Assim, a separação entre as camadas apenas é dada com a exclusão de um dos elementos da interface. Após a ruptura, o contato entre as camadas é definido por ERODING_NODES_TO_SURFACE de forma mutua entre estas.

A outra forma de modelagem das interfaces entre as camadas do TFML utiliza contato do tipo SURFACE_TO_SURFACE_TIEBREAK. Nesta condição não há compartilhamento de nós, estando estes inicialmente ligados. Quando a tensão na interface atinge condições limite de esforços normais ou cisalhantes, ocorre a separação dos nós, sendo respeitada uma taxa e dissipação de energia por área em direção normal, $G_{I}$, e tangencial, $G_{I I}$. Estes parâmetros foram extraídos do trabalho de Reyes (Reyes e Cantwell, 1998), onde a camada adesiva foi caracterizada, sendo tais parâmetros apresentados na Tabela 45. Após a separação das camadas, o contato entre os elementos é dado por SURFACE_TO_SURFACE_TIEBREACK de forma mutua.

Tabela 45: Propriedades da camada adesiva (Reyes e Cantwell, 1998).

\begin{tabular}{ccccc}
\hline \multicolumn{2}{c}{ Iniciação do dano } & & \multicolumn{2}{c}{ Evolução do dano } \\
\cline { 1 - 1 } \cline { 5 - 5 }$\sigma_{n}$ & $140 \mathrm{MPa}$ & & $G_{I}$ & $2000 \mathrm{~J} / \mathrm{m}^{2}$ \\
$\sigma_{t}$ & $300 \mathrm{MPa}$ & & $G_{I I}$ & $3000 \mathrm{~J} / \mathrm{m}^{2}$ \\
\hline
\end{tabular}

Os modos espúrios de energia (também conhecido por hourglass) são formas inconsistentes que os elementos numéricos podem assumir. Nesta condição, a maIha deformada assume formas tipo "zigue-zague" ou estreitamentos (similares ao formato de uma ampulheta), absorvendo grande parte da energia mecânica existente no modelo. Este fenômeno ocorre em condições onde existem grandes deformações e diferenças de rigidez entre dois elementos. Foi observado que a modelagem o TFML é sensível à ocorrência de hourglass, uma vez que existem elementos metálicos e poliméricos em contato permanentemente, e que ambos são submetidos a grandes deformações. Este fenômeno pode ser controlado com o refino da malha, mudança de formulação de elementos e utilização de algoritmos de controle de hourglass. Para a malha adotada como base para o estudo, a qual é substancial- 
mente refinada, o hourglass pode ser controlado com a utilização do algoritmo de Flanagan-Belytschko, $I H Q=4$, (Hallquist, 2006) disponibilizado pelo programa LsDyna.

O controle do tempo de integração é definido automaticamente pelo programa, sendo consideradas as menores dimensões da malha e velocidade de propagação dos elemento críticos. Este passo de tempo é alterado conforme a deformação dos elementos ao longo da simulação e podem ser escalonados pelo usuário através do parâmetro TSSFAC. Para a simulação do TFML foram utilizados valores de TSSFAC de 0,90 a 0,75 , conforme necessidade observada na análise. $O$ controle de passo de tempo por escalonamento de massa não foi utilizado.

Três configurações de modelo numérico foram desenvolvidas para simulação do TFML. A configuração de modelo numérico denominado MN-1 utiliza elementos sólido e material MAT-24 (sem ortotropia e com efeitos de taxa de deformação) para modelagem das camadas de reforços, sendo adotada uma camada adesiva perfeitamente aderida (nós compartilhados). A configuração de modelo numérico denominado MN-2 modela a camada de reforço de forma semelhante à utilizada em $\mathrm{MN}-1$, porém a camada adesiva é considerada, possibilitando o descolamento destas.

A configuração de modelo numérico MN-3 utiliza elementos "thick-shell" e material MAT-58 (com ortotropia e sem efeitos de taxa de deformação) para modelagem das camadas de reforços, sendo adotada a condição perfeitamente aderida entre as camadas do TFML (nós compartilhados). O modelo utilizando "thick-shell" e com possibilidade de descolamento entre as camadas apresentou instabilidades numéricas que inviabilizaram a sua utilização neste estudo.

Tabela 46: Especificações dos modelos numéricos analisados.

\begin{tabular}{cccc}
\hline & $\begin{array}{c}\text { Modelagem das camadas } \\
\text { metálicas }\end{array}$ & $\begin{array}{c}\text { Modelagem das camadas } \\
\text { de reforço }\end{array}$ & Modelagem da interface \\
\hline MN-1 & Sólido / MAT-15 & Sólido / MAT-24 & Nós compartilhados \\
MN-2 & Sólido / MAT-15 & Sólido / MAT-24 & Contato adesivo \\
MN-3 & Sólido / MAT-15 & Thick-shell / MAT-58 & Nós compartilhados \\
\hline
\end{tabular}

Detalhes sobre os modelos de materiais e critérios de falha estão apresentados nos itens 6.2.2 e 6.3.2. A utilização de elementos adesivos apresentou grande instabilidade numérica, não sendo considerada para este estudo. A Tabela 46 sumariza as configurações de modelos numéricos utilizados. Os resultados provenientes 
destes modelos serão comparados com modelos teóricos e resultados experimentais no Item 8.2.

\subsection{AVALIAÇÃO DO DESEMPENHO DOS MODELOS NUMÉRICOS}

Neste item, o TFML 4/3 (P4B039) será simulado numericamente em eventos de impacto de baixa e alta velocidade, utilizando modelos numéricos MN-1, MN-2 e MN-3. Por fim, será escolhido à configuração de modelo numérico que melhor representa o comportamento do TFML.

\subsubsection{Impacto em baixa velocidade}

$\mathrm{Na}$ Tabela 47 é apresentada a comparação qualitativa de resultados numéricos e experimentais da secção do corte transversal da placa de TFML 4/3 P4B039 após o impacto de baixa velocidade. Observa-se uma boa correlação com os resultados obtidos pelos modelos $\mathrm{MN}-1$ e $\mathrm{MN}-2$ com comportamento global do material. Assim como o resultado experimental, é possível observar ruptura nas camadas internas do material, e pouca quantidade de descolamento das camadas de reforço e metal. Apesar disso, estes modelos apresentaram uma ruptura prematura das camadas de alumínio, com a retirada de lascas e trincas ramificadas, não observadas experimentalmente. $\mathrm{O}$ modelo $\mathrm{MN}-3$ apresentou descolamento acentuado da camada oposta ao impacto com redução localizada da espessura do material.

Todos os modelos numéricos considerados foram capazes de representar as forma de ruptura observada em ensaios experimentais de impacto de baixa velocidade. Tomando-se energia de impacto crescente, primeiramente não é observada falha nas camadas do TFML, sendo então observada falha na face oposta ao impacto $(F O)$ e por fim tem-se a falha na face impactada (FI), ocorrendo de forma combinada com FO. As falhas FO ocorrem geralmente em uma direção principal, eventualmente com ramificações. Por sua vez, a falha FI ocorre de forma circunferencial, na região de contato com o indentador. Na Tabela 53 é apresentada a comparação 
numérico-experimental das formas da ruptura das chapas de TFML em eventos de impacto de baixa velocidade. Na Figura 100 é apresentado o diagrama de falha obtido nos modelos numéricos e ensaio experimental. Uma boa correlação foi observado com o modelo $\mathrm{MN}-3$ com relação à predição da condição de formação de falha visual.

Tabela 47: Comparação qualitativa de resultados numéricos e experimentais.

\begin{tabular}{c|c}
\hline & P4B039 - Vista em corte \\
\hline$V_{\text {in }} / \mathrm{G}$ & $3,55 \mathrm{~m} / \mathrm{s} / 4,65 \mathrm{~kg}$ \\
$\mathrm{MN}-1$ & \\
$\mathrm{MN}-2$ & \\
\hline
\end{tabular}

Tabela 48: Comparação numérica e experimental das formas de falha identificadas para o TFML P3B039 em eventos de impacto de baixa velocidade.

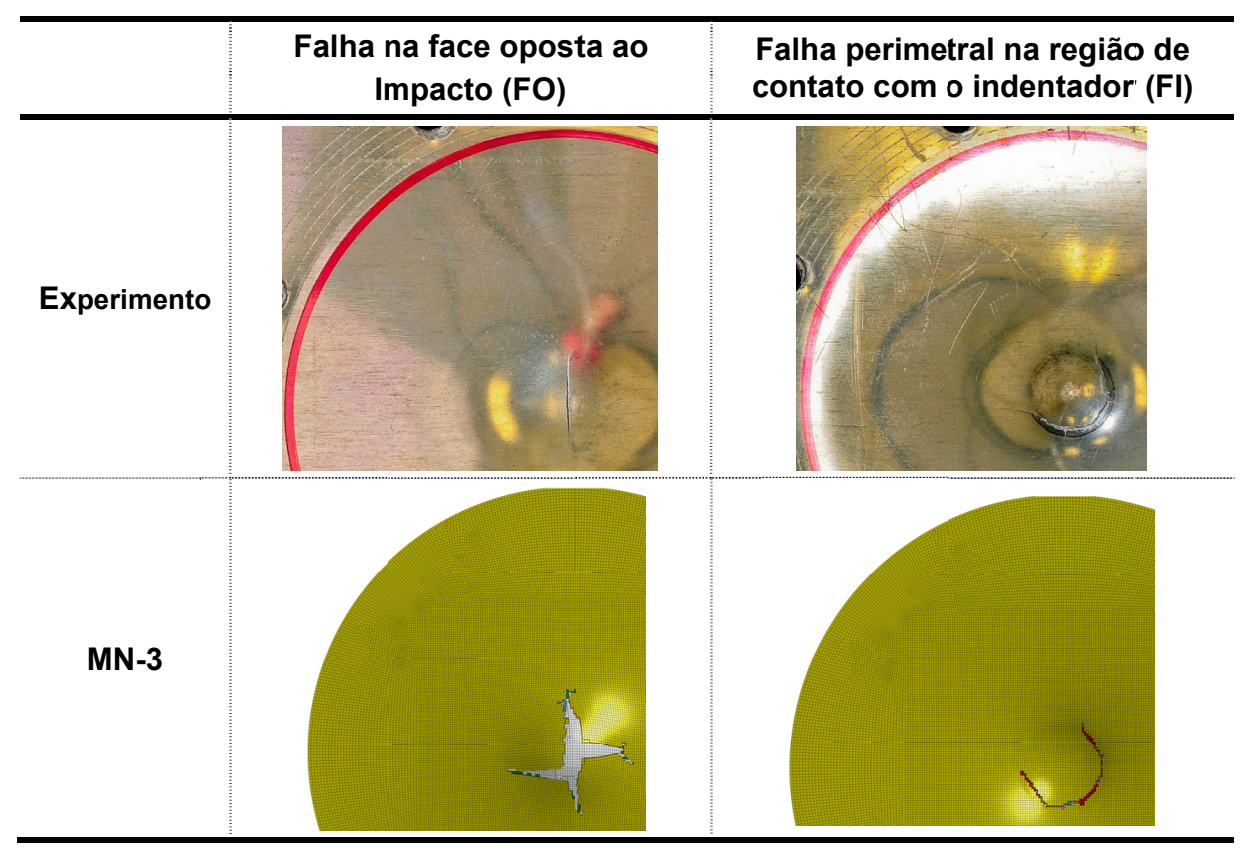




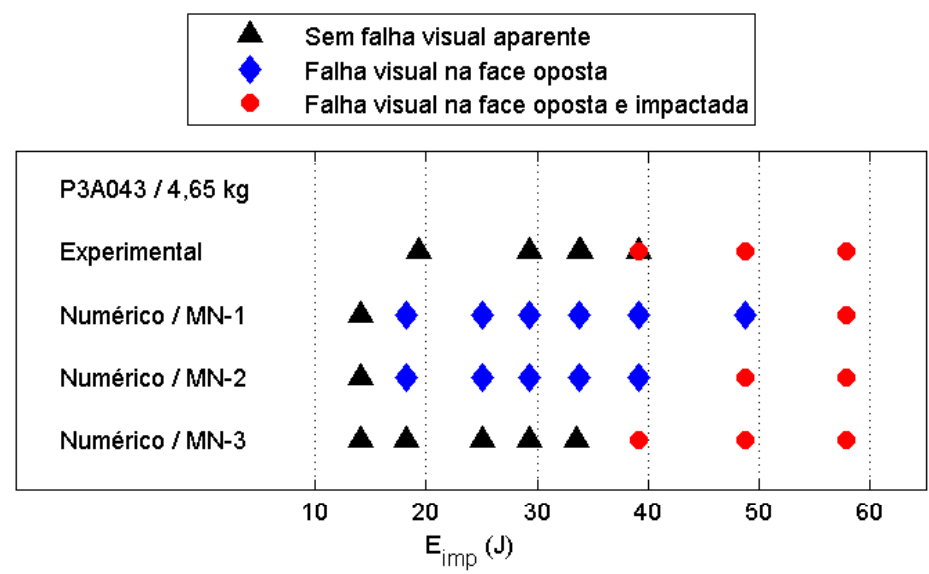

Figura 100: Comparação numérico-experimental do diagrama de falha do TFML P4B039.

Na Tabela 49 são apresentados os resultados provenientes dos modelos numéricos considerados onde são apresentados o deslocamento central residual, $w_{f}, \mathbf{e}$ velocidade residual, $V_{\text {res }}$. A Tabela 50 apresenta a comparação numéricoexperimental da velocidade residual do indentador, sendo observado um erro percentual similar em todos os modelos, variando de $-17 \%$ a $-24 \%$ para os modelos MN-1 e MN-2 respectivamente. Nota-se que em todos os casos o modelo numérico apresenta velocidade residual sempre menor que o observado experimentalmente.

Tabela 49: Resultados quantitativos da modelagem numérica do TFML P4B039.

\begin{tabular}{|c|c|c|c|c|c|c|c|c|c|c|}
\hline \multicolumn{2}{|c|}{ Material } & \multirow{2}{*}{\multicolumn{3}{|c|}{ MN-1 }} & & & & & & \\
\hline \multirow[b]{2}{*}{ Esp. } & \multirow[b]{2}{*}{$\begin{array}{c}V_{i n c} \\
(\mathrm{~m} / \mathrm{s})\end{array}$} & & & & \multicolumn{3}{|c|}{ MN-2 } & \multicolumn{3}{|c|}{ MN-3 } \\
\hline & & $\begin{array}{r}\left|V_{\text {res }}\right| \\
(\mathrm{m} / \mathrm{s}) \\
\end{array}$ & $\begin{array}{c}w_{f} \\
(\mathrm{~mm})\end{array}$ & Falha & $\begin{array}{l}\left|V_{\text {res }}\right| \\
(\mathrm{m} / \mathrm{s})\end{array}$ & $\begin{array}{c}w_{f} \\
(\mathrm{~mm})\end{array}$ & Falha & $\begin{array}{l}\left|V_{r e s}\right| \\
(\mathrm{m} / \mathrm{s})\end{array}$ & $\begin{array}{c}w_{f} \\
(\mathrm{~mm})\end{array}$ & Falha \\
\hline- & 2,46 & 1,23 & 2,53 & SF & 1,04 & 3,17 & SF & 1,19 & 3,8 & SF \\
\hline 19 & 2,8 & 1,24 & 3,18 & FO & 1,11 & 3,65 & FO & 1,27 & 4,6 & SF \\
\hline- & 3,28 & 1,32 & 4,10 & FO & 1,15 & 4,48 & $\mathrm{FO}$ & 1,45 & 5,48 & SF \\
\hline 18 & 3,55 & 1,35 & 4,57 & FO & 1,19 & 4,97 & FO & 1,45 & 5,95 & SF \\
\hline 17 & 3,81 & 1,36 & 5,07 & FO & 1,22 & 5,61 & FO & 1,53 & 6,43 & SF \\
\hline 13 & 4,10 & 1,38 & 5,57 & FO & 1,21 & 6,38 & $\mathrm{FO}$ & 1,08 & 6,82 & $\mathrm{FO}+\mathrm{FI}$ \\
\hline 12 & 4,58 & 1,36 & 6,66 & FO & 1,14 & 7,57 & $\mathrm{FO}+\mathrm{FI}$ & 0,82 & 7,79 & $\mathrm{FO}+\mathrm{FI}$ \\
\hline 11 & 4,99 & 1,23 & 7,37 & $\mathrm{FO}+\mathrm{Fl}$ & 1,14 & 8,44 & $\mathrm{FO}+\mathrm{FI}$ & 0,81 & 9,60 & $\mathrm{FO}+\mathrm{FI}$ \\
\hline
\end{tabular}


Tabela 50: Resultados numéricos e experimentais da velocidade residual do indentador para o material P4B039 após o impacto.

\begin{tabular}{c|c|c|c|c|c|c|c|c|c}
\hline Material & P4B039 & \multicolumn{10}{|c|}{ MN-2 } & \multicolumn{2}{|c|}{ MN-3 } \\
\hline \hline \multirow{2}{*}{ Esp. } & $\begin{array}{c}V_{\text {inc }} \\
(\mathrm{m} / \mathrm{s})\end{array}$ & $\begin{array}{c}V_{\text {res }} \\
(\mathrm{m} / \mathrm{s})\end{array}$ & $\begin{array}{c}V_{\text {res }} \\
(\mathrm{m} / \mathrm{s})\end{array}$ & $\mathbf{E r r o}$ & $\begin{array}{c}V_{\text {res }} \\
(\mathrm{m} / \mathrm{s})\end{array}$ & Erro & $\begin{array}{c}V_{\text {res }} \\
(\mathrm{m} / \mathrm{s})\end{array}$ & Erro \\
\hline 19 & 2,80 & 1,50 & 1,24 & $-20,97 \%$ & 1,11 & $-26,00 \%$ & 1,27 & $-15,33 \%$ \\
\hline 18 & 3,55 & 1,68 & 1,35 & $-24,44 \%$ & 1,19 & $-29,17 \%$ & 1,45 & $-13,69 \%$ \\
\hline 17 & 3,81 & 1,75 & 1,36 & $-28,68 \%$ & 1,22 & $-30,29 \%$ & 1,53 & $-12,57 \%$ \\
\hline 13 & 4,1 & 1,48 & 1,38 & $-7,25 \%$ & 1,21 & $-18,24 \%$ & 1,08 & $-27,03 \%$ \\
\hline 12 & 4,58 & 1,50 & 1,36 & $-10,29 \%$ & 1,14 & $-24,00 \%$ & 1,12 & $-25,33 \%$ \\
\hline 11 & 4,99 & 1,39 & 1,23 & $-13,01 \%$ & 1,14 & $-17,99 \%$ & 1,11 & $-20,14 \%$ \\
\hline & & & $\begin{array}{c}\text { Erro } \\
\text { Médio }\end{array}$ & $-17,44 \%$ & $\begin{array}{c}\text { Erro } \\
\text { Médio }\end{array}$ & $-24,28 \%$ & $\begin{array}{c}\text { Erro } \\
\text { Médio }\end{array}$ & $-19,02 \%$ \\
\hline
\end{tabular}

Na Figura 101 é apresentada a comparação do deslocamento central residual para as abordagens teórica, numérica e experimental do estudo do fenômeno de impacto. Foram considerados resultados numéricos com falha visual aparente nesta comparação, em desacordo com o modelo teórico, que não é aplicável a esta condição. Apesar disso, uma boa correlação foi obtida entre as três abordagens, sendo que o limite superior do modelo teórico e modelo MN-1 presentam resultados substancialmente semelhantes aos resultados experimentais, assim como os modelos MN-2 e MN-2 superestimam o deslocamento residual do TFML 4/3 P4B039, porém ainda apresentando boa correlação.

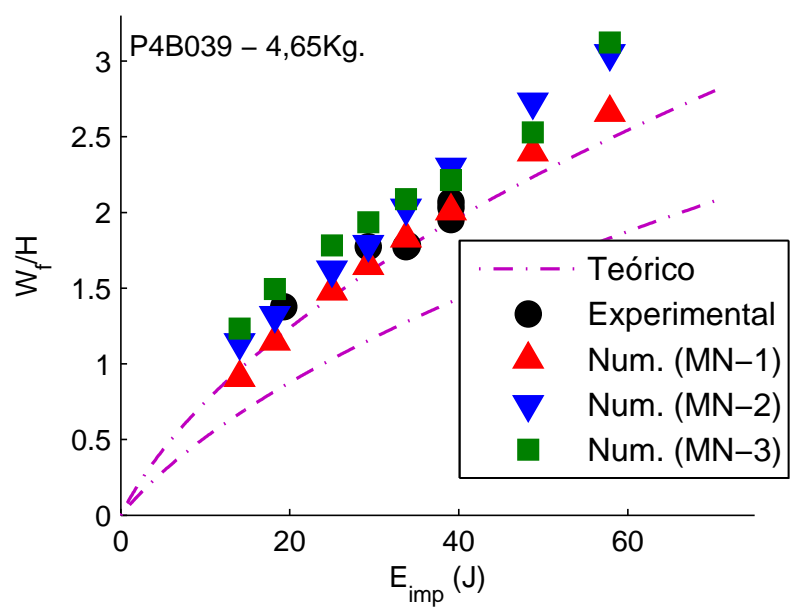

Figura 101: Comparação numérica, teórica e experimental para o deslocamento central residual do TFML P4B039 em impacto de baixa velocidade. 
Na Figura 102 é apresentada a comparação numérico-experimental da curva força-deslocamento para o TFML P4B039 em duas condições de impacto de baixa velocidade. Para o caso com velocidade de impacto de $2,88 \mathrm{~m} / \mathrm{s}$, sem ocorrência de falha visual ou falha significativa, é possível notar o comportamento qualitativo semelhante das curvas, apresentando comportamento contínuo durante o carregamento e descarregamento deste. Todos os modelos numéricos apresentaram comportamento substancialmente semelhante ao observado experimentalmente, com maior semelhança para o modelo MN-3.

Para a condição de impacto a $4,58 \mathrm{~m} / \mathrm{s}$, a ruptura do material é esperada, sendo identificada por todos os modelos numéricos. Durante o carregamento também é possível identificar o comportamento contínuo da curva e sendo tembém observadas descontinuidades após a condição de força máxima, ruptura e início do descarregamento. Apesar disso, nenhum resultado numérico foi similar ao descarregamento observado experimentalmente, apresentando valores substancialmente menores de força máxima. Este aspecto remete a limitação da aplicação dos modelos em questão para condições elevadas de ruptura do material em regime de impacto de baixa velocidade.
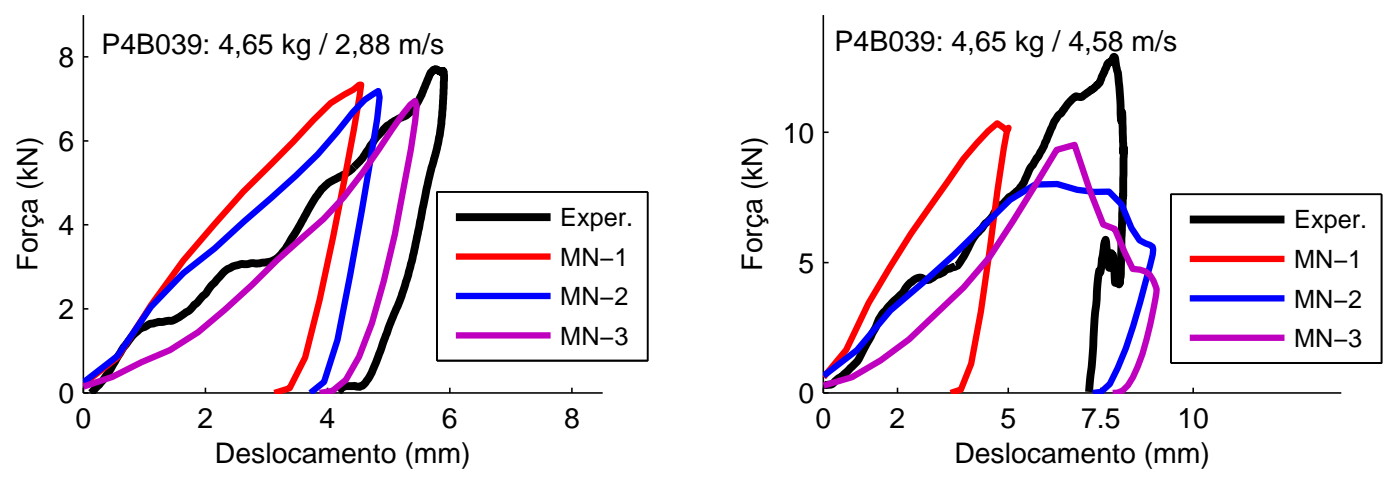

Figura 102: Comparação numérico-experimental da curva força-deslocamento para o TFML

P4B039. 
Tabela 51: Velocidade limite de falha visual para o TFML P4B039.

\begin{tabular}{c|c|c}
\hline Material & P4B039 & \multicolumn{1}{|c}{} \\
\hline \hline Abordagem & $V L F(\mathrm{~m} / \mathrm{s})$ & Erro $(\%)$ \\
\hline Experimental & 4,10 & - \\
\hline Numérica $(\mathrm{MN}-1)$ & 2,63 & $-35,85 \%$ \\
\hline Numérica $(\mathrm{MN}-2)$ & 2,63 & $-35,85 \%$ \\
\hline Numérica $(\mathrm{MN}-3)$ & 4,34 & $+5,12 \%$ \\
\hline
\end{tabular}

Na Tabela 51 é apresentada a predição da condição limite de falha visual para os modelos numéricos avaliados. Uma boa correlação foi obtida pelo modelo MN3 , apresentando erro em torno de $5 \%$ na predição de tal condição.

\subsubsection{Impacto em alta velocidade}

A Tabela 52 apresenta a comparação numérico-experimental de resultados qualitativos da face aposta após o impacto de alta velocidade. É observado que os modelos $\mathrm{MN}-1$ e MN-2 resultam em TFMLs mais frágeis do que os materiais reais. Nestes, há formação de lascas na ruptura das camadas metálicas, diferentemente do observado experimentalmente, onde houve a formação de pétalas, Figura 103. Acredita-se que este fato ocorre devido à utilização de modelo de material isotrópico e de um critério de falha simples para as camadas poliméricas. Isto ocasiona a ruptura prematura do reforço e das camadas metálicas.

O modelo MN-3 apresenta resultados qualitativamente mais semelhantes aos obtido experimentalmente, sendo capaz de representar falha do tipo "pétala", "rasgamento" e "mista", conforme apresando na Tabela 54. Não foi observada falha perimetral nos resultados provenientes do modelo numérico.

Quando a secção transversal da placa após o impacto é analisada, Tabela 54, também é possível observar o melhor desempenho do modelo MN-3 na representação qualitativa da resposta do material. Neste, é possível observar claramente a formação das rótulas plástica axissimétricas formadas na região periférica à fixação da placa e na região periférica ao impacto, de forma semelhante ao observado experimentalmente. A separação entre as camadas também e observada no modelo $\mathrm{MN}$ 3 de forma semelhante ao observado experimentalmente. 
Tabela 52: Comparação qualitativa de resultados numéricos e experimentais: ruptura na face oposta ao impacto.

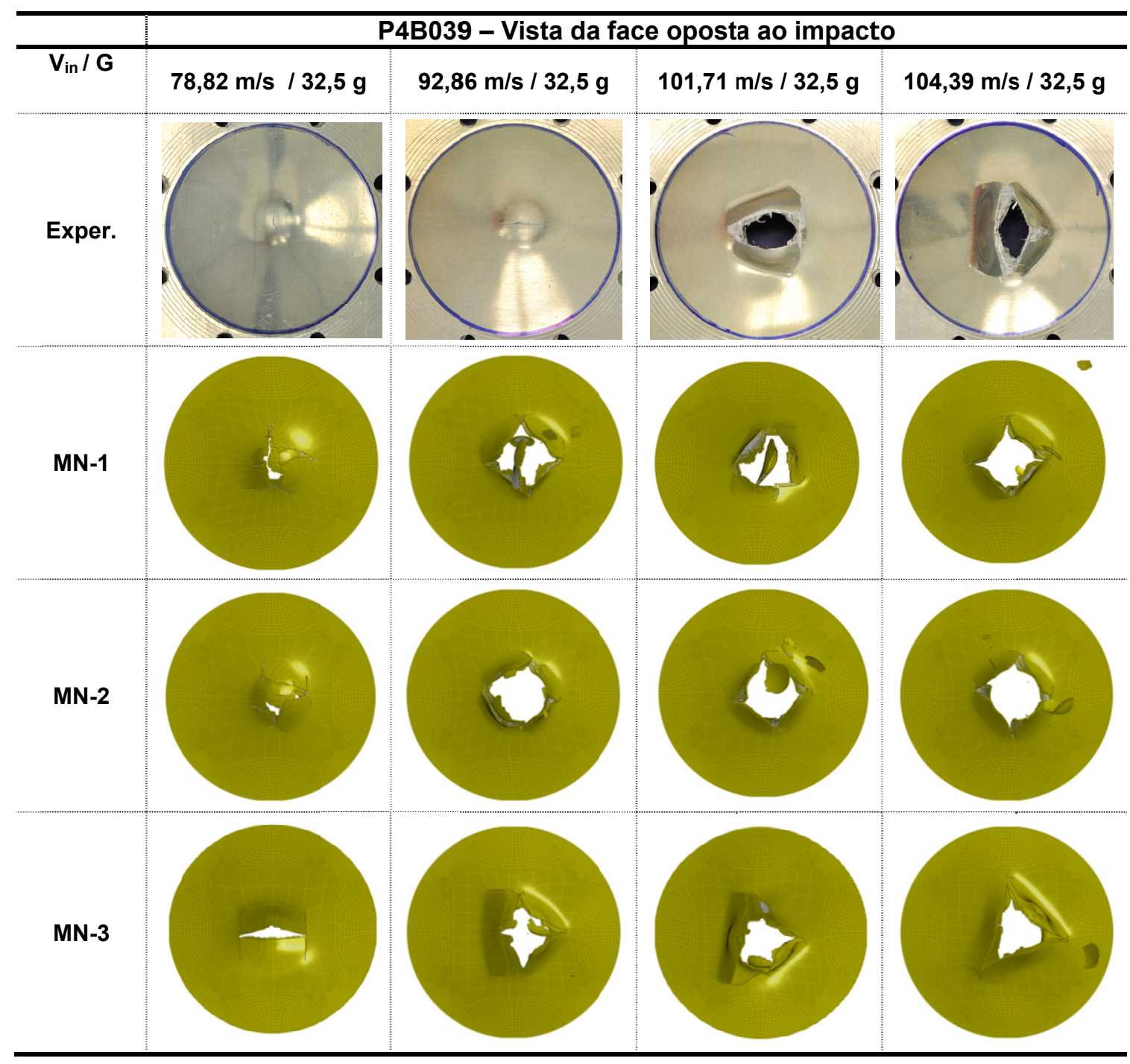

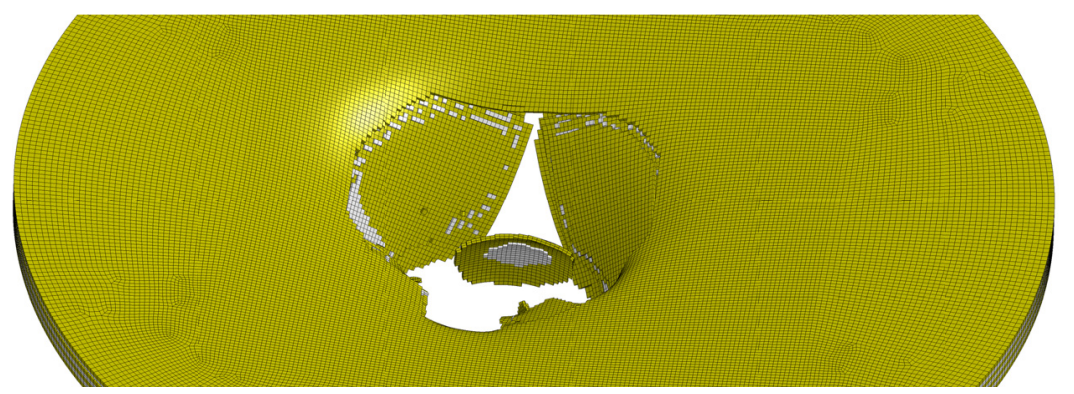

Figura 103: Ruptura das camadas metálicas nos modelos MN-1 e MN-2, não observadas experimentalmente. 
Tabela 53: Comparação qualitativa de resultados numéricos e experimentais: tipos de falha.

Experimento

Tabela 54: Comparação qualitativa de resultados numéricos e experimentais.

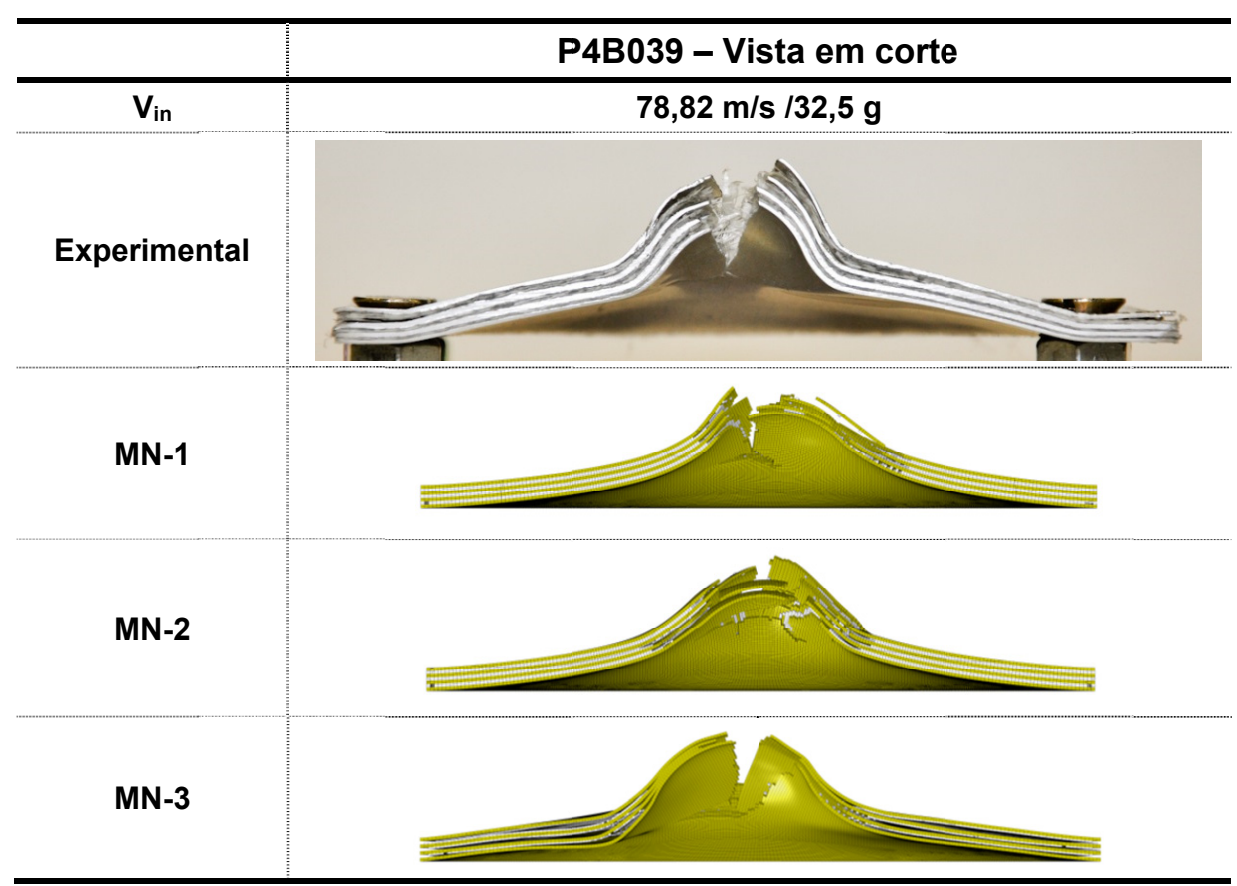

$\mathrm{Na}$ Tabela 56 são apresentados resultados numéricos e experimentais de velocidade residual do projétil. É possível notar uma diferenciação com relação a velocidade residual obtida, mais acentuada nos casos onde foi observado atravessamento do material. Acredita-se que este fato se dá devido ao critério de dano utilizado, o qual causa uma falha prematura no material. Aspectos como de tribologia e mecânica da fratura podem influenciar os resultados nesta condição, não sendo abordados nesta tese. 
Tabela 55: Resultados numéricos para o material TFML P4B039 em impacto de alta velocidade.

\begin{tabular}{|c|c|c|c|}
\hline Material & P4B039 & & \\
\hline$V_{i n c}(\mathbf{m} / \mathbf{s})$ & $\begin{array}{c}\mathbf{M N}-\mathbf{1} \\
V_{r e s}(\mathrm{~m} / \mathrm{s})\end{array}$ & $\begin{array}{c}\mathbf{M N}-\mathbf{2} \\
V_{r e s}(\mathrm{~m} / \mathrm{s})\end{array}$ & $\begin{array}{c}\text { MN-3 } \\
V_{r e s}(\mathrm{~m} / \mathrm{s})\end{array}$ \\
\hline 77,00 & $+10,60$ & $+6,90$ & $+5,91$ \\
\hline 78,82 & $+10,90$ & $+5,23$ & $+3,71$ \\
\hline 82,00 & $+5,89$ & $+4,59$ & $-29,60$ \\
\hline 87,00 & $-17,30$ & $-26,50$ & $-38,00$ \\
\hline 92,86 & $-39,00$ & $-33,20$ & $-50,00$ \\
\hline 97,00 & $-47,50$ & $-44,10$ & $-56,70$ \\
\hline 101,71 & $-57,00$ & $-52,90$ & $-66,40$ \\
\hline 105,17 & $-59,70$ & $-60,00$ & $-72,80$ \\
\hline
\end{tabular}

Tabela 56: Resultados numéricos e experimentais para o material TFML P4B039 em impacto de alta velocidade.

\begin{tabular}{|c|c|c|c|c|c|}
\hline Material & P4B039 & & & & \\
\hline Espécime & $V_{i n c}(\mathbf{m} / \mathbf{s})$ & $\begin{array}{c}\text { Experimental } \\
V_{\text {res }}(\mathrm{m} / \mathrm{s})\end{array}$ & $\begin{array}{c}\mathbf{M N}-\mathbf{1} \\
V_{\text {res }}(\mathrm{m} / \mathrm{s})\end{array}$ & $\begin{array}{c}\text { MN-2 } \\
V_{\text {res }}(\mathrm{m} / \mathrm{s})\end{array}$ & $\begin{array}{c}\mathbf{M N}-\mathbf{3} \\
V_{\text {res }}(\mathrm{m} / \mathrm{s})\end{array}$ \\
\hline 10 & $-78,82$ & $+8,97$ & $+10,90$ & $+5,23$ & $+3,70$ \\
\hline 1 & $-92,86$ & $+8,75$ & $-39,00$ & $-33,20$ & $-50,00$ \\
\hline 3 & $-101,71$ & $-21,75$ & $-57,00$ & $-52,90$ & $-66,40$ \\
\hline 8 & $-104,39$ & $-24,56$ & $-59,70$ & $-60,00$ & $-72,80$ \\
\hline
\end{tabular}

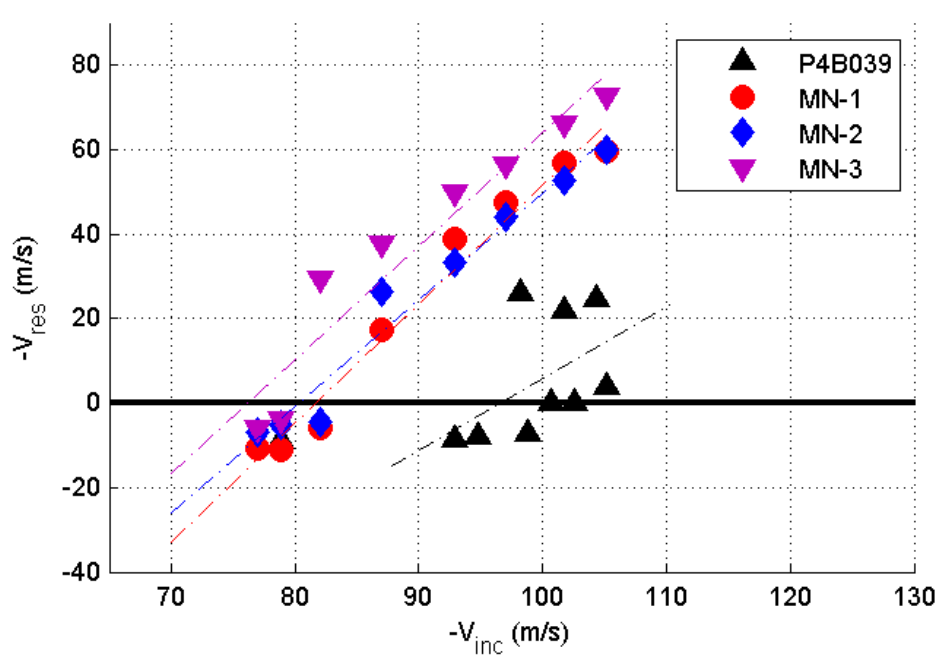

Figura 104: Resultados numéricos e experimentais para o diagrama de velocidade do material P4B039.

$\mathrm{Na}$ Tabela 55 são apresentados resultados de velocidade residual para o os eventos simulados numericamente. Estes resultados estão representados no diagrama de velocidades, Figura 105, onde também são apresentados os resultados 
provenientes dos experimentos de impacto. O limite balístico foi definido a partir da interpolação linear dos resultados desse diagrama, procedimento semelhante ao utilizando nos ensaios experimentais. Tais resultados estão apresentados na Tabela 57 e Figura 105.

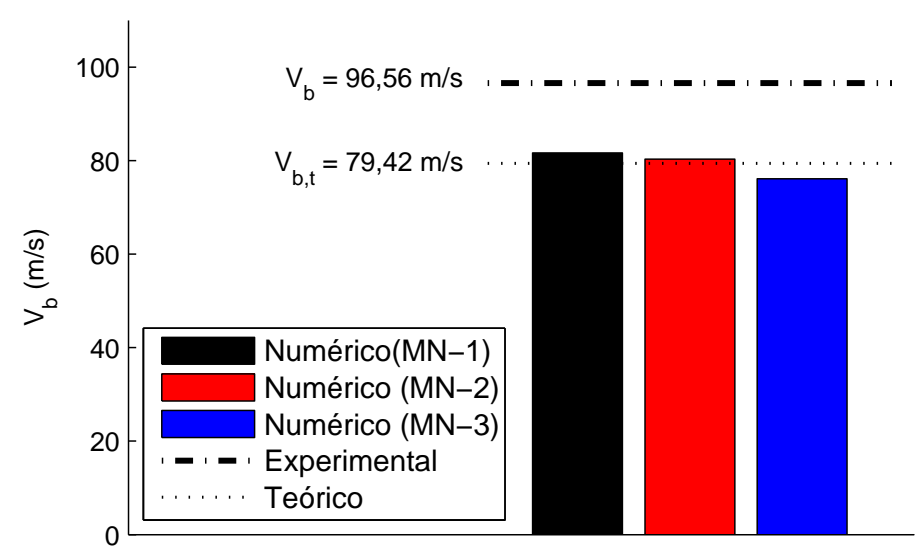

Figura 105: Resultados numérico, teórico e experimental para o limite balístico do material P4B039.

Tabela 57: Limite balístico para o material P4B039.

\begin{tabular}{c|c|c}
\hline Material & P4B039 & \\
\hline \hline Abordagem & $\left|V_{b}\right|(\mathrm{m} / \mathrm{s})$ & Erro (\%) \\
\hline Experimental & 96,56 & - \\
Teórica & 90,76 & $-16,37 \%$ \\
\hline Numérica (MN-1) & 81,65 & $-15,44 \%$ \\
\hline Numérica (MN-2) & 80,30 & $-16,84 \%$ \\
\hline Numérica (MN-3) & 76,11 & $-21,18 \%$ \\
\hline
\end{tabular}

Observa-se que todos os modelos numéricos, assim como o modelo teórico, subestimam o valor de limite balístico para o material P4B039. No entanto o erro presentado por tais análises estão entre 16\% e 21\%. Considerando a complexidade do fenômeno em questão, estes resultados são satisfatórios. 


\subsubsection{Escolha do modelo numérico}

De maneira geral, todos os modelos numéricos aqui avaliados puderam prever o comportamento do TFML em regime de impacto de alta e baixa velocidade, apresentando variação de aproximadamente $20 \%$ com resultados experimentais.

Os modelos $\mathrm{MN}-1$ e $\mathrm{MN}-2$, apesar de considerarem o efeito da taxa de deformação no comportamento do reforço polimérico, utilizam um critério de falha simples e desconsideram a ortotropia deste material. Acredita-se que por este motivo tais modelos apresentam falha prematura do material em regime de impacto de alta e baixa velocidade. Foi observado também que a utilização de condições de contato que modelam a adesão entre as camadas poliméricas e metálicas possibilita a dissipação de energia de impacto. No entanto, a contribuição desta é modesta, não representando influência significativa no comportamento do TFML quando modelado numericamente.

O modelo numérico $\mathrm{MN}-3$, apesar de desconsiderar o efeito da taxa de deformação no comportamento do reforço polimérico, considera a ortotropia do material e utiliza um critério de falha compatível. Este modelo apresentou bons resultados qualitativos em alta e baixa velocidade, pode prever a condição limite de falha em baixa velocidade $(V L F)$ com erro em torno de $5 \%$ e pôde prever o limite balístico do material em regime de impacto em alta velocidade de forma satisfatória. Assim, este modelo foi adotado como base para e estudo do comportamento ao impacto de TFML, apresentado no Capítulo 9.

\subsection{CONSIDERAÇÕES FINAIS}

Neste capítulo foi desenvolvido um modelo numérico capaz de representar satisfatoriamente o comportamento do TFML em regime de impacto de alta e baixa velocidade.

O modelo numérico $\mathrm{MN}-3$ foi escolhido para o estudo do comportamento de TFML ao impacto, apresentado no Capítulo 9. Apesar de serem encontradas limitações na implementação da sensibilidade à taxa de deformação do reforço polimérico e modelagem da camada adesiva, este modelo representa o comportamento do ma- 
terial com diferenciação média em torno de $20 \%$. Tendo em vista a complexidade do fenômeno estudado, acredita-se que este valor é aceitável e satisfatório para a continuação deste estudo. 


\section{AVALIAÇÃO DO COMPORTAMENTO DO TFML AO IMPACTO}

Uma vez que o comportamento do TFML foi identificado (Capitulo 5) e modelado (Capítulo 6 e 7), neste capítulo serão avaliados os aspectos que influenciam o comportamento do TFML ao impacto. O uso de ferramentas numéricas possibilita grande flexibilidade e facilidade da avaliação de modificações na estrutura do material, o que seria oneroso obter experimentalmente.

A influência da forma de empilhamento, efeitos de taxa de deformação e geometria do indentador no comportamento do TFML ao impacto serão abordados, tomando-se como referencia o TFML 4/3 (P4B039), anteriormente estudado. O desempenho do TFML 4/3 também será comparado com outras configurações equivalentes de TFML e alumínio. Por fim, uma configuração otimizada do TFML será proposta.

Neste capítulo busca-se uma abordagem simples e direta de cada aspecto de forma separada, gerando-se orientações para o projeto e melhoria do desempenho do TFML ao impacto.

\subsection{INFLUÊNCIA DA TAXA DE DEFORMAÇÃO}

Buscando identificar a influência da taxa de deformação no comportamento do TFML ao impacto, dois eventos de impacto com mesma energia foram modelados, com velocidades e massas distintas. Um impacto de $18 \mathrm{~J}$ foi considerado, ocorrendo com massa de $10 \mathrm{~kg}$ e velocidade de $1,9 \mathrm{~m} / \mathrm{s}$ e outro considerou massa de 15 g e velocidade $50 \mathrm{~m} / \mathrm{s}$. Para tal análise, o modelo numérico $\mathrm{MN}-1$ foi utilizado, uma vez que este considera o efeito de taxa de deformação nas camadas metálicas e de reforço.

Nas Figuras 106 e 107 são apresentado os históricos de deformações plásticas, $\varepsilon_{p}$, na camada metálica oposta ao impacto, para diversas posições da placa, em eventos de impacto de baixa e alta velocidade. É possível observar que o material está submetido a taxas de até deformação de 110/s e 680/s para eventos de impac- 
to de baixa e alta velocidade, respectivamente, o que demostra que os ensaios experimentais de caracterização mecânica, realizados até 200/s, conseguiram representar de forma satisfatória o comportado do material nos eventos de impacto em questão. É possível observar também que as deformações, assim com a taxa de deformação, também diminuem rapidamente conforme a distância do centro da placa (região de impacto) é aumentada. Para posições com $r>20 \mathrm{~mm}$, foi observado níveis de deformação praticamente em regime elástico, com taxas de deformações baixas.

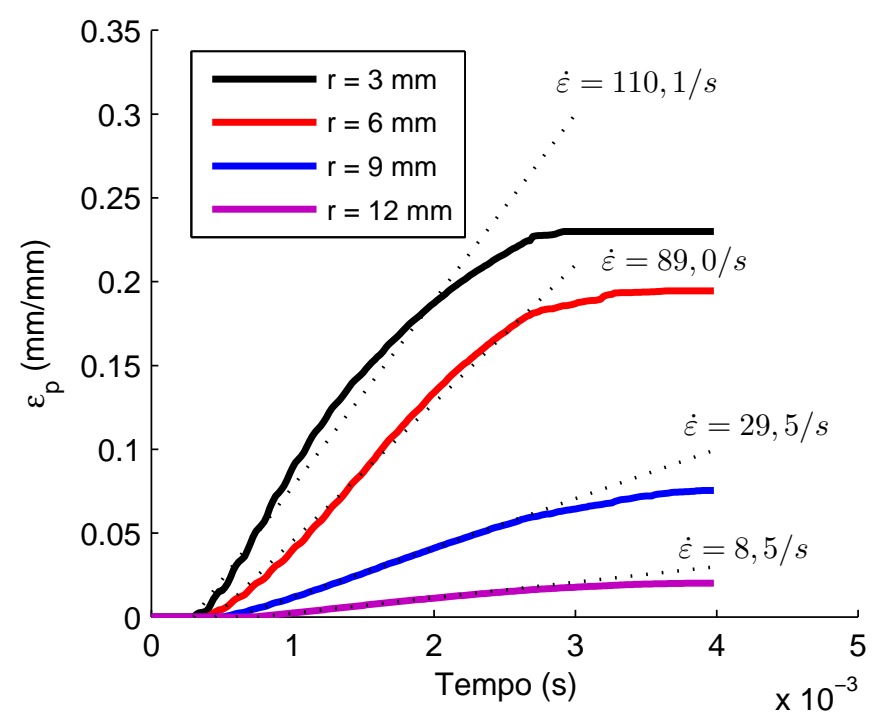

Figura 106: Histórico de deformação para o TFML em evento de impacto de baixa velocidade.

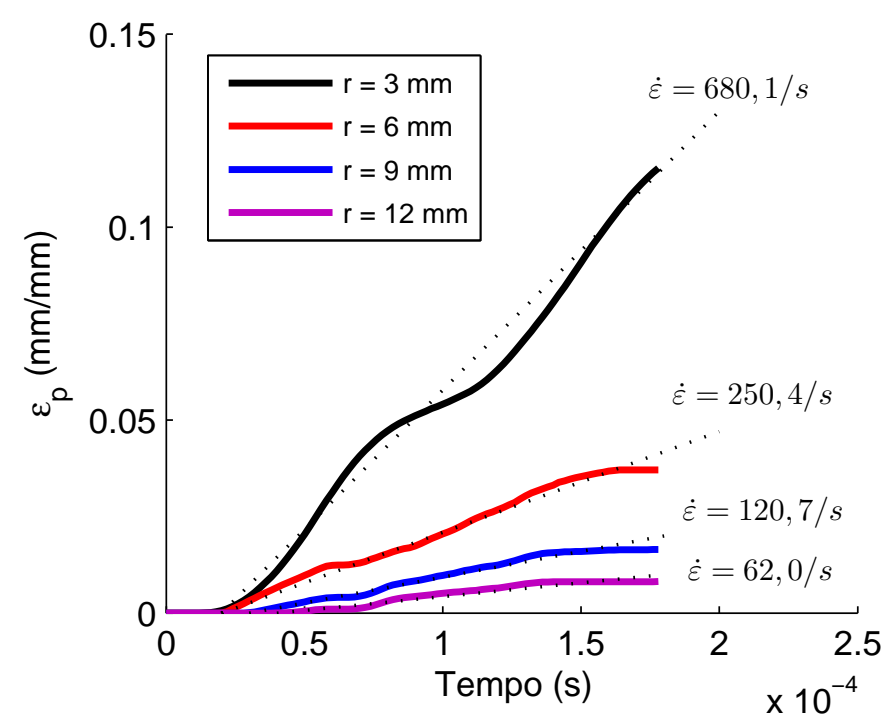

Figura 107: Histórico de deformação para o TFML em evento de impacto de baixa velocidade. 
A Figura 108 apresenta a comparação qualitativa do comportamento em ambos os casos, sendo possível notar diferenciação na forma de ruptura e comportamento residual das camadas. No impacto de alta velocidade é possível notar maior quantidade de elementos excluídos nas camadas de reforços, assim como um maior deslocamento residual da ultima camada metálica. Para o caso de baixa velocidade foi observado menor quantidade de elementos excluídos nas camadas de reforços, assim como a ruptura da camada externa de alumínio. Este aspecto é causado pelo efeito da taxa de deformação considerado no modelo numérico. O SRPP tem a rigidez aumentada e ruptura a menores deformações em regime dinâmico, assim como o alumínio, que apresenta sensibilidade a taxa de deformação no critério de dano utilizado.

(a)
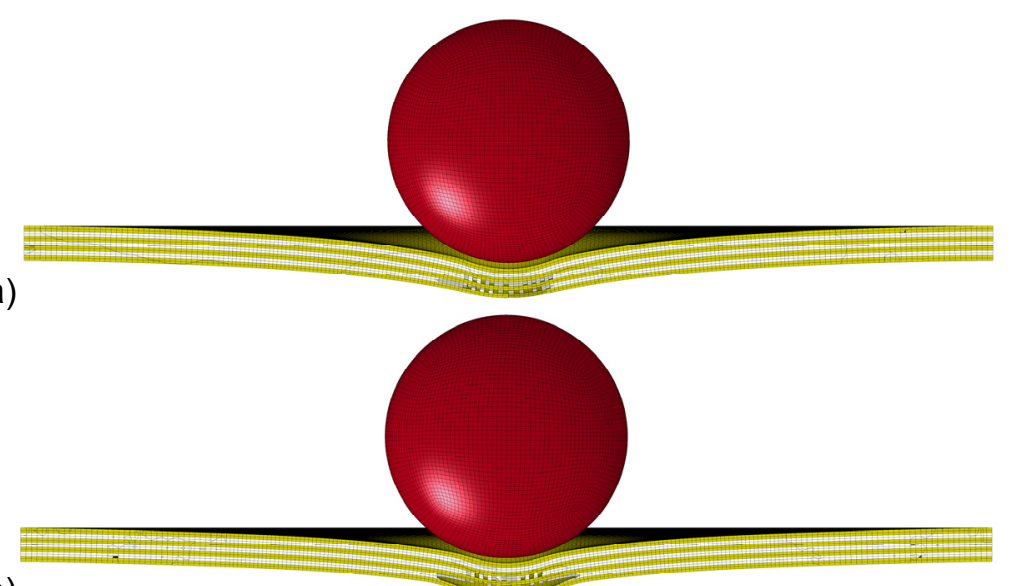

(b)

Figura 108: Comparação qualitativa do comportamento do TFML em impacto de mesma energia e velocidades diferentes: (a) $10 \mathrm{~kg} / 1,9 \mathrm{~m} / \mathrm{s}$ e (b) $15 \mathrm{~g} / 50 \mathrm{~m} / \mathrm{s}$.

A Figura 109 apresenta as curvas força-deslocamento para os eventos de impacto em questão. É possível observar significativa distinção entre estas. Em baixa velocidade, observa-se o comportamento esperado, com respostas contínuas durante o carregamento e descarregamento. No caso em alta velocidade, observa-se grande oscilação na curva. Acredita-se que o motivo deste fato seja a baixa inercia do projétil, possibilitando maior sensibilidade durante a exclusão de elementos e efeitos de propagações de ondas. Nota-se na porção inicial da curva um aparente aumento de rigidez da placa, possivelmente causado pela sensibilidade a taxa de deformação do reforço. Após isso, observam-se oscilações possivelmente oriundas 
a falha dos elementos da camada de reforço. Vale ressaltar que este fenômeno foi observado experimentalmente em (Sadighi, Alderliesten e Benedictus, 2012)

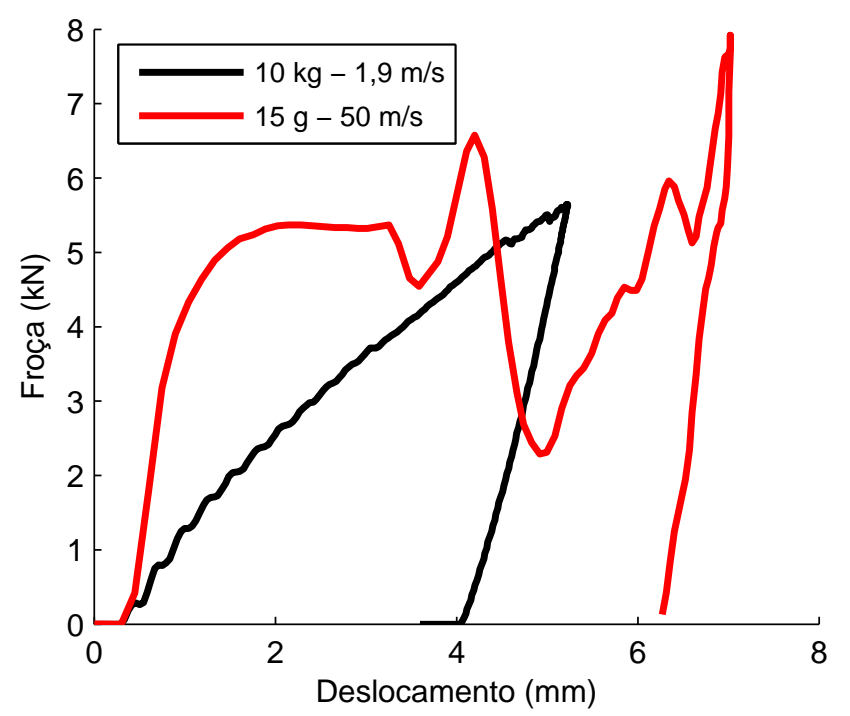

Figura 109: Curva força-deslocamento para o TFML ao impacto em baixa e alta velocidade.

Tabela 58: Resultado da análise comparativa de TFML de referência e a configuração proposta.

\begin{tabular}{c|c|c}
\hline Evento & $w_{f, \max }(\mathrm{mm})$ & $E_{\text {res }}(\mathrm{J})$ \\
\hline $\begin{array}{c}\text { Baixa velocidade } \\
(10 \mathrm{~kg} / 1,9 \mathrm{~m} / \mathrm{s})\end{array}$ & 4,47 & 3,40 \\
\hline $\begin{array}{c}\text { Alta velocidade } \\
(15 \mathrm{~g} / 50 \mathrm{~m} / \mathrm{s})\end{array}$ & 6,46 & 1,96 \\
\hline
\end{tabular}

Na Tabela 58 são apresentados resultados quantitativos na análise, sendo observado que, em alta velocidade, o material deformou mais e absorveu mais energia durante o impacto, o que demostra que o TFML apresenta comportamento influenciado pela velocidade da solicitação (ou taxa de deformação).

\subsection{INFLUÊNCIA DA GEOMETRIA DO INDENTADOR}

Buscando identificar a influência da geometria do indentador no comportamento ao impacto do TMFL, o evento de impacto de uma massa de $15 \mathrm{~g}$ chocandose contra o centro de uma placa circular de TFML 4/3 (P4B039) foi modelado. Um 
projétil esférico com $20 \mathrm{~mm}$ de diâmetro e um cilindro com $20 \mathrm{~mm}$ diâmetro, impactado pela face plana, foram considerados. Eventos de impacto de $18 \mathrm{~J}(50 \mathrm{~m} / \mathrm{s})$ e $180 \mathrm{~J}(155 \mathrm{~m} / \mathrm{s})$ foram modelados, buscando representar eventos com e sem perfuração completa do material.

A Figura 110 apresenta a comparação qualitativa dos eventos de impacto a $18 \mathrm{~J}$. Apesar da aparente diferenciação na forma de identação do material (de acordo com a geometria do projétil), foi observado o comportamento global do material muito semelhante, no tocante ao deslocamento máximo, perfil de deslocamento da placa e velocidade residual após impacto, conforme apresentado na Tabela 59. Este aspecto reafirma a hipótese adotada no modelo teórico de Jones para impacto de baixa velocidade sem ruptura (Capítulo 7), onde a geometria do indentador é ignorado, sendo considerado apenas o diâmetro deste.

(a)

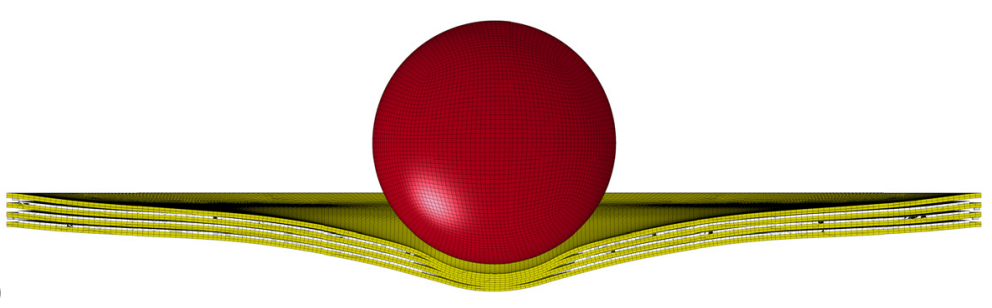

(b)

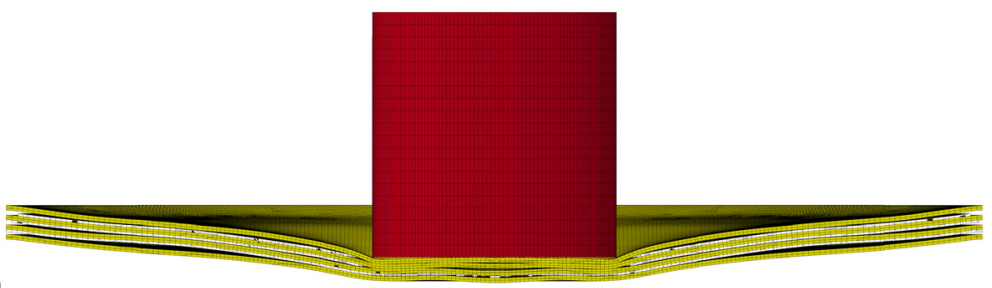

Figura 110: Comparação qualitativa do impacto em TFML sem ruptura com projéteis (a) esférico e (b) cilíndrico.

Tabela 59: Desempenho das amostras de TFML ao impacto de ruptura, utilizando indentadores esféricos e cilíndricos.

\begin{tabular}{c|c|c}
\hline Evento & $w_{f, \max }(\mathrm{mm})$ & $V_{\text {res }}(\mathrm{m} / \mathrm{s})$ \\
\hline $\begin{array}{c}\text { Esfera } \\
(15 \mathrm{~g} / 50 \mathrm{~m} / \mathrm{s})\end{array}$ & 6,27 & 23,40 \\
\hline $\begin{array}{c}\text { Cilindro } \\
(15 \mathrm{~g} / 50 \mathrm{~m} / \mathrm{s})\end{array}$ & 5,28 & 22,94 \\
\hline
\end{tabular}

A diferenciação do comportamento para diferentes geometrias de indentadores foi observada nos eventos de impacto com perfuração completa do material. $\mathrm{Na}$ Figura 111 é apresentada a forma de ruptura do material utilizando indentadores es- 
féricos ou cilíndricos. No primeiro caso é possível observar que o formato da identação induz a ruptura do material por tensões de membrana, com falha tipo pétala. Para o caso com indentador cilíndrico é possível observar que o mesmo induz extração de um disco do material durante impacto, propiciando a ruptura por cisalhamento do material na maioria das camadas do TFML. Este fenômeno já foi observado experimentalmente em (Compston et al., 2001).

(a)
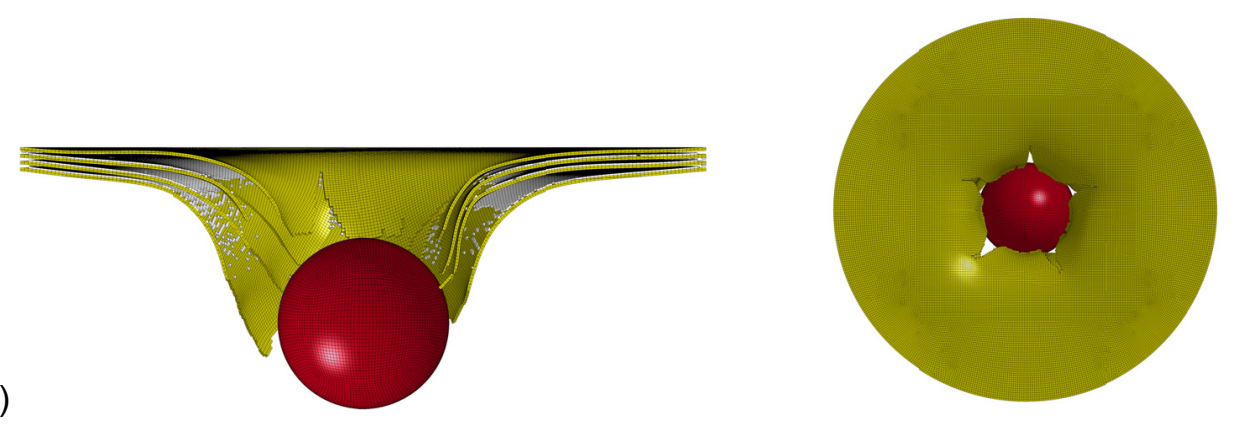

(b)
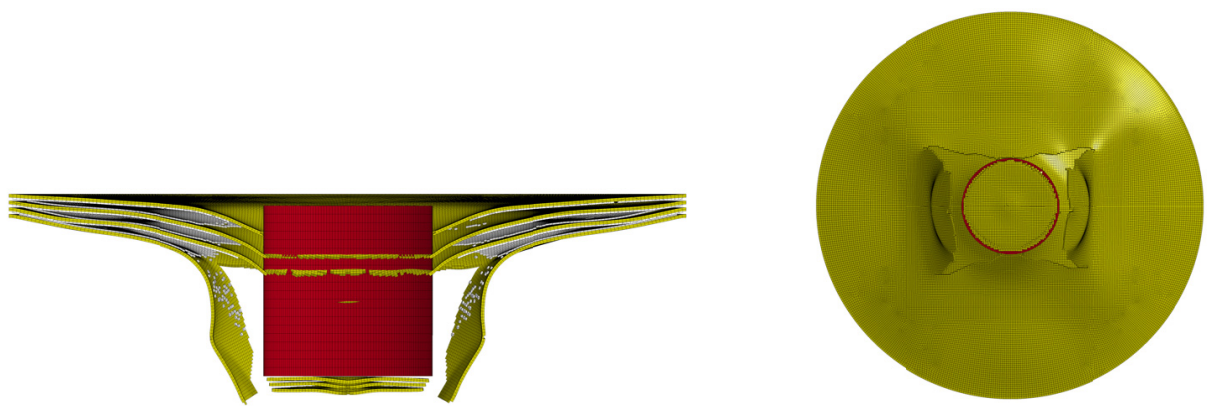

Figura 111: Forma de ruptura observada em eventos de impacto em TFML com indentadores (a) esférico e (b) cilíndrico.

A Tabela 60 apresenta a velocidade residual do indentador após o impacto. Apesar de ser sabido que a ruptura por cisalhamento absorve menos energia que a ruptura por tensões de membrana, observa-se que a velocidade residual do indentador cilíndrico é menor, o que indica que menos energia foi absorvida pelo material. Este fato é dado pelo formato do indentador. No caso esférico, após a passagem da secção transversal com maior diâmetro, o atravessamento do indentador é facilitado. Por sua vez, o caso cilíndrico, após a entrada no material, ocorre o contato deste com o material ao longo de todo o seu comprimento, o que gera dissipação de energia. Além disso, a ruptura na última camada gerou grande quantidade de deslocamento de material, o que também contribui para dissipação. Uma comparação mais adequada do desempenho ao impacto dos dois indentadores seria dada com a utili- 
zação de um indentador semi-hemisferico, em uma face, e cilíndrico na face oposta, ao invés da geometria esférica.

Tabela 60: Desempenho das amostras de TFML ao impacto com ruptura, utilizando indentadores esféricos e cilíndricos.

\begin{tabular}{c|c}
\hline Evento & $V_{\text {res }}(\mathrm{m} / \mathrm{s})$ \\
\hline Esfera & $-110,67$ \\
$(15 \mathrm{~g} / 155 \mathrm{~m} / \mathrm{s})$ & \\
\hline $\begin{array}{c}\text { Cilindro } \\
(15 \mathrm{~g} / 155 \mathrm{~m} / \mathrm{s})\end{array}$ & $-89,43$ \\
\hline
\end{tabular}

\subsection{INFLUÊNCIA DA EXCENTRICIDADE DO IMPACTO}

Buscado identificar a influência da excentricidade de impacto no comportamento do material, uma série simulações numéricas do evento de impacto de uma esfera rígida com $15 \mathrm{~g}$, a velocidade de $75 \mathrm{~m} / \mathrm{s}$ contra uma placa circular do TFML 4/3 (P4B039) de referência foram realizadas. Considera-se excentricidade a distância entre o centro da placa e a posição de contato com a esfera. A Tabela 61 sumariza as análises realizadas.

Tabela 61: Modelos utilizados para avaliação do efeito de excentricidade do impacto do TFML.

\begin{tabular}{c|c|c}
\hline Análise & Excentricidade $(\mathrm{mm})$ & Representação \\
\hline $\mathrm{ME}-1$ & 0,00 \\
$\mathrm{ME}-2$ & 3,00 \\
\hline $\mathrm{ME}-3$ & 6,00 \\
\hline $\mathrm{ME}-4$ & 10,00 \\
\hline
\end{tabular}


$\mathrm{Na}$ Tabela 62 são apresentados resultados de tal análise, sendo observado que excentricidades de até $6 \mathrm{~mm}$ apresentam um desvio de comportamento aceitável, com diferenciação de 5,18 \% e 9,82 \% para o deslocamento máximo e velocidade residual. Este fato indica que os ensaios experimentais de impacto de alta velocidade, apresentados no Capítulo 5, podem ser comparados uns aos outros e podem ser considerados como se tivessem sido realizados no centro da placa, uma vez que foram realizados com excentricidades menores $5 \mathrm{~mm}$. Além disso, vale ressaltar que a excentricidade média dos ensaios experimentais foi considerada no modelo numérico apresentado no Capítulo 8, quando a modelagem do comportamento ao impacto do TFML 4/3 (P4B038) foi objetivada.

Tabela 62: Resultados na análise da excentricidade no impacto em TFMLs.

\begin{tabular}{c|c|c|c|c|c}
\hline Material & Excentricidade & $w_{f, \max }(\mathrm{mm})$ & Erro $(\%)$ & $V_{\text {res }}(\mathrm{m} / \mathrm{s})$ & Erro $(\%)$ \\
\hline ME-1 & $0 \mathrm{~mm}$ & 6,57 & - & 23,42 & - \\
\hline ME-2 & $3 \mathrm{~mm}$ & 6,45 & $1,83 \%$ & 22,82 & $2,56 \%$ \\
\hline ME-3 & $6 \mathrm{~mm}$ & 6,23 & $5,18 \%$ & 19,12 & $9,82 \%$ \\
\hline ME-4 & $10 \mathrm{~mm}$ & 5,72 & $12,94 \%$ & 13,02 & $44,40 \%$ \\
\hline
\end{tabular}

\subsection{ESTUDO COMPARATIVO}

Neste item será realizado o estudo comparativo do TFML 4/3 (P4B039) em possíveis variações de sua configuração. A equivalência entre as configurações foi tomada de forma que fosse mantida a densidade areal do material, ou para o caso de impacto em chapas planas circulares, que fosse mantido o peso total da placa. Para todos os casos, foi considerado o impacto de uma esfera com $20 \mathrm{~mm}$ de diâmetro, com massa de $15 \mathrm{~g}$, impactando na velocidade de $75 \mathrm{~m} / \mathrm{s}$ ao centro de uma placa circular com $80 \mathrm{~mm}$ de diâmetro e densidade superficial de $1,9 \mathrm{~g} / \mathrm{cm}^{3}$, semeIhante ao material de referência. Deslocamento máximo residual, velocidade residual e ocorrência de falha foram tomados como parâmetros de comparação de desempenho entre as amostras testadas. 
Uma vez que este estudo visa identificar o efeito das espessuras dos constituintes do TFML, não foi considerada a viabilidade técnica de fabricação de materiais com as espessuras exploradas nos itens.

\subsubsection{Avaliação preliminar}

Os modelo teóricos de Jones e Reid-Wen foram utilizado para identificação preliminar da influência da fração em massa dos constituintes do TFML em seu comportamento ao impacto. Para isso, foram analisadas as respostas para TFMLs com diferentes composições de alumínio e reforços, sendo identificado o limite balístico e deslocamento residual para impacto de baixa velocidade de $40 \mathrm{~J}$.

Conforme explorados no Capítulo 6, ambos os modelos teóricos foram utilizados de acordo com o procedimento que forneceu a resposta mais concordante com os resultados experimentais. Para o caso do modelo de Jones, a resposta do material foi considerada como curva referente ao limite superior para o deslocamento máximo residual. Na Figura 112 apresenta-se os resultados dessa análise, sendo considerada uma ampla faixa possível de composição dos constituintes, mantendose a densidade superficial igual ao material de referência.

(a)

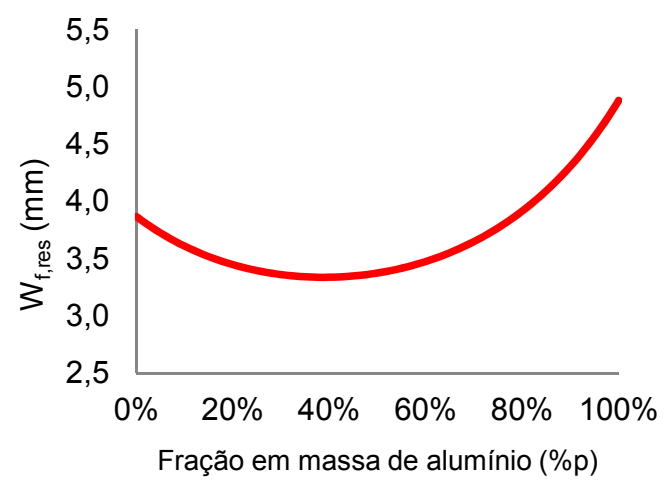

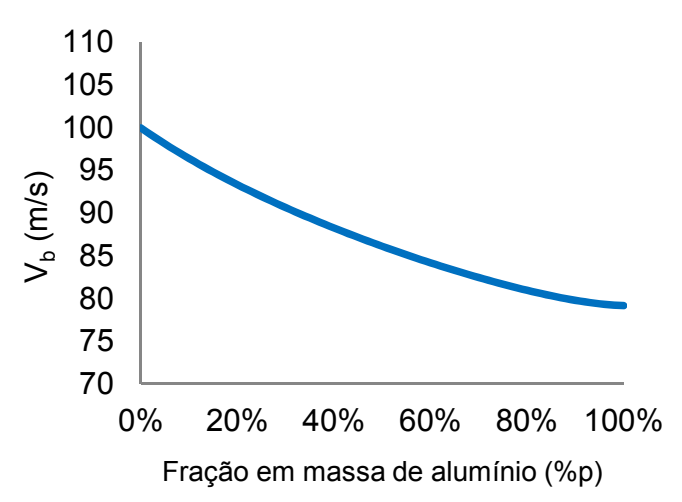

(b) dade balística para materiais equivalentes ao TFML 4/3 (P4B039).

Foi observado que para composições próximas a $42 \%$ p de alumínio e $58 \%$ p de SRPP apresentam deslocamento residual mínimo para a energia de impacto em 
questão. Nesta condição, o TFML apresenta deslocamento residual $16 \%$ menor que o SRPP monolítico equivalente e $27,5 \%$ menor que o alumínio monolítico equivalente.

Com relação ao limite balístico, têm-se a redução contínua deste com o aumento da composição de alumínio, o que demostra que quanto maior a composição de SRPP no TFML, maior será o limite balístico do TFML. Em condições limites, tem-se que os TFMLs apresentam limite balístico maior que materiais monolíticos equivalentes de alumínio e menor que equivalentes de SRPP. Uma vez que a densidade do SRPP é $72 \%$ menor que a do alumínio, apesar da menor resistência mecânica, o material equivalente de SRPP apresenta espessura cerca de 2,6 vezes maior que o equivalente de alumínio, o que justifica o limite balístico maior neste caso.

Vale ressaltar que ambos os modelos, assim com as modificações a eles implementadas, não foram avaliadas para utilização em materiais monolíticos. Assim, as conclusões aqui apresentadas são preliminares, identificando a tendência do comportamento esperado do material. Além disso, os modelos teóricos não consideram diferenciações na organização e espessura de cada camada dos constituintes do TFML.

\subsubsection{Comparação com materiais monolíticos equivalentes}

Material monolítico de alumínio 2024-T3 foi modelado numericamente, assim como o TFML de referência. A Tabela 63 apresenta as características relevantes dos materiais modelados analisados na condição de impacto descrita anteriormente.

Tabela 63: Característica dos modelos utilizados para análise comparativa com materiais monolíticos.

\begin{tabular}{c|c|c}
\hline Material & Representação & Característica \\
\hline $\begin{array}{c}\text { MA-1 } \\
\text { (P4B039) }\end{array}$ & & Material TFML de referência. \\
MA-2 & & $\begin{array}{c}\text { Material monolítico equivalen- } \\
\text { te de SRPP Pure. }\end{array}$ \\
(SRPP - & & \\
\hline
\end{tabular}


Na Figura 113 é apresentado o resultados qualitativo de tais análises. Os resultados de deslocamento central máximo, $W_{f, \max }$, e velocidade residual, $V_{\text {res }}$, estão sumarizados na Tabela 64. Observa-se que o TFML apresenta deslocamento residual menor que o material monolítico de alumínio, estando de acordo com a análise teórica preliminar. Além disso, o metal apresentou ruptura completa, diferentemente do TFML, que apresentou falha apenas nas camadas de reforço. Este fato mostra que o TFML mantem a estanqueidade da estrutura após impacto de mesma magnitude, característica relevante em fuselagens ou estrutura de proteções.

Com relação à absorção de energia, observou-se que o monolítico de alumínio pôde absorver mais energia que o TFML. No entanto deve-se frisar neste caso parte dessa energia foi dissipada com a ruptura e rasgamento da chapa, fato inexistente no TFML. Além disso, tais resultados demostram que o limite balístico do TFML é superior ao do alumínio equivalente.

(a)

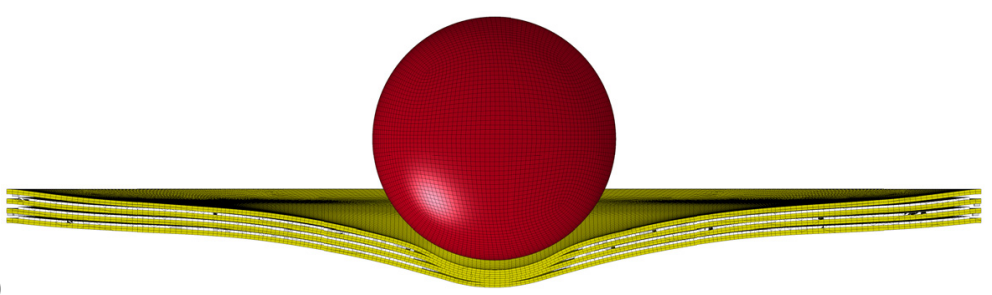

(b)

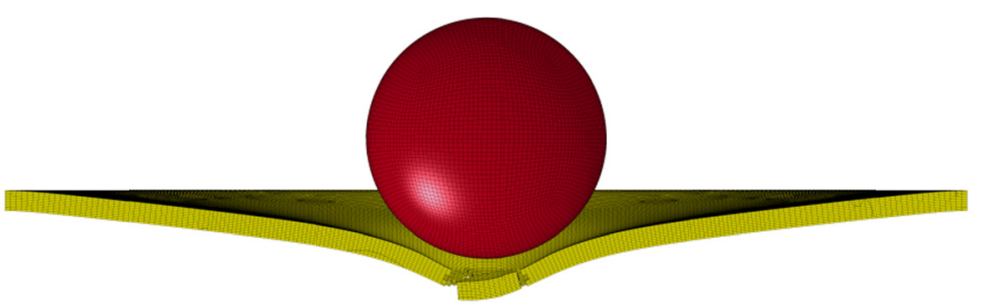

Figura 113: Resultado qualitativo das análises (a) MA-1 e (b) MA-2.

Tabela 64: Resultado da análise comparativa com materiais monolíticos.

\begin{tabular}{c|c|c|c|c}
\hline Material & Representação & $w_{f, \max }(\mathrm{mm})$ & $V_{\text {res }}(\mathrm{m} / \mathrm{s})$ & Falha \\
\hline MA-1 & & 6,57 & 23,42 & Ruptura do reforço \\
& & & & \\
\hline MA-2 & & 6,88 & 19,35 & Ruptura do material \\
\hline
\end{tabular}


Assim, pode-se concluir que o uso do TFML apresenta ganhos quando comparado ao monolítico equivalente de alumínio uma vez que apresentam menor deslocamento máximo, estanqueidade e maior limite balístico.

\subsubsection{Comparação com diferentes configurações de TFML}

TFMLs de configurações 3/2 e 5/4 foram modelados numericamente para comparação de desempenho com o material de referência, o TFML 4/3 (P4B039). Estes materiais apresentam fração volumétrica de constituintes e densidade areal iguais aos do material de referência. Detalhes dos materiais aqui considerados estão apresentados na Tabela 65. Todos estes foram avaliados de forma semelhante ao impacto descrito anteriormente.

Tabela 65: Característica dos modelos utilizados para análise comparativa com outras configurações de TFML.

\begin{tabular}{c|c|c|c}
\hline Material & Configuração & Representação & Característica \\
\hline $\begin{array}{c}\text { MA-1 } \\
\text { (P4-B-039) }\end{array}$ & $4 / 3$ & & Material TFML de referência. \\
$\begin{array}{c}\text { MA-3 } \\
\text { (P3-053-059) }\end{array}$ & $3 / 2$ & & \\
\hline $\begin{array}{c}\text { MA-4 } \\
\text { (P5-032-029) }\end{array}$ & $5 / 4$ & & TFML 3/2 equivallente. \\
\hline
\end{tabular}

(a)

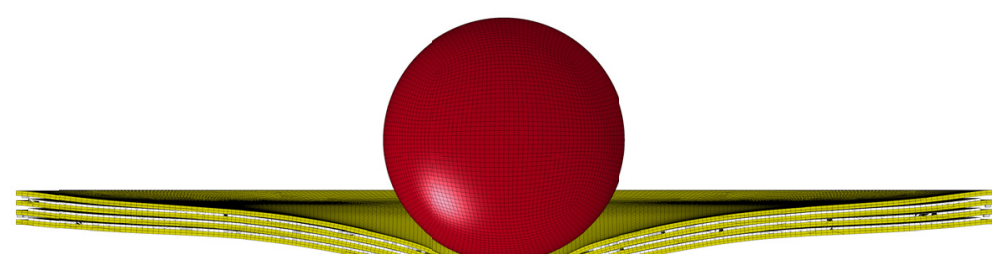

(b)

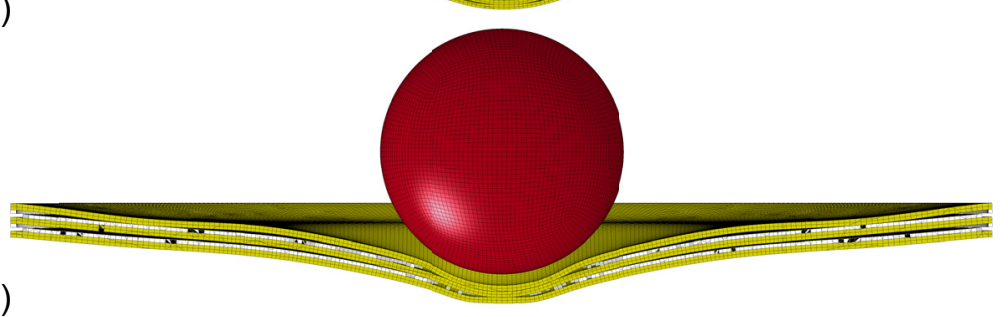


(c)

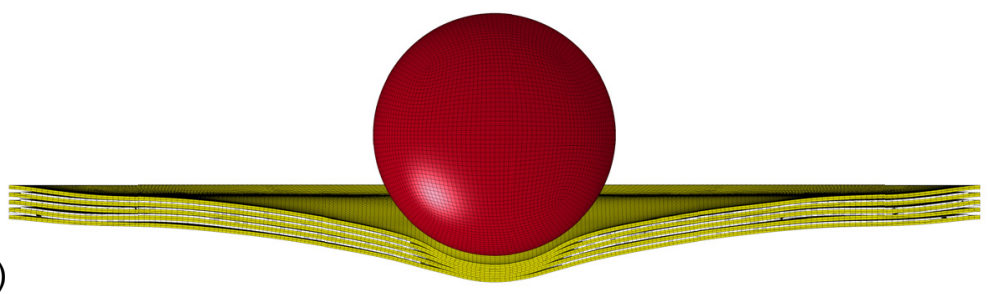

Figura 114: Resultado qualitativo das análises (a) MA-1, (b) MA-3i e (c) MA-4.

$\mathrm{Na}$ Tabela 66 são apresentos os resultados deslocamento central máximo, $w_{f, \text { max }}$, e velocidade residual, $V_{\text {res }}$. Na Figura 114 são apresentados resultados qualitativos dos modelos após o impacto, sendo observadas rupturas apenas nas camadas de SRPP.

Tabela 66: Resultado da análise comparativa de TFML com configurações diferentes.

\begin{tabular}{c|c|c|c}
\hline Material & Representação & $w_{f, \max }(\mathrm{mm})$ & $V_{\text {res }}(\mathrm{m} / \mathrm{s})$ \\
\hline MA-1 & & 6,57 & 23,42 \\
& & & \\
MA-3 & & 6,58 & 23,56 \\
& & 6,54 & 23,48 \\
\hline MA-4 & & & \\
\hline
\end{tabular}

Nas análises descritas acima não foram identificadas diferenciações significativas no comportamento ao impacto de TFML 3/2, 4/3 e 5/4 equivalentes.

\subsubsection{Comparação com TFML com diferentes espessuras de SRPP}

TFML equivalentes foram modelados numericamente, sendo adotadas $200 \%$, $50 \%$ e $25 \%$ da espessura de SRPP do TFML de referência, mantendo-se, no entanto, a mesma densidade superficial através da alteração da espessura das camadas de metal. Estudos também foram conduzidos no intuito de identificar o efeito da combinação de diferentes espessuras de SRPP no comportamento do TFML, sendo 
mantida a fração de constituintes do material de referência. Detalhes de tais materiais estão apresentados na Tabela 67. Estes foram avaliados em eventos de impacto conforme descrito anteriormente.

Tabela 67: Característica dos modelos utilizados para análise comparativa com outras configurações de TFML.

\begin{tabular}{|c|c|c|c|}
\hline Material & $\begin{array}{l}\text { Espessura } \\
\text { de SRPP }\end{array}$ & Representação & Característica \\
\hline $\begin{array}{c}\text { MA-1 } \\
\text { (P4-B-039) }\end{array}$ & $\begin{array}{c}3 \times 0,390 \\
\mathrm{~mm}\end{array}$ & 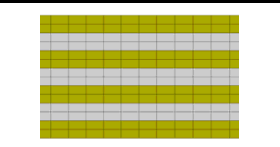 & Material TFML de referência. \\
\hline $\begin{array}{c}\mathrm{MA}-5 \\
(\mathrm{P} 4-032-078)\end{array}$ & $\begin{array}{c}3 \times 0,780 \\
\mathrm{~mm}\end{array}$ & 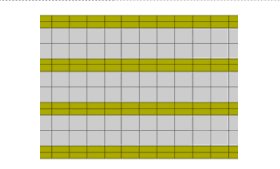 & $\begin{array}{l}\text { TFML equivalente com camadas de } \\
\text { SRPP com o dobro da espessura. }\end{array}$ \\
\hline $\begin{array}{c}\text { MA-6 } \\
\text { (P4-044-019) }\end{array}$ & $3 \times 0,20 \mathrm{~mm}$ & 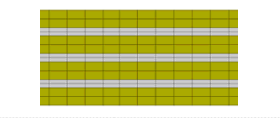 & $\begin{array}{l}\text { TFML equivalente com camadas de } \\
\text { SRPP com metade da espessura. }\end{array}$ \\
\hline $\begin{array}{c}\text { MA-7 } \\
(\mathrm{P} 4-046-010)\end{array}$ & $3 \times 0,10 \mathrm{~mm}$ & & $\begin{array}{l}\text { TFML equivalente com camadas de } \\
\text { SRPP um quarto da espessura. }\end{array}$ \\
\hline $\begin{array}{c}M A-8 \\
(\mathrm{P} 4 \mathrm{~B}[047 / 023 / 047])\end{array}$ & $\begin{array}{c}0,468 \mathrm{~mm} \\
0,243 \mathrm{~mm} \text { e } \\
0,468 \mathrm{~mm}\end{array}$ & 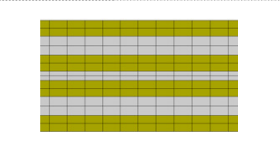 & $\begin{array}{l}\text { TFML equivalente com camadas } \\
\text { externas de SRPP mails espessas. }\end{array}$ \\
\hline $\begin{array}{c}\text { MA-9 } \\
\text { (P4B[029/059/029]) }\end{array}$ & $\begin{array}{c}0,293 \mathrm{~mm} \\
0,585 \mathrm{~mm} \text { e } \\
0,293 \mathrm{~mm}\end{array}$ & 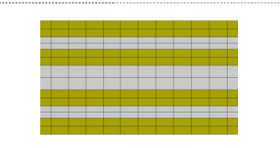 & $\begin{array}{l}\text { TFML equivalente com camada cen- } \\
\text { tral de SRPP mais espessa. }\end{array}$ \\
\hline $\begin{array}{c}\text { MA-10 } \\
\text { (P4B[059/029/029]) }\end{array}$ & $\begin{array}{c}0,585 \mathrm{~mm} \\
0,293 \mathrm{~mm} \mathrm{e} \\
0,293 \mathrm{~mm}\end{array}$ & +2 & $\begin{array}{l}\text { TFML equivalente com camada de } \\
\text { SRPP do lado impactado mais es- } \\
\text { pessa. }\end{array}$ \\
\hline $\begin{array}{c}\text { MA-11 } \\
\text { (P4B[029/029/059]) }\end{array}$ & $\begin{array}{c}0,293 \mathrm{~mm} \\
0,293 \mathrm{~mm} \mathrm{e} \\
0,585 \mathrm{~mm}\end{array}$ & 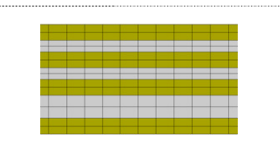 & $\begin{array}{l}\text { TFML equivalente com camada de } \\
\text { SRPP do lado oposto ao impacto } \\
\text { mais espessa. }\end{array}$ \\
\hline
\end{tabular}

A Figura 115 apresenta resultados qualitativos das analises $\mathrm{MN}-1, \mathrm{MN}-5, \mathrm{MN}-$ 6 e MN-7, sendo incluído a análise MN-7. Com exceção no modelo MN-2, apenas falha nas camadas de SRPP são observadas. Para o caso do material MA-5 foi observado um aparente colapso do material, com deslocamento total de todas as camadas do TFML. A Tabela 69 apresenta os resultados deslocamento central máximo, $w_{f, \max }$, velocidade residual, $V_{\text {res }}$ para estas amostras, os quais também estão apresentados na Figura 116. 
(a)

(b)
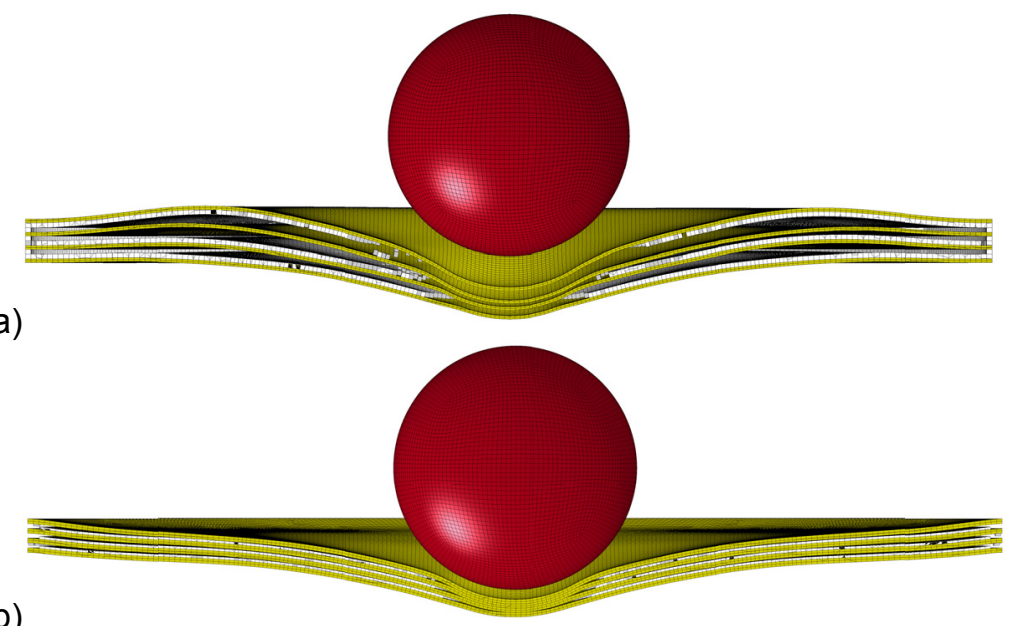

(c)

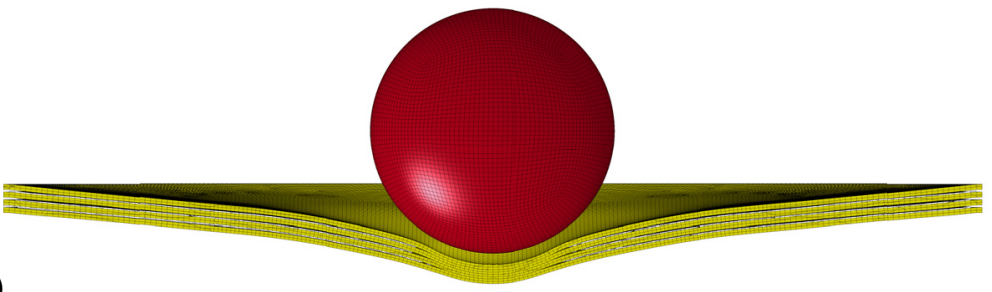

(d)

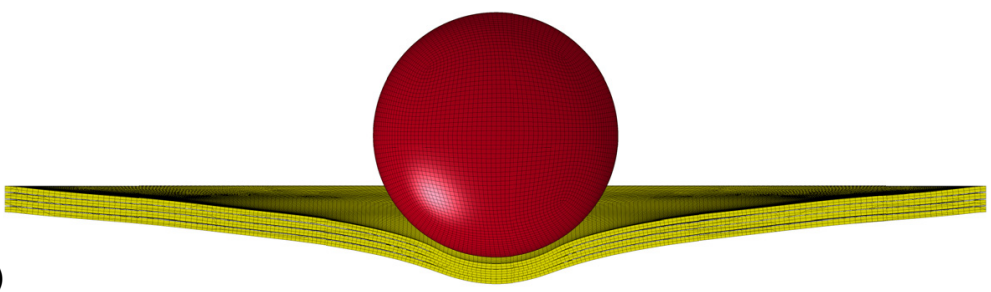

(e)

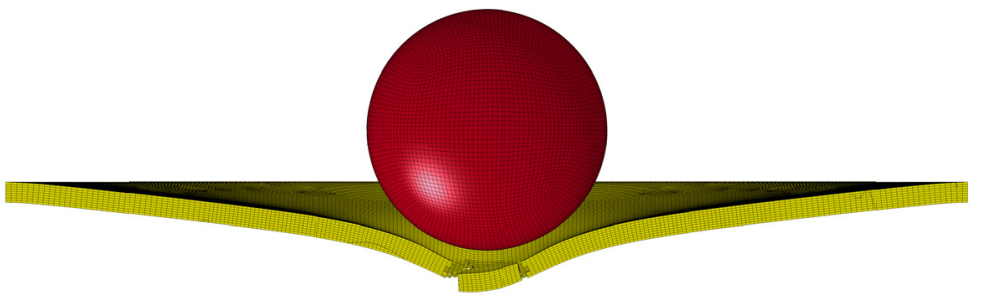

Figura 115: Comparação de resultadlos qualitativo das análises (a) MA-5, (b) MA-1, (c)MA-6, (d)MA-7 e (e)MA-2.

Observa-se que com o aumento da espessura de SRPP tem-se a redução do deslocamento máximo. Este fato se dá pelo aumento do momento de inércia do material, assim como pelo consumo de energia para a compressão e ruptura do SRPP. No entanto esta análise remonta a existência de condições limites, havendo, de um lado, o monolítico de alumínio, com ruptura após impacto ruptura, e, de outro, o modelo MA-5, com uma aparente excesso de SRPP, demostrando descolamento total das camadas e colapso do material após o impacto. Em ambos os casos limites, tem-se uma maior absorção de energia (com redução da velocidade residual) causada pela ruptura excessiva do material e consequente colapso. Entre tais limites, têm-se os TFMLs MA-1, MA-6 e MA-7, com comportamento estável e sem ruptura 
completa do material. Vale lembrar também o aumento de $W_{f, \max }$ com a diminuição das espessuras das camadas de SRPP, de acordo com a análise teórica apresentada anteriormente.

Tabela 68: Resultado da análise comparativa de TFML com diferentes espessuras de SRPP.

\begin{tabular}{c|c|c|c}
\hline Material & Representação & $w_{f, \max }(\mathrm{mm})$ & $V_{\text {res }}(\mathrm{m} / \mathrm{s})$ \\
\hline MA-5 & & 6,31 & 14,62 \\
& & 6,57 & 23,42 \\
MA-1 & & 6,77 & 23,45 \\
\hline MA-6 & & 6,83 & 23,56 \\
MA-7 & & 6,88 & 19,35 \\
\hline MA-2 & & & \\
\hline
\end{tabular}
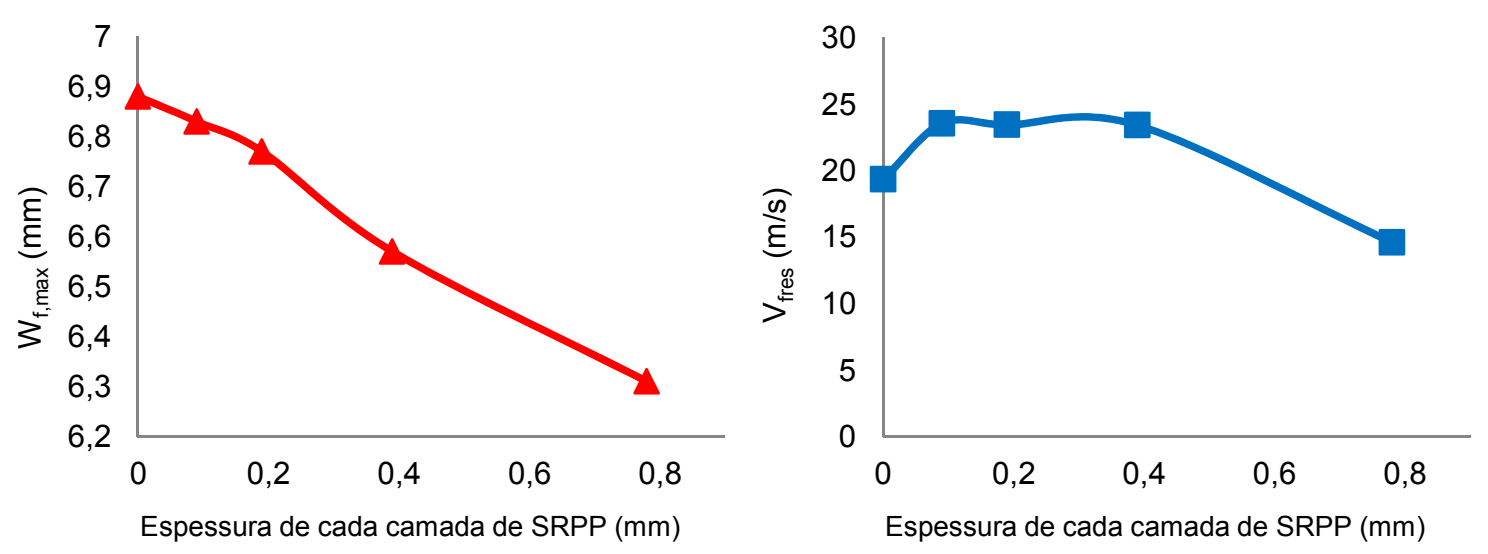

Figura 116: Resultados de deslocamento máximo e velocidade residual TFMLs com várias espessuras de SRPP e monolítico equivalentes.

A Tabela 69 apresenta resultados quantitativos para as análises MA-1, MA-8, MA-9, MA-10 e MA-11, considerando diferentes combinações de espessuras de SRPP em um mesmo TFML. Nenhuma diferenciação significativa foi observada entra as análises MA-8, MA-9 e MA-10, no entanto foi identificado um desempenho levemente superior para o caso MA-11, o qual apresenta maior espessura de SRPP na face oposta ao impacto, no tocante ao deslocamento máximo do material. Neste 
caso, tal camada, que esta mais afastada da região de impacto, está menos sucinta ao esmagamento e decorrente falha prematura causada pelo contato do indentador. Além disso, nesta condição o SRPP está submetido a esforços de membrana mais significativos, apresentado melhor desempenho estrutural no material. A Figura 117 apresenta o corte transversal dos materiais após o impacto.

Tabela 69: Resultado da análise comparativa de TFML com diferentes esipessuras de SRPP.

\begin{tabular}{c|c|c|c}
\hline Material & Representação & $w_{f, \max }(\mathrm{mm})$ & $V_{\text {res }}(\mathrm{m} / \mathrm{s})$ \\
\hline MA-1 & & 6,57 & 23,42 \\
& & 6,60 & 23,64 \\
MA-8 & & 6,60 & 22,95 \\
MA-9 & & 6,67 & 23,47 \\
MA-10 & & 6,51 & 23,24 \\
\hline MA-11 & & & \\
\hline
\end{tabular}

(a)

(b)

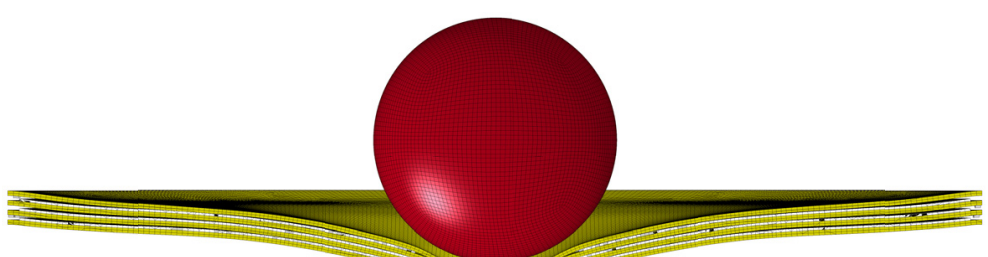

(c)
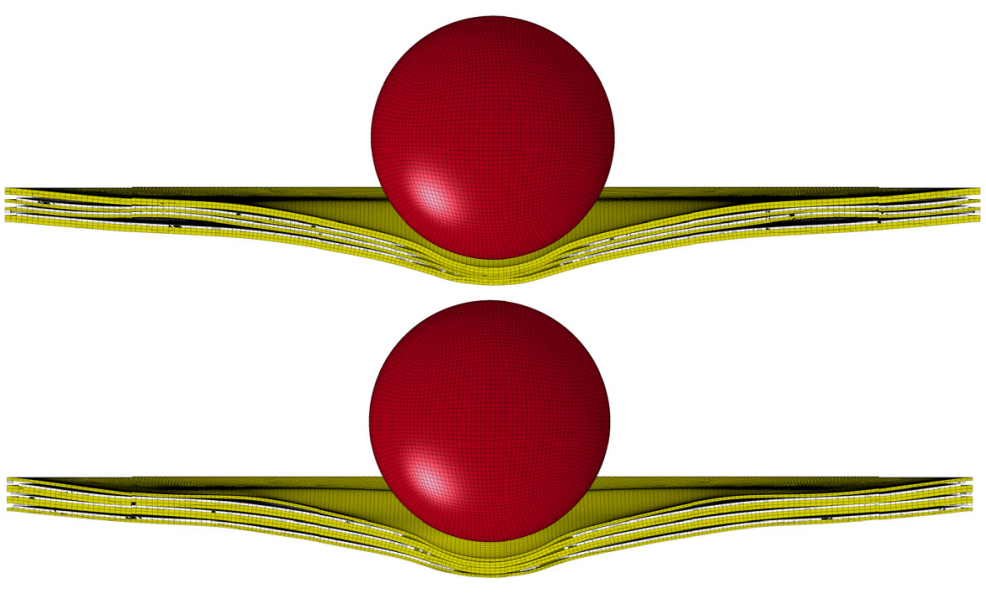
(d)

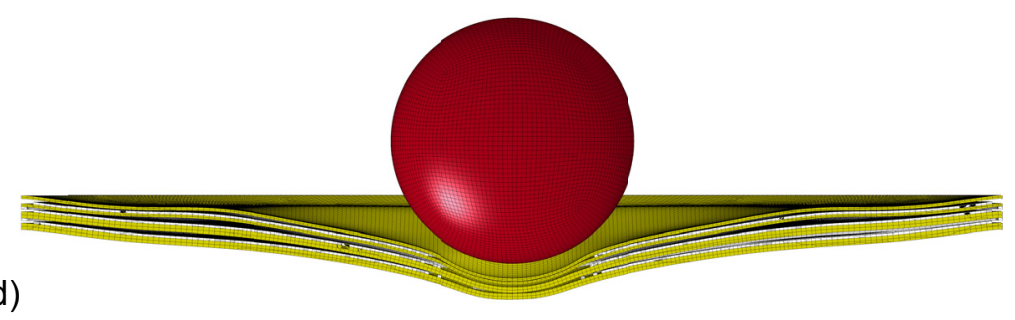

(e)

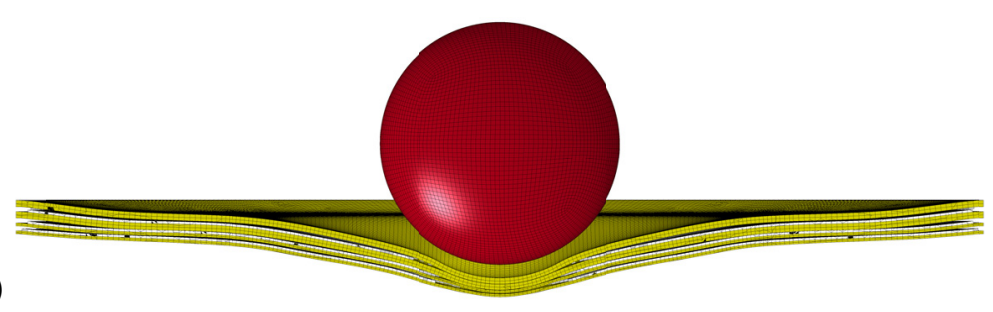

Figura 117: Secção transversal das amostras (a)MA-1, (b)MA-8, (c)MA-9, (d)MA-10, (e)MA-11 após impacto.

\subsubsection{Comparação TFML 4/3 com diferentes espessuras de metais}

TFML equivalentes ao material de referência foram modelados utilizando diferentes espessuras de camadas metálicas, sendo mantida a mesma fração dos constituintes e densidade superficial. A Tabela 70 sumariza as características relevantes dos materiais considerados. Estes materiais foram avaliados na mesma condição de impacto utilizada anteriormente.

$\mathrm{Na}$ Tabela 71 são apresentados os resultados quantitativos das análises em questão. Não foi observada diferença significativa entre as análises MA-1, MA-12 e MA-13. Para a análise MA-14, o qual apresenta camadas metálicas mais espessas na face oposta ao impacto, foi observado uma maior deslocamento máximo. Por sua vez, a análise MA-15, que apresenta camadas metálicas mais espessas na face impactada, apresentou o menor deslocamento máximo. $O$ fato aqui observado é causado pelo motivo que as camadas mais espessas na face impactada evitam o esmagamento, e consequente falha prematura, das camadas de SRPP, conforme apresentado na comparação apresentada na Figura 118. 
Tabela 70: Característica dos modelos utilizados para análise comparativa de TFML com diferentes espessuras de camadas metálicas.

\begin{tabular}{|c|c|c|}
\hline Material & Representação & Característica \\
\hline $\begin{array}{c}\text { MA-1 } \\
(\mathrm{P} 4-\mathrm{B}-039)\end{array}$ & 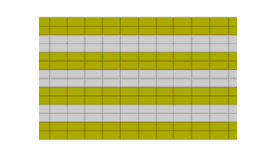 & Material TFML de referência. \\
\hline $\begin{array}{c}\mathrm{MA}-12 \\
(\mathrm{P} 4[054 / 026 / 026 / 054] 039)\end{array}$ & 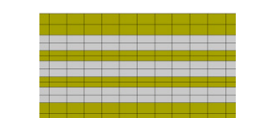 & $\begin{array}{l}\text { TFML equivalente com camadas metálicas ex- } \\
\text { ternas com o dobro da espessura. }\end{array}$ \\
\hline $\begin{array}{c}\mathrm{MA}-13 \\
(\mathrm{P} 4[026 / 054 / 054 / 026] 039)\end{array}$ & +2 & $\begin{array}{l}\text { TFML equivalente com duas camadas metálicas } \\
\text { internas com o dobro da espessura. }\end{array}$ \\
\hline $\begin{array}{c}M A-11 \\
(\mathrm{P} 4[026 / 026 / 054 / 054] 039)\end{array}$ & 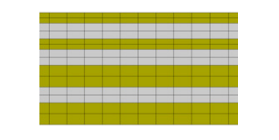 & $\begin{array}{l}\text { TFML equivalente com duas camadas metálicas } \\
\text { do lado oposto ao impacto com o dobro da es- } \\
\text { pessura. }\end{array}$ \\
\hline $\begin{array}{c}\text { MA-14 } \\
\text { (P4[054/054/026/026]039) }\end{array}$ & +2 & $\begin{array}{l}\text { TFML equivalente com duas camadas metálicas } \\
\text { do lado impactado com o dobro da espessura. }\end{array}$ \\
\hline
\end{tabular}

Tabela 71: Resultado da análise comparativa de TFML com diferentes espessuras de metal.

\begin{tabular}{c|c|c|c}
\hline Material & Representação & $w_{f, \max }(\mathrm{mm})$ & $V_{\text {res }}(\mathrm{m} / \mathrm{s})$ \\
\hline MA-1 & & 6,57 & 23,42 \\
& & 6,56 & 21,84 \\
\hline MA-12 & & 6,63 & 23,66 \\
& & & \\
MA-13 & & 6,75 & 23,53 \\
& & & \\
MA-14 & & 6,44 & 21,78 \\
\hline MA-15 & & & \\
\hline
\end{tabular}


(a)

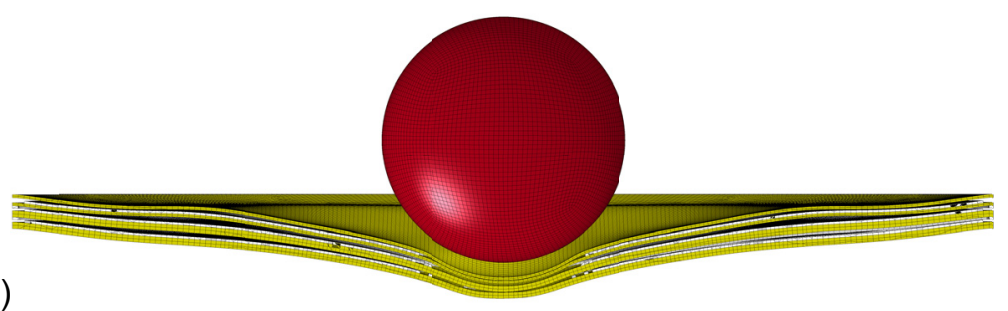

(b)

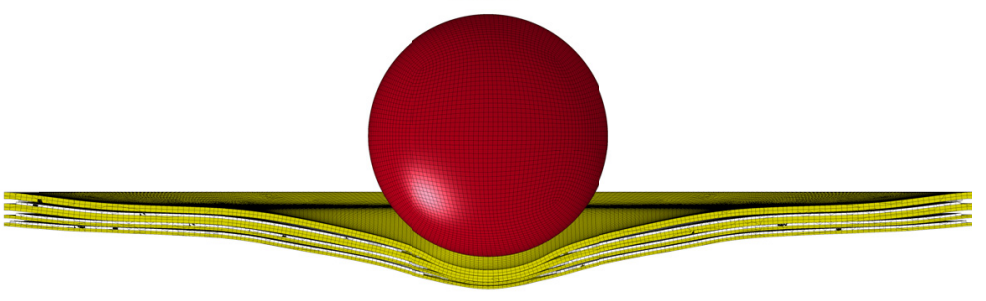

Figura 118: Comparação do comportamento de (a) MA-14 e (b) MA-15.

\subsubsection{Proposição de uma configuração de TFML}

Com base nas análises apresentadas nos itens 9.4.1 a 9.4.5, uma configuração de TFML foi proposta, visando a melhoria do seu desempenho ao impacto. Optou-se por utilizar um TFML com mesma configuração e fração de constituintes do material de referência, além da mesma densidade superficial. Foi proposta a utilização de camadas metálicas mais espessas na face impactada e camadas de SRPP mais espessas na face oposta ao impacto. Este material foi modelado em um evento de impacto semelhante ao utilizando para avaliação nos itens anteriores. A Tabela 72 sumaria as características relevantes desse material, assim como o material de referência.

Tabela 72: Configuração de TFML proposta.

\begin{tabular}{|c|c|c|}
\hline Material & Representação & Característica \\
\hline $\begin{array}{c}\text { MA-1 } \\
(\mathrm{P} 4-\mathrm{B}-039)\end{array}$ & 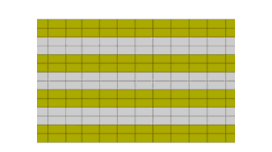 & Material TFML de referência. \\
\hline $\begin{array}{c}\mathrm{MA}-16 \\
(\mathrm{P} 4[054 / 054 / 026 / 026] \\
[029 / 029 / 059]))\end{array}$ & 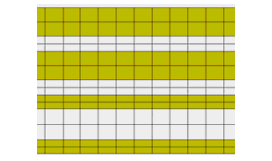 & $\begin{array}{l}\text { TFML equivalente com duas camadas metálicas } \\
\text { espessas na face impactada e camadas de } \\
\text { SRPP espessas na face oposta ao impacto. }\end{array}$ \\
\hline
\end{tabular}

Na Figura 119 é apresentada a comparação qualitativa dos materiais após o impacto, sendo possível observar o retardamento da ruptura do SRPP para a confi- 
guração propostas. A Tabela 73 apresenta os resultados dessa análise, sendo possível observar que o TFML proposto apresenta velocidade residual cerca de $14 \%$ menor e absorve cerca de $27 \%$ a mais de energia que o material de referência equivalente, quando submetidos a mesma condição de impacto. Assim como material de referência, não houve ruptura completa dos TFMLs após o impacto. Vale ressaltar que o aqui obtido é oriundo apenas da redistribuição da camadas do TFML, sendo mantida a mesma composição e densidade areal do material original.

(a)

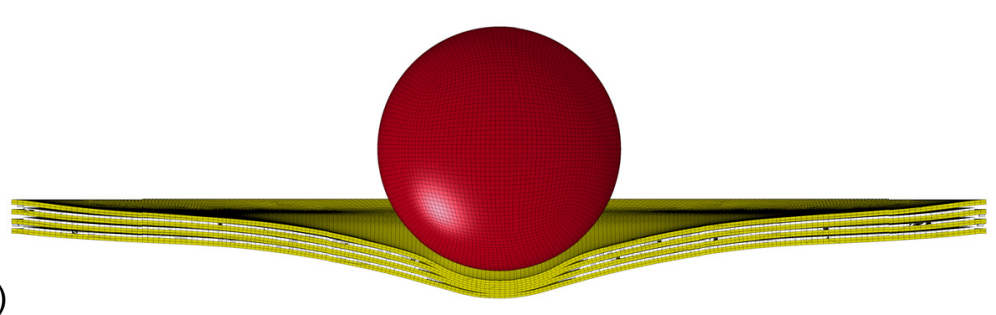

(b)

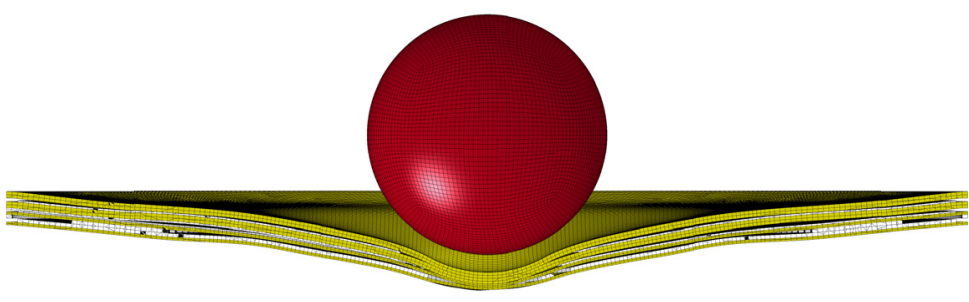

Figura 119: Comparação do comportamento de MA-1 e MA-16 após o impacto.

Tabela 73: Resultado da análise comparativa de TFML de referência e a configuração proposta.

\begin{tabular}{|c|c|c|c|}
\hline Material & Representação & $w_{f, \max }(\mathrm{mm})$ & $V_{r e s}(\mathrm{~m} / \mathrm{s})$ \\
\hline MA-1 & 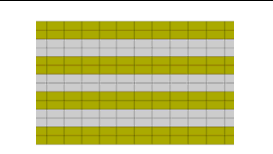 & 6,57 & 23,42 \\
\hline MA-16 & 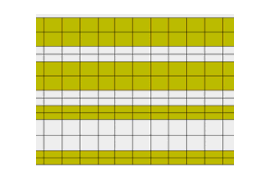 & 6,19 & 20,04 \\
\hline
\end{tabular}

\subsection{CONSIDERAÇÕES FINAIS}

Neste capítulo aspectos que influenciam o desempenho ao impacto de TFML foram avaliados. Foi observado que o material apresenta sensibilidade à taxa de deformação, absorvendo mais energia em eventos de impacto de alta velocidade. A 
geometria do indentador foi avaliada, sendo observado que o comportamento do material apenas é influenciado significativamente em eventos onde ocorrem ruptura completa do material e penetração. A localização do impacto foi avaliada, sendo observado que, para o caso de placas circulares com $80 \mathrm{~mm}$ de diâmetro, excentricidades de até $6 \mathrm{~mm}$ causam variações pouco significativas no comportamento do material ao impacto.

Os três estudos apresentados acima realizados endossam o desenvolvimento e as hipóteses adotadas durante a pesquisa, no tocante de caracterização dinâmica de materiais, necessária pela sensibilidade à taxa de deformação do material; hipóteses adotadas para a utilização do modelo teórico de Jones, onde o desenho do indentador fora desconsiderado; e comparação de eventos e impacto de alta velocidade, onde foi observada excentricidade entre nos experimentos.

Estudos também foram conduzidos no intuito de comparar numericamente o comportamento do TFML ao impacto com placa monolíticas de alumínio 2023-T3, apresentando superioridade com relação à ruptura total do material e deslocamento máximo residual. Foi observada também a influência da forma de empilhamento das camadas do TFML, sendo que camadas mais espessas de alumínio na face impactada e camadas mais espessas de SRPP na face oposta ao impacto melhoram o desempenho ao impacto de TFML. Uma redistribuição de camadas ao material de referência (TFML 4/3 P4B039), com desempenho ao impacto $14 \%$ superior em absorção de cargas de impacto.

Neste capítulo, um modelo numérico, cujos resultados foram satisfatoriamente comparados com resultados experimentais anteriormente, foi intensamente explorado buscando identificar e aperfeiçoar o comportamento do TFML ao impacto. Este procedimento realça a real facilidade das ferramentas numéricas, uma vez que o estudo aqui realizado seria oneroso se realizado de forma experimental. No entanto a maioria dos resultados aqui explorados são de natureza comparativa, devendo as conclusões finais aqui apresentadas serem avaliadas de forma experimental para obtenção de uma conclusão definitiva. 


\section{CONCLUSÕES}

Neste trabalho foi realizado o estudo ao impacto de um laminado fibra-metal utilizando material inovador de polipropileno como reforço (TFML, do inglês thermoplastic fibre-metal laminates), sendo que foram desenvolvidas abordagens teórica, numérica e experimental para isso.

Amostras do material foram fabricadas utilizando processo termomoldagem, cujos detalhes estão apresentados no Capítulo 4. Eventos de impacto de baixa e alta velocidade foram realizados utilizando um martelo de impacto e canhão pneumático, respectivamente. Amostras de FML comerciais, utilizando reforços vidro/epóxi, também foram ensaiadas para fins de comparação de desempenho. Pode-se observar que o TFML apresenta resistência mecânica inferior ao FML comercial. Porém, uma vez que este apresenta menor densidade, o comportamento do TFML se equivale ou supera ao do FML comercial quando o peso estrutural é levado em consideração. Vale ressaltar que o TFML apresentou fragilidade na interface metal-polímero, o que causou descolamento excessivo de camadas após o impacto.

Um dispositivo foi desenvolvido para realização de ensaios de tração a médias taxas de deformação, utilizando a energia de uma massa em queda livre, capaz de caracterizar polímeros e materiais nas taxas de deformação de 20/s a 200/s. Este equipamento, combinado com máquinas de ensaio universal comerciais, foi utilizado para a caracterização do TFML e seus constituintes em uma ampla faixa de taxas de deformação.

O alumínio 2024-T3 foi caracterizado em regime estático e dinâmico, sendo identificada a curva tensão-deformação real nestas condições. Parâmetros constitutivos e de dano foram identificado para este material, utilizando o modelo de material MAT-15 do programa comercial LS-Dyna. O material autoreforçado inovador de polipropileno (SRPP) foi caracterizado em tração e compressão nos regimes estático e dinâmico. Foi observado que o material apresenta um comportamento visco-elástico linear em ambos os casos, com sensibilidade à taxa de deformação. Ensaios de cisalhamento do material também foram realizados, sendo observada uma resposta não linear. Parâmetros constitutivos do SRPP foram identificados, utilizando os mo- 
delos de material MAT-58 e MAT-24 do programa comercial LS-Dyna. Ensaios de tração quase estáticos também foram conduzidos em amostras de TFMLs.

Os modelos teóricos de Jones e Reid-Wen foram adaptados para a predição do deslocamento máximo residual e limite balístico de TFML ao impacto, respectivamente. Coma utilização da Regra das misturas para homogeneização das propriedades, ambos os modelos poderam prever o comportamento do material ao impacto, possíveis de serem utilizado em projeto preliminar ou avaliação de elementos ao impacto.

Um modelo numérico do fenômeno de impacto de alta e baixa velocidade foi desenvolvido utilizando o programa comercial LS-Dyna, sendo capaz de representar o comportamento qualitativo e quantitativo do TFML ao impacto, provendo resultados aproximadamente $15 \%$ divergentes dos resultados experimentais. O desenvolvimento deste modelo está detalhadamente descrito no Capítulo 8, para possíveis utilizações em outros trabalhos relacionados com o TFML.

Uma vez que o fenômeno e o material foram modelados satisfatoriamente, o comportamento do TFML ao impacto foi avaliado, buscando identificar parâmetros relevantes que influenciam no comportamento do material. O comportamento TFML foi comparado ao monolítico de alumínio 2024-T3, apresentado superioridade no tocante ao deslocamento máximo residual. Além disso, o alumínio equivalente apresentou ruptura completa após impacto, não observada nas amostras de TFML. Teoricamente observou-se que quanto maior a fração de SRPP na composição do TFML, melhor será o desempenho deste ao impacto. Porém, a análise numérica deste fato demostra que existe um limite para o qual o excesso de SRPP causa descolamento entre camadas e colapso do material durante o impacto.

Numericamente, foi observado que TFML com camadas metálicas espessas na face impactada e camadas de SRPP espessas na face oposta ao impacto apresentam melhor desempenho, evitando a ruptura prematura das camadas de reforços. Uma configuração aprimorada de TFML foi sugerida, apresentado desempenho $14 \%$ superior no que diz respeito a energia absorvida durante o impacto, quando comparado a TFML de referência.

Após o desenvolvimento deste trabalho, pode-se concluir que o TFML aqui estudado possui características promissoras para utilização em elementos leves submetidos a cargas de impacto, apresentando desempenho semelhante ou superi- 
or a FML comerciais utilizados na atualidade, ainda somadas ao menor custo de fabricação, menor peso e possibilidade de reciclagem.

São exemplos de possíveis aplicações desse material: estruturas aeronáuticas submetidas ao impacto, como bordos de ataque de asas e parte frontal de aeronaves; elementos de absorção de impacto automotivo, como estrutura interna de para-choques ou capô; material para blindagem militar e equipamentos de proteção pessoal, como capacetes e joelheiras.

No entanto, alguns aspectos dos TFMLs ainda devem ser avaliados para viabilização de sua utilização comercial. Assim, os seguintes tópicos são sugeridos para a continuação desse trabalho:

- Melhoria da adesão entre metal e polímero;

- Avaliação das propriedades de TFMLs em temperaturas elevadas;

- Processos de união de TFMLs;

- Processos de fabricação de peças com TFML;

- Tolerância do dano;

- Resistência residual de TFMLs após impacto;

- Avaliação da durabilidade de TFMLs

- Processos de reparo em TFMLs;

- Processo de reciclabilidade de TFMLs;

- Estudo de viabilidade econômica de TFMLs. 



\section{REFERÊNCIAS BIBLIOGRÁFICAS}

ABDULLAH, M.; CANTWELL, W. The impact resistance of polypropylene-based fibre-metal laminates. Composites Science and Technology, v. 66, p. 1682-1693, 2006.

ALCOCK, B.; Cabrera, NO; Barkoula, NM; Pejis, T. Low velocity impact performance of recyclable all-polypropylene composites. Composites Science and Technology, v. 66, p. 1724-1737, 2006.

ALCOCK, B.; CABRERA, NO; BARKOULA, NM; PEJIS, T. The effect of temperature and strain rate on the mechanical properties of highly oriented polypropylene tapes and all-polypropylene composites. Composites Science and Technology, v. 67, p. 2061-2070, 2007.

ALCOCK, B.; CABRERA, NO; BARKOULA, NM; PEJIS, T. The mechanical properties of woven tape all-polypropylene composites. Composites Part a-Applied Science and Manufacturing, v. 38, p. 147-161, 2007.

ALVES, M.; KARAGIOZOVA, D.; MICHELLI, G. B.; CALLE, M. A. G. Limiting the influence of friction on the split Hopkinson pressure bar tests by using a ring specimen. International Journal of Impact Engineering, v. 49, p. 130-141, 2012.

ASTM - AMERICAM SOCIETY FOR TESTING AND MATERIALS. D3039 - 08 . Test Method for Tensile Properties of Polymer Matrix Composite Materials. West Conshohocken, 2008.

ASTM - AMERICAM SOCIETY FOR TESTING AND MATERIALS. D3518 - 07. Test Method for In-Plane Shear Response of Polymer Matrix Composite Materials by Tensile Test of a 45 Laminate. West Conshohocken, ASTM International, 2013.

ASTM - AMERICAM SOCIETY FOR TESTING AND MATERIALS. E 8/E 8M - 08. Test Methods for Tension Testing of Metallic Materials. West Conshohocken, ASTM International 2013.

AVALLE, M.; PERONI, L.; PERONI, M. The mechanical behaviour of aluminium foam structures in different loading conditions. International Journal of Impact Engineering, v. 35, p. 644-658, 2008.

BROWN, K. A.; BROOKS, R.; WARRIOR, N. A. The static and high strain rate behaviour of a commingled E-glass/polypropylene woven fabric composite. Composites Science and Technology, v. 70, p. 272-283, 2010.

BUYUK, M.; LOIKKANEN, M.; KAN, C. Explicit finite element analysis of 2024T3/T351 aluminum material under impact loading for airplane engine containment and fragment shielding. DOT/FAA/AR-08/36. National Technical Information Service (NTIS), 2008. 
CALLISTER, W. D. Materials science and engineering : an introduction. 6th. New York, NY: John Wiley \& Sons, 2003.

CHEN, W.; SONG, B. Slip Hopkinson (Kolsky) Bar: Design, testing and Applications. United States: Spinger New York Dordrecht Heidelberg London, 2011.

COLE, B.; STURGES, J. The flying wedge: a method for high strain rate tensile testing. Part 2: Characteristics of the device. International Journal of Impact Engineering, v. 28, p. 891-908, 2003.

COMPSTON, P.; CANTWELL, W. J.; JONES, C.; JONES, N. et al. Impact perforation resistance and fracture mechanisms of a thermoplastic based fiber-metal laminate. Journal of Materials Science Letters, v. 20, p. 597-599, 2001.

CORTES, P.; CANTWELL, W. Fracture properties of a fiber-metal laminates based on magnesium alloy. Journal of Materials Science, v. 39, p. 1081-1083, 2004.

DANIEL, I. M.; ISHAI, O. Engineering mechanics of composite materials. 2nd. New York: Oxford University Press, 2006, $411 \mathrm{p}$.

FAN, J.; GUAN, Z.; CANTWELL, W. Numerical modelling of perforation failure in fibre metal laminates subjected to low velocity impact loading. Composite Structures, v. 93, p. 2430-2436, 2011.

FATT, M.; LIN, C. F.; REVILOCK, D. M.; HOPKINS, D. A. Ballistic impact of GLARE (TM) fiber-metal laminates. Composite Structures, v. 61, p. 73-88, 2003.

FERNIE, R.; WARRIOR, N. A. Impact test rigs for high strain rate tensile and compressive testing of composite materials. Strain, v. 38, p. 69-73, 2002.

FGI. Twintex standard product especification. Estados Unidos 2013.

FLEISHER, H. J. Desing and exposive testing of a blast resistant luggage container. Structures under shock and impact IV. WIT Press, 1996.

GUAN, Z.; CANTWELL, W.; ABDULLAH, R. Numerical Modeling of the Impact Response of Fiber-Metal Laminates. Polymer Composites, v. 30, p. 603-611, 2009.

HALLQUIST, J. LS-Dyna Theory Manual. United States, 2006.

JONES, N. Structural impact. 1st pbk. Cambridge; New York: Cambridge University Press, 1997, 575 p.

JONES, N. On the mass impact loading of ductile plates. Defence Science Journal, v. 53, p. 15-24, 2003.

JONES, N.; KIM, S. B.; LI, Q. M. Response and failure of ductile circular plates struck by a mass. Journal of Pressure Vessel Technology-Transactions of the Asme, v. 119, p. 332-342, 1997. 
KAMINSKI, P. Desenvolvendo produtos com planejamento, criatividade e qualidade. $1^{\circ} \mathrm{ed}$. LTC, 2000.

KARAGIOZOVA, D.; LANGSON, G. S.; NURICK, G. N.; YUEN, S. C. K. Simulation of the response of fibre-metal laminates to localised blast loading. International Journal of Impact Engineering, v. 37, p. 766-782, 2010.

KARIEM, M.; BEYNON, J.; RUAN, D. Misalignment effect in the split Hopkinson pressure bar technique. International Journal of Impact Engineering, v. 47, p. 60-70, 2012.

LANGDON, G.; CANTWELL, W.; NURICK, G. The blast response of novel thermoplastic-based fibre-metal laminates - some preliminary results and observations. Composites Science and Technology, v. 65, p. 861-872, 2005.

LANGDON, G.; CANTWELL, W.; NURICK, G. Localised blast loading of fibre-metal laminates with a polyamide matrix. Composites Part B-Engineering, v. 38, p. 902913, 2007.

LANGDON, G. S.; CHI, Y.; NURICK, G. N.; HAUPT, P. Response of GLARE (c) panels to blast loading. Engineering Structures, v. 31, p. 3116-3120, 2009.

LANGDON, G. S.; CHI, Y.; NURICK, G. N.; HAUPT, P. Behaviour of fibre-metal laminates subjected to localised blast loading: Part I - Experimental observations. International Journal of Impact Engineering, v. 34, p. 2007.

LANGDON, G. S.; CHI, Y.; NURICK, G. N.; HAUPT, P. Failure characterisation of blast-loaded fibre-metal laminate panels based on aluminium and glass-fibre reinforced polypropylene. Composites Science and Technology, v. 67, p. 1385-1405, 2007.

LANGDON, G. S.; NURICK, G. N.; CANTWELL, W. J. The response of fibre metal laminate panels subjected to uniformly distributed blast loading. European Journal of Mechanics a-Solids, v. 27, p. 107-115, 2008.

LANKHORST. PURE: thermoplastic composite material with ultimate properties. Sneek, 2011.

LEMANSKI, S. L.; LANGDON, G. S.; NURICK, G. N.; SIMMONS, M. C.; CANTWELL, W. J.; SCHLEYER, G. K. Behaviour of fibre metal laminates subjected to localised blast loading - Part II: Quantitative analysis. International Journal of Impact Engineering, v. 34, p. 1223-1245, 2007.

LSTC. LS-Dyna Keyword user's manua, vol. 1 , version 971. Livermore software Technology Coorporation. 2: 1064 p. 2012a.

LSTC. LS-Dyna Keyword user's manua, vol. 2 , version 971. Livermore Software Technology Corporation. $12012 b$. 
MCCARTHY, M.; XIAO, J. R.; PETRINIC, N.; KAMOULAKOS, A.; MELITO, V. Modelling of bird strike on an aircraft wing leading edge made from fibre metal laminates - Part 1: Material modelling. Applied Composite Materials, v. 11, p. 295315, 2004.

MCCARTHY, M.; XIAO, J. R.; PETRINIC, N.; KAMOULAKOS, A.; MELITO, V. Modelling of bird strike on an aircraft wing leading edge made from fibre metal laminates - Part 2: Modelling of impact with SPH bird model. Applied Composite Materials, v. 11, p. 317-340, 2004.

MCKOWN, S.; CANTWELL, W. Investigation of strain-rate effects in self-reinforced polypropylene composites. Journal of Composite Materials, v. 41, p. 2457-2470, 2007.

MOTT, P. H.; TWIGG, J. N.; ROLAND, D. F.; SCHRADER, H. S.; PATHAK, J. A.; ROLAND, C. M. High-speed tensile test instrument. Review of Scientific Instruments, v. 78, 2007.

MOURA, R. T.; CLAUSEN, A. H.; LANGSETH, M.; ALVES, M. Dynamic mechanical behaviour of polyethylene. Dymat 2009: 9th International Conference on the Mechanical and Physical Behaviour of Materials Under Dynamic Loading, Vol 1, p. 497-502, 2009.

NURICK, G. N.; LANGDON, G. S.; LEMANSKI, S. L.; SIMMONS, M. C.; CANTWELL. W. J.; SCHLEYER, G. K. Behaviour of fibre-metal laminates subjected to localised blast loading: Part I - Experimental observations. International Journal of Impact Engineering, v. 34, p. 1202-1222, 2007.

OTHMAN, R.; GUEGAN, P.; CHALLITA, G.; PASCO, F.; LEBRETON, D. A modified servo-hydraulic machine for testing at intermediate strain rates. International Journal of Impact Engineering, v. 36, p. 460-467, 2009.

REID, S. R.; WEN, H. M. Perforation of FRP laminates and sandwich panels subjected to missile impact. Impact Behaviour of Fibre-Reinforced Composite Materials and Structures. Cambridge, Woodhead Publishing, 200, p. 239-279.

REYES, G.; CANTWELL, W. J. The effect of strain rate on the interfacial fracture properties of carbon fiber-metal laminates. Journal of Materials Science Letters, v. 17, p. 1953-1955, 1998.

REYES, G.; CANTWELL, W. J. The mechanical properties of fibre-metal laminates based on glass fibre reinforced polypropylene. Composites Science and Technology, v. 60, p. 1085-1094, 2000.

REYES, G.; KANG, H. Mechanical behavior of lightweight thermoplastic fiber-metal laminates. Journal of Materials Processing Technology, v. 186, p. 284-290, 2007.

SADIGHI, M.; ALDERLIESTEN, R.; BENEDICTUS, R. Impact resistance of fibermetal laminates: A review. International Journal of Impact Engineering, v. 49, p. 7790, 2012. 
SHARPE, W. N. Springer handbook of experimental solid mechanics. Berlin, Springer, 2008.

SHOKRIEH, M. M.; OMIDI, M. J. Compressive response of glass-fiber reinforced polymeric composites to increasing compressive strain rates. Composite Structures, v. 89 , n. 4, p. 517-523, 2009.

SHOKRIEH, M. M.; OMIDI, M. J. Investigation of strain rate effects on in-plane shear properties of glass/epoxy composites. Composite Structures, v. 91, p. 95-102, 2009.

SHOKRIEH, M. M.; OMIDI, M. J. Tension behavior of unidirectional glass/epoxy composites under different strain rates. Composite Structures, v. 88, p. 595-601, 2009.

SHOKRIEH, M. M.; OMIDI, M. J. Investigating the transverse behavior of GlassEpoxy composites under intermediate strain rates. Composite Structures, v. 93, p. 690-696, 2011.

SLYCKEN, J.; VERLEYSEN, P.; DEGRIECK, J.; BOUQUEREL, J.; BREBBIA, C. A. Characterisation of the high strain rate properties of advanced high strength steels. High Performance Structures and Materials III, v. 85, p. 259-268, 2006.

SINMAZÇELIK, T.; AVCU, E.; BORA, M. Ö.; ÇOBAN, O. A review: fibre metal laminates, background, bonding types and applied test methods. Material and design, v. 32, p. 3671-3685, 2011.

STURGES, J. L.; COLE, B. N. The flying wedge: A method for high-strain-rate tensile testing. Part 1. Reasons for its development and general description. International Journal of Impact Engineering, v. 25, p. 251-264, 2001.

STURGES, J. L.; COLE, B. N. The flying wedge: a method for high strain rate tensile testing. Part 2: Characteristics of the device. International Journal of Impact Engineering, v. 28, p. 891-908, 2003.

TARIGOPULA, V.; ALBERTINI, C.; LANGSETH, M.; HOPPERSTAD, O. S.; CLAUSEN, A. H. A hydro-pneumatic machine for intermediate strain-rates: Set-up, tests and numerical simulations. Dymat 2009: 9th International Conference on the Mechanical and Physical Behaviour of Materials Under Dynamic Loading, Vol 1, p. 381-387, 2009.

TIMOSHENKO, S. Theory of elasticity. 1st. New York,: McGraw-Hill, 1934, 416 p.

VLOT, A. Impact tests on aluminium 2024-T3, Aramid and glass reinforced laminates and thermoplastic composites. Delft University of Technology. Delft, Holanda, p.43. 1987.

VLOT, A. Impact loading on Fibre Metal Laminates. International Journal of Impact Engineering, v. 18, p. 291-307, 1996. 
VLOT, A. Glare : history of the development of a new aircraft material. Dordrecht ; Boston: Kluwer Academic Publishers, 2001, 222 p.

WEN, H.; JONES, N.; BULSON, P. Semiempirical equations for the perforation of plates struck by a mass. Structures Under Shock and Impact II, p. 369-380, 1992.

WU, G.; YANG, J.; HAHN, H. The impact properties and damage tolerance and of bidirectionally reinforced fiber metal laminates. Journal of Materials Science, v. 42, p. 948-957, 2007. 


\section{APÊNDICE 1 - PARÂMETROS CONSTITUTIVOS DOS MATERIAIS}

$\mathrm{Na}$ Tabela 1, são apresentados os parâmetros constitutivos utilizados para modelamento da liga de alumínio 2024-T3, para o modelo de material MAT-15.

Tabela 1: Parâmetros constitutivos utilizados para o alumínio 2024-T3.

\begin{tabular}{cccc}
\hline Parâmetro & Descrição & Valor utilizado & Fonte \\
\hline$r o$ & Densidade volumétrica do material & $2,78 \times 10^{-9} \mathrm{ton} / \mathrm{mm}^{3}$ & Buyuk el al., 2008 \\
$e$ & Módulo de elasticidade & $73,100 \mathrm{GPa}$ & Buyuk el al., 2008 \\
$g$ & Módulo transversal & $27,580 \mathrm{GPa}$ & Buyuk el al., 2008 \\
$p r$ & Coeficiente de Poisson & 0,2858 & Experimentos \\
$a$ & Parâmetro constitutivo de JC & $284,96 \mathrm{MPa}$ & Experimentos \\
$b$ & Parâmetro constitutivo de JC & $504,81 \mathrm{MPa}$ & Experimentos \\
$c$ & Parâmetro constitutivo de JC & 0,0083 & Buyuk el al., 2008 \\
$n$ & Parâmetro constitutivo de JC & 0,5871 & Experimentos \\
$m$ & Parâmetro constitutivo de JC & 1,700 & Buyuk el al., 2008 \\
$d 1$ & Parâmetro de dano de JC & 0,155 & Buyuk el al., 2008 \\
$d 2$ & Parâmetro de dano de JC & 0,155 & Buyuk el al., 2008 \\
$d 3$ & Parâmetro de dano de JC & $-1,150$ & Buyuk el al., 2008 \\
$d 4$ & Parâmetro de dano de JC & 0,011 & Buyuk el al., 2008 \\
$d 5$ & Parâmetro de dano de JC & 0,000 & Buyuk el al., 2008 \\
\hline
\end{tabular}

Na Tabela 2 e Tabela 3, são apresentados os parâmetros constitutivos utilizados para modelamento do SRPP Pure, para o modelo de material MAT-24 e MAT58 , respectivamente.

Tabela 2: Parâmetros constitutivos utilizados do SRPP Pure, para o modelo de material MAT-24.

\begin{tabular}{cccc}
\hline Parâmetro & Descrição & Valor utilizado & Fonte \\
\hline$r o$ & Densidade volumétrica do material. & $7,80 \times 10^{-10}$ ton $/ \mathrm{mm}^{3}$ & Buyuk el al., 2008 \\
$e$ & Módulo elástico. & $7,244 \mathrm{GPa}$ & Experimentos \\
$p r$ & Coeficiente de Poisson. & 0,8994 & Experimentos \\
sigy & Tensão de escoamento. & $13,30 \mathrm{MPa}$ & Experimentos \\
\hline
\end{tabular}


Tabela 3: Parâmetros constitutivos utilizados do SRPP Pure, para o modelo de material MAT-58.

\begin{tabular}{|c|c|c|c|}
\hline Parâmetro & Descrição & Valor utilizado & Fonte \\
\hline 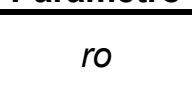 & Densidade volumétrica do material. & $\begin{array}{l}7,80 \times 10^{-10} \\
\text { ton } / \mathrm{mm}^{3}\end{array}$ & Lankhorst, 2011 \\
\hline ea & Módulo aparente na direção 1 (ou a). & $1,602 \mathrm{GPa}$ & Experimentos \\
\hline$e b$ & Módulo aparente na direção 2 (ou b). & $1,602 \mathrm{GPa}$ & Experimentos \\
\hline prba & Coeficiente de Poisson no plano ba & 0,8994 & Experimentos \\
\hline tau1 & $\begin{array}{c}\text { Tensão limite para comportamento não-linear em cisa- } \\
\text { Ihamento. }\end{array}$ & $14,98 \mathrm{MPa}$ & Experimentos \\
\hline gamma1 & $\begin{array}{l}\text { Deformação limite para comportamento não-linear em } \\
\text { cisalhamento. }\end{array}$ & 0,0952 & Experimentos \\
\hline $\begin{array}{l}g a b \\
g b c\end{array}$ & $\begin{array}{l}\text { Módulo de cisalhamento no plano ab. } \\
\text { Módulo de cisalhamento no plano bc. }\end{array}$ & $\begin{array}{l}415,53 \mathrm{MPa} \\
415,53 \mathrm{MPa}\end{array}$ & $\begin{array}{l}\text { Experimentos } \\
\text { Experimentos }\end{array}$ \\
\hline gca & Módulo de cisalhamento no plano ca. & $415,53 \mathrm{MPa}$ & Experimentos \\
\hline slimt1 & $\begin{array}{l}\text { Fator para determinar o comportamento após condição } \\
\text { de tensão máxima, em tração na direção } 1\end{array}$ & 0,10 & Lstc, 2012 \\
\hline slimc1 & $\begin{array}{l}\text { Fator para determinar o comportamento após condição } \\
\text { de tensão máxima, em compressão na direção } 1 \text {. }\end{array}$ & 1,00 & Lstc, 2012 \\
\hline slimt2 & $\begin{array}{l}\text { Fator para determinar o comportamento após condição } \\
\text { de tensão máxima, em tração na direção } 2 \text {. }\end{array}$ & 0,10 & Lstc, 2012 \\
\hline slimc2 & $\begin{array}{l}\text { Fator para determinar o comportamento após condição } \\
\text { de tensão máxima, em compressão na direção } 2 \text {. }\end{array}$ & 1,00 & Lstc, 2012 \\
\hline slimms & $\begin{array}{l}\text { Fator para determinar o comportamento após condição } \\
\text { de tensão de cisalhamento máximo. }\end{array}$ & 0,10 & Lstc, 2012 \\
\hline fs & $\begin{array}{c}\text { Critério de falha com superfície facetada, recomendado } \\
\text { para tecidos. }\end{array}$ & $-1,00$ & Lstc, 2012 \\
\hline e11c & Deformação máxima na direção 1 em compressão. & 0,0102 & Experimentos \\
\hline e11t & Deformação máxima na direção 1 em tração. & 0,1033 & Experimentos \\
\hline$e 22 c$ & Deformação máxima na direção 2 em compressão. & 0,0102 & Experimentos \\
\hline$e 22 t$ & Deformação máxima na direção 2 em tração. & 0,1033 & Experimentos \\
\hline gms & Distorção máxima. & 0,5400 & Experimentos \\
\hline$x c$ & Tensão máxima na direção 1 em compressão. & 23,26 & Experimentos \\
\hline$x t$ & Tensão máxima na direção 1 em tração. & 156,32 & Experimentos \\
\hline$y c$ & Tensão máxima na direção 2 em compressão. & 23,26 & Experimentos \\
\hline$y t$ & Tensão máxima na direção 2 em tração. & 156,32 & Experimentos \\
\hline$s c$ & Tensão de cisalhamento máxima. & 31,96 & Experimentos \\
\hline
\end{tabular}




\section{APÊNDICE 2 - DETALHES DO DESENVOLVIMENTO DO MODELO TEÓRICO PARA IMPACTO DE BAIXA VELOCIDADE EM PLACAS CIRCULARES.}

Com relação conservação do momento linear da placa e elemento impactante no instante anterior e posterior ao contato deste, na

Figura 120 são apresentadas as representações de tais instantes.

(a)

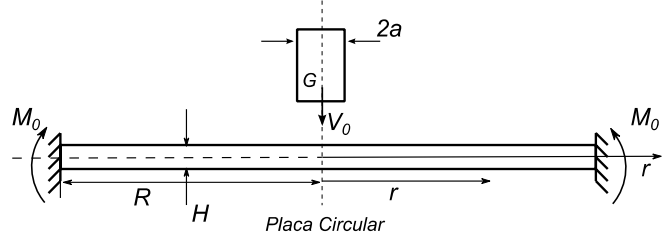

(b)

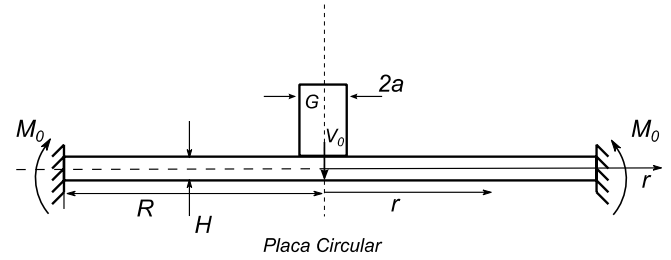

Figura 120: Configuração (a) anterior e (b) posterior ao contato entre a massa e a chapa.

Uma vez que a quantidade de movimento é definida por $\vec{P}=m \vec{v}$, para o instante anterior ao impacto, tem-se

$$
\mathrm{P}_{z, i}=G V_{0}
$$

e, após o impacto,

$$
\mathrm{P}_{z, f}=G \dot{W}_{0}+\int_{A} \mu \dot{w} d A
$$

Com relação à área da chapa circular, um elemento diferencial fica

$$
\begin{gathered}
d A(r)=\pi(r+d r)^{2}-\pi r^{2} \\
d A(r)=\pi\left(r^{2}+2 r d r+d r^{2}\right)-\pi r^{2},
\end{gathered}
$$

considerando que $d r^{2} \sim 0$, tem-se $d A(r)=2 \pi r d r$. Igualando-se as equações (50) e (51), tem-se 


$$
G V_{0}=G \dot{W}_{0}+\mu \pi a^{2} \dot{W}_{0}+\int_{a}^{R} 2 \mu \pi r \dot{W}_{0}\left(\frac{R-r}{R-a}\right) d r .
$$

Considerado os adimensionais $\gamma=G / \mu \pi R^{2}$ e $\rho=a / R$ para reescrever a equação (52) e desenvolvendo-se, tem-se:

$$
\begin{aligned}
& G V_{0}=G \dot{W}_{0}+\mu \pi a^{2} \dot{W}_{0}+\frac{2 \mu \pi \dot{W}_{0}}{(R-a)} \int_{a}^{R} r(R-r) d r \\
& G V_{0}=G \dot{W}_{0}+\mu \pi a^{2} \dot{W}_{0}+\frac{2 \mu \pi \dot{W}_{0}}{(R-a)} \int_{a}^{R}\left(R r-r^{2}\right) d r \\
& G V_{0}=G \dot{W}_{0}+\mu \pi a^{2} \dot{W}_{0}+\frac{2 \mu \pi \dot{W}_{0}}{(R-a)}\left[\left.R \frac{r^{2}}{2}\right|_{a} ^{R}-\left.\frac{r^{3}}{3}\right|_{a} ^{R}\right] \\
& G V_{0}=G \dot{W}_{0}+\mu \pi a^{2} \dot{W}_{0}+\frac{2 \mu \pi \dot{W}_{0}}{(R-a)}\left[\frac{R\left(R^{2}-a^{2}\right)}{2}-\frac{\left(R^{3}-a^{3}\right)}{3}\right] \\
& G V_{0}=G \dot{W}_{0}+\mu \pi a^{2} \dot{W}_{0}+\frac{2 \mu \pi \dot{W}_{0}}{(R-a)}\left[\frac{(R-a)^{2}(2 a+R)}{6}\right] \\
& G V_{0}=G \dot{W}_{0}+\mu \pi a^{2} \dot{W}_{0}+2 \mu \pi \dot{W}_{0}\left[\frac{(R-a)(2 a+R)}{6}\right] \\
& \frac{G V_{0}}{\mu \pi R^{2}}=\frac{G \dot{W}_{0}}{\mu \pi R^{2}}+\frac{\mu \pi a^{2} \dot{W}_{0}}{\mu \pi R^{2}}+\frac{2 \mu \pi \dot{W}_{0}}{\mu \pi R^{2}}\left[\frac{(R-a)(2 a+R)}{6}\right] \\
& \gamma V_{0}=\gamma \dot{W}_{0}+\frac{a^{2}}{R^{2}} \dot{W}_{0}+\frac{2 \dot{W}_{0}(2 a+R)(R-a)}{6 R^{2}} \\
& \gamma V_{0}=\gamma \dot{W}_{0}+\rho^{2} \dot{W}_{0}+2 \dot{W}_{0}\left[\frac{1 / 6-\rho^{2} / 2+\rho^{3} / 3}{(1-\rho)}\right] \\
& \gamma V_{0}=\dot{W}_{0}\left\{\gamma+\rho^{2}+2\left[\frac{1 / 6-\rho^{2} / 2+\rho^{3} / 3}{(1-\rho)}\right]\right\} \\
& \frac{V_{0}}{\dot{W}_{0}}=1+\frac{\rho^{2}}{\gamma}+2\left[\frac{1 / 6-\rho^{2} / 2+\rho^{3} / 3}{\gamma(1-\rho)}\right] \\
& \frac{V_{0}}{\dot{W}_{0}}=1+\frac{(1-\rho) \rho^{2}+\left(1 / 3-\rho^{2}+2 \rho^{3} / 3\right)}{\gamma(1-\rho)} \\
& \frac{V_{0}}{\dot{W}_{0}}=1+\frac{\left(1-\rho^{3}\right)}{3 \gamma(1-\rho)}
\end{aligned}
$$




$$
\frac{V_{0}}{\dot{W}_{0}}=1+\frac{\left(1+\rho+\rho^{2}\right)}{3 \gamma} .
$$

Assim, chega-se a seguinte expressão

$$
\frac{\dot{W}_{0}}{V_{0}}=\left[1+\frac{\left(1+\rho+\rho^{2}\right)}{3 \gamma}\right]^{-1} .
$$

Com relação ao desenvolvimento da expressão

$$
\begin{aligned}
& -G \ddot{W}_{0} \dot{W}_{0}-\int_{A} \mu \ddot{w} \dot{w} d A= \\
& \quad=\int_{A}\left[\left(M_{r}+w N_{r}\right) \dot{\kappa}_{r}+\left(M_{\theta}+w N_{\theta}\right) \dot{\kappa}_{\theta}\right] d A+ \\
& \quad+\sum_{m=1}^{n} \int_{C_{m}}\left(M_{r}+w N_{r}\right)(\partial \dot{w} / \partial r)_{m} d C_{m}+ \\
& \quad+\sum_{u=1}^{v} \int_{C_{u}} Q_{r}(\dot{w})_{u} d C_{u}
\end{aligned}
$$

para o caso específico da placa circular em questão, tem-se que esta pode ser simplificada da seguinte forma, uma vez que as considerações apresentadas no Item 7.4 são aplicadas a expressão

$$
\begin{aligned}
& -G \ddot{W}_{0} \dot{W}_{0}-\int_{A} \mu \ddot{w} \dot{w} d A= \\
& \quad=\int_{A}\left[\left(M_{r}+w N_{r}\right) \dot{\kappa}_{r}+\left(M_{\theta}+w N_{\theta}\right) \dot{\kappa}_{\theta}\right] d A+, \\
& \quad+\sum_{m=1}^{n} \int_{C_{m}}\left(M_{r}+w N_{r}\right)(\partial \dot{w} / \partial r)_{m} d C_{m}
\end{aligned}
$$

podendo ser desenvolvida da seguinte forma 


$$
\begin{aligned}
& -G \ddot{W}_{0} \dot{W}_{0}-2 \pi \mu \int_{a}^{r} \ddot{w} \dot{w} r d r= \\
& =2 \pi \int_{a}^{R}\left(M_{\theta}+w N_{\theta}\right) r \dot{\kappa}_{\theta} d r+\left.M_{0} \dot{\psi}\right|_{r=a} \int_{a} d C_{m}+\left.W_{0} N_{0} \dot{\psi}\right|_{r=a} \int_{a} d C_{m}+\left.\left(-M_{0}\right) \dot{\psi}\right|_{r=R} \int_{R} d C_{m} \\
& \left\|\dot{\psi}_{r}\right\|=\frac{\dot{W}_{0}}{(R-a)} \\
& \text { para } \mathrm{r}=\mathrm{a}, \dot{\kappa}_{r}>\left.0 \rightarrow \dot{\psi}_{r}\right|_{r=a}=\frac{\dot{W}_{0}}{(R-a)} \text {. } \\
& \text { para } \mathrm{r}=\mathrm{R}, \dot{\kappa}_{r}<\left.0 \rightarrow \dot{\psi}_{r}\right|_{r=R}=-\frac{\dot{W}_{0}}{(R-a)} \text {. } \\
& -G \ddot{W}_{0} \dot{W}_{0}-\frac{2 \pi \mu \ddot{W}_{0} \dot{W}_{0}}{(R-a)^{2}} \int_{a}^{r}(R-r)^{2} r d r= \\
& =2 \pi M_{0} \int_{a}^{R} \frac{\dot{W}_{0}}{r(R-a)} r d r+2 \pi N_{0} \int_{a}^{R} \frac{W_{0}(R-r)}{(R-a)} \frac{\dot{W}_{0}}{r(R-a)} r d r+ \\
& +2 \pi a M_{0}\left[\frac{\dot{W}_{0}}{(R-a)}\right]+2 \pi a W_{0} N_{0}\left[\frac{\dot{W}_{0}}{(R-a)}\right]+2 \pi R\left(-M_{0}\right)\left[-\frac{\dot{W}_{0}}{(R-a)}\right] \\
& -G \ddot{W}_{0} \dot{W}_{0}-\frac{2 \pi \mu \ddot{W}_{0} \dot{W}_{0}}{(R-a)^{2}} \int_{a}^{r}\left(R^{2} r-2 R r^{2}+r^{3}\right) d r= \\
& =\frac{2 \pi M_{0} \dot{W}_{0}}{(R-a)} \int_{a}^{R} d r+\frac{2 \pi N_{0} \dot{W}_{0} W_{0}}{(R-a)^{2}} \int_{a}^{R}(R-r) d r+\frac{2 \pi a M_{0} \dot{W}_{0}}{(R-a)}+\frac{2 \pi a \dot{W}_{0} W_{0} N_{0}}{(R-a)}+\frac{2 \pi R M_{0} \dot{W}_{0}}{(R-a)} \\
& -G \ddot{W}_{0} \dot{W}_{0}-\frac{2 \pi \mu \ddot{W}_{0} \dot{W}_{0}}{(R-a)^{2}}\left[\left.R^{2}\left(\frac{r^{2}}{2}\right)\right|_{a} ^{R}-\left.2 R\left(\frac{r^{3}}{3}\right)\right|_{a} ^{R}+\left.\left(\frac{r^{4}}{4}\right)\right|_{a} ^{R}\right]= \\
& =\frac{2 \pi M_{0} \dot{W}_{0}}{(R-a)}\left[\left.(r)\right|_{a} ^{R}\right]+\frac{2 \pi N_{0} \dot{W}_{0} W_{0}}{(R-a)^{2}}\left[\left.R(r)\right|_{a} ^{R}-\left.\left(\frac{r^{2}}{2}\right)\right|_{a} ^{R}\right]+\frac{2 \pi \dot{W}_{0}}{(R-a)}\left(a M_{0}+a W_{0} N_{0}+R M_{0}\right) \\
& -G \ddot{W}_{0} \dot{W}_{0}-\frac{2 \pi \mu \ddot{W}_{0} \dot{W}_{0}}{(R-a)^{2}}\left[R^{2}\left(\frac{R^{2}-a^{2}}{2}\right)-2 R\left(\frac{R^{3}-a^{3}}{3}\right)+\left(\frac{R^{4}-a^{4}}{4}\right)\right]= \\
& =\frac{2 \pi M_{0} \dot{W}_{0}}{(R-a)}(R-a)+\frac{2 \pi N_{0} \dot{W}_{0} W_{0}}{(R-a)^{2}}\left[R(R-a)-\left(\frac{R^{2}-r^{2}}{2}\right)\right]+\frac{2 \pi \dot{W}_{0}}{(R-a)}\left[(R+a) M_{0}+a W_{0} N_{0}\right] \\
& -G \ddot{W}_{0} \dot{W}_{0}-\frac{2 \pi \mu \ddot{W}_{0} \dot{W}_{0}}{(R-a)^{2}}\left[\frac{(R-a)^{3}}{12}(R+3 a)\right]= \\
& =\frac{2 \pi M_{0} \dot{W}_{0}}{(R-a)}(R-a)+\frac{2 \pi N_{0} \dot{W}_{0} W_{0}}{(R-a)^{2}}\left[\frac{(R-a)^{2}}{2}\right]+\frac{2 \pi \dot{W}_{0}}{(R-a)}\left[(R+a) M_{0}+a W_{0} N_{0}\right] \\
& -G \ddot{W}_{0}-\pi \mu \ddot{W}_{0}\left[\frac{(R-a)}{6}(R+3 a)\right]=2 \pi M_{0}+\pi N_{0} W_{0}+\frac{2 \pi M_{0}(R+a)}{(R-a)}+\frac{2 \pi a N_{0} W_{0}}{(R-a)}
\end{aligned}
$$




$$
\begin{gathered}
\ddot{W}_{0}\left[-G-\frac{\pi \mu(R-a)(R+3 a)}{6}\right]=W_{0}\left[\pi N_{0}+\frac{2 \pi a N_{0}}{(R-a)}\right]+\left[2 \pi M_{0}+\frac{2 \pi M_{0}(R+a)}{(R-a)}\right] \\
\ddot{W}_{0}\left[-G-\frac{\pi \mu(R-a)(R+3 a)}{6}\right]=W_{0}\left\{\pi N_{0}\left[1+\frac{2 a}{(R-a)}\right]\right\}+2 \pi M_{0}\left[1+\frac{(R+a)}{(R-a)}\right] \\
\ddot{W}_{0}\left[-G-\frac{\pi \mu(R-a)(R+3 a)}{6}\right]-W_{0}\left\{\pi N_{0}\left[\frac{(R+a)}{(R-a)}\right]\right\}=2 \pi M_{0}\left[1+\frac{(R+a)}{(R-a)}\right] \\
\ddot{W}_{0}\left\{-\left[G+\frac{\pi \mu(R-a)(R+3 a)}{6}\right]\right\}-W_{0}\left\{\pi N_{0}\left[\frac{(R+a)}{(R-a)}\right]\right\}=\frac{4 \pi R M_{0}}{(R-a)} \\
\ddot{W}_{0}+\frac{\pi N_{0}\left[\frac{(R+a)}{(R-a)}\right]}{G+\frac{\pi \mu(R-a)(R+3 a)}{6}} W_{0}=\frac{-\left[G+\frac{\pi \mu(R-a)(R+3 a)}{6}\right]}{\frac{4 \pi R M_{0}}{(R-a)}}
\end{gathered}
$$

A equação (56) pode ser escrita na seguinte forma

$$
\ddot{W}_{0}+g^{2} W_{0}=f
$$

sendo

$$
\begin{gathered}
g^{2}=\frac{\pi N_{0}(R+a) /(R-a)}{G+\pi \mu\left(R^{2}-3 a^{2}+2 a R\right) / 6} \\
f=\frac{-4 \pi R M_{0} /(R-a)}{G+\pi \mu\left(R^{2}-3 a^{2}+2 a R\right) / 6}
\end{gathered}
$$

Buscando facilitar o entendimento do desenvolvimento apresentado, a solução da equação diferencial apresentada na equação (57) encontra-se apresentada no Anexo III, sendo esta

$$
\begin{gathered}
W_{0}=C_{1} \cos (g t)+C_{2} \sin (g t)+\frac{f}{g^{2}} \\
\dot{W}_{0}=g C_{1} \sin (g t)-g C_{2} \cos (g t)
\end{gathered}
$$


As seguintes condições de contorno devem ser aplicadas à equação diferencial:

- Condição inicial:

$$
\begin{gathered}
\text { Sendo } W_{0}(0)=0 \text { e } W_{0}(0)=C_{1}+\frac{f}{g^{2}}, \log 0 \\
C_{1}=-\frac{f}{g^{2}} .
\end{gathered}
$$

- Velocidade inicial:

Considerando a equação (53), tem-se

$$
\dot{W}_{0}(0)=\left[1+\frac{\left(1+\rho+\rho^{2}\right)}{3 \gamma}\right]^{-1} \frac{V_{0}}{g},
$$

logo $\dot{W}_{0}(0)=-C_{2}$, assim

$$
C_{2}=-\left[1+\frac{\left(1+\rho+\rho^{2}\right)}{3 \gamma}\right]^{-1} \frac{V_{0}}{g},
$$

ou, reescrito na forma

$$
C_{2}=\frac{K V_{0}}{g}
$$

com

$$
K=-\left[1+\frac{\left(1+\rho+\rho^{2}\right)}{3 \gamma}\right]^{-1}
$$

O máximo deslocamento ocorre quando o movimento cessa, e em $t=T$, temse $\dot{W}_{0}(T)=0$ e 


$$
\dot{W}_{0}(T)=g C_{1} \sin (g T)-g C_{2} \cos (g T) \text {. }
$$

Assim,

$$
\begin{gathered}
g C_{1} \sin (g T)-g C_{2} \cos (g T)=0 \\
g C_{1} \sin (g T)=g C_{2} \cos (g T) \\
\frac{\sin (g T)}{\cos (g T)}=\frac{C_{2}}{C_{1}} \\
\tan (g T)=\frac{C_{2}}{C_{1}} \\
T=\frac{1}{g} \tan ^{-1}\left(\frac{C_{2}}{C_{1}}\right)
\end{gathered}
$$

Substituindo a equação (65) na equação (60), têm-se

$$
W_{\max }=C_{1} \cos \left[\tan ^{-1}\left(\frac{C_{2}}{C_{1}}\right)\right]+C_{2} \sin \left[\tan ^{-1}\left(\frac{C_{2}}{C_{1}}\right)\right]+\frac{f}{g^{2}} .
$$

Uma vez que

$$
\cos \left[\tan ^{-1}(x)\right]=\frac{1}{\sqrt{1+x^{2}}} \mathrm{e} \sin \left[\tan ^{-1}(x)\right]=\frac{x}{\sqrt{1+x^{2}}}
$$

a equação (66) pode ser reescrita na forma

$$
W_{\max }=C_{1} \cos \frac{1}{\sqrt{1+\left(\frac{C_{2}}{C_{1}}\right)^{2}}}+C_{2} \frac{\left(\frac{C_{2}}{C_{1}}\right)}{\sqrt{1+\left(\frac{C_{2}}{C_{1}}\right)^{2}}}+\frac{f}{g^{2}}
$$

Substituindo as equações (62) e (63), na equação (67), tem-se 


$$
\begin{array}{r}
W_{\max }=\frac{f-f \sqrt{1+\frac{g^{2} K^{2} V_{0}^{2}}{f^{2}}}}{W_{\max }=\frac{f}{g^{2}}\left(1-\sqrt{1+\frac{g^{2} K^{2} V_{0}^{2}}{f^{2}}}\right)} \\
W_{\max }=\frac{f}{g^{2}}\left(1-\sqrt{1+\frac{g^{2} K^{2} V_{0}^{2}}{f^{2}}}\right)
\end{array}
$$

As equações (58) e (59) podem ser reescritas utilizando os adimensionais na forma

$$
\begin{gathered}
g^{2}=\frac{\pi N_{0}(R+a) /(R-a)}{G+\pi \mu\left(R^{2}-3 a^{2}+2 a R\right) / 6} \\
g^{2}=\frac{\pi \frac{4 M_{0}}{H} \frac{\left(\frac{R}{R}+\frac{a}{R}\right)}{\left(\frac{R}{R}-\frac{a}{R}\right)}}{\left(\frac{R^{2}}{R^{2}}-\frac{3 a^{2}}{R^{2}}+\frac{2 a R}{R^{2}}\right)} \\
g^{2}=\frac{G}{\gamma \mu \pi R^{2}+\pi \mu R^{2}\left(1-3 \rho^{2}+2 \rho\right) / 6} \frac{6}{R^{2}} \\
g^{2}=\frac{\left.\pi \pi R^{2}\right)}{\pi \frac{(1-\rho)}{(1+\rho)}} \\
\mu \pi R^{2}\left[\gamma+\frac{\left(1+2 \rho-3 \rho^{2}\right)}{6}\right]
\end{gathered}
$$




$$
\begin{gathered}
f=\frac{-4 \pi R M_{0} /(R-a)}{G+\pi \mu\left(R^{2}-3 a^{2}+2 a R\right) / 6} \\
f=-\frac{\left(\frac{4 \pi R M_{0}}{R}\right)}{\frac{\left(\frac{R-a}{R}\right)}{\left(\frac{R^{2}}{R^{2}}-\frac{3 a^{2}}{R^{2}}+\frac{2 a R}{R^{2}}\right)}} \\
\frac{G}{\left(\mu \pi R^{2}\right)}\left(\mu \pi R^{2}\right)+\mu \pi \frac{6}{R^{2}} \\
f=-\frac{\frac{4 \pi M_{0}}{(1-\rho)}}{\mu \pi R^{2}\left[\gamma+\frac{\left(1+2 \rho-3 \rho^{2}\right)}{6}\right]} \\
f=-\frac{(1-\rho)}{\gamma R^{2}\left[\frac{\left(1+2 \rho-3 \rho^{2}\right)}{6}\right]}
\end{gathered}
$$

As equações (64), (69) e (70) podem ser substituídas na equação (68), da seguinte forma

$$
\begin{gathered}
\frac{f}{g^{2}}=-\frac{\frac{4 \pi M_{0}}{(1-\rho)}}{\pi \frac{4 M_{0}(1+\rho)}{H} \frac{f(1-\rho)}{g^{2}}=-\frac{H}{(1+\rho)}} \\
\frac{g^{2} K^{2} V_{0}^{2}}{f^{2}}=\frac{\pi \frac{4 M_{0}}{H} \frac{(1+\rho)}{(1-\rho)} V_{0}^{2} \mu \pi R^{2}\left[\gamma+\frac{\left(1+2 \rho-3 \rho^{2}\right)}{6}\right]}{\left.\frac{\left[4 \pi M_{0}\right.}{(1-\rho)}\right]^{2}\left[1+\frac{\left(1+\rho+\rho^{2}\right)}{3 \gamma}\right]^{2}} \\
\frac{g^{2} K^{2} V_{0}^{2}}{f^{2}}=\frac{\frac{(1+\rho)}{H} V_{0}^{2} \mu R^{2}\left[\frac{6 \gamma+1+2 \rho-3 \rho^{2}}{6}\right]}{\frac{4 M_{0}}{(1-\rho)}\left[\frac{\left(3 \gamma+1+\rho+\rho^{2}\right)}{3 \gamma}\right.}
\end{gathered}
$$




$$
\begin{gathered}
\frac{g^{2} K^{2} V_{0}^{2}}{f^{2}}=\frac{\mu V_{0}^{2} R^{2}}{M_{0} H} \frac{(1+\rho)(1-\rho)}{4}\left[\frac{6 \gamma+1+2 \rho-3 \rho^{2}}{6}\right]\left[\frac{9 \gamma^{2}}{\left(3 \gamma+1+\rho+\rho^{2}\right)}\right] \\
\frac{g^{2} K^{2} V_{0}^{2}}{f^{2}}=\lambda \frac{\left(1-\rho^{2}\right)}{4}\left[\frac{6 \gamma+1+2 \rho-3 \rho^{2}}{2}\right]\left[\frac{3 \gamma^{2}}{\left(3 \gamma+1+\rho+\rho^{2}\right)}\right] \\
\frac{g^{2} K^{2} V_{0}^{2}}{f^{2}}=\frac{3 \gamma^{2} \lambda\left(1-\rho^{2}\right)\left(6 \gamma+1+2 \rho-3 \rho^{2}\right)}{8\left(3 \gamma+1+\rho+\rho^{2}\right)} \\
W_{\max }=-\frac{H}{(1+\rho)}\left(1-\sqrt{\frac{1+\frac{3 \gamma^{2} \lambda\left(1-\rho^{2}\right)\left(6 \gamma+1+2 \rho-3 \rho^{2}\right)}{8\left(3 \gamma+1+\rho+\rho^{2}\right)}}{g^{2}}}\right) \\
\frac{W_{\max }}{H}=\frac{\left.1-\sqrt{1+\frac{g^{2} K^{2} V_{0}^{2}}{f^{2}}}\right)}{(1+\rho)}\left(\sqrt{1+\frac{3 \gamma^{2} \lambda\left(1-\rho^{2}\right)\left(6 \gamma+1+2 \rho-3 \rho^{2}\right)}{8\left(3 \gamma+1+\rho+\rho^{2}\right)}}-1\right)
\end{gathered}
$$

chegando à expressão:

$$
\frac{W_{\max }}{H}=\frac{1}{(1+\rho)}\left\{\left[1+\frac{3 \gamma^{2} \lambda\left(1-\rho^{2}\right)\left(6 \gamma+1+2 \rho-3 \rho^{2}\right)}{8\left(3 \gamma+1+\rho+\rho^{2}\right)^{2}}\right]^{1 / 2}-1\right\} .
$$




\section{APÊNDICE 3 - RESOLUÇÃO DA EQUAÇÃO DIFERENCIAL NÃO HOMOGÊNEA}

Considera-se a seguinte equação diferencial

$$
\ddot{y}+g^{2} y=f,
$$

sendo $y=f(t)$.

A solução da equação diferencial, $y$, pode ser considerada como $y=y_{s}+y_{h}$, sendo $y_{h}$ a solução homogênea associada e $y_{e}$ a solução específica.

A equação homogênea associada à equação (72) é

$$
\ddot{y}_{h}+g^{2} y_{h}=0 .
$$

Adota-se que a solução homogênea, $y_{h}$, seja da forma.

$$
\begin{gathered}
y_{h}(t)=e^{r t} \\
\dot{y}_{h}(t)=r e^{r t} . \\
\ddot{y}_{h}(t)=r^{2} e^{r t}
\end{gathered}
$$

Substituindo a equação (74) na equação (73), tem-se

$$
\begin{gathered}
r^{2} e^{r x}+g^{2} e^{r x}=0 \\
e^{r x}\left(r^{2}+g^{2}\right)=0 \\
\text { as } e^{r x} \neq 0, \\
r^{2}+g^{2}=0
\end{gathered}
$$

sendo

$$
\begin{aligned}
& r_{1}=0+g i \\
& r_{1}=0-g i
\end{aligned} .
$$


Desse modo, a solução homogênea fica

$$
y_{h}(t)=C_{1} \cos (g t)+C_{2} \sin (g t)
$$

Por sua vez, a solução específica, $y_{e}$, é considerada na forma

$$
\begin{aligned}
& y_{e}(t)=A \\
& \dot{y}_{e}(t)=0 . \\
& \ddot{y}_{e}(t)=0
\end{aligned}
$$

Substituindo a equação (76) na equação (72), tem-se

$$
\begin{aligned}
\ddot{y}_{s}+g^{2} y_{s} & =f \\
0+g^{2} y_{s} & =f
\end{aligned},
$$

sendo

$$
y_{s}=\frac{f}{g^{2}}
$$

Assim, a solução da equação diferencial fica

$$
y(t)=C_{1} \cos (g t)+C_{2} \sin (g t)+\frac{f}{g^{2}} .
$$

